\title{
The development of exhaled breath condensate: a noninvasive method of measuring airway inflammation
}

Citation for published version (APA):

Rosias, P. P. R. (2008). The development of exhaled breath condensate: a noninvasive method of measuring airway inflammation. [Doctoral Thesis, Maastricht University]. Universiteit Maastricht. https://doi.org/10.26481/dis.20080214pr

Document status and date:

Published: 01/01/2008

DOI:

10.26481/dis.20080214pr

Document Version:

Publisher's PDF, also known as Version of record

\section{Please check the document version of this publication:}

- A submitted manuscript is the version of the article upon submission and before peer-review. There can be important differences between the submitted version and the official published version of record. People interested in the research are advised to contact the author for the final version of the publication, or visit the DOI to the publisher's website.

- The final author version and the galley proof are versions of the publication after peer review.

- The final published version features the final layout of the paper including the volume, issue and page numbers.

Link to publication

\footnotetext{
General rights rights.

- You may freely distribute the URL identifying the publication in the public portal. please follow below link for the End User Agreement:

www.umlib.nl/taverne-license

Take down policy

If you believe that this document breaches copyright please contact us at:

repository@maastrichtuniversity.nl

providing details and we will investigate your claim.
}

Copyright and moral rights for the publications made accessible in the public portal are retained by the authors and/or other copyright owners and it is a condition of accessing publications that users recognise and abide by the legal requirements associated with these

- Users may download and print one copy of any publication from the public portal for the purpose of private study or research.

- You may not further distribute the material or use it for any profit-making activity or commercial gain

If the publication is distributed under the terms of Article $25 \mathrm{fa}$ of the Dutch Copyright Act, indicated by the "Taverne" license above, 


\section{The Development of Exhaled Breath Condensate}

a noninvasive method of measuring airway inflammation

Philippe Pieter Roger Rosias 



\title{
The Development of Exhaled Breath Condensate
}

a noninvasive method of measuring airway inflammation

\author{
PROEFSCHRIFT \\ ter verkrijging van de graad van doctor \\ aan de Universiteit Maastricht, \\ op gezag van de Rector Magnificus, \\ Prof. mr. G. P.M.F. Mols \\ volgens het besluit van het College van Decanen, \\ in het openbaar te verdedigen op \\ donderdag 14 februari 2008 om 16.00 uur
}

door

\section{Philippe Pieter Roger Rosias}

13 november 1966, Tongeren (B) 


\section{Promotores}

Prof. dr. C.P. van Schayck

Prof. Dr. L.J.I. Zimmermann

\section{Co-promotores}

Dr. E. Dompeling

Dr. Q. Jöbsis

\section{Beoordelingscommissie}

Prof. dr. F-J. van Schooten, voorzitter

Prof. dr. J-W. Cohen Tervaert

Prof. dr. J.C. de Jongste, Sophia Kinderziekenhuis, Erasmus Universiteit Rotterdam

Financial support for the publication of this thesis was provided by:

Abbott

AstraZeneca

Bristol Myers Squibb

Covidien NL

Friso Kindervoeding

GlaxoSmithKline

Maastricht Instruments

Mead Johnson Nutritionals

Merck Sharp \& Dohme

Meda Pharma

Novartis Pharma

Nycomed

Romedic

Sanofi-Aventis

Schering-Plough

Teva Pharma NL

Zambon NL 



\section{Design and Layout:}

D\&L graphics

www.dlgraphics.nl

\section{Cover:}

D\&L graphics

Printed by:

Schrijen-Lippertz-Huntjens

ISBN: 978-90-8590-026-9

ISBN: 978-90-8590-027-6 (Audio Visual Media) 


\section{Contents}

Chapter 1 General introduction: new perspectives in monitoring lung inflammation: analysis of exhaled breath condensate in children

Chapter 2 Exhaled breath condensate in children: pearls and pitfalls

Chapter 3 Childhood asthma: exhaled markers of airway inflammation, asthma control score, and lung function tests

Chapter 4.1 Exhaled breath condensate: a space odyssey, where no one has gone before

Chapter 4.2 Breath condenser coatings affect measurement of biomarkers in exhaled breath condensate

Chapter 5 Biomarker reproducibility in exhaled breath condensate collected with different condensers

Chapter 6 Free radicals in exhaled breath condensate in cystic fibrosis and healthy subjects

Chapter 7 Biomarkers in exhaled breath condensate indicate presence and severity of cystic fibrosis in children

Chapter 8 New method to collect exhaled breath condensate, and to assess airway inflammation in wheezing preschool children

Chapter 9 General discussion

Summary and conclusions

Samenvatting en conclusies

Dankwoord 


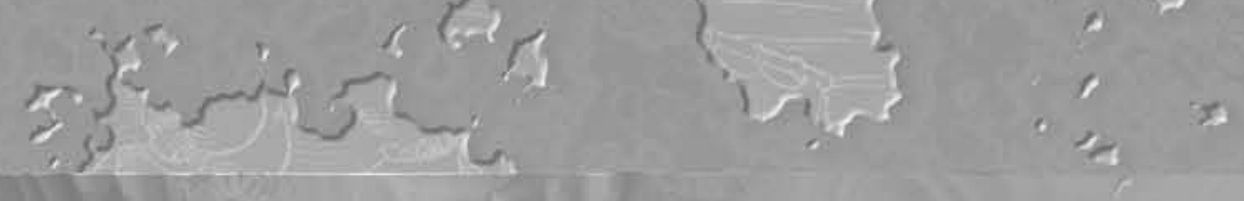

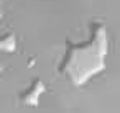

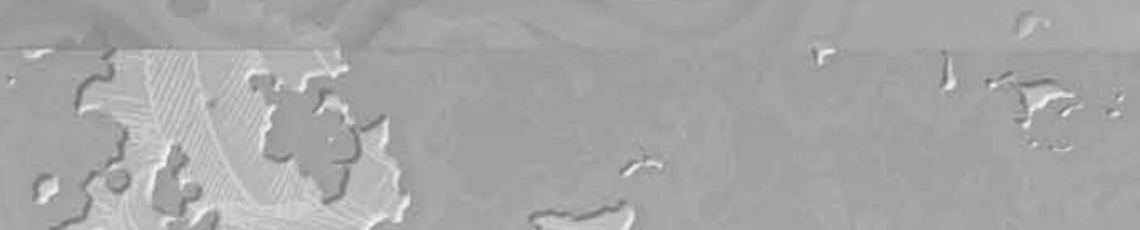

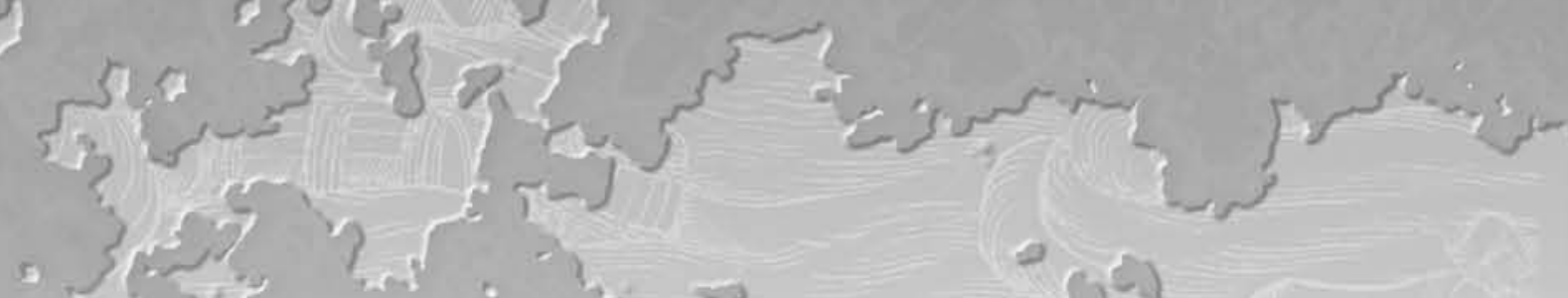

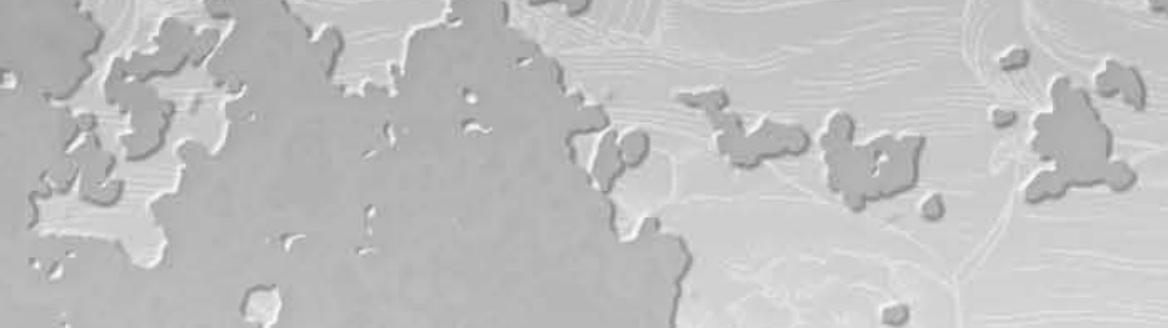

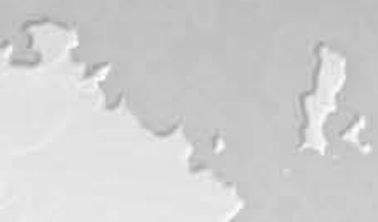

- 3 ?

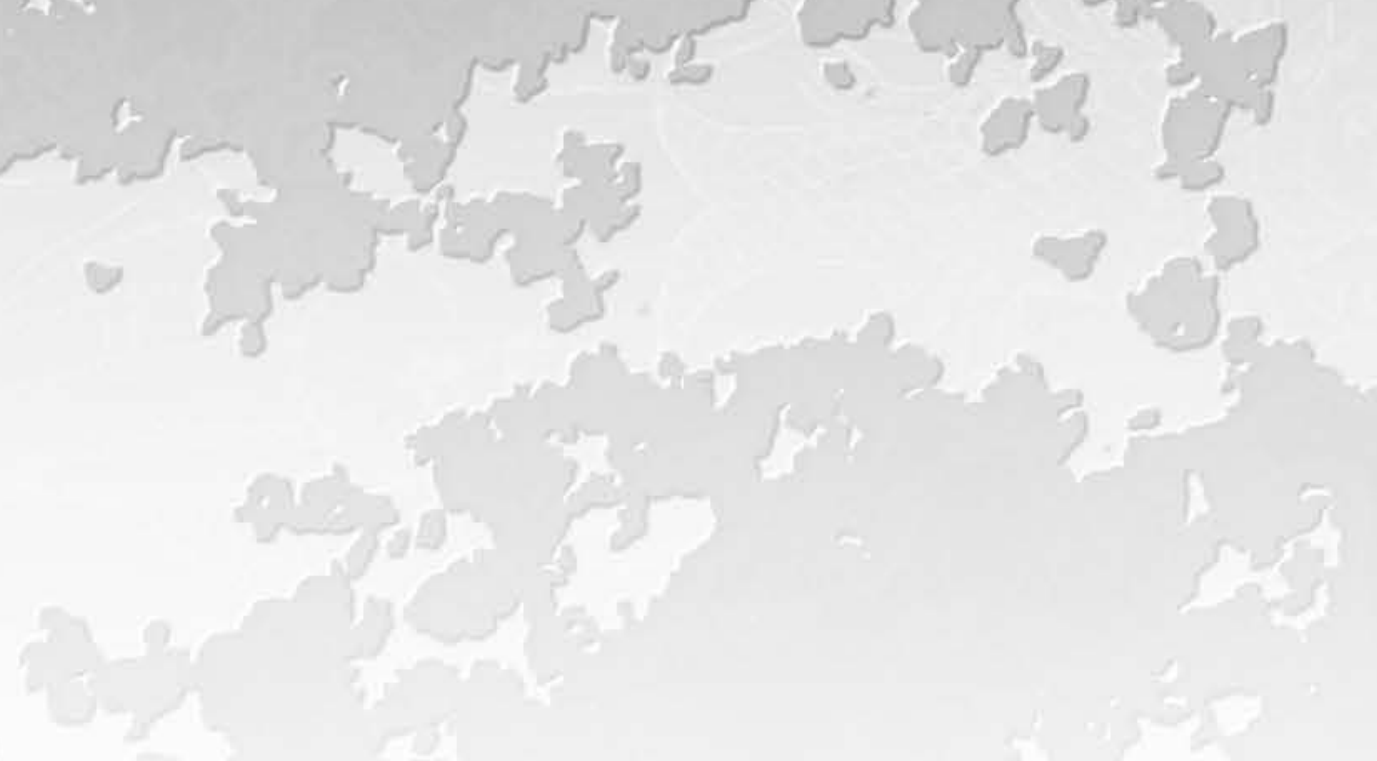




\section{CHAPTER 1}

\section{GeNERAL InTRODUCTION}
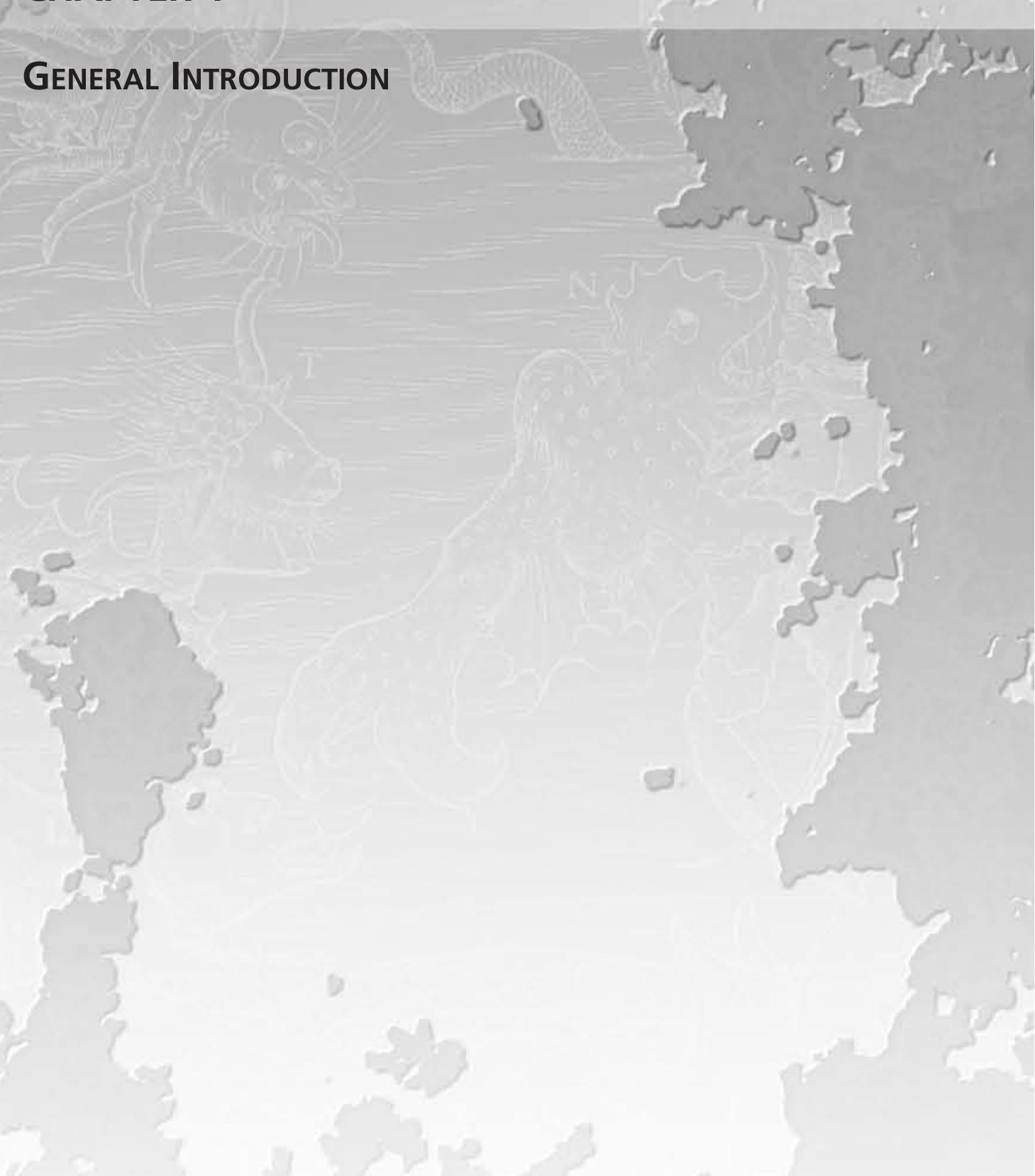

Published in part:

Jöbsis Q, Rosias PPR. Analysis of exhaled breath condensate in children. In: New perspectives in monitoring lung inflammation. Montuschi $P$, editor. Taylor \& Francis Publishers, London, 2004 (ISBN 0415324653) 


\section{Contents}

1.1. Respiratory disorders in children

1.2. Chronic respiratory inflammation in children

1.3. Assessment of chronic respiratory disease in children

1.4. Noninvasive inflammometry in children

1.5. Objectives of the thesis

1.6. New perspectives in monitoring lung inflammation: analysis of exhaled breath condensate in children

1.6.1. Collection of EBC in children

1.6.2. Inflammatory mediators detected in EBC of children

1.6.3. Conclusion 


\section{General Introduction}

\subsection{Respiratory disorders in children.}

Children differ from adults, and have unique medical needs. It is essential to understand that the developing child is not only undergoing alveolisation, until the age of two to four years, and lung growth, but also embodies complex interactions of many processes, both endogenous, such as genetic background and immune maturation, as well as exogenous, including environmental influences and influences in utero. ${ }^{\text {1-10 }}$ Furthermore, it is equally essential to comprehend that evidence-based medicine has become the 'gold standard' for clinical practice and treatment guidelines. ${ }^{11-12}$ However, this concept does not apply to an individual, but to a group of individuals with clinical features sufficiently distinct from other groups to represent a useful clinical entity or distinct disease phenotype. ${ }^{13-14}$ Moreover, evidence-based guidelines do not solve their problem of inductive reasoning, as the question will always remain to which extent results are generalisable. ${ }^{14}$ Nevertheless, disease manifestations in the developing child, that sound or look similar, may be the expression of distinctly different underlying mechanisms. ${ }^{15}$ Most physicians have seen children with wheeze and/or cough, which become manifest during different time periods in childhood or adolescence, and persist and progress, or disappear, and sometimes even relapse at other time periods.

Wheezing is a common symptom of respiratory disease, and is reported in no less than 30 per cent of children during the first three years of life, with a prevalence falling to about half in older children. ${ }^{13,15-16}$ Especially in young children, wheeze is poorly characterised, implying a high-pitched sighing or whistling sound that is mainly heard during expiration. ${ }^{13}$ Common accompaniments are cough and breathlessness, and particularly during common viral respiratory tract infections, rattly sounds may mask wheeze or may be mislabelled as wheeze. ${ }^{13,17}$ Parental misclassification of noisy breathing in young children is widespread. ${ }^{18,19}$ Hence, wheezing phenotypes in children are hard to classify unequivocally.

In preschool children, exclusively viral wheeze is the most common clinical phenotype, that accounts for about two-thirds of all wheezers. ${ }^{13}$ It is characterised by acute episodes of wheeze, cough and breathlessness in association with viral (upper) respiratory tract infections, particularly respiratory syncytial virus, rhinovirus and parainfluenza virus, with few or no interval symptoms. ${ }^{13,20-24}$ Many of these children have a good prognosis since 60 per cent will have stopped wheezing by their early school years. ${ }^{16}$ This form of transient early wheeze is not related to atopy and allergic conditions. ${ }^{15}$ Risk factors associated with transient wheezing are maternal smoking during pregnancy, premature birth and low birth weight. ${ }^{15}$ Reduced lung function after birth, before any wheezing illness has occurred, may contribute to the underlying mechanism. 5, 15,25-26 Furthermore, current findings suggest that respiratory syncytial virus has a similar effect on subsequent wheeze as other confirmed viral infections, being a mainly nonallergic condition that resolves with age. ${ }^{23-24,27-30}$ On the other hand, a preschool persistent wheezing illness resembling classical asthma can be 
distinguished from transient viral wheeze, and is characterised by chronic interval symptoms between episodes and often an atopic personal and family history. ${ }^{13}$

By school age, children with the atopic wheezing phenotype are most likely to develop a chronic course, with exacerbations not only induced by viral infections, but also by other factors, such as exercise, allergen exposure, irritants and stress. ${ }^{15}$ Children with atopic wheezing may develop significant impairment in lung function as well as airway hyperresponsiveness. ${ }^{15}$ However, there is also a significant number of children with the nonatopic wheezing phenotype. ${ }^{15}$ They are thought to have symptoms triggered by viral infections alone, to lack airway hyperresponsiveness, and to retain normal lung function in long-term follow-up studies. ${ }^{15,31-33}$

Allergic asthma is the most persistent and usually the more severe form of recurrent wheeze, associated with immunoglobulin E-mediated immune responses to food and/or aeroallergens. ${ }^{15}$ Most children already have their first symptoms during early life. ${ }^{16,34-36}$ The level of allergen exposure has been fiercely discussed as a potential determinant of the development of asthma, although this is not supported by recent studies. ${ }^{15,37-39}$ During and after adolescence, a significant number of children lose their symptoms, which may in part be attributable to the vanishing disease expression of the nonatopic wheezing phenotype associated with viral infections. ${ }^{15}$ On the other hand, new onset of illness is also seen, particularly among female adolescents and/or associated with taking up active smoking. ${ }^{15,40}$ Persistent illness is associated with severe atopy and airway hyperresponsiveness. ${ }^{15,40}$

The role of viral infections in exacerbating wheeze and/or inducing wheeze and asthma-like symptoms is debated extensively. ${ }^{15,24}$ Recent observations in infants suggest that the configuration of the immune response prior to any viral infection determines the risk of virally induced wheeze. ${ }^{41}$ However, it is also conceivable that a child's increased exposure to viral infections through day care can influence the phenotypic expression and foster a milder form of wheezing by suppressing the atopic component. ${ }^{24,42-45}$ Each particular virus will exert an effect depending on its own specific invasive properties, the elicited immune response, and the interacting host factors, including genetic factors. ${ }^{24}$

The hygiene hypothesis, firstly proposed in 1989 by David Strachan, states that infections and unhygienic contact might actually render protection against the development of allergic illness. ${ }^{24,45}$ Interleukin-12 is a dominant mediator that may skew the T-helper 1 to T-helper 2 balance away from allergy-promoting T-helper 2 cells towards T-helper 1 cells. ${ }^{24,46}$ The so-called farm studies suggest that environmental exposure in the first years of life to nonviable microbial products, such as the evolutionarily highly conserved endotoxin from gram-negative bacteria, stimulate immune responses in a way that protects against allergies. ${ }^{24,45,47-48}$ However, there are conflicting data regarding the hygiene hypothesis. ${ }^{24,49-57}$ Alternatively, Holt et al have recently proposed a theoretical maturation model for the airways (and atopic asthma), based on common-shared genetic variations in kinetics of postnatal maturation of T- 
helper 1 competence. ${ }^{58}$ These collectively result in delayed maturation and 'sluggish' postnatal T-helper 1 function, and hereby increase susceptibility to both viral infection and its subsequent spread, as well as programming T-helper 2-polarized memory against aeroallergens. ${ }^{28,58-60}$ Nevertheless, to date a truly unifying concept has not yet emerged, but various pieces of a complex interplay between genetic background, immune response of the host, characteristics of the invading micro-organism, and the level and variety of the environmental exposure become apparent.5,8-9,24

Two distinct disease entities also account for various respiratory symptoms in childhood, in casu 'new' bronchopulmonary dysplasia and cystic fibrosis.

Infants with bronchopulmonary dysplasia suffer prolonged (id est more than 28 days) oxygen dependency, troublesome respiratory symptoms, lung function abnormalities at follow-up, pulmonary and systemic hypertension, and neurodevelopmental delay. ${ }^{61-63}$ Risk factors for the development of bronchopulmonary dysplasia include oxygen toxicity, volutrauma and infection, as well as prematurity. ${ }^{61}$ Infants described as having 'new' bronchopulmonary dysplasia, have abnormal lung growth with a markedly decreased number of alveoli, which is more prominent in 'new' bronchopulmonary dysplasia than the fibrosis and smooth muscle increase of mediumsized airways as previously seen in classical bronchopulmonary dysplasia. ${ }^{61,64-66}$

Cystic fibrosis is the most common life-limiting recessive genetic multisystem disease in Caucasians, caused by a defect in the cystic fibrosis transmembrane conductance regulator gene. ${ }^{67-70}$ The phenotype of typical cystic fibrosis includes the well-known respiratory manifestations, but the hallmark is pancreatic insufficiency. ${ }^{67,69}$ Diagnosis is established in the majority of patients by one year of age, but in eight percent not until after ten years of age. ${ }^{69,71}$ Often, the problem is remembering to do the sweat test. ${ }^{67,72}$ Although newborn screening becomes more widely introduced, it does not preclude the need to consider cystic fibrosis in many differential diagnoses, ${ }^{67,73-74}$ and the difficulty will be classifying and/or diagnosing patients with atypical, difficult, subclinical or pre-cystic fibrosis. ${ }^{67,75-77}$

There are less frequent or even rare but specific disorders, such as congenital airway disorders, obliterative bronchiolitis and primary ciliary dyskinesia, that may also have a wheezy component. However, they fall beyond the scope of this general introduction.

Finally, overlap or coincidental occurrence of two independent disorders in an individual creates a wide potential spectrum and at the same time it creates the sort of uncertainty that makes clinical paediatric medicine such a challenge. ${ }^{13}$

\subsection{Chronic respiratory inflammation in children.}

Having explored to some extent a wide clinical diversity of respiratory disorders from infancy to adolescence, and having designated their complex and multi-dimensional nature, comprising at least the affected phenotype, time, environment and genetic 
susceptibility, it now seems appropriate to attempt to address the featuring phenotypes of chronic respiratory inflammation in children.

Asthma is characterised by a variable degree of airflow obstruction, bronchial hyperresponsiveness, and airway inflammation. ${ }^{78}$ At autopsy, patients with fatal asthma have shown a cellular infiltrate of neutrophils and eosinophils, degranulated mast cells, reticular basement membrane thickening, loss of epithelial cell integrity, occlusion of the bronchial lumen by mucus, and hyperplasia and hypertrophy of bronchial smooth muscle and hyperplasia of goblet cells. ${ }^{78}$ In patients with mild to moderate asthma, infiltration by lymphocytes and eosinophils can occur throughout the central and peripheral airways, often varying with disease severity. ${ }^{78}$ In airways, resident mast cells, macrophages and epithelial cells, and recruited inflammatory cells generate chemotactic chemokines and cytokines, which activate transcription factors, such as nuclear factor- $\kappa \mathrm{B}$, that bind to the promoter region of genes that encode inflammatory cytokines, chemokines, adhesion molecules and other proteins that induce and perpetuate inflammation. ${ }^{78-79}$

To initiate immunoglobulin E-mediated inflammation in allergic asthma, inhaled allergens must encounter dendritic cells that line the airways and then migrate to draining lymph nodes, where they present processed antigen to $T$ and $B$ cells. ${ }^{78,80}$ Interactions among these cells elicit responses that are influenced by cytokines. Thelper 2-mediated interleukin-4 and interleukin-13 promote B cells to switch to synthesise, and to release specific immunoglobulin $E^{24,78,81}$ This immunoglobulin binds to high-affinity immunoglobulin E receptors on the surface of mast cells in tissue or peripheral-blood basophils, and to low-affinity immunoglobulin E receptors on the surface of lymphocytes, eosinophils, platelets and macrophages. ${ }^{24,78,81}$ Subsequently inhaled allergen interacts with receptor-bound immunoglobulin E (cross-linking), and causes activation of the cell membrane and cytosolic pathways of mast cells and Thelper 2 cells in the airways. ${ }^{78,82-83}$ This causes the release of preformed mediators such as histamine, and initiates the synthesis of arachidonic acid metabolites and Thelper 2 cytokines, including interleukin-4 and interleukin-5. ${ }^{78,82-83}$

However in childhood asthma, data from mucosal biopsy studies and bronchoalveolar lavage studies are inconsistent and often not in accordance with studies in adults. ${ }^{84}$ In fact, the presence and nature of airway inflammation in common clinical expressions of childhood asthma is largely unknown, and it is quite likely that it differs considerably from the findings in adults. ${ }^{84}$ The only really consistent finding is thickening of the reticular basement membrane, a key feature of airway wall remodelling, which was observed in almost all biopsy studies, even in young children. ${ }^{60,84-95}$ It is not clear whether these structural changes precede, or occur early and in parallel with, or develop as a result of airway inflammation. ${ }^{60,89,93,95-97}$ Nevertheless, interference with normal airway growth and lung development at crucial time periods may have particularly long-term effects and cannot be overstated. ${ }^{93,98}$ 
Inhaled corticosteroids have become the cornerstone of maintenance therapy in childhood asthma, although it is not clear at what point such treatment should begin and indeed whether anti-inflammatory therapy can influence the natural course of the disease. ${ }^{32,78,84,99-108}$ A further complication is the fact that, idealised asthma guidelines do not reflect the reality of individual asthma management. ${ }^{84,109-116}$

There is good evidence to show that preschool children with exclusively viraltriggered wheeze do not have chronic eosinophilic airway inflammation, and that during an acute viral-triggered attack, neutrophilic inflammation predominates. ${ }^{13,117-}$ 121 However, a minority of preschool wheezers have eosinophilic airways inflammation between viral-triggered attacks. ${ }^{13,122-126}$ On the other hand, it is possible that exclusively viral wheeze is atopic asthma but without the propensity to develop chronic inflammation. ${ }^{13,127-128}$ Furthermore, it currently remains unclear whether respiratory syncytial virus infections directly damage the infant's respiratory system and promote the development of later recurrent wheezing, or if bronchiolitis unmasks some inherent susceptibility or pre-existing lung function abnormalities, or even both. ${ }^{23}$ The T-helper 1 to T-helper 2 paradigm is not necessarily followed, ${ }^{23,129-133}$ and it is plausible that small infants with a less mature immune response are unable to mount a strong antiviral T-helper 1 response, making them most vulnerable to severe disease. ${ }^{58-59,134}$

In bronchopulmonary dysplasia, neutrophilic lung inflammation is a key feature. ${ }^{61,135-136}$ The inflammatory phase may commence antenatally, with infection being the most likely initiator. ${ }^{137}$ Alveolar macrophages appear to mediate resolution of the acute lung injury, and are likely responsible for dysregulated lung growth, as they release growth factors. ${ }^{61}$ Alternatively, the capillary network may fail to expand, as vascular endothelial growth factor is significantly decreased in bronchopulmonary dysplasia. ${ }^{138}$

In cystic fibrosis, there is no dispute that the two main components of airway disease are chronic infection and an exuberant host inflammatory response. ${ }^{67}$ What is not clear is their relationship. ${ }^{67,139-145} \mathrm{New}$ data are strongly suggestive that the dysregulated inflammatory response in cystic fibrosis is not related to the underlying cystic fibrosis transmembrane conductance regulator defect, but is a secondary response to prolonged and chronic infection. ${ }^{146-147}$ It would seem likely that early on in cystic fibrosis, the inflammatory response is beneficial and wards off early infection with Pseudomonas aeruginosa, but that in late-stage cystic fibrosis, it is clearly both ineffectual and harmful. ${ }^{67}$ What is not known is when the transition to harm occurs, which is important, as steroids are definitely beneficial in late disease, but may not be helpful early on. ${ }^{67,148}$ Moreover, it is also not clear why there is persistent acute (neutrophilic), rather than chronic infection in the cystic fibrosis airway. ${ }^{67}$

In summary, common respiratory symptoms, such as wheezing, coughing, shortness of breath, chest tightness and fatigue, in the developing child, with its specific genetic background, and undergoing alveolisation, lung growth, immune 
maturation as well as environmental influences, may be attributed to different pulmonary diseases, ranging from transient viral wheeze to life-limiting cystic fibrosis, all featuring some phenotype of respiratory inflammation. Although our theoretical and clinical knowledge is increasing, and several global concepts or hypotheses have been proposed, many questions still remain unanswered and await disentanglement. The practical need for tailored individual monitoring of the natural course of disease or response to treatment, as well as the need for accurate, objective and early assessment of respiratory inflammation, in little or non-cooperative children is obvious.

\subsection{Assessment of chronic respiratory disease in children.}

The key question is how to identify those children with an underlying disease and separate them from the large group of children with benign and self-limiting problems. ${ }^{149}$

Medical advice often relies on gathered information on symptoms and quality of life as perceived by the child or her/his parents. Each physician should balance, on one hand, his own professional findings and misunderstandings, and, on the other hand, potential parental or patient's misclassification of noisy breathing, mismatched prevalence of symptoms, poor adherence to treatment, and perception of quality of life and disease control. ${ }^{18-19,84,109-110,113,150-159}$ Also, disease outcomes are influenced by emotional characteristics, disease management behaviours and psychological factors. ${ }^{160}$ It has become obvious that poor disease control is not only a problem of education, both for patients and providers, but also a problem of mutual communication between patients and providers. ${ }^{84,110,113}$

Pulmonary function tests, mainly spirometry, are generally considered the standard criterion for objective assessment of paediatric lung disease. ${ }^{99-100,149,161}$ The poor cooperation of children under six years of age in performing the required manoeuvres has limited lung function evaluation. ${ }^{149}$ In the 'cooperative' child (id est more than six years old) spirometry is the most used pulmonary function test, as, in these children, it is relatively not difficult to perform and it is repeatable. ${ }^{84,149}$ Paediatric guidelines have recently been published. ${ }^{162}$ In asthmatic children, spirometric parameters detect airflow limitation and help to diagnose and monitor the disease. ${ }^{107}$ Forced expiratory volume in one second is the most reliable spirometric parameter and is used, along with symptom frequency and medication usage, to classify the severity of airway disease. ${ }^{108}$ However, asthma is a condition with intermittent airway obstruction, and in 5 to 18 year old asthmatic children forced expiratory volume in one second is generally normal, which does not exclude disease, however. ${ }^{149,152,163-164}$ Whereas guidelines recommend that the monitoring of asthma should be based on symptoms and lung function tests, often insufficient attention has been paid to the underlying airway inflammation. ${ }^{84}$ Additional markers of airway inflammation may be helpful to improve disease outcome. ${ }^{84,165-166}$

The main pathological factors that underlie bronchial hyperreactivity are presumably airway inflammation and bronchial remodeling. ${ }^{149,167}$ Guidelines for 
bronchial challenge tests have been published. ${ }^{168-169}$ However, the relationship between bronchial hyperreactivity and asthma is complex in children. While asthmatic children have bronchial hyperreactivity, bronchial hyperreactivity is not the same as asthma. ${ }^{149,170}$ It has also been reported in children with cystic fibrosis, allergic rhinitis and even in asymptomatic children. ${ }^{171}$ Indirect stimuli, such as exercise and cold air, correlate better with airway inflammation than direct stimuli, such as metacholine and histamine. ${ }^{167-168,172}$ Bronchial hyperreactivity may be important in difficult cases: a direct challenge will be very helpful in ruling out asthma (when negative), while it will not be able to confirm it (when positive), and conversely, an indirect challenge will be more helpful in confirming a diagnosis of asthma (when positive), than ruling it out (when negative). ${ }^{167}$

Sputum induction may directly assess airway inflammation in children. ${ }^{173} \mathrm{It}$ implies a semi-invasive induction procedure through inhalation of an ultrasonic aerosol of hypertonic saline, and allows examination of the cellular and soluble content. ${ }^{174-176}$ Although methodological guidelines have been published, a wide variety of sputum induction and processing protocols have been used. ${ }^{175,177-180}$ In children, reported side-effects include not only minor symptoms and discomfort in 6 to 26 per cent, but also airway obstruction, even after beta-2-agonist-pretreatment, in 10 and 19 per cent, respectively, of children with mild and severe disease. ${ }^{173,175,181-187}$ In children, the reported success rate depends on disease severity and age (id est few children aged less than seven years), and varies from 61 to 100 per cent. ${ }^{166,173,175,181-185,188-189}$ All studies report high requirements for technical support and expertise to process, stain and interpret induced sputum samples, hereby limiting its use to tertiary centers. ${ }^{176}$ In asthmatic children, sputum induction can provide information on eosinophilic inflammation and treatment response and is associated with several measures of asthma control. ${ }^{166,173,190-192}$ In children with difficult asthma, abnormal sputum cytology is only present in a minority, whereas it has been suggested recently that sputum eosinophilia in these children may predict their response to systemic corticosteroids. ${ }^{181,193}$ Also, in children with cystic fibrosis, limited data suggest that induced sputum may provide useful markers of inflammation and infection. ${ }^{192,194-197}$

To date, endobronchial biopsy remains the 'golden standard' by which to determine airway inflammation. This invasive diagnostic procedure is safe, even in children with severe asthma, if it is performed by experienced operators with back-up from doctors skilled in airway management and the monitoring of sick children. ${ }^{93,198-202}$ Moreover, there is no reason not to use the opportunities afforded by clinically indicated bronchoscopy to carry out research, if sound ethical principles are followed. $89,93,95,203-$ 205 However, bronchoscopy has considerable limitations: (i) it is an invasive procedure for specific indications only and not suitable for repeated use; ${ }^{199,201}$ (ii) data are lacking on the reproducibility of several parameters in children; ${ }^{206}$ (iii) specimens are small and vulnerable to damage during the biopsy procedure, and can only be obtained from the larger airways; and (iv) many physiological, infectious and mechanical complications are associated with the procedure. ${ }^{174,198,201,207-208}$ 
During bronchoscopy, bronchoalveolar lavage fluid can be obtained for microbiological and cytological analysis. ${ }^{93,117,201,209}$ However, there are many difficulties in the interpretation of findings: (i) bronchoalveolar lavage does not sample a static space or volume of airway surface fluid, as there is a constant exchange of fluid, electrolytes and other soluble constituents across the airway and alveolar epithelium, and as there is no practical way to obtain a pure bronchial or alveolar fraction; (ii) the concentration of any material or cell type in the bronchoalveolar lavage fluid depends on the volume of fluid used for the lavage, the efficiency of mixing and recovery (id est usually 40 to 60 per cent fluid return), the initial concentration in the epithelial lining fluid, and the rate of flux of the material or fluid into the bronchoalveolar lavage fluid during the procedure; and (iii) available normal values are poly-interpretable. ${ }^{174}$

In summary, it may be clear that there exist many limitations of, and discrepancies between: (i) subjectively reported and objectively assessed airway symptoms; (ii) pulmonary function tests reflecting airflow limitation; and (iii) direct or indirect markers of airway inflammation. Moreover, endobronchial biopsy, bronchoalveolar lavage and sputum induction are relatively difficult direct measures of inflammation and not suitable for routine use in clinical practice, whereas it should be stressed again that these are highly valuable basic and clinical research tools. ${ }^{84}$ Obviously, pulmonary function tests and sputum induction require more than minimal cooperation of a child, and thus, success rate substantially declines in children aged six to seven years or less. In general, procedures in favour of children should be suitable at any age, rapid and easy to perform, requiring only minimal cooperation, as well as harmless and painless, and thus, by definition, should never be invasive or semi-invasive. Furthermore, as there is such heterogeneity in chronic respiratory disease expression, it seems only logical that: (i) noninvasive specific single markers, indicating diagnosis, disease control and airway inflammation, have to be assessed at an individual level; and that (ii) if generally applied, a set of various markers is more likely to be useful in larger populations. ${ }^{84,116,210}$ Hence, the leitmotif being the development of novel individualised therapeutical strategies that may replace the current paradigm of strategies aimed at the whole of a certain population. ${ }^{84}$ Therefore, it is crucial to attempt to define additional noninvasive markers that can be applied in clinical practice over a wide range, that may be specific for the evaluation and monitoring of certain disease patterns, including early disease events, and/or response to treatment, and that may give relevant information on the individual child. ${ }^{84,149,211}$

\subsection{Noninvasive inflammometry in children.}

Having explored, in the previous chapter, the various reasons why there is a need for additional noninvasive markers of various phenomena associated with chronic respiratory diseases, especially in the growing child, we will now explore some possibilities that may address this issue. Ideally, we need a noninvasive, rapid and easy to perform method that can be used repeatedly to obtain direct samples of the airways without any risk, that is standardised and successful at any age, that requires no cooperation, and that offers direct measures that are not only sensitive and specific but also reproducible. ${ }^{212}$ Clearly, such a well-defined ideal does not exist in the realities 
of life. Nevertheless, we may unremittingly pursue amelioration, while learning from the past. When Antoine Laurent de Lavoisier published in Paris his 'Traité Elémentaire de Chimie' in 1789, not only the French Revolution was imminent, but also modern chemistry was born by demonstrating that air is not a simple element but actually a composite. ${ }^{213}$ This principle is the basis of this thesis. Indeed, exhaled air or breath potentially has many advantages that approximate the characteristics of an ideal marker of the airways. Analysis of exhaled air shows the presence of volatile substances, such as nitric oxide. ${ }^{207,212}$ Furthermore, exhalation against a cold surface or condenser yields exhaled breath condensate (EBC) that in turn may be collected and analysed for volatile and nonvolatile macromolecules. ${ }^{212,214}$

Nitric oxide, biosynthesised from arginine and oxygen by various nitric oxide synthase enzymes, is now known as a widespread signalling molecule in various organ systems. In 1987, Salvador Moncada (married to Her Royal Highness Princess MariaEsmeralda of Belgium) et al showed unambiguously that nitric oxide was made by endothelial cells and that the actions of nitric oxide (id est full relaxant response of blood vessels) could explain the actions of the formerly known endothelium-derived relaxing factor. ${ }^{215}$ In 1991, Lars Gustafsson et al first described the presence of endogenous nitric oxide in exhaled breath of animals and humans. ${ }^{216}$ In 1998, Robert F Furchgott, Louis J Ignarro and Ferid Murad were jointly awarded the Nobel Prize in Physiology or Medicine for their discoveries concerning nitric oxide as a signalling molecule of the cardiovascular system. ${ }^{217}$

Since the 1990s, the exhaled nitric oxide fraction has been extensively studied and validated as a noninvasive marker in asthma that reflects eosinophilic airway inflammation in the bronchial mucosa and shows a rapid, dose-dependent response to corticosteroids. ${ }^{149,207,212,218}$ Exhaled nitric oxide has been standardised for use in clinical practice, and there are detailed guidelines for the online and offline measurement of exhaled nitric oxide in children aged four to five years and more. ${ }^{219-}$ 220 Normative values have been published for children aged four years and more. ${ }^{221}$ In these cooperative children, the single-breath online measurement method using a chemiluminescence analyser is the preferred technique. ${ }^{149,219-220}$ Results are immediately available. ${ }^{149}$ Recently, compact hand-held analysers have been developed and will facilitate more widespread introduction. ${ }^{149}$ Possible applications of exhaled nitric oxide inflammometry include diagnosis of asthma, prediction of steroid response, monitoring of steroid treatment and treatment compliance, steroid dose titration, prediction of exacerbation or relapse, and screening for asthma. ${ }^{149,207,212,222}$ Recently, several studies have shown not only the feasibility of exhaled nitric oxide measurement in paediatric clinical practice, but also suggested a significant benefit of additionally monitoring exhaled nitric oxide in childhood asthma, as treatment with inhaled corticosteroids can be adjusted individually to prevent under- or over-treatment. ${ }^{207,223-}$ 226 In children and adolescents, elevated exhaled nitric oxide has been shown to correlate well with induced sputum eosinophil counts, ${ }^{219,227-229}$ but not with bronchial hyperrresponsiveness. ${ }^{229-231}$ However, in adolescents in clinical remission of atopic asthma, exhaled nitric oxide and airway responsiveness were significantly correlated 
with each other, as well as with eosinophil counts in bronchial biopsies. ${ }^{85,232}$ Also, in children with difficult asthma, after treatment with oral steroids, a correlation was seen between biopsy eosinophil score and exhaled nitric oxide. ${ }^{233}$

On the other hand in infants and preschool children, although suggestions for the measurement of exhaled nitric oxide have been published, more research is needed to resolve various confounding methodological issues related to spontaneous breathing with or without controlled flow rate, contamination from the upper airways, and forced exhalation. ${ }^{149,219-220,234-245}$

Various other diseases have been associated with high exhaled nitric oxide values, ${ }^{246-258}$ variable exhaled nitric oxide values, ${ }^{259-275}$ and low levels of exhaled nitric oxide. ${ }^{276-288}$ In children with cystic fibrosis, low exhaled nitric oxide levels may be explained by deficient or reduced inducible nitric oxide synthase expression, and/or by trapping and metabolisation of nitric oxide in airways secretions and mucus. ${ }^{278-282,289}$ Children with primary ciliary dyskinesia, characterized by chronic airway infection and bronchiectasis due to a genetic defect leading to reduced ciliary function and impaired mucociliary clearance, have not only abnormally low exhaled nitric oxide values, but also low nasal nitric oxide that is even more discriminative and is now recommended as the screening tool of choice for primary ciliary dyskinesia. ${ }^{149,219,290}$

EBC represents a bi-phasic technique, implicating at first the cooling of exhaled breath to collect the condensate, and subsequently its analysis. ${ }^{212}$ There is strong evidence that abnormalities in EBC composition may reflect biochemical changes of the airway lining fluid, and thus may constitute an alternative approach for noninvasive inflammometry. ${ }^{214}$

Although the EBC procedure is experimental, the guiding and cooling of exhaled breath into a breath condenser system appears to be noninvasive, rapid and relatively easy to perform, as well as being a technique that may be used repeatedly as it does not interact with the ongoing processes in the airways, which, by consequence, may guarantee a high degree of safety to the subjected individual.

Moreover, the bi-phasic nature of the EBC technique may even offer some advantages compared with exhaled nitric oxide: (i) the collection of EBC requires only minimal cooperation of a normal (id est tidal) breathing subject; (ii) therefore, the potential to improve the feasibility of EBC collection, especially in the younger child; (iii) the analysis of EBC may reveal the presence of multiple biomarkers, instead of only one specific volatile substance; and (iv) hence, EBC analysis may prove to be useful in discriminating and/or monitoring more than one inflammatory lung disease.

\subsection{Objectives of the thesis.}

As stated previously, this thesis is based on the principle that air is a composite, and hence, analysis of breath condensate may offer new perspectives in monitoring lung inflammation. ${ }^{213}$ In this thesis, we hypothesise that the noninvasive methodology of 
EBC collection and analysis can be improved and adapted based on objective experimental findings, in order to evolve from a simple home made experimental research tool into a new and potentially useful means of assessing inflammatory disease status, especially in preschool children with chronic respiratory disorders. By consequence, the scope of this thesis is the further development of EBC methodology.

In chapter 1.6 we present a state of the art on the collection and analysis of EBC in children, corresponding to our knowledge in the early years of the new millennium.

In order to facilitate future comparison and interpretation of data on this rapidly growing field of research, we proceed in chapter 2 with an elaboration, from a paediatric point of view, of the pearls and pitfalls of each single aspect of EBC collection and preservation, and, of the markers that yet have been detected in condensate in children.

In chapter 3 we compare new exhaled markers, comprising exhaled nitric oxide, exhaled carbon monoxide, condensate acidity, and cytokines in EBC, with conventional asthma measures, such as lung function parameters and the asthma control questionnaire of Juniper, in a cross sectional study in 32 children.

Triggered by the previous study results, we discuss in chapter 4.1 our increasing awareness of the confounding factors due to the bi-phasic nature of EBC methodology (id est standardisation of collection versus reproducibility of analysis). Consequently, this leads us to proceed with research that intends to integrate more consistently the following three equivalent key issues: (i) engineering of an optimal condensate collection device, (ii) using improved or new techniques suitable to analyse the resulting condensate, and (iii) clinical application in subsets of patients with chronic respiratory disease.

In chapter 4.2 we investigate, both in vitro and in vivo, our hypothesis that the adhesive properties of different condenser coatings interfere with the detection and measurements of eicosanoids and proteins in EBC, as this may prove to be a crucial factor to the further development of a standardised condensate collection system.

In chapter 5 we study the reproducibility of different condensate markers, such as hydrogen peroxide, 8-isoprostane, and cytokines, using different condenser coating systems, including a newly developed glass condenser, in order to find a more reliable condenser. Furthermore, we describe the use of $\mathrm{XMAP}^{\circledR}$ technology, a liquid bead array multiplexing system to simultaneously measure multiple cytokines within a small, single condensate sample.

In chapter 6 we investigate the use of electron paramagnetic resonance spectroscopy to directly detect the presence of free radicals, and thus directly assessing oxidative stress, in EBC in 21 children with cystic fibrosis and healthy controls. Secondly, we examine the possible source of these free radicals. 
In chapter 7 we explore, in a cross sectional design, the ability of exhaled inflammatory markers, including exhaled nitric oxide, condensate acidity, nitrite, nitrate, hydrogen peroxide, 8-isoprostane, interferon-gamma, tumor necrosis factor-alpha, interleukin2, interleukin-4, interleukin-5 and interleukin-10 in EBC, to discriminate between cystic fibrosis and healthy controls, and to indicate disease exacerbation and severity, in a large cohort of 98 children.

In chapter 8 we investigate the feasibility of EBC collection in 70 preschool children, with and without wheezing illness, using a newly modified glass condenser system with breath recirculation system. Furthermore, we study the profiles of interleukin-4, interleukin-5, interleukin-6, interleukin-8, interleukin-10, interleukin-12p70, interleukin13 , and tumor necrosis factor-alpha in EBC, measured by multiplexed XMAP ${ }^{\circledR}$ technology, in different preschool wheezing phenotypes.

Finally, in chapter 9 we present the general discussion of this thesis. 


\subsection{New perspectives in monitoring lung inflammation: analysis of exhaled breath condensate in children.}

Airway inflammation plays an important role in various respiratory disorders of childhood, including recurrent wheezing, asthma, cystic fibrosis, bronchopulmonary dysplasia, and respiratory distress syndrome. ${ }^{291-294}$ In daily clinical practice, indirect indices of airway inflammation like symptoms and lung function measurements are routinely used for diagnosis and follow-up of inflammatory respiratory disorders. Especially in young children, these indirect indices of disease severity are less valuable than in adults; lung function studies in young children are often not possible because of lack of cooperation. Furthermore, reporting of symptoms by parents is much dependent on perception of symptoms with the potential risk for both under or overperception. Therefore in children, there is a strong need for objective and early criteria to detect and monitor airway inflammation in order to prevent or minimize the irreversible changes which are described in various chronic respiratory disorders including asthma, cystic fibrosis and bronchopulmonary dysplasia. 291-295 The analysis of airway inflammatory cells and mediators has traditionally been performed by bronchoscopy on samples of bronchial mucosal biopsies or on bronchoalveolar lavage fluid samples. In children both methods are limited in their applicability because of the invasive procedure of bronchoscopy. It is clear that in daily clinical practice, (serial) measurements of airway inflammation is not feasible using such invasive methods. A less invasive procedure to assess the presence and activity of airway inflammation would be of great benefit for early diagnosis and monitoring of inflammatory airway diseases in children. ${ }^{296}$

Inflammatory markers can be measured in blood or in urine. ${ }^{296}$ The noninvasiveness of these methods is an advantage, but their indirect nature is a limitation. Measurements of certain inflammatory markers in blood and urine represents whole body production and does not necessarily reflect production of these inflammatory markers in the respiratory tract. It is reasonable to assume that the composition of respiratory tract secretions might closer reflect airway inflammation than substances in blood or urine. Sputum is one of the respiratory secretions which can be used in the assessment of airway inflammation. ${ }^{297-298}$ Sputum can be obtained noninvasively, spontaneously or during chest physiotherapy. Sputum examination has been limited by difficulties in obtaining adequate samples. When sputum can not be produced spontaneously, it can be induced by inhalation of an aerosol of hypertonic saline. With this technique, sputum samples can be obtained in up to 75 to 100 per cent of asthmatic and healthy adults. ${ }^{298}$ In children, the succes rate in obtaining adequate samples is definitely lower. ${ }^{188}$ In general sputum induction in children aged less than 6 years is not feasible. Other practical considerations of sputum induction include an inevitability of pretreatment with short acting beta-2-agonists in order to prevent an obstructive airway response provoked by inhalation of hypertonic saline, and the timeconsuming procedure for inducing sputum and processing induced sputum samples. Furthermore, several studies have shown that repeated sputum induction in itself induces changes in airway inflammation within 8 to 24 hours after sputum induction, which limits the usefulness of this method for serial measurements. ${ }^{299-300}$ 
EBC is a recently rediscovered vehicle of substances from the respiratory tract, in which several potential markers of airway inflammation can be detected. In contrast with the other sampling methods mentioned above, EBC offers the advantage that it can be obtained completely noninvasively. Exhaled air carries components from the lower respiratory airways, and does not disturb the airways, in contrast to bronchial biopsies, bronchoalveolar lavage and induced sputum, and it can be obtained with minimal risk and inconvenience from both adults and children.

\subsubsection{Collection of EBC in children}

In children from the age of 4 years and over the EBC collection method(s) as used in adults, can be applied in almost the same way. There is a variety of condensor systems to collect EBC, altough they are fundamentally similar, based on condensation of exhaled air on a cold surface. In general, EBC is collected from adults and children from the age of 4 years by tidal breathing through a mouthpiece and a two-way nonrebreathing valve, which can also serve as a saliva trap, connected to a cooled condensing system. Minimal co-operation from the child is required for this technique of EBC collection. In children, the main issue for success of EBC sampling is if they are able to use a mouthpiece properly for approximatly 10 to 15 minutes. Adequate instruction of the procedure and distraction of the child, for example by using video cartoons, increases the success rate of EBC collection in children. Collecting EBC in children is not only a simple non-invasive procedure, but it is also a safe and feasible method of sampling substances from the respiratory tract. No adverse effects were seen in an EBC collection study in 93 healthy children aged 8 to 13 years, and all the children were able to complete the EBC collection procedure successfully. ${ }^{301}$ In a study of 91 children with asthma of varying severity, the EBC procedure proved to be safe even in children with an asthma exacerbation. ${ }^{302}$ No significant changes in forced expiratory volume in one second were found after the EBC collection. The success rate was 100 per cent starting from 4 years of age. The volume of collected condensate depends on different variables, like minute ventilation or total respired volume, condensor material and temperature, and turbulence characteristics. ${ }^{303}$ Minute ventilation seems to be the most important determinant of the condensate volume over time. So, in children it will take more time to collect the same amount of condensate as in adults. In general, a collection time of 15 to 20 minutes will yield 1 to $3 \mathrm{~mL}$ of EBC in children aged 4 years and over. It has been shown that the collected condensate volume significantly correlates with the age of children. ${ }^{302}$

In infants and young children, who are not able to use a mouthpiece properly, a facemask can be used. In a small number of infants, who are preferential nasal breathers, it was shown that collection of EBC through a facemask was feasible. ${ }^{304-}$ 305 In a sampling time of almost 30 minutes a mean condensate volume of $101.6 \mu \mathrm{L}$ was recovered. ${ }^{304}$ In the condensate of healthy infants and cystic fibrosis infants nitrite and nitrate was detected. However, significant nasal contribution to the total nitrite to nitrate was found, suggesting to limit EBC analysis in infants to compounds not affected by nasal contribution, or to limit EBC collection to sedated infants with induced oral breathing. ${ }^{305}$ 
Nasal collection of EBC is reported in minimal co-operative patients like healthy infants from 4 weeks of age for the analysis of hydrogen peroxide. ${ }^{306}$ Nasal prongs are serially connected to two polypropylene tubes, submerged in a cold trap, and in turn connected to an electric air suction pump. The condensate volume obtained, increased significantly with age, up to 18 years, and was about 45 per cent less in 1 to 6 year old children. It averaged about 20 to 30 per cent of the exhaled breath water vapour. However, contamination with nasal secretions may interfere with the actual concentration of inflammatory mediators in the lower respiratory tract.

\subsubsection{Inflammatory mediators detected in EBC of children}

$E B C$ is presently an active research area. Over the last years an increasing number of EBC data are being presented. However, most data are obtained in adults. For the results of inflammatory mediators in EBC of children we will focus on data published in the international literature as peer-reviewed full articles.

A variety of inflammatory markers have been detected in EBC of children. In contrast to the condensate volume, the studied inflammatory marker levels in EBC are not age dependent.

The most commonly studied mediator is hydrogen peroxide, a marker of oxidative stress. The concentration of hydrogen peroxide in EBC of stable asthmatic children is significantly increased compared to healthy children. ${ }^{307}$ In stable asthmatic children the hydrogen peroxide concentrations were lower in those who used inhaled corticosteroids. In children with unstable asthma higher concentrations have been reported than in stable asthmatic children. ${ }^{308}$ Reference values on hydrogen peroxide have been described in a group of 93 healthy children with a mean age of 10 years. ${ }^{301}$ Hydrogen peroxide was not age-dependent, nor was there a correlation with sex or lung function. ${ }^{301}$ In children, it was demonstrated that atmospheric nitric oxide influenced exhaled hydrogen peroxide levels. ${ }^{309}$ Besides asthma, hydrogen peroxide concentration has also been detected in EBC of cystic fibrosis children with an acute infectious pulmonary exacerbation, and significantly decreased during intravenous antbiotic treatment. ${ }^{310}$

Another marker of oxidative stress which can be measered in the EBC of children is 8-isoprostane. Children with stable asthma had higher exhaled 8-isoprostane concentrations than healthy children. ${ }^{311}$ In the asthmatic group, treatment with inhaled corticosteroids showed no difference in exhaled 8-isoprostane concentrations. The same study also showed, in contrast to the 8-isoprostane results, no significant difference in exhaled prostaglandin E2 concentrations between asthmatic and healthy children. In children with an asthma exacerbation there is a significant reduction of exhaled 8-isoprostane after a 5 day course of oral prednisone..$^{312}$

Leukotrienes can also be measured in EBC. In asthmatic children cysteinyl leukotrienes and leukotriene B4 were significantly increased compared with healthy children. ${ }^{313}$ After a course of oral corticosteroid therapy, a reduction was seen in cysteinyl-leukotrienes in children with an asthma exacerbation. ${ }^{312}$ 
In children with asthma and cystic fibrosis higher levels of nitrite in EBC have been found compared to children with non-asthmatic episodic cough and healthy children. ${ }^{314}$ No significant differences were noted between the asthmatic and cystic fibrosis children, nor the episodic cough and healthy groups. In cystic fibrosis, there was no significant correlation between condensate nitrite levels and age, lung function or use of inhaled corticosteroids. ${ }^{315}$ Children with primary ciliary dyskinesia have been shown to have very low levels of exhaled oral and nasal nitric oxide. ${ }^{283}$ However, no differences were found in the EBC levels of nitric oxide metabolites such as nitrite, nitrate, and S-nitrosothiol between children with primary ciliary dyskinesia and healthy children, despite the marked decrease in exhaled nitric oxide levels in primary ciliary dyskinesia patients. ${ }^{316}$

Cytokines reported in EBC of children include interleukin-8, interleukin-4 and interferon-gamma. In cystic fibrosis, interleukin-8 could only be detected in 33 per cent of the condensate samples. ${ }^{315}$ Altough the interleukin-8 values were higher in cystic fibrosis children than in healthy controls, there was no statistically significant difference. Increased levels of interleukin-4 and decreased levels of interferon-gamma were detected in EBC of stable asthmatic children. ${ }^{317}$ The use of inhaled corticosteroids was associated with a significant change in interleukin-4 concentration, in contrast to interferon-gamma concentration. Interferon-gamma was detectable in all EBC samples, whereas interleukin-4 was detectable in 92 per cent of the samples.

Aldehydes and glutathione are biomarkers of oxidant induced damage and antioxidant status, respectively. Malondialdehyde and glutathione are detectable in EBC of children. ${ }^{318}$ In children with an asthma exacerbation, malondialdehyde levels were higher and glutathione levels were lower compared to healthy children. ${ }^{318}$ After a 5 day course of oral prednisone malondialdehyde decraesed to values no longer different from those of the healthy control children, whereas glutathione levels increased. In healthy subjects as well as in asthmatic children, malondialdehyde and glutathione were negatively correlated. Malondialdehyde and glutathione concentrations were not dependent of exhaled flow rate $(200,150,100$, and $50 \mathrm{~mL} /$ second), and no correlation was found between spirometric values and these oxidant versus antoxidant levels in EBC. 
Table 1. Inflammatory markers in EBC of children with asthma or cystic fibrosis

\begin{tabular}{lccc} 
& Asthma & Cystic Fibrosis & References \\
\hline hydrogen peroxide & $\Uparrow$ & $\Uparrow$ & $307,308,310$ \\
8-isoprostane & $\Uparrow$ & $(-)$ & 311,312 \\
prostaglandin E2 & $\Uparrow$ & $(-)$ & 311 \\
cysteinyl leukotrienes & $\Uparrow$ & $(-)$ & 312,313 \\
leukotriene B4 & $\Uparrow$ & $(-)$ & 313 \\
nitrite & $\Uparrow$ & $(-)$ & 314,315 \\
interleukin-4 & $\Uparrow$ & $=$ & 317 \\
interleukin-8 & $(-)$ & $(-)$ & 315 \\
interferon-gamma & $\Downarrow$ & $(-)$ & 317 \\
aldehyde & $\Uparrow$ & $(-)$ & 318 \\
glutathione & $\Downarrow$ & & 318 \\
\hline \multicolumn{5}{c}{} \\
EBC exhaled breath condensate & & \\
$\Uparrow \quad$ significantly increased compared to healthy children & & \\
$\Downarrow \quad$ significantly decreased compared to healthy children & & \\
$=$ & no significant difference compared to healthy children & \\
(-) no paediatric data &
\end{tabular}

Table 1 summarizes paediatric results of inflammatory markers in EBC of children with asthma or cystic fibrosis.

\subsubsection{Conclusion}

Assesment of inflammatory mediators in EBC is a challenging new technique for the diagnosis and management of various inflammatory lung diseases. Because of the non-invasive character of EBC and the general lack of appropiate other techniques to characterize airway inflammation in children, it is particularly interesting for paediatric respiratory medicine. EBC is not only a simple and noninvasive procedure, but it is also a safe and feasible method of sampling inflammatory mediators from the respiratory tract in children from the age of 4 years and over. A variety of inflammatory markers have been detected in EBC of children. Potentially, this noninvasive method will allow early and appropriate anti-inflammatory treatment in children, which hopefully will prevent, or at least limit, the later development of chronic respiratory diseases in adults. However, the clinical relevance of exhaled inflammatory markers first needs to be established in longitudinal studies in various respiratory disorders, with repeated measurements in individual patients. 


\section{References}

1. Merkus PJFM, Hislop AA. Lung development from infancy to adulthood. In: Frey U, Gerritsen J, eds. Respiratory diseases in infants and children. Eur Respir Mon 2006; 37: 8-21.

2. Hislop A, Wigglesworth JS, Desai R. Alveolar development in the human fetus and infant. Early Hum Dev 1986; 13: 1-11.

3. Mead J. Dysanapsis in normal lungs assessed by the relationship between maximal flow, static recoil, and vital capacity. Am Rev Respir Dis 1980; 121: 339-342.

4. LeSouëf $P$, Kabesch $M$. Impact of genetic factors on lung development in health and disease. In: Frey U, Gerritsen J, eds. Respiratory diseases in infants and children. Eur Respir Mon 2006; 37: 93-107.

5. Gerritsen J, Reijmerink NE, Kerkhof M, Postma DS. Gene-environment interaction and respiratory disease in children. In: Frey $U$, Gerritsen J, eds. Respiratory diseases in infants and children. Eur Respir Mon 2006; 37: 108-119.

6. Darwin C. On the origin of species by means of natural selection, or the preservation of favoured races in the struggle for life. London, John Murray, ed., 1859.

7. Jaenisch R, Bird A. Epigenetic regulation of gene expression: how the genome integrates intrinsic and environmental signals. Nat Genet 2003; 33: 245-254.

8. Schaub B, Lauener R, Prescott SL. Immunology and defence mechanism of the developing lung. In: Frey U, Gerritsen J, eds. Respiratory diseases in infants and children. Eur Respir Mon 2006; 37: 60-78.

9. Custovic A, Lødrup Carlsen KC, Håkon Carlsen K. Allergy and the paediatric lung during development. In: Frey U, Gerritsen J, eds. Respiratory diseases in infants and children. Eur Respir Mon 2006; 37: 79-92.

10. Takeda K, Akira S. Toll-like receptors in innate immunity. Int Immunol 2005; 17: 1-14.

11. Cochrane AL. Effectiveness and efficiency: random reflections on Health services. London 1972, Nuffield Provincial Hospitals Trust.

12. Centre for Evidence-Based Medicine. What is EBM? www.cebm.net/?o=1014. Date last accessed: May 282007.

13. Grigg J, Silverman M. Wheezing disorders in young children: one disease or several phenotypes? In: Frey U, Gerritsen J, eds. Respiratory diseases in infants and children. Eur Respir Mon 2006; 37: 153-169.

14. Tonelli MR. The limits of evidence-based medicine. Respir Care 2001; 46: 1435-1440.

15. von Mutius E. Epidemiology of respiratory diseases in infants and children. In: Frey U, Gerritsen J, eds. Respiratory diseases in infants and children. Eur Respir Mon 2006; 37: 1-7.

16. Martinez FD, Wrigth AL, Taussig LM, Holberg CJ, Halonen M, Morgan WJ. Asthma and wheezing in the first six years of life. N Engl J Med 1995; 332: 133-138.

17. Elphick HE, Ritson S, Rodgers H, Everard ML. When a "wheeze" is not a wheeze: acoustic analysis of breath sounds in infants. Eur Respir J 2000; 16: 593-597.

18. Cane RS, Ranganathan SC, McKenzie SA. What do parents of wheezy children understand by "wheeze" ? Arch Dis Child 2000; 82: 327-332.

19. Chauliac ES, Silverman M, Zwahlen M, Strippoli M-PF, Brooke AM, Kuehni CE. The therapy of preschool wheeze: appropriate and fair? Pediatr Pulmonol 2006; 41: 829-838. 
20. Silverman $M$, Wang $M$, Hunter $G$, Taub N. Episodic viral wheeze in preschool children: effect of topical nasal corticosteroid prophylaxis. Thorax 2003; 58: 431-434.

21. Johnston SL. Overview of virus-induced airway disease. Proc Am Thorac Soc 2005; 2: $150-156$

22. Lemanske RF Jr, Jackson DJ, Gangnon RE, Evans MD, Li Z, Shult PA, Kirk CJ, Reisdorf E, Roberg KA, Anderson EL, Carlson-Dakes KT, Adler KJ, Gilbertson-White S, Pappas TE, Dasilva DF, Tisler CJ, Gern JE. Rhinovirus illnesses during infancy predict subsequent childhood wheezing. J Allergy Clin Immunol 2005; 116: 571-577.

23. Kimpen JLL, Hammer J. Bronchiolitis in infants and children. In: Frey U, Gerritsen J, eds. Respiratory diseases in infants and children. Eur Respir Mon 2006; 37: 170-190.

24. Schaub B, Lauener R, von Mutius E. The many faces of the hygiene hypothesis. $J$ Allergy Clin Immunol 2006; 117: 969-977.

25. Tager I, Ngo L, Hanrahan J. Maternal smoking during pregnancy. Effects on lung function during the first 18 months of life. Am J Respir Crit Care Med 1995; 152 : 977-983.

26. Hanrahan J, Tager IB, Segal MR, Tosteson TD, Castile RG, Van Vunakis H, Weiss ST, Speizer FE. The effect of maternal smoking during pregnancy on early infant lung function. Am Rev Respir Dis 1992; 145: 1129-1135.

27. Nafstad P, Brunekreef B, Skrondal A, Nystad W. Early respiratory infections, asthma, and allergy: 10 year follow-up of the Oslo Birth Cohort. Pediatrics 2005; 116: e255-e262.

28. Stein RT, Sherrill D, Morgan WJ, Holberg CJ, Halonen M, Taussig LM, Wright AL, Martinez FD. Respiratory syncytial virus in early life and risk of wheeze and allergy by age 13 years. Lancet 1999; 354: 541-545.

29. Bont L, Steijn M, Van Aalderen WMC, Brus F, Draaisma JMTh, Van DiemenSteenvoorde RA, Pekelharing-Berghuis M, Kimpen JL. Seasonality of long term wheezing following respiratory syncytial virus lower respiratory tract infection. Thorax 2004; 59: 512-516.

30. Korppi M, Piippo-Savolainen E, Korhonen K, Remes S. Respiratory morbidity 20 years after RSV infection in infancy. Pediatr Pulmonol 2004; 38: 155-160.

31. Phelan P, Robertson C, Olinsky A. The Melbourne Asthma Study: 1964-1999. J Allergy Clin Immunol 2002; 109: 189-194.

32. Sears MR, Greene JM, Willian AR. A longitudinal, population-based, cohort study of childhood asthma followed to adulthood. N Eng J Med 2003; 349: 1414-1422.

33. Kurukulaaratchy RJ, Matthews S, Arshad SH. Defining childhood atopic phenotypes to investigate the association of atopic sensitization with allergic disease. Allergy 2005; 60: 1280-1286.

34. Halonen M, Stern DA, Wright AL, Taussig LM, Martinez FD. Alternaria as a major allergen for asthma in children raised in a desert environment. Am J Respir Crit Care Med 1997; 155: 1356-1361.

35. Illi S, von Mutius E, Lau S, Nickel R, Niggemann B, Sommerfeld C, Wahn U; Multicenter Allergy Study Group. The pattern of atopic sensitization is associated with the development of asthma in childhood. J Allergy Clin Immunol 2001; 108: 709-714.

36. Wahn U, Bergmann R, Kulig M, Forster J, Bauer CP. The natural course of sensitisation and atopic disease in infancy and childhood. Pediatr Allergy Immunol 1997; 8: Suppl.10, 16-20. 
37. Lau S, Illi S, Sommerfeld C, Niggemann B, Bergmann R, von Mutius E, Wahn U. Early exposure to house dust mite and cat allergens and the development of childhood asthma. Lancet 2000; 356: 1392-1397.

38. Brussee JE, Smit HA, van Strien RT, Corver K, Kerkhof M, Wijga AH, Aalberse RC, Postma D, Gerritsen J, Grobbee DE, de Jongste JC, Brunekeef B. Allergen exposure in infancy and the development of sensitization, wheeze, and asthma at 4 years. $J$ Allergy Clin Immunol 2005; 115: 946-952.

39. Woodcock A, Lowe LA, Murray CS, Simpson BM, Pipis SD, Kissen P, Simpson A, Custovic A; NAC Manchester Asthma and Allergy Study Group. Early life environmental control: effect on symptoms, sensitization, and lung function at age of 3 years. Am J Respir Crit Care Med 2004; 170: 433-439.

40. Strachan DP, Butland BK, Anderson HR. Incidence and prognosis of asthma and wheezing illness from early childhood to age 33 in a national British cohort. BMJ 1996; 312: 1195-1199.

41. Gern JE, Brooks GD, Meyer P, Chang A, Shen K, Evans MD, Tisler C, Dasilva D, Roberg KA, Mikus LD, Rosenthal LA, Kirk CJ, Shult PA, Bhattacharya A, Li Z, Gangnon $\mathrm{R}$, Lemanske RF Jr. Bidirectional interactions between viral respiratory illnesses and cytokine responses in the first year of life. J Allergy Clin Immunol 2006; 117: 72-78.

42. Celedon JC, Wright RJ, Litonjua AA, Sredl D, Ryan L, Weiss ST, Gold DR. Day care attendance in early life, maternal history of asthma, and asthma at the age of 6 years. Am J Respir Crit Care Med 2003; 167: 1239-1243.

43. Ball TM, Castro-Rodriguez JA, Griffith KA, Holberg CJ, Martinez FD, Wright AL. Siblings, day-care attendance, and the risk of asthma and wheezing during childhood. N Eng J Med 2000; 343: 538-543.

44. Kramer U, Heinrich J, Wjst M, Wichmann HE. Age of entry to day nursery and allergy in later childhood. Lancet 1999; 353: 450-454.

45. Strachan DP. Hay fever, hygiene and household size. BMJ 1989; 299: 1259-1260.

46. Martinez FD, Holt PG. Role of microbial burden in aetiology of allergy and asthma. Lancet 1999; 354 (suppl.2): II12-15.

47. Riedler J, Braun-Fahrlander C, Eder W, Schreuer M, Waser M, Maisch S, Carr D, Schierl R, Nowak D, von Mutius E; ALEX Study Team. Exposure to farming in early life and development of asthma and allergy: a cross-sectional survey. Lancet 2001; 358: 1129-1133.

48. Radon K, Ehrenstein V, Praml G, Nowak D. Childhood visits to animal buildings and atopic diseases in adulthood: an age-dependent relationship. Am J Ind Med 2004; 46: 349-356.

49. Platts-Mills TA, Woodfolk JA, Sporik RB. Con: the incresase in asthma cannot be ascribed to cleanliness. Am J Respir Crit Care Med 2001; 164: 1107-1109.

50. Bach JF. The effect of infections on susceptibility to autoimmune and allergic diseases. N Eng J Med 2002; 347: 911-920.

51. Yazdanbakhsh M, van den Biggelaar A, Maizels RM. Th2 responses without atopy: immunoregulation in chronic helminthic infections and reduced allergic disease. Trends Immunol 2001; 22: 372-377. 
52. Eisenbarth SC, Piggott DA, Huleatt JW, Visintin I, Herrick CA, Bottomly K. Lipopolysaccharide-enhanced, toll-like receptor 4-dependent $\mathrm{T}$ helper cell type 2 responses to inhaled antigen. J Exp Med 2002; 196: 1645-1651.

53. Braun-Fahrlander C, Riedler J, Herz U, Eder W, Waser M, Grize L, Maisch S, Carr D, Gerlach F, Bufe A, Lauener RP, Schierl R, Renz H, Nowak D, von Mutius E; Allergy and Endotoxin Study Team. Environmental exposure to endotoxin and its relation to asthma in school-age children. N Eng J Med 2002; 347: 869-877.

54. Akdis CA, Blaser K, Akdis M. Genes of tolerance. Allergy 2004; 59: 897-913.

55. Belkaid Y, Piccirillo CA, Mendez S, Shevach EM, Sacks DL. CD4+CD25+ regulatory T cells control Leishmania major persistence and immunity. Nature 2002; 420: 502507.

56. Beeson PB. Tolerance to bacterial pyrogens. J Exp Med 1947; 86: 29.

57. Fan H, Cook JA. Molecular mechanisms of endotoxin tolerance. J Endotoxin Res 2004; 10: 71-84.

58. Holt PG, Upham JW, Sly PD. Contemporaneous maturation of immunologic and respiratory functions during early childhood: implications for development of asthma prevention strategies. J Allergy Clin Immunol 2005; 116: 16-24.

59. Culley FJ, Pollot J, Openshaw PJM. Age at first viral infection determines the pattern of T-cell-mediated disease during reinfection in adulthood. J Exp Med 2002; 196 : 1381-1386.

60. Pohunek P, Warner JO, Turzikova J, Kudrmann J, Roche WR. Markers of eosinophilic inflammation and tissue re-modelling in children before clinically diagnosed bronchial asthma. Pediatr Allergy Immunol 2005; 16: 43-51.

61. Greenough A, Kotecha S, Vrijlandt E. Bronchopulmonary dysplasia: current models and concepts. In: Frey U, Gerritsen J, eds. Respiratory diseases in infants and children. Eur Respir Mon 2006; 37: 217-233.

62. Johnson AH, Peacock JL, Greenough A, Marlow N, Limb ES, Marston L, Calvert SA; United Kingdom Oscillation Study Group. High-frequency oscillatory ventilation for the prevention of chronic lung disease of prematurity. N Eng J Med 2002; 347: 633-642.

63. Jobe AH, Bancalari E. Bronchopulmonary dysplasia. Am J Respir Crit Care Med 2001; 163: $1723-1729$.

64. Husain AN, Siddiqui NH, Stocker JT. Pathology of arrested acinar development in post-surfactant bronchopulmonary dysplasia. Hum Pathol 1998; 29: 710-717.

65. Kotecha S. Lung growth: implications for the newborn infant. Arch Dis Child Fetal Neonatal Ed 2000; 82: F69-F74.

66. Northway WH Jr, Rosan RC, Porter DY. Pulmonary disease following respirator therapy of hyaline-membrane disease: bronchopulmonary dysplasia. N Eng J Med 1967; 276: 357-368.

67. Bush A, Götz M. Cystic Fibrosis. In: Frey U, Gerritsen J, eds. Respiratory diseases in infants and children. Eur Respir Mon 2006; 37: 234-290.

68. Bush A. Cystic Fibrosis. In: European Respiratory Society/ European Lung Foundation. Lung Health in Europe Facts and Figures. Loddenkemper R, Gibson GJ, Sibille Y, eds. Sheffield, UK, ERSJ, 2003: pp.89-95.

69. Rosenstein BJ, Cutting GR, for the Cystic Fibrosis Foundation Consensus Panel. The diagnosis of cystic fibrosis: a consensus statement. J Pediatr 1998; 132: 589-595. 
70. Rowe SM, Miller S, Sorscher EJ. Cystic Fibrosis. Mechanisms of disease. N Eng J Med 2005; 352: 1992-2001.

71. Cystic Fibrosis Foundation. Patient Registry 1995 Annual Data Report. Bethesda, Cystic Fibrosis Foundation 1996.

72. Guidelines for the performance of the sweat test for the investigation of cystic fibrosis in the UK www. guideline.gov/summary/summary. aspx?ss=15\&doc id=5059\&nbr=3543. Date last accessed: May 282007.

73. Massie J, Olzen M, Glazner J, Robertson C, Francis I. Newborn screening for cystic fibrosis in Victoria : 10 years' experience (1989-1998). Med J Aust 2000; 172: 584587.

74. Groman JD, Meyer ME, Wilmott RW, Zeitlin PL, Cutting GR. Variant cystic fibrosis phenotypes in the absences of CFTR mutations. N Eng J Med 2002; 347: 401-407.

75. Bishop MD, Freedman SD, Zielenski J, et al. The cystic fibrosis transmembrane conductance regulator gene and ion channel function in patients with idiopathic pancreatitis. Hum Genet 2005; 118: 372-381.

76. Eaton TE, Weiner Miller P, Garrett JE, Cutting GR. Cystic fibrosis transmembrane conductance regulator gene mutations: do they play a role in the aetiology of allergic bronchopulmonary aspergillosis? Clin Exp Allergy 2002; 32: 756-761.

77. Bush A, Wallis C. Time to think again: cystic fibrosis is not an "all or none" disease. Pediatr Pulmonol 2000; 30: 139-144.

78. Busse WW, Lemanske RF Jr. Advances in immunology: asthma. N Eng J Med 2001; 344: 350-362.

79. Chung KF, Barnes PJ. Cytokines in asthma. Thorax 1999; 54: 825-857.

80. Noah TL, Becker S. Chemokines in nasal secretions of normal adults experimentally infected with respiratory syncytial virus. Clin Immunol 2000; 97: 43-49.

81. Geha RS, Jabara HH, Brodeur SR. The regulation of immunoglobulin E class-switch recombination. Nat Rev Immunol 2003; 3: 721-732.

82. Bacharier LB, Jabara H, Geha RS. Molecular mechanisms of immunoglobulin E regulation. Int Arch Allergy Immunol 1998; 115: 257-269.

83. Lane SJ, Lee TH. Mast cell effector mechanisms. J Allergy Clin Immunol 1996; 98 : S67-S72.

84. Wildhaber JH, Sennhauser FH, Brand PLP. Asthma in school-aged children and adolescents. In: Frey U, Gerritsen J, eds. Respiratory diseases in infants and children. Eur Respir Mon 2006; 37: 191-216.

85. van den Toorn LM, Overbeek SE, de Jongste JC, Leman K, Hoogsteden HC, Prins JB. Airway inflammation is present during clinical remission of atopic asthma. Am J Respir Crit Care Med 2001; 164: 2107-2113.

86. Cokugras H, Akcakaya N, Seckin, Camcioglu Y, Sarimat N, Aksoy F. Ultrastructural examination of bronchial biopsy specimens from children with moderate asthma. Thorax 2001; 56: 25-29.

87. Payne DN, Rogers AV, Ädelroth E, Bandi V, Guntupalli KK, Bush A, Jeffery PK. Early thickening of the reticular basement membrane in children with difficult asthma. Am J Respir Crit Care Med 2003; 167: 78-82.

88. Jenkins HA, Cool C, Szefler SJ, Covar R, Brugman S, Gelfand EW, Spahn JD. Histopathology of severe childhood asthma: a case series. Chest 2003; 124: 32-41. 
89. Barbato A, Turato G, Baraldo S, Bazzan E, Calabrese F, Tura M, Zuin R, Beghe B, Maestrelli P, Fabbri LM, Saetta M. Airway inflammation in childhood asthma. Am J Respir Crit Care Med 2003; 168: 798-803.

90. Payne DN, Qiu Y, Zhu J, Peachey L, Scallan M, Bush A, Jeffery PK. Airway inflammation in children with difficult asthma: relationships with airflow limitation and persistent symptoms. Thorax 2004; 59: 862-869.

91. de Blic J, Tillie-Leblond I, Tonnel AB, Jaubert F, Scheinmann P, Gosset P. Difficult asthma in children: an analysis of airway inflammation. J Allergy Clin Immunol 2004; 113: $94-100$

92. Saglani S, Malmstrom K, Pelkonen AS, Malmberg LP, Lindahl H, Kajosaari M, Turpeinen M, Rogers AV, Payne DN, Bush A, Haahtela T, Makela MJ, Jeffery PK. Airway remodeling and inflammation in symptomatic infants with reversible airflow obstruction. Am J Respir Crit Care Med 2005; 171: 722-727.

93. Payne DN, Saglani S, Bush A. Remodelling in paediatric respiratory disease and impact on growth and development. In: Frey U, Gerritsen J, eds. Respiratory diseases in infants and children. Eur Respir Mon 2006; 37: 41-59.

94. Bousquet J, Jeffery PK, Busse WW, Johnson M, Vignola AM. Asthma, from bronchoconstriction to airways inflammation and remodelling. Am J Respir Crit Care Med 2000; 161: 1720-1745.

95. Fedorov IA, Wilson SJ, Davies DE, Holgate ST. Epithelial stress and structural remodelling in childhood asthma. Thorax 2005; 60: 389-394.

96. Holgate ST. Inflammation and remodelling in asthma and allied disorders. Summary and conclusions. Clin Exp Allergy Rev 2001; 1: ix-xiii.

97. Baldwin L, Roche WR. Does remodelling of the airway wall precede asthma? Paediatr Respir Rev 2002; 3: 315-320.

98. Morgan WJ, Stern DA, Sherrill DL, Guerra S, Holberg CJ, Guilbert TW, Taussig LM, Wright AL, Martinez FD. Outcome of asthma and wheezing in the first six years of life: follow-up through adolescence. Am J Respir Crit Care Med 2005; 172: 12531258

99. British Thoracic Society, Scottish Intercollegiate Guidelines Network. British guideline on the management of asthma. Thorax 2003; 58: Suppl.1, i1-i94.

100. NAEPP Expert Panel. Guidelines for the diagnosis and management of asthma update on selected topics 2002. NIH publication no. 02-5075. 2002. Bethesda, National Institutes of Health, 2002.

101. Childhood Asthma Management Program Research Group. Long-term effects of budesonide or nedocromil in children with asthma. N Eng J Med 2000; 343: 1054-1063.

102. Merkus PJ, van Pelt W, van Houwelingen JC, van Essen-Zandvliet LE, Duiverman EJ, Kerrebijn KF, Quanjer $\mathrm{PH}$. Inhaled corticosteroids and growth of airway function in asthmatic children. Eur Respir J 2004; 23: 861-868.

103. Pauwels RA, Pedersen S, Busse WW, Tan WC, Chen YZ, Ohlsson SV, Ullman A, Lamm CJ, O'Byrne PM; START Investigators Group. Early intervention with budesonide in mild persistent asthma: a randomised, double-blind trial. Lancet 2003; 361: 1071-1076.

104. Martinez FD. Towards asthma prevention - does all that really matters happen before we learn to read? N Eng J Med 2003; 349: 1473-1475. 
105. Rasmussen F, Taylor DR, Flannery EM, Cowan JO, Greene JM, Herbison GP, Sears MR. Risk factors for airway remodelling in asthma manifested by a low postbronchodilator FEV1/vital capacity ratio: a longitudinal population study from childhood to adulthood. Am J Respir Crit Care Med 2002; 165: 1480-1488.

106. Kamps AW, Brand PL, Kimpen JL, Maille AR, Overgoor-van de Groes AW, van Helsdingen-Peek LC, Roorda RJ. Outpatient management of childhood asthma by paediatrician or asthma nurse: randomised controlled study with one year follow up. Thorax 2003; 58: 968-973.

107. NHLBI/WHO. NHLBI/WHO Workshop Report. Global strategy for asthma mangement and prevention. Publication no. 02-3659, issued 1995 and revised 2002. Bethesda, Maryland, USA, National Institute of Health.

108. NAEPP Expert Panel Report 2. Guidelines for the diagnosis and management of asthma. Publication no. 97-4051, issued 1997 and revised 2002. Bethesda, Maryland, USA, National Institute of Health.

109. Rabe KF, Adachi M, Lai CK, Soriano JB, Vermeire PA, Weiss KB, Weiss ST. Worldwide severity and control of asthma in children and adults: the global asthma insights and reality surveys. J Allergy Clin Immunol 2004; 114: 40-47.

110. Rabe KF, Vermeire PA, Soriano JB, Maier WC. Clinical management of asthma in 1999: the Asthma Insights and Reality in Europe (AIRE) study. Eur Respir J 2000; 16 : 802-807.

111. Kaur B, Anderson HR, Austin J, Burr M, Harkins LS, Strachan DP, Warner JO. Prevalence of asthma symptoms, diagnosis, and treatment in 12-14 year old children across Great Britain (international study of asthma and allergies in childhood, ISAAC UK). BMJ 1998; 316: 118-124.

112. Paterson NAM, Peat JK, Mellis CM, Xuan W, Woolcock AJ. Accuracy of asthma treatment in schoolchildren in NSW, Australia. Eur Respir J 1997; 10: 658-664.

113. Kuehni CE, Frey U. Age-related differences in perceived asthma control in childhood: guidelines and reality. Eur Respir J 2002; 20: 880-889.

114. Balfour-Lynn IM. Difficult asthma: beyond the guidelines. Arch Dis Child 1999; 80: 201-206.

115. Milgrom H, Bender B, Ackerson L, Bowry P, Smit B, Rand C. Noncompliance and treatment failure in children with asthma. J Allergy Clin Immunol 1996; 98: 1051-1057.

116. Custovic A, Simpson A. Environmental allergen exposure, sensitisation and asthma: from whole populations to individuals at risk. Thorax 2004; 59: 825-827.

117. Stevenson EC, Turner G, Heaney LG, Schock BC, Taylor R, Gallagher T, Ennis M, Shields MD. Bronchoalveolar lavage findings suggest two different forms of childhood asthma. Clin Exp Allergy 1997; 27: 1027-1035.

118. Maclennan C, Hutchinson P, Holdsworth S, Bardin PG, Freezer NJ. Airway inflammation in asymptomatic children with episodic wheeze. Pediatr Pulmonol 2006; 41: 577-583.

119. Le Bourgeois $M$, Goncalves $M$, Le Clainche $L$, et al. Bronchoalveolar cells in children $<3$ years old with severe recurrent wheezing. Chest 2002; 122: 791-797.

120. Krawiec ME, Westcott JY, Chu HW, et al. Persistent wheezing in very young children is associated with lower respiratory inflammation. Am J Respir Crit Care Med 2001; 163: 1338-1343. 
121. McKean MC, Hewitt C, Lambert PC, Myint S, Silverman M. An adult model of exclusively viral wheeze: inflammation in the upper and lower respiratory tracts. Clin Exp Allergy 2003; 33: 912-920.

122. Saglani S, Nicholson AG, Scallan M, Balfour-Lynn I, Rosenthal M, Payne DN, Bush A. Investigation of young children with severe recurrent wheeze: any clinical benefit? Eur Respir J 2006; 27: 29-35.

123. Ward C, Pais M, Bish R, Reid D, Feltis B, Johns D, Walters EH. Airway inflammation, basement membrane thickening and bronchial hyperresponsiveness in asthma. Thorax 2002; 57: 309-316.

124. Oommen A, McNally T, Grigg J. Eosinophil activation and preschool viral wheeze. Thorax 2003; 58: 876-879.

125. Oommen A, Lambert PC, Grigg J. Efficacy of a short course of parent-initiated oral prednisolone for viral wheeze in children aged 1-5 years: randomised controlled trial. Lancet 2003; 362: 1433-1438.

126. Oommen A, Patel R, Browning M, Grigg J. Systemic neutrophil activation in acute preschool viral wheeze. Arch Dis Child 2003; 88: 529-531.

127. Grissell TV, Powell H, Shafren DR, Boyle MJ, Hensley MJ, Jones PD, Whitehead BF, Gibson PG. Interleukin-10 gene expression in acute virus-induced asthma. Am J Respir Crit Care Med 2005; 172: 433-439.

128. Douwes J, Gibson P, Pekkanen J, Pearce N. Non-eosinophilic asthma: importance and possible mechanisms. Thorax 2002; 57: 643-648.

129. Lindemans CA, Coffer PJ, Schellens I, de Graaf PM, Kimpen JLL, Koenderman L. Respiratory syncytial virus prolongs granulocytes survival. Proc Am Thorac Soc 2005; 2: A683.

130. Beyer M, Bartz H, Hörner K, Doths S, Koerner-Rettberg C, Schwarze J. Sustained increases in numbers of pulmonary dendritic cells after respiratory syncytial virus infection. J Allergy Clin Immunol 2004; 113: 127-133.

131. Gill MA, Palucka AK, Barton T, Ghaffar F, Jafri H, Banchereau J, Ramilo O. Mobilization of plasmacytoid and myeloid dendritic cells to mucosal sites in children with respiratory infections. J Infect Dis 2005; 191: 1105-1115.

132. de Graaff PM, de Jong EC, van Capel TM, van Dijk ME, Roholl PJ, Boes J, Luytjes W, Kimpen JL, van Bleek GM. Respiratory syncytial virus infection of monocyte-derived dendritic cells decreases their capacity to activate CD4 T cells. J Immunol 2005; 175: 5904-5911.

133. Bont L, Heijnen CJ, Kavelaars A, van Aalderen WM, Brus F, Draaisma JT, Geelen SM, Kimpen JL. Monocyte IL-10 production during respiratory syncytial virus bronchiolitis is associated with recurrent wheezing in a one-year follow-up study. Am J Respir Crit Care Med 2000; 161: 1518-1523.

134. Bont L, Heijnen CJ, Kavelaars A, van Aalderen WM, Brus F, Draaisma JM, PekelharingBerghuis M, van Diemen-Steenvoorde RA, Kimpen JL. Local interferon-gamma levels during respiratory syncytial virus lower respiratory tract infections are associated with disease severity. J Infect Dis 2001; 184: 355-358.

135. Kotecha S. Cytokines in chronic lung disease of prematurity. Eur J Pediatr 1996; 155 : Suppl. 2, S14-S17. 
136. Groneck P, Speer CP. Inflammatory mediators and bronchopulmonary dysplasia. Arch Dis Child 1995; 73: F1-F3.

137. Yoon BH, Romero R, Jun JK, Park KH, Park JD, Ghezzi F, Kim BI. Amniotic fluid cytokines (interleukin-6, tumor necrosis factor-alpha, interleukin-1-beta, and interleukin-8) and the risk for the development of bronchopulmonary dysplasia. Am J Obstet Gynecol 1997; 177: 825-830.

138. Kasahara Y, Tuder RM, Taraseviciene-Stewart L, Le Cras TD, Abman S, Hirth PK, Waltenberger J, Voelkel NF. Inhibition of VEGF-receptors causes lung cell apoptosis and emphysema. J Clin Invest 2000; 106: 1311-1319.

139. Tirouvanziam R, de Bentzmann S, Hubeau C, Hinnrasky J, Jacquot J, Peault B, Puchelle E. Inflammation and infection in naïve human cystic fibrosis airway grafts. Am J Respir Cell Mol Biol 2000; 23: 121-127.

140. Muhlebach MS, Stewart PW, Leigh MW, Noah TL. Quantification of inflammatory response to bacteria in young cystic fibrosis and control patients. Am J Respir Crit Care Med 1999; 160: 186-191.

141. Armstrong DS, Hook SM, Jamsen KM, Nixon GM, Carzino R, Carlin JB, Robertson CF, Grimwood K. Lower airway inflammation in infants with cystic fibrosis detected by newborn screening. Pediatr Pulmonol 2005; 40: 500-510.

142. Bonfield TL, Konstan MW, Burfeind P, Panuska JR, Hilliard JB, Berger M. Normal bronchial epithelial cells constitutively produce the anti-inflammatory cytokine interleukin-10, which is down-regulated in cystic fibrosis. Am J Respir Cell Mol Biol 1995; 13: 257-261.

143. Karp CL, Flick LM, Park KW, Softic S, Greer TM, Keledjian R, Yang R, Uddin J, Guggino WB, Atabani SF, Belkaid Y, Xu Y, Whitsett JA, Accurso FJ, Wills-Karp M, Petasis NA. Defective lipoxin-mediated anti-inflammatory activity in the cystic fibrosis airway. Nat Immunol 2004; 5: 388-392.

144. Davies JC, Stern M, Dewar A, Caplen NJ, Munkonge FM, Pitt T, Sorgi F, Huang L, Bush A, Geddes DM, Alton EW. CFTR gene transfer reduces the binding of Pseudomonas aeruginosa to cystic fibrosis respiratory epithelium. Am J Respir Cell Mol Biol 1997; 16: 657-663.

145. Scheid P, Kempster L, Griesenbach U, Davies JC, Dewar A, Weber PP, Colledge WH, Evans MJ, Geddes DM, Alton EW. Inflammation in cystic fibrosis airways: relationship to increased bacterial adherence. Eur Respir J 2001; 17: 27-35.

146. Saadane A, Soltys J, Berger M. Role of IL-10 deficiency in excessive nuclear factorkappa? activation and lung inflammation in cystic fibrosis transmembrane conductance regulator knockout mice. J Allergy Clin Immunol 2005; 115: 405-411.

147. van Heeckeren AM, Schluchter MD, Drumm ML, Davis PB. Role of CFTR genotype in the response to chronic Pseudomonas aeruginosa lung infection in mice. Am J Physiol Lung Cell Mol Physiol 2004; 287: L944-L952.

148. Eigen H, Rosenstein B, Fitxsimmons S, Schidlow D. A multi-center study of alternate day prednisolone therapy in patients with cystic fibrosis. J Pediatr 1995; 126: 515523.

149. de Jongste JC, Baraldi E, Lombardi E. Clinically relevant early functional and diagnostic markers of lung disease in children. In: Frey U, Gerritsen J, eds. Respiratory diseases in infants and children. Eur Respir Mon 2006; 37: 120-141. 
150. Cabana MD, Rand CS, Becher OJ, Rubin HR. Reasons for paediatrician nonadherence to asthma guidelines. Arch Pediatr Adolesc Med 2001; 155: 1057-1062.

151. Hilliard TN, Witten H, Male IA, Langton Hewer S, Peddon PC. Management of acute childhood asthma: a prospective multicentre study. Eur Respir J 2000; 15: 1102-1105.

152. Bacharier LB, Strunk RC, Mauger D, White D, Lemanske RF Jr, Sorkness CA. Classifying asthma severity in children: mismatch between symptoms, medication use, and lung function. Am J Respir Crit Care Med 2004; 170: 426-432.

153. Cane RS, McKenzie SA. Parents' interpretations of children's respiratory symptoms on video. Arch Dis Child 2001; 84: 31-34.

154. Fiese $\mathrm{BH}$, Wamboldt FS, Anbar RD. Family asthma management routines: connections to medical adherence and quality of life. J Pediatr 2005; 146: 171-176.

155. Merikallio VJ, Mustalahti K, Remes RT, Valovirta EJ, Kaila M. Comparison of quality of life between asthmatic and healthy school children. Pediatr Allergy Immunol 2005; 16: 332-340.

156. Williams J, Williams K. Asthma-specific quality of life questionnaires in children: Are they useful and feasible in routine clinical practice? Pediatr Pulmonol 2003; 35: 114 118.

157. Juniper EF, Guyatt GH, Feeny DH, Ferrie PJ, Griffith LE, Townsend M. Measuring quality of life in children with asthma. Qual Life Res 1996; 5: 35-46.

158. Janse AJ, Sinnema G, Uiterwaal CSPM, Kimpen JLL, Gemke RJBJ. Quality of life in chronic illness: perception of parents and paediatricians. Arch Dis Child 2005; 90 : 486-491.

159. Fonseca JA, Delgado L, Costa-Pereira A, Tavares C, Moreira A, Morete A, de Oliveira F, Rodrigues J, Vaz M. Evaluation of the Asthma Life Quality test for the screening and severity assessment of asthma. Allergy 2004; 59: 1198-1204.

160. Kaugars AS, Klinnert MD, Bender BG. Family influences on pediatric asthma. J Pediatr Psychol 2004; 29: 475-491.

161. Quanjer Ph, Stocks J, Polgar G, Wise M, Karlberg J, Borsboom G. Compilation of reference values for lung function measurements in children. Eur Respir J 1989; 2: Suppl. 4, 184S-261S.

162. Merkus PJFM, de Jongste JC, Stocks J. Respiratory function measurements in infants and children. In: Gosselink R, Stam H, eds. Lung Function Testing. Eur Respir Mon 2005; 31: 166-194.

163. Spahn JD, Cherniack R, Paull K, Gelfand EW. Is forced expiratory volume in one second the best measure of severity in childhood asthma? Am J Respir Crit Care Med 2004; 169: 784-786.

164. American Thoracic Society. Standardisation of spirometry: 1994 update. Am J Respir Crit Care Med 1995; 152: 1107-1136.

165. Sont JK, Willems LN, Bel EH, van Krieken JH, Vandenbroucke JP, Sterk PJ. Clinical control and histopathologic outcome of asthma when using airway hyperresponsiveness as an additional guide to long-term treatment. The AMPUL study group. Am J Respir Crit Care Med 1999; 159: 1043-1051.

166. Zacharasiewicz A, Wilson N, Lex C, et al. Clinical use of noninvasive measurements of airway inflammation in steroid reduction in children. Am J Respir Crit Care Med 2005; 171: 1077-1082. 
167. De Meer G, Marks GB, Postma DS. Direct or indirect stimuli for branchial challenge testing: what is the relevance for asthma epidemiology? Clin Exp Allergy 2004; 34: 9-16.

168. Joos GF, O'Connor BJ, on behalf of the ERS Task Force. Indirect airway challenges. Eur Respir J 2003; 21: 1050-1068.

169. American Thoracic Society. Guidelines for metacholine and exercise challenge testing - 1999. Am J Respir Crit Care Med 2000; 161: 309-329.

170. Pattemore PK, Asher MI, Harrison AC, Mitchell EA, Rea HH, Stewart AW. The interrelationship among bronchial hyperresponsiveness, the diagnosis of asthma, and asthma symptoms. Am Rev Respir Dis 1990; 142: 549-554.

171. Salome CM, Peat JK, Britton WJ, Woolcok AJ. Bronchial hyperresponsiveness in two populations of Australian children. I. Relation to respiratory symptoms and diagnosed asthma. Clin Allergy 1987; 17: 271-281.

172. Cockcroft DW. How best to measure airway hyperresponsiveness. Am J Respir Crit Care Med 2001; 163: 1514-1515.

173. Covar RA, Spahn JD, Martin RJ, Silkoff PE, Sundstrom DA, Murphy J, Szefler SJ. Safety and application of induced sputum analysis in childhood asthma. J Allergy Clin Immunol 2004; 114: 575-582.

174. Wood RE. Diagnostic and therapeutic procedures in pediatric pulmonary patients. In: Taussig LM, Landau LI, eds. Pediatric Respiratory Medicine. Philadelphia, USA, Mosby Inc, 1999; pp. 244-262.

175. Gibson PG, Grootendorst DC, Henry RL, Pin I, Rytila PH, Wark P, Wilson N, Djukanovic R. Sputum induction in children. Eur Respir J 2002; 20: 44s-46s.

176. Paggiaro PL, on behalf of working group 1. Sputum induction. Eur Respir J 2002; 20: Suppl. 37, 3s-8s.

177. Spanevello A, Beghé B, Bianchi A, Migliori GB, Ambrosetti M, Neri M, Ind PW. Comparison of two methods of processing induced sputum: selected versus entire sputum. Am J Respir Crit Care Med 1998; 157: 665-668.

178. Djukanovic R, Sterk PJ, Fahy JV, Hargreave FE. Standardised methodology of sputum induction and processing. Eur Respir J 2002; 20: Suppl. 37, 1s-2s.

179. Efthimiadis A, Spanevello A, on behalf of working group 3. Methods of sputum processing for cell counts, immunocytochemistry and in situ hybridisation. Eur Respir J 2002; 20: Suppl. 37, 19s-23s.

180. Kelly MM, on behalf of working group 4. Analysis of fluid-phase mediators. Eur Respir J 2002; 20: Suppl. 37, 24s-39s.

181. Lex C, Payne DNR, Zacharasiewicz A, Li AM, Wilson NM, Hansel TT, Bush A. Sputum induction in children with difficult asthma: safety, feasibility, and inflammatory cell pattern. Pediatr Pulmonol 2005; 39: 318-324.

182. Jones PD, Hankin R, Simpson J, Gibson PG, Henry RL. The tolerability, safety, and success of sputum induction and combined hypertonic saline challenge in children. Am J Respir Crit Care Med 2001; 164: 1146-1149.

183. De Boeck K, Alifier M, Vandeputte S. Sputum induction in young cystic fibrosis patients. Eur Respir J 2000; 16: 91-94.

184. Suri R, Marshall L, Wallis C, Metcalfe C, Shute JK, Bush A. Safety and use of sputum induction in children with cystic fibrosis. Pediatr Pulmonol 2003; 35: 309-313. 
185. Reinhardt N, Chen CIU, Loppow D, Schink T, Kleinau I, Jörres RA, Wahn U, Magnussen $\mathrm{H}$, Paul KP. Cellular profiles of induced sputum in children with stable cystic fibrosis: comparison with BAL. Eur Respir J 2003; 22: 497-502.

186. Pizzichini $E$, on behalf of working group 2. Safety of sputum induction. Eur Respir $J$ 2002; 20: Suppl. 37, 9s-18s.

187. Li AM, Tsang TW, Chan DF, Lam HS, So HK, Sung RY, Fok TF. Sputum induction in children with asthma: a tertiary-center experience. Pediatr Pulmonol 2006; 41: 720-725.

188. Wilson NM, Bridge P, Spanevello A, Silverman M. Induced sputum in children: feasibility, repeatability, and relation of findings to asthma severity. Thorax 2000; 55 : 768-774.

189. Li AM, Lex C, Zacharasiewicz A, Wong E, Erin E, Hansel T, Wilson NM, Bush A. Cough frequency in children with mild asthma: correlation with lung function, exhaled nitric oxide, and sputum eosinophil count. Thorax 2003; 58: 974-978.

190. Gibson PG, Simpson JL, Hankin R, Powell H, Henry RL. Relationship between induced sputum eosinophils and the clinical pattern of childhood asthma. Thorax 2003; 58 : 116-121.

191. Papadopouli E, Tzanakis N, Tsoumakidou M, Kyriakoy D, Plataki M, Mantzouranis EC, Siafakes NM. Comparison of induced sputum inflammometry profiles between childhood and adult-onset asthma. Respir Med 2006; 100: 1442-1450.

192. Sloane AJ, Lindner RA, Prasad SS, Sebastian LT, Pedersen SK, Robinson M, Bye PT, Nielson DW, Harry JL. Proteomic analysis of sputum from adults and children with cystic fibrosis and from control subjects. Am J Respir Crit Care Med 2005; 172: 1416 1426.

193. Lex C, Jenkins G, Wilson NM, Zacharasiewicz A, Erin E, Hansel TT, Bush A, Payne DN. Does sputum eosinophilia predict the response to systemic corticosteroids in children with difficult asthma? Pulmonol 2007; 42: 298-303.

194. Sagel SD, Kapsner R, Osberg I, Sontag MK, Accurso FJ. Airway inflammation in children with cystic fibrosis and healthy children assessed by sputum induction. Am J Respir Crit Care Med 2001; 164: 1425-1431.

195. Sagel SD, Sontag MK, Wagener JS, Kapsner RK, Osberg I, Accurso FJ. Induced sputum inflammatory measures correlate with lung function in children with cystic fibrosis. J Pediatr 2002; 141: 811-817.

196. Ho SA, Ball R, Morrison LJ, Brownlee KG, Conway SP. Clinical value of obtaining sputum and cough swab samples following inhaled hypertonic saline in children with cystic fibrosis. Pediatr Pulmonol 2004; 38: 82-87.

197. Ordonez CL, Kartashov Al, Ellen M. Variability of markers of inflammation and infection in induced sputum in children with cystic fibrosis. J Pediatr 2004; 145: 689-692.

198. Vignola AM, Bousquet J, Chanez P, Gagliardo R, Merendino AM, Chiappara G, Bonsignore G. Assessment of airway inflammation in asthma. Am J Respir Crit Care Med 1998; 157: S184-S187.

199. Payne D, McKenzie SA, Stacey S, Misra D, Haxby E, Bush A. Safety and ethics of bronchoscopy and endobronchial biopsy in difficult asthma. Arch Dis Child 2001; 84: 423-426.

200. Bush A. Bronchoscopy in paediatric intensive care. Paediatr Respir Rev 2003; 4: 6773. 
201. Balfour-Lynn IM, Spencer H. Bronchoscopy - how and when? Paediatr Respir Rev 2002; 3: 255-264.

202. Nussbaum E. Pediatric fiberoptic bronchoscopy: clinical experience with 2836 bronchoscopies. Pediatr Crit Care Med 2002; 3: 171-176.

203. Saglani S, Payne DN, Nicholson AG, Scallan M, Haxby E, Burh A. Safety and quality of endobronchial biopsy in children under five years old. Thorax 2003; 58: 10531057.

204. Salva PS, Theroux C, Schwartz D. Safety of endobronchial biopsy in 170 children with chronic respiratory symptoms. Thorax 2003; 58: 1058-1060.

205. Payne DN, Wilson NM, James A, Hablas H, Agrafioti C, Bush A. Evidence for different subgroups of difficult asthma in children. Thorax 2001; 56: 345-350.

206. Faul JL, Demers EA, Burke CM, Poulter LW. The reproducibility of repeat measures of airway inflammation in stable atopic asthma. Am J Respir Crit Care Med 1999; 160: 1457-1461.

207. Pijnenburg M. Towards better treatment of childhood asthma: inflammometry with exhaled nitric oxide. PhD-Thesis Erasmus University Rotterdam, 2006

208. Haahtela T, Laitinen A, Laitinen LA. Using biopsies in the monitoring of inflammation in asthmatic patients. Allergy 1993; 48: 65-69.

209. Ennis M, Turner G, Schock BC, Stevenson EC, Brown V, Fitch PS, Heaney LG, Taylor $\mathrm{R}$, Shields MD. Inflammatory mediators in bronchoalveolar lavage samples from children with and without asthma. Clin Exp Allergy 1999; 29: 362-366.

210. Stempel DA, Fuhlbrigge AL. Defining the responder in asthma therapy. J Allergy Clin Immunol 2005; 115: 466-469.

211. Braunstahl GJ. The unified immune system: respiratory tract: nasobronchial interaction mechanisms in allergic airway disease. J Allergy Clin Immunol 2005; 115 : 142-148.

212. Jöbsis Q. Exhaled hydrogen peroxide and nitric oxide. PhD-Thesis Erasmus University Rotterdam, 2000.

213. Lavoisier A. Traité élémentaire de chimie, présenté dans un ordre nouveau et d'après les découvertes modernes, 2 volumes. Paris, Chez Cuchet, ed. 1789.

214. Scheideler L, Manke HG, Schwulera U, Inacker O, Hämmerle H. Detection of nonvolatile macromolecules in breath. A possible diagnostic tool? Am Rev Respir Dis 1993: 148: 778-784.

215. Palmer RMJ, Ferrige AG, Moncada S. Nitric oxide release accounts for the biological activity of endothelium-derived relaxing factor. Nature 1987; 327: 524-526.

216. Gustafsson LE, Leone AM, Persson MG, Wiklund NP, Moncada S. Endogenous nitric oxide is present in the exhaled air of rabbits, guinea pigs and humans. Biochem Biophys Res Commun 1991; 181: 852-857.

217. The Nobel Foundation.

http://nobelprize.org/nobel_prizes/medicine/laureates/1998/index.html.

Date last accessed: May 282007.

218. Kharitonov SA, Gonio F, Kelly C, Meah S, Barnes PJ. Reproducibility of exhaled nitric oxide measurements in healthy and asthmatic adults and children. Eur Respir J 2003; 21: $433-438$. 
219. American Thoracic Society. ATS/ERS recommendations for standardized procedures for the online and offline measurement of exhaled lower respiratory nitric oxide and nasal nitric oxide, 2005. Am J Respir Crit Care Med 2005; 171: 912-930.

220. Baraldi E, de Jongste JC. Measurement of exhaled nitric oxide in children, 2001. Eur Respir J 2002; 20: 223-237.

221. Buchvald F, Baraldi E, Carraro S, Gaston B, de Jongste J, Pijnenburg MW, Silkoff PE, Bisgaard $\mathrm{H}$. Measurements of exhaled nitric oxide in healthy subjects age 4 to 17 years. J Allergy Clin Immunol 2005; 115: 1130-1136.

222. Kharitonov SA. Exhaled markers of inflammatory lung diseases: ready for routine monitoring? Swiss Med Wkly 2004; 134: 175-192.

223. Pijnenburg MW, Bakker EM, Hop WC, de Jongste JC. Titrating steroids on exhaled nitric oxide in children with asthma. Am J Respir Crit Care Med 2005; 172: 831-836.

224. Pijnenburg MW, Hofhuls W, Hop WC, de Jongste JC. Exhaled nitric oxide predicts asthma relapse in children with clinical asthma remission. Thorax 2005; 60: 215-218.

225. Smith AD, Cowan JO, Brassett KP, Filsell S, McLachlan C, Monti-Sheehan G, Peter Herbison G, Robin Taylor D. Exhaled nitric oxide: a predictor of steroid response. Am J Respir Crit Care Med 2005; 172: 453-459.

226. Smith AD, Cowan JO, Brasset KP, Herbison GP, Taylor DR. Use of exhaled nitric oxide measurements to guide treatment in chronic asthma. N Eng J Med 2005; 352: $2163-$ 2173.

227. Mattes J, Storm van's Gravesande K, Reining U, Alving K, Ihorst G, Henschen M, Kuehr J. NO in exhaled air is correlated with markers of eosinophilic airway inflammation in corticosteroid-dependent childhood asthma. Eur Respir J 1999; 13: 1391-1395.

228. Piacentini GL, Bodini A, Costella S, Vicentini L, Mazzi P, Sperandio S, Boner AL. Exhaled nitric oxide and sputum eosinophil markers of inflammation in asthmatic children. Eur Respir J 1999; 13: 1386-1390.

229. Thomas PS, Gibson PG, Wang H, Shah S, Henry RL. The relationship of exhaled nitric oxide to airway inflammation and responsiveness in children. J Asthma 2005; 42 : 291-295.

230. del Giudice MM, Brunese FP, Piacentini GL, Pedulla M, Capristo C, Decimo F, Capristo AF. Fractional exhaled nitric oxide (FeNO), lung function and bronchial hyperresponsiveness in naïve atopic asthmatic children. J Asthma 2004; 41: 759-765.

231. Piacentini GL, Bodini A, Costella S, Suzuki Y, Zerman L, Peterson CG, Boner AL. Exhaled nitric oxide, serum ECP and airway responsiveness in mild asthmatic children. Eur Respir J 2000; 15: 839-843.

232. Van den Toorn LM, Prins JB, Overbeek SE, Hoogsteden HC, de Jongste JC. Adolescents in clinical remission of atopic asthma have elevated exhaled nitric oxide levels and bronchial hyperresponsiveness. Am J Respir Crit Care Med 2000; 162: 953-957.

233. Payne DN, Adcock IM, Wilson NM, Oates T, Scallan M, Bush A. Relationship between exhaled nitric oxide and mucosal eosinophilic inflammation in children with difficult asthma, after treatment with oral prednisolone. Am J Respir Crit Care Med 2001; 164: 1376-1381. 
234. Buchvald $\mathrm{F}$, Bisgaard $\mathrm{H}$. FeNO measured at fixed exhalation flow rate during controlled tidal breathing in children from the age of 2 yr. Am J Respir Crit Care Med 2001; 163: 699-704.

235. Baraldi E, Dario C, Ongaro R, Scollo M, Azzolin NM, Panza N, Paganini N, Zacchello F. Exhaled nitric oxide concentrations during treatment of wheezing exacerbation in infants and young children. Am J Respir Crit Care Med 1999; 159: 1284-1288.

236. Avital A, Uwyyed K, Berkman N, Godfrey S, Bar-Yishay E, Springer C. Exhaled nitric oxide and asthma in young children. Pediatr Pulmonol 2001; 32: 308-313.

237. Hall GL, Reinmann B, Wildhaber JH, Frey U. Tidal exhaled nitric oxide in healthy, unsedated newborn infants with prenatal tobacco exposure. J App/ Physio/ 2002; 92: 59-66.

238. Gabriele C, Asgarali R, Moll HA, Hop W, Hofman A, de Jongste JC. Measurement of fractional exhaled nitric oxide in 6-month-old infants: the generation $\mathrm{R}$ study. Eur Respir J 2005; 2: A312.

239. Franklin PJ, Turner SW, Mutch RC, Stick SM. Measuring exhaled nitric oxide in infants during tidal breathing: methodological issues. Pediatr Pulmonol 2004; 37: 24-30.

240. Wildhaber JH, Hall GL, Stick SM. Measurements of exhaled nitric oxide with the single-breath technique and positive expiratory pressure in infants. Am J Respir Crit Care Med 1999; 159: 74-78.

241. Daniel PF, Klug B, Valerius NH. Measurement of exhaled nitric oxide in young children during tidal breathing through a facemask. Pediatr Allergy Immunol 2005; 16: 248253.

242. Martinez TM, Weist AD, Williams T, Clem C, Silkoff P, Tepper RS. Assessment of exhaled nitric oxide kinetics in healthy infants. J App/ Physiol 2003; 94: 2384-2390.

243. Malmberg LP, Pelkonen AS, Haahtela T, Turpeinen M. Exhaled nitric oxide rather than lung function distinguishes preschool children with probable asthma. Thorax 2003; 58: 494-499.

244. Napier E, Turner SW. Methodological issues related to exhaled nitric oxide measurement in children aged four to six years. Pediatr Pulmonol 2005; 40: 97-104.

245. Latzin P, Kuehni CE, Baldwin DN, Roiha HL, Casaulta C, Frey U. Elevated exhaled nitric oxide in newborns of atopic mothers precedes respiratory symptoms. Am J Respir Crit Care Med 2006; 174: 1292-1298.

246. Henriksen AH, Sue-Chu M, Lingaas Holmen T, Langhammer A, Bjermer L. Exhaled and nasal NO levels in allergic rhinitis: relation to sensitization, pollen season and bronchial hyperresponsiveness. Eur Respir J 1999; 13: 301-306.

247. de Gouw HW, Grunberg K, Schot R, Kroes AC, Dick EC, Sterk PJ. Relationship between exhaled nitric oxide and airway hyperresponsiveness following experimental rhinovirus infection in asthmatic subjects. Eur Respir J 1998; 11: 126-132.

248. Murphy AW, Platts-Mills TA, Lobo M, Hayden F. Respiratory nitric oxide levels in experimental human influenza. Chest 1998; 114: 452-456.

249. Kharitonov SA, Yates D, Barnes PJ. Increased nitric oxide in exhaled air of normal human subjects with upper respiratory tract infections. Eur Respir J 1995; 8: 295-297.

250. Sanders SP, Proud D, Permutt S, Siekierski ES, Yachechko R, Liu MC. Role of nasal nitric oxide in the resolution of experimental rhinovirus infection. J Allergy Clin Immunol 2004; 113: 697-702. 
251. Cremona G, Higenbottam TW, Mayoral V, Alexander G, Demoncheaux E, Borland C, Roe P, Jones GJ. Elevated exhaled nitric oxide in patients with hepatopulmonary syndrome. Eur Respir J 1995; 8: 1883-1885.

252. Rolla G, Brussino L, Bertero MT, Colagrande P, Converso M, Bucca C, Polizzi S, Caligaris-Cappio F. Increased nitric oxide in exhaled air of patients with systemic lupus erythematosus. J Rheumatol 1997; 24: 1066-1071.

253. Rolla G, Brussino L, Colagrande P, Scappaticci E, Morello M, Bergerone S, Ottobrelli A, Cerutti E, Polizzi S, Bucca C. Exhaled nitric oxide and impaired oxygenation in cirrhotic patients before and after liver transplantation. Ann Intern Med 1998; 129: 375-378.

254. Brightling CE, Symon FA, Birring SS, Bradding P, Wardlaw AJ, Pavord ID. Comparison of airway immunopathology of eosinophilic bronchitis and asthma. Thorax 2003; 58 : 528-532.

255. Fisher AJ, Gabbay E, Small T, Doig S, Dark JH, Corris PA. Cross sectional study of exhaled nitric oxide levels following lung transplantation. Thorax 1998; 53: 454-458.

256. Gabbay E, Walters EH, Orsida B, Whitford H, Ward C, Kotsimbos TC, Snell Gl, Williams TJ. Post-lung transplant bronchiolitis obliterans syndrome (BOS) is characterized by increased exhaled nitric oxide levels and epithelial inducible nitric oxide synthase. Am J Respir Crit Care Med 2000; 162: 2182-2187.

257. Verleden GM, Dupont LJ, Van Raemdonck DE, Vanhaecke J. Accuracy of exhaled nitric oxide measurements for the diagnosis of bronchiolitis obliterans syndrome after lung transplantation. Transplantation 2004; 78: 730-733.

258. Brugiere O, Thabut G, Mal H, Marceau A, Dauriat G, Marrash-Chahla R, Castier $Y$, Leseche G, Colombat M, Fournier M. Exhaled NO may predict the decline in lung function in bronchiolitis obliterans syndrome. Eur Respir J 2005; 25: 813-819.

259. Maziak W, Loukides S, Culpitt S, Sullivan P, Kharitonov SA, Barnes PJ. Exhaled nitric oxide in chronic obstructive pulmonary disease. Am J Respir Crit Care Med 1998; 157: 998-1002.

260. Rutgers SR, Meijer RJ, Kerstjens HA, van der Mark TW, Koeter GH, Postma DS. Nitric oxide measured with single-breath and tidal-breathing methods in asthma and COPD. Eur Respir J 1998; 12: 816-819.

261. Clini E, Bianchi L, Vitacca M, Porta R, Foglio K, Ambrosino N. Exhaled nitric oxide and exercise in stable COPD patients. Chest $2000 ; 117: 702-707$.

262. Delen FM, Sippel JM, Osborne ML, Law S, Thukani N, Holden WE. Increased exhaled nitric oxide in chronic bronchitis : comparison with asthma and COPD. Chest 2000; 117: 695-701.

263. Papi A, Romagnoli M, Baraldo S, Braccioni F, Guzzinati I, Saetta M, Ciaccia A, Fabbri LM. Partial reversibility of airflow limitation and increased exhaled NO and sputum eosinophilia in chronic obstructive pulmonary disease. Am J Respir Crit Care Med 2000; 162: 1773-1777.

264. Kharitonov SA, Wells AU, Oçonnor BJ, Cole PJ, Hansell DM, Logan-Sinclair RB, Barnes PJ. Elevated levels of exhaled nitric oxide in bronchiectasis. Am J Respir Crit Care Med 1995; 151: 1889-1893.

265. Tsang KW, Leung R, Fung PC, Chan SL, Tipoe GL, Ooi GC, Lam WK. Exhaled and sputum nitric oxide in bronchiectasis: correlation with clinical parameters. Chest 2002; 121: 88-94. 
266. Ho LP, Innes JA, Greening AP. Exhaled nitric oxide is not elevated in the inflammatory airways diseases of cystic fibrosis and bronchiectasis. Eur Respir J 1998; 12: 12901294.

267. Rolla G, Colagrande P, Scappaticci E, Chiavassa G, Dutto L, Cannizzo S, Bucca C, Morello M, Bergerone S, Bardini D, Zaccagna A, Puiatti P, Fava C, Cortese G. Exhaled nitric oxide in systemic sclerosis: relationships with lung involvement and pulmonary hypertension. J Rheumatol 2000; 27: 1693-1698.

268. Kharitonov SA, Cailes JB, Black CM, du Bois RM, Barnes PJ. Decreased nitric oxide in the exhaled air of patients with systemic sclerosis and pulmonary hypertension. Thorax 1997; 52: 1051-1055.

269. Moodley YP, Lalloo UG. Exhaled nitric oxide is elevated in patients with progressive systemic sclerosis without interstitial disease. Chest 2001; 119: 1449-1454.

270. Baraldi E, Bonetto G, Zacchello F, Filippone M. Low exhaled nitric oxide in school-age children with bronchopulmonary dysplasia and airflow limitation. Am J Respir Crit Care Med 2005; 171: 68-72.

271. Storme L, Riou Y, Leclerc F, Dubois A, Deschildre A, Pierre MH, Logier R, Robin H, Lequien P. Exhaled nitric oxide (NO) and respiratory function measured with body plethysmography in children. Arch Pediatr 1998; 5: 389-396.

272. Mieskonen ST, Malmberg LP, Kari MA, Pelkonen AS, Turpeinen MT, Hallman NM, Sovijari AR. Exhaled nitric oxide at school age in prematurely born infants with neonatal chronic lung disease. Pediatr Pulmonol 2002; 33: 347-355.

273. Paredi P, Kharitonov SA, Loukides S, Pantelidis P, du Bois RM, Barnes PJ. Exhaled nitric oxide is increased in active fibrosing alveolitis. Chest 1999; 115: 1352-1356.

274. Moodley YP, Chetty R, Lalloo UG. Nitric oxide levels in exhaled air and inducible nitric oxide synthase immunolocalization in pulmonary sarcoidosis. Eur Respir $J 1999 ; 14$ : 822-827.

275. Ziora D, Kaluska K, Kozielski J. An increase in exhaled nitric oxide is not associated with activity in pulmonary sarcoidosis. Eur Respir J 2004; 24: 609-614.

276. Dotch J, Demirakca S, Terbrack HG, Huls G, Rascher W, Kuhl PG. Airway nitric oxide in asthmatic children and patients with cystic fibrosis. Eur Respir J 1996; 9: 2537-2540.

277. Grasemann H, Michler E, Wallot M, Ratjen F. Decreased concentration of exhaled nitric oxide (NO) in patients with cystic fibrosis. Pediatr Pulmonol 1997; 24: 173-177.

278. Kelley TJ, Drumm ML. Inducible nitric oxide synthase expression is reduced in cystic fibrosis murine and human airway epithelial cells. J Clin Invest 1998; 102: 12001207.

279. Downey D, Elborn JS. Nitric oxide, iNOS, and inflammation in cystic fibrosis. J Pathol 2000; 190: 115-116.

280. Grasemann H, Ioannidis I, Tomkiewicz RP, de Groot H, Rubin BK, Ratjen F. Nitric oxide metabolites in cystic fibrosis lung disease. Arch Dis Child 1998; 78: 49-53.

281. Ojoo JC, Mulrennan SA, Kastelik JA, Morice AH, Redington AE. Exhaled breath condensate $\mathrm{pH}$ and exhaled nitric oxide in allergic asthma and in cystic fibrosis. Thorax 2005; 60: 22-26.

282. Ho LP, Innes JA, Greening AP. Nitrite levels in breath condensate of patients with cystic fibrosis is elevated in contrast to exhaled nitric oxide. Thorax 1998; 53: 680684. 
283. Narang I, Ersu R, Wilson NM, Bush A. Nitric oxide in chronic airway inflammation in children: diagnostic use and pathophysiological significance. Thorax 2002; 57: 586-589.

284. Karadag B, James AJ, Gultekin E, Wilson NM, Bush A. Nasal and lower airway level of nitric oxide in children with primary ciliary dyskinesia. Eur Respir J 1999; 13: 14021405 .

285. Horvath I, Loukides S, Wodehouse T, Csiszer E, Cole PJ, Kharitonov SA, Barnes PJ. Comparison of exhaled and nasal nitric oxide and exhaled carbon monoxide levels in bronchiectatic patients with and without primary ciliary dyskinesia. Thorax 2003; 58: 68-72.

286. Brett SJ, Evans TW. Measurement of endogenous nitric oxide in the lungs of patients with the acute respiratory distress syndrome. Am J Respir Crit Care Med 1998; 157: 993-997.

287. Loveless MO, Phillips CR, Giraud GD, Holden WE. Decreased exhaled nitric oxide in subjects with HIV infection. Thorax 1997; 52: 185-186.

288. Riley MS, Porszasz J, Miranda J, Engelen MP, Brundage B, Wasserman K. Exhaled nitric oxide during exercise in primary pulmonary hypertension and pulmonary fibrosis. Chest 1997; 111: 44-50.

289. Moeller A, Horak FJ, Lane C, Knight D, Kicic A, Brennan S, et al. Inducible NO synthase expression is low in airway epithelium from young children with cystic fibrosis. Thorax 2006; 61: 514-520.

290. Corbelli R, Bringolf-Isler B, Amacher A, Sasse B, Spycher M, Hammer J. Nasal nitric oxide measurements to screen children for primary ciliary dyskinesia. Chest 2004; 126: 1013-1014.

291. Tattersfield AE, Knox AJ, Britton JR, Hall IP. Asthma. Lancet 2002; 360: 1313-1322.

292. Dakin CJ, Numa AH, Wang H, Morton JR, Vertzyas CC, Henry RL. Inflammation, infection, and pulmonary function in infants and young children with cystic fibrosis. Am J Respir Crit Care Med 2002; 165: 904-910.

293. Özdemir A, Brown MA, Morgan WJ. Markers and mediators of inflammation in neonatal lung disease. Pediatr Pulmonol 1997; 23: 292-306.

294. Eber E, Zach MS. Long term sequellae of bronchopulmonary dysplasia (chronic lung diseas of infancy). Thorax 2001; 56: 317-323.

295. De Rose V. Mechanisms and markers of airway inflammation in cystic fibrosis. Eur Respir J 2002; 19: 333-340.

296. Scheinmann P, Pedersen S, Warner JO, de Blic J. Methods for assesment of airway inflammation: paediatrics. Eur Respir J 1998; 26: 53s-58s.

297. Kim JS, Hackley GH, Okamoto K, Rubin BK. Sputum processing for evaluation of inflammatory mediators. Pediatr Pulmonol 2001; 32: 152-158.

298. Kips JC, Fahy JV, Hargreave FE, Ind PW, in't Veen JC. Methods for sputum induction and analysis of induced sputum: a method for assessing airway inflammation in asthma. Eur Respir J 1998; 11: 9s-12s.

299. Nightingale JA, Rogers DF, Barnes PJ. Effect of repeated sputum induction on cell counts in normal volunteers. Thorax 1998; 53: 87-90.

300. Holz O, Richter K, Jorres RA, Speckin P, Mucke M, Magnussen H. Changes in sputum composition between two inductions performed on consecutive days. Thorax 1998; 53: 83-86. 
301. Jöbsis Q, Raatgreep HC, Schellekens SL, Hop WC, Hermans PW, de Jongste JC. Hydrogen peroxide in exhaled air of healthy children: reference values. Eur Respir J 1998; 12: 483-485.

302. Baraldi E, Ghiro L, Piovan V, Carraro S, Zacchello F, Zanconato S. Safety and success of exhaled breath condensate collection in asthma. Arch Dis Child 2003; 88: 358360.

303. Hunt J. Exhaled breath condensate: an evolving tool for noninvasive evaluating of lung disease. J Allergy Clin Immuol 2002; 110: 28-34.

304. Horak FJr, Stoer H, Holler B. Measurement of nitrite in the breathing-condensate of healthy infants and infants with cystic fibrosis. Am J Respir Crit Care Med 2002; 165: A485.

305. Moeller A, Franklin PJ, Hall GL, Stick SM. Limitations of breath condensates in infants. Am J Respir Crit Care Med 2003; 167: A987.

306. Griese M, Latzin P, Beck J. A noninvasive method to collect nasally exhaled air condensate in humans of all ages. Eur J Clin Invest 2001; 31: 915-920.

307. Jöbsis Q, Raatgreep HC, Hermans PW, de Jongste JC. Hydrogen peroxide in exhaled air is increased in stable asthmatic children. Eur Respir J 1997; 10: 519-521.

308. Dohlman AW, Black HR, Royall JA. Expired breath hydrogen peroxide is a marker of acute airway inflammation in pediatric patients with asthma. Am Rev Respir Dis 1993; 148: 955-960.

309. Latzin P, Griese M. Exhaled hydrogen peroxide, nitrite and nitric oxide in healthy children: decrease of hydrogen peroxide by atmospheric nitric oxide. Eur J Med Res 2002; 30: 353-358.

310. Jöbsis Q, Raatgreep HC, Schellekens SL, Kroesbergen A, Hop WC, de Jongste JC. Hydrogen peroxide and nitric oxide in exhaled air of children with cystic fibrosis during antibiotic treatment. Eur Respir J 2000; 16: 95-100.

311. Baraldi E, Ghiro L, Piovan V, Carraro S, Ciabattoni G, Barnes PJ, Montuschi P. Increased exhaled 8-isoprostane in childhood asthma. Chest 2003; 124: 25-31.

312. Baraldi E, Carraro S, Alinovi R, Pesci A, Ghiro L, Bodini A, Piacentini G, Zacchello F, Zanconato S. Cysteinyl leukotrienes and 8-isoprostane in exhaled breath condensate of children with asthma exacerbations. Thorax 2003; 58: 505-509.

313. Csoma Zs, Kharitonov SA, Balint B, Bush A, Wilson NM, Barnes PJ. Increased leukotrienes in exhaled breath condensate in childhood asthma. Am J Respir Crit Care Med 2002; 166: 1345-1349.

314. Formanek W, Inci D, Lauener RP, Wildhaber JH, Frey U, Hall GL. Elevated nitrite in breath condensates of children with respiratory disease. Eur Respir J 2002; 19: 487-491.

315. Cunningham S, McColm JR, Pei Ho L, Greening AP, Marshall TG. Measurement of inflammatory markers in the breath condensate of children with cystic fibrosis. Eur Respir J 2000; 15: 955-957.

316. Csoma Zs, Bush A, Wilson NM, Donnelly L, Balint B, Barnes PJ, Kharitonov SA. Nitric oxide metabolites are not reduced in exhaled breath condensate of patients with primary ciliary dyskinesia. Chest 2003; 124: 633-638.

317. Shahid SK, Kharitonov SA, Wilson NM, Bush A, Barnes PJ. Increased interleukin-4 and decreased interferon-g in exhaled breath condensate of children with asthma. Am J Respir Crit Care Med 2002; 165: 1290-1293. 
318. Corradi M, Folesani G, Andreoli R, Manini P, Bodini A, Piacentini G, Carraro S, Zanconato S, Baraldi E. Aldehyde and glutathione in exhaled breath condensate of children with asthma exacerbation. Am J Respir Crit Care Med 2003; 167: 395-399. 


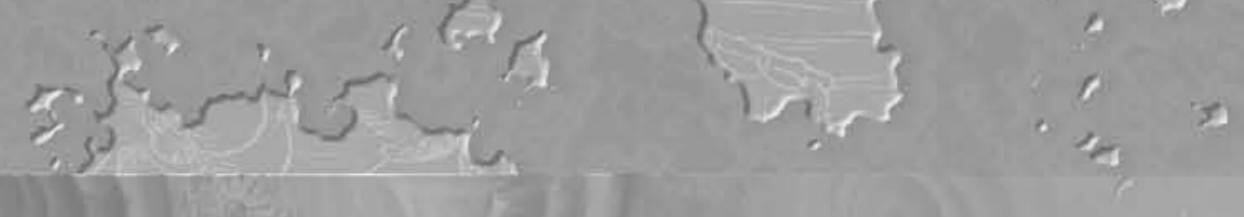

H

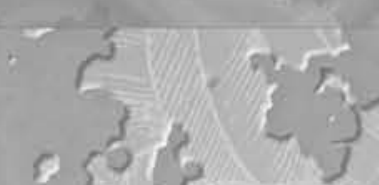

is

3

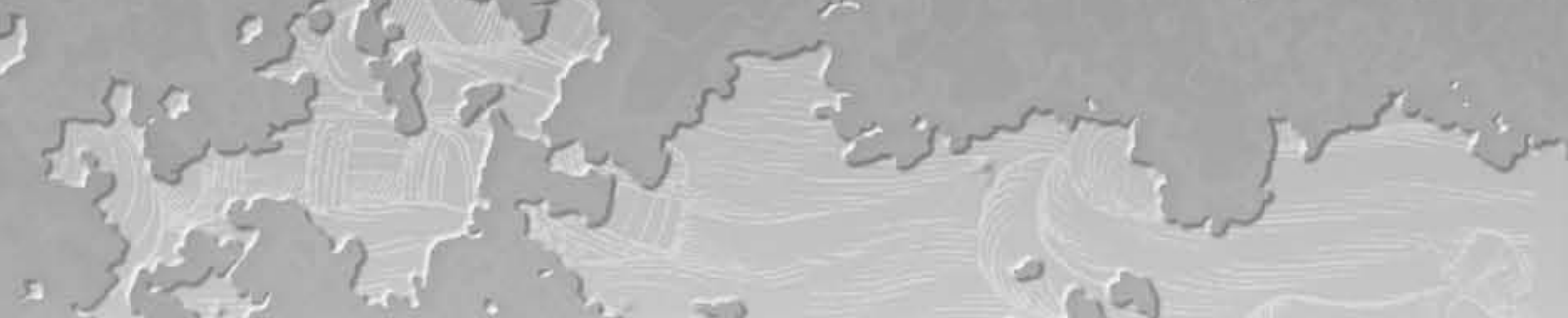

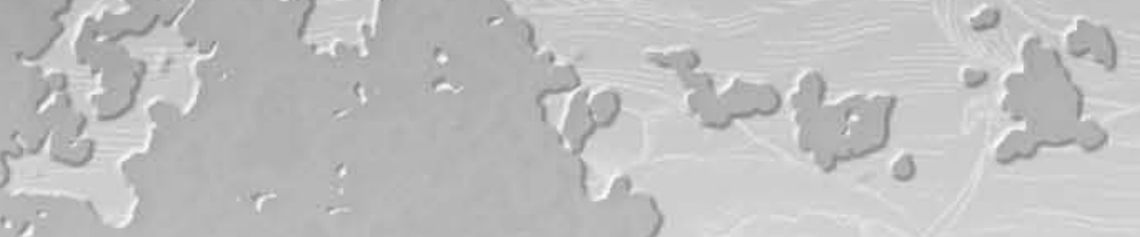

25, है,

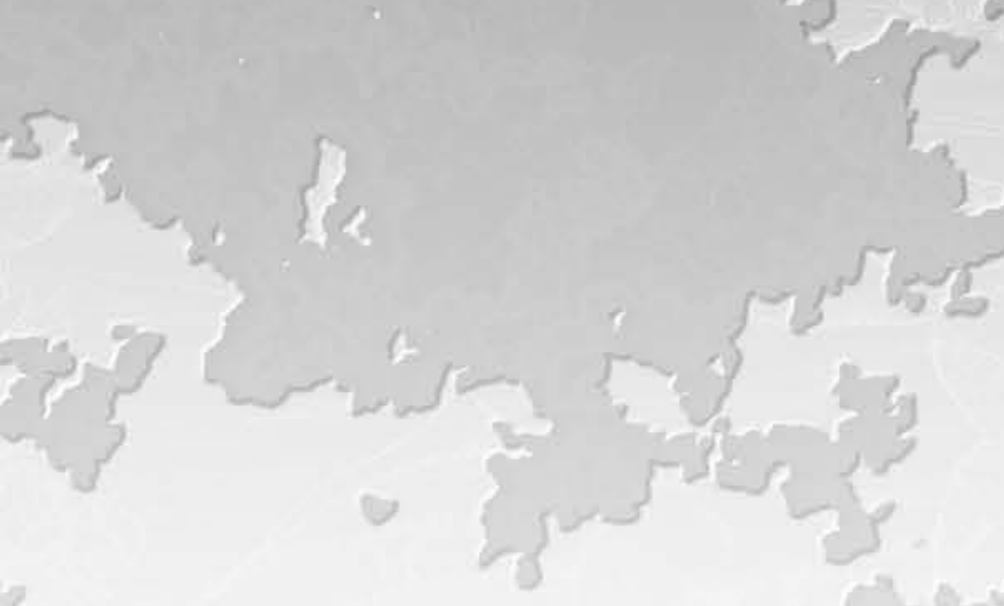

9

$\left\{r^{2}\right.$

6

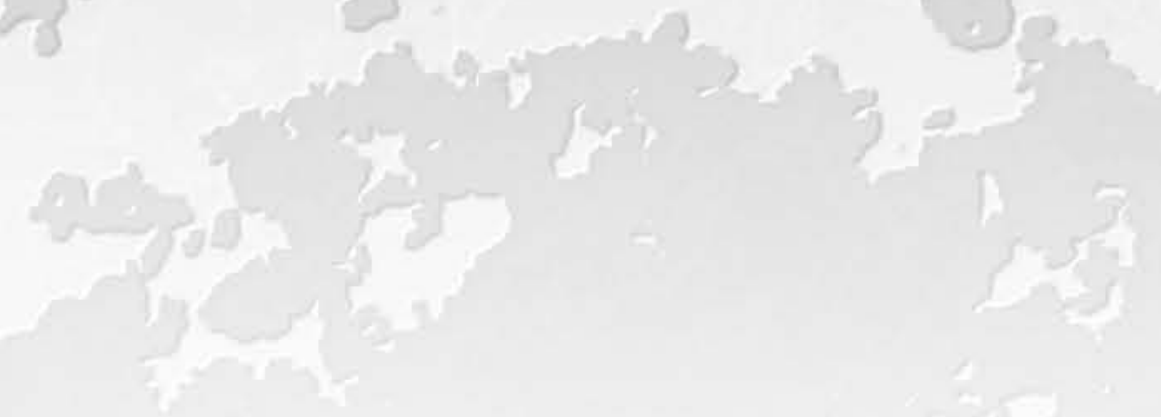




\section{CHAPTER 2}

\section{Exhaled Breath Condensate in Children:}

\section{Pearls and Pitfalls.}

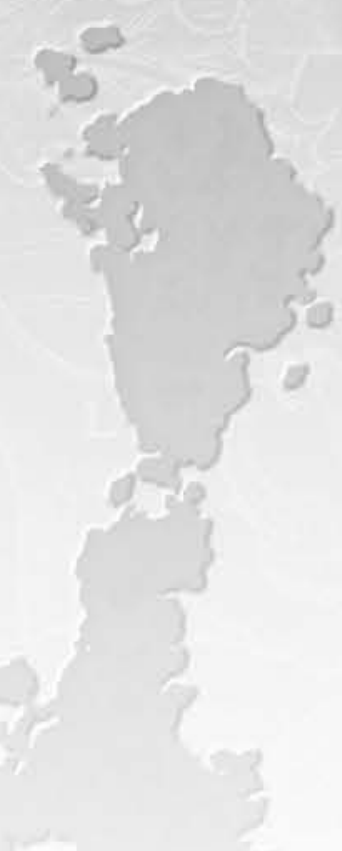

Rosias PPR, Dompeling E, Hendriks JH, Heijnens JW, Donckerwolcke RAMG, Jöbsis Q.

Pediatric Allergy and Immunology 2004; 15: 4-19. 


\section{Abstract}

Exhaled breath condensate (EBC) is a rapidly growing field of research in respiratory medicine. Airway inflammation is a central feature of chronic lung diseases, like asthma, cystic fibrosis, bronchopulmonary dysplasia and primary ciliary dyskinesia. EBC may be a useful technique for non-invasive assessment of markers of airway inflammation. The non-invasive character of EBC 'inflammometry' and the general lack of appropriate other techniques makes it particularly interesting for paediatrics.

We provide a detailed update on the methods currently used for EBC collection and measurement of mediators. We emphasise on paediatric data. The apparent simplicity of the EBC method must not be over-stated, as numerous methodological pitfalls have yet to overcome. Comparison and interpretation of data on this rapidly growing field of research is mainly hampered by the lack of standardisation and the lack of specific high-sensitivity immunochemical or colorimetric assays. The initiative of the European Respiratory Society to institute a task force on this topic is a first step towards a uniform technique of EBC. Meanwhile, when using this technique or when interpreting research data, one should be fully aware of the possible methodological pitfalls.

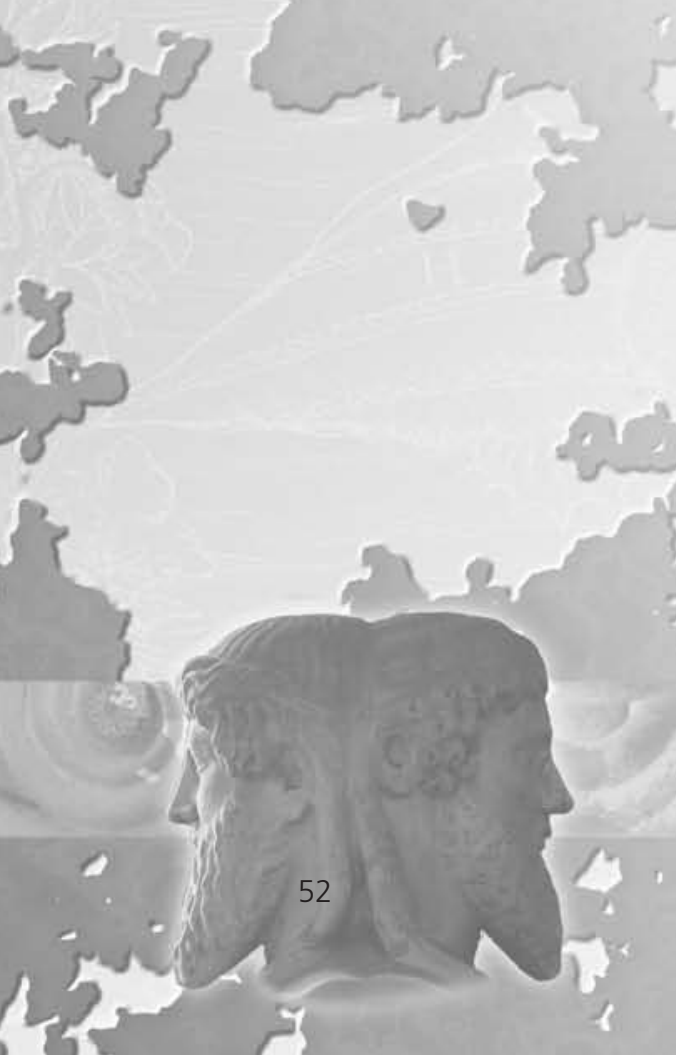




\section{Introduction}

Coughing, wheezing and dyspnoea are common presenting respiratory symptoms in children. They constitute a major diagnostic challenge, not only due to the coexistence of different types of inflammatory lung diseases in infancy and childhood, like asthma, cystic fibrosis, bronchopulmonary dysplasias and primary ciliary dyskinesia, but also due to the lack of appropriate diagnostic techniques in young children ${ }^{1-4}$.

Markers of airway inflammation may help to: distinguish between different inflammatory phenotypes, assess the severity of airway inflammation, monitor customized treatment, and develop new therapeutic strategies, resulting in more accurate use of anti-inflammatory medication. Furthermore, it may improve compliance and disease control, and may even lead to new pathophysiological insights ${ }^{5}$. Especially in young children, there is a strong need for a reliable non-invasive assessment of airway inflammation or 'inflammometry'.

The collection of exhaled breath condensate (EBC) has been proposed as a simple, quick, safe, comfortable and non-invasive technique suitable for assessment of airway inflammation by obtaining samples from the lower respiratory tract of humans with inflammatory lung disease at any age, without disturbing the ongoing inflammation ${ }^{6-13}$.

EBC 'inflammometry' is particularly interesting for paediatrics. The purpose of this review is to facilitate comparison and interpretation of data on this rapidly growing field of research, by assessing its pearls and pitfalls. Therefore, we provide a detailed update on the methods currently used for EBC collection and measurement of mediators. If available, we emphasise on paediatric data, from full papers rather than abstracts (which are known not to have undergone peer review and, therefore, are marked with an asterisk).

\section{Principles of EBC}

Exhaled breath is saturated with water vapour, which will condensate by breathing through a cooling or freezing system. Although the condensate consists mostly of water vapour, it also contains aerosol particles or respiratory fluid droplets. These droplets are released from the lung epithelial lining fluid, and they contain traces of non-volatile solutes, which can be recovered in EBC samples $6,13-16,17^{\star}-18^{\star}$.

The mechanism of formation of aerosol particles has not yet been fully elucidated. Aerosolization of extracellular lining fluid can occur as a result of turbulence in the airways, or during the popping-open of closed respiratory bronchioles and alveoli in the absence of bulk flow ${ }^{3}$. The number of aerosol particles formed in the respiratory tract depends on the current velocity of air and the surface tension of extracellular lining fluid: a higher velocity and a lower surface tension favour the production of aerosols 3,8 . The balance between low velocity and high surface tension at alveolar 
level determines the generation of aerosols. In addition, turbulent flow and higher number of edges in branching points may facilitate aerosol formation ${ }^{3,8}$. The bronchial circulation is essential in humidification of inspired air, which in turn may be a determinant of the rate at which EBC is formed ${ }^{19}$. In mechanical ventilation, increased pressure amplitude leads to an increase in EBC volume (per total respired volume), due to increased alveolar closure and reopening. This pressure amplitude-induced shear stress results in generation of aerosolized droplets ${ }^{20 *}$.

During tidal breathing, concentrations of aerosol particles range between $<0.1$ and 4 particles $/ \mathrm{cm}^{3}$, depending upon the subject and its activity. Subjects at rest exhale lower concentrations of particles, whereas exercise causes an increase in the number of exhaled particles. Their mean diameter is $<0.3 \mu \mathrm{m}$, and few particles $(<2 \%)$ have diameters $>1 \mu \mathrm{m}^{6,21-22}$.

Various inflammatory diseases and each of their different stages may influence aerosol formation in a particular way. In asthma, laser spectroscopy of EBC showed different particle distribution at different stages of disease: preponderant small particles (diameter ranging from 51 to $200 \mathrm{~nm}$ ) in severe forms of asthma, and more large particles (diameter $>600 \mathrm{~nm}$ ) in mild and moderate asthma ${ }^{23^{*}}$.

The exact location where aerosol particles originate in the respiratory tract and their proportional contribution to EBC composition is not fully understood $24^{*}-26^{*}$. To our knowledge, no paediatric data on this subject have been published.

\section{Collection of EBC}

\section{Condenser systems}

Currently, different research groups use different condenser systems, all based on the same principle of cooling exhaled air $27-31,32^{*}-33^{*}$. Most widely used designs include immersion of a Teflon-lined tubing in an ice-filled bucket, and a specially designed double-wall borosilicate glass condenser system (Fig. 1). Commercially available condensers are EcoScreen (Erich Jaeger $\mathrm{GmbH}$, Hoechberg, Germany) and RTube breath condensate collector (Respiratory Research Inc, Charlottesville, USA). Although cooling of exhaled air, conducted through a Teflon-lined tubing, can be readily achieved using wet ice as well as dry ice or liquid nitrogen, complete obstruction of the collection tube has been reported ${ }^{8}$. The EcoScreen system conducts exhaled air through a lamellar condenser with a sample collection vial inserted into a cooling cuff (electric refrigerator) ${ }^{12}$. Alternative methods are the use of countercurrent circulating ice-water for cooling of exhaled air which is conducted through a double-wall borosilicate glass condenser system, or the portable RTube breath condensate collector which consists of a re-usable and pre-cooled aluminium sleeve, placed over the outside of a disposable vertical condensation or collection (polypropylene) tube, and connected to two one-way valves and a mouthpiece. The latter systems are not associated with the problem of complete obstruction. 


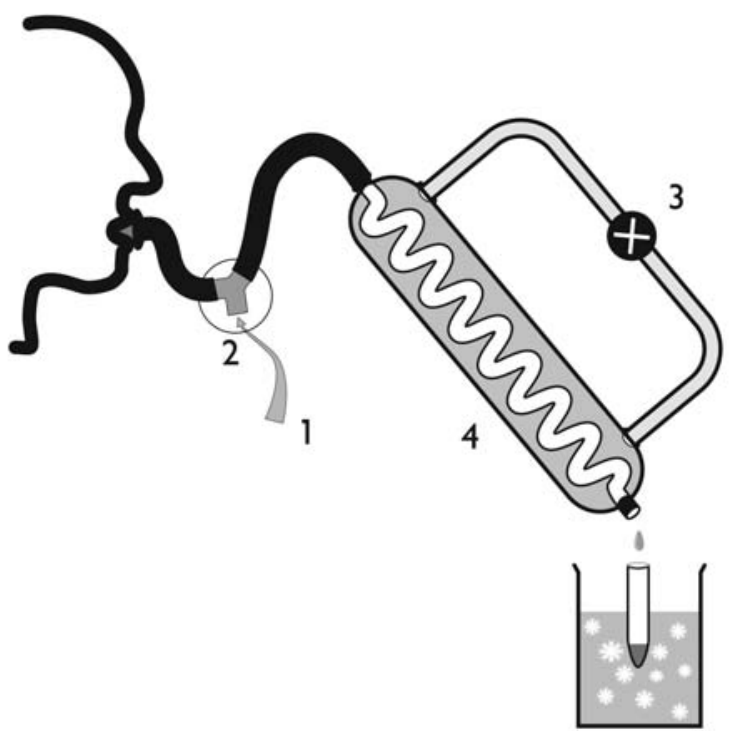

Figure. 1. Schematic representation of an exhaled breath condensate collection device The subject breaths tidally and inhales room air (1) through a two-way non-rebreathing valve (2). Exhaled air is guided by the tubing through a double-wall glass condenser (4), which is cooled by a counter-current circulating ice-water pump (3). The two-way non-rebreathing valve (2) and tubing also serve as a saliva trap.

Minimal or no adaptation is necessary for use of these condenser systems either in children, or in mechanically ventilated subjects, which are connected through the expiratory limb of the ventilatory tubing 27 .

The main obstacle for developing a standardised sampling device, may be the variety of physical characteristics associated with each condenser system design. The coating or adhesive properties of the inner surface of the condenser system and even of the collection container and/or the aliquot vials have to be compared, because this can influence the concentration of the inflammatory mediator in the collected condensate. Ideal coating properties for one specific type of mediator(s) may not hold for another. When analysis of bioactive lipids is planned, polypropylene should be considered for collection to avoid the problem of adsorption that can occur with borosilicate glass or polystyrene containers ${ }^{8}$.

Nasal collection of EBC is reported in minimal co-operative patients like children aged 4 weeks and older for the analysis of hydrogen peroxide ${ }^{34}$. Nasal prongs are serially connected to two polypropylene tubes, submerged in a cold trap, and in turn connected to an electric air suction pump. This procedure allows the collecting of only a fraction of about $20-30 \%$ of the exhaled breath water vapour ${ }^{34}$. However, contamination with nasal secretions may interfere with the actual concentration of the mediator in the lower respiratory tract. 


\section{EBC collecting procedure}

Minimal co-operation from the subjects is required for the technique of EBC collection. In children, the main issue for inclusion for EBC sampling is if they are able to use a mouthpiece properly for 10-15 minutes. Adequate instruction of the procedure and distraction of the child, for example by using video cartoons, is important. Collecting EBC is not only a simple procedure, but also a safe one. No adverse effects were seen in an EBC collection study in 93 healthy children aged 8-13 years ${ }^{35}$. In a study of 91 children with asthma of varying severity, the EBC procedure proved to be safe, even in children with an asthma exacerbation. The success rate was 100\% starting from 4 years of age ${ }^{36}$.

Currently, the most widely used procedure is to breath tidally and directly into the tubing system. Often, a mouthpiece is used, connected to a two-way non-rebreathing valve, which also prevents potential re-breathing of exhaled breath samples. Minute ventilation (or total respired volume) and breathing pattern are the major determinants of EBC volume over time ${ }^{37-40,41^{*}}$. It is suggested to describe these respiratory parameters per EBC measurement, because their influence on mediator concentration is not yet known. Exhalation flow may influence the concentration of biomarkers in EBC as it does in exhaled nitric oxide measurements. Therefore, assessing the flow dependence of different biomarkers is crucial for the standardization and reproducibility of measurements. On the basis of the flow dependence, EBC sampling will be carried out either at a constant flow rate for a fixed time, or at a constant total exhaled volume for a variable time ${ }^{5}$.

The use of nose clips in the prevention of contamination of the EBC with nasal air, remains controversial ${ }^{9,12}$. Application of nose clips could open the nasopharyngeal velum, thereby contaminating the exhaled breath with nasal air. This could be relevant when measuring mediators, such as eicosanoids, which are also formed in the nose and paranasal sinuses 8,12 . Alternatively, a facemask that separates nasal from oral exhaled air can be used. In infants, who are preferential nasal breathers, collection of EBC via a facemask is feasible ${ }^{42^{*}}$. However, significant nasal contribution to total nitrite/nitrate was found, suggesting to limit EBC analysis in infants to compounds not affected by nasal contribution, or to limit EBC collection to sedated infants with induced oral breathing ${ }^{42^{*}}$.

The influence of paranasal sinuses is shown in a study on nitric oxide and humming, which generates an oscillating airflow and enhances paranasal sinus ventilation ${ }^{43}$. Humming increases significantly (15-fold) nasal nitric oxide levels compared with quiet exhalation ${ }^{43}$. Prostanoid levels in healthy subjects are the same with or without using a nose clip ${ }^{4 *}$. The volume of EBC is larger when subjects inhale through the nose, but mediator levels of adenosine, hypoxanthine, inosine, ammonia and thromboxaneB2 are the same as with oral breathing ${ }^{45}$.

Salivary contamination influences the level of several markers that are detectable in EBC. Therefore, prevention of salivary contamination is important. This can be 
achieved by using a gravity-saliva trap, rinsing of the mouth/mouth-washing with sodium bicarbonate $4.5 \%$ prior to collection, periodic swallowing of the accumulated saliva to maintain a dry mouth during collection, and prevention of coughing or forced expiration $8,46^{*}$. Amylase and phosphorus measurements can be used to exclude salivary contamination of the condensate ${ }^{6,15,47^{*}}$.

Fluctuations of environmental and breath temperature during the sampling period may influence the preservation of some labile lipid mediators ${ }^{9}$. Leukotriene-B4 and 8-isoprostane values, but not ammonia and nitrite, are independent of collection temperature in healthy subjects ${ }^{48^{*}}$. Furthermore, environmental ozone concentration at the time of collecting samples is significantly related to the hydrogen peroxide concentration in EBC ${ }^{49^{*}}$. A study on the short-term exposure to ozone showed induction of airway inflammatory mediators: an immediate increase of hydrogen peroxide and 8-isoprostane levels in EBC, and a delayed increase (at 18 hours after exposure) of leukotriene-B4 and thiobarbituric acid reactive substances ${ }^{50}$.

It is unclear whether a circadian rhythm in mediator concentrations exists $51^{*}-53^{*}, 54$. Afternoon collection of EBC may increase or maximize the volume of EBC ${ }^{55^{*}}$.

The duration of EBC collection is variable. In general, a collection time of 15-20 minutes will yield 1-3 $\mathrm{ml}$ of EBC in children aged 4 years and over (own unpublished data). A rapid two-minute method of EBC collection for ammonia and $\mathrm{pH}$ measurements yields $0.25-0.35 \mathrm{ml}^{3,56 *}$.

In summary, an optimal procedure for one specific mediator may not hold for another, emphasising that during EBC collection one should systematically run through a checklist of possible influencing factors or co-determinants (Table 1).

\section{Preservation of EBC}

In general, condensate is collected in small containers 'on ice'. This method allows subsequent pipetting of separate aliquot vials. This is not possible when the condensate is collected in frozen condition, as with the EcoSscreen. The temperature of the cooling sleeve of the RTube breath condensate collector can be chosen by the investigator, and depends on the temperature of the refrigerator where the sleeve was stored in ${ }^{3}$.

Subsequently, each separate aliquot vial can in turn rapidly be frozen and stored at $-20^{\circ} \mathrm{C}$ to $-70^{\circ} \mathrm{C}$ until analysis is performed. In general, an EBC sample volume of $0.05-0.5 \mathrm{ml}$ is sufficient to perform one of the currently used assays.

Sequences of changing phases (gas-fluid-frozen) may influence the concentration of some unstable EBC constituents, and should be kept limited. The value of high velocity freezing processes (for example submerging the aliquot vials in a solution of isopentane) needs to be investigated, as well as the effect of techniques to prevent rapid degradation of instable proteins or cytokines (by adding bovine serum albumin, phosphate buffer solution, or proteinase inhibitors). However, bovine serum albumin 
may disturb the determination of some mediators, as nitrite and hydrogen peroxide. Furthermore, storage time and temperature itself may also be biomarker-dependent. Acceptable storage conditions have to be evaluated.

Table 1. Checklist of procedure for exhaled breath condensate collection.

\section{Condenser}

\begin{tabular}{|c|c|}
\hline & $\begin{array}{l}\text { System } \\
\text { Coating } \\
\text { Cooling temperature }\end{array}$ \\
\hline \multicolumn{2}{|l|}{ Subject } \\
\hline & Age \\
\hline & Sexe \\
\hline & Weigth \\
\hline & Length \\
\hline & Disease (smoking / upper airway infection) \\
\hline & Medication \\
\hline & Breathing pattern (tidal breathing / forced exhalation) \\
\hline & Respiratory parameters (frequency / minute ventilation / total exhaled volume) \\
\hline & Flow \\
\hline & Breath temperature \\
\hline & Lung function parameters \\
\hline & Noseclip / face mask \\
\hline & Prevention of salivary contamination (gravity trap / rinsing mouth / swallowing) \\
\hline \multicolumn{2}{|c|}{ Environment } \\
\hline & Temperature \\
\hline & Ozone \\
\hline & Humidity \\
\hline \multicolumn{2}{|c|}{ Collection } \\
\hline & Date / hour \\
\hline & Phase of sample (solid / liquid) \\
\hline & Duration \\
\hline & Adverse effects \\
\hline & Volume of exhaled breath condensate \\
\hline \multicolumn{2}{|c|}{ Preservation } \\
\hline & Aliquot vial volume \\
\hline & Sample numbers \\
\hline & Products added \\
\hline & Storage temperature \\
\hline & Storage time \\
\hline \multicolumn{2}{|c|}{ Analysis } \\
\hline & Data \\
\hline & Assay \\
\hline & Detection limit \\
\hline
\end{tabular}




\section{Analysis of EBC}

EBC is a human body fluid that contains not only aerosol particles or respiratory fluid droplets with traces of non-volatile solutes, but also large amounts of pure water vapour. Therefore, changes in the concentration of inflammatory mediators in EBC may vary by a factor 100 or more, depending on variations in the concentration gradient between respiratory fluid droplets and water vapour.

The concentration of mediators or non-volatile substances in the respiratory tract lining fluid may be calculated by a method reported by Effros and co-workers, which is based upon urea or electrolyte concentrations in the condensate $14,18^{*}, 57,58^{*}-59^{*}$. These measurements of condensate reference indicators may permit a semi-quantitative analysis of non-volatile substances in respiratory lining fluid, but need further modification ${ }^{60^{*}}$.

Currently, samples of EBC are mostly analysed by commercially available and sensitive assays, developed for use in other media with higher mediator concentrations than condensate. Their lower limits of detection are usually situated near the reported concentrations of markers in EBC. Condensate measurements can be made more reliable by the development of new, high-sensitivity assays, adapted to the unique nature of $E B C$ 3,14,61-62. However, current immunochemical or colorimetric assays lack reference methods and are affected by poor sensitivity, specificity and selectivity ${ }^{63}$. These assays need to be validated with more specific analytical methods, such as gas chromatography/mass spectrometry or high-performance liquid chromatography 5,63 . These techniques are considered the reference techniques for the determination of complex mixtures of organic compounds present at nanomol levels in aqueous matrices 62-63. Recently, modified analytical methods have also been described to quantitate low concentrations of the nitrite/nitrate balance as well as free 3-nitrotyrosine in EBC ${ }^{64^{*}-65^{*}}$.

Freeze-drying may be of additional value to facilitate subsequent biochemical analysis of certain non-lipid mediators.

The first study identifying surface-active properties of EBC was published in Russia in $1980{ }^{66}$. In the 1990s, this technique was rediscovered ${ }^{6}$. Since then, several inflammatory mediators have been identified in EBC. However, results from studies using a wide variety of inflammatory markers have only shown group differences between specific patient-populations and healthy control subjects, but evidence for the diagnostic use of these markers in individual patients is scarce ${ }^{10}$. Furthermore, correlations between mediators in EBC and other biological measurements of lung inflammation, as well as the level of disease control have not yet been demonstrated sufficiently. Recently, in an animal model, a similar pattern of nitrite and total protein levels was found in EBC and bronchoalveolar lavage fluid ${ }^{67^{*}}$.

Although it is presently an area of active research and an increasing number of abstracts * are being presented, few studies have been published on children 28,35 36,63,68-75. We reviewed the available data on this age group until June 2003. 


\section{Hydrogen peroxide}

Oxidative stress describes an imbalance between oxidants (reactive oxygen species) and anti-oxidants (superoxide dismutase, catalase, glutathione, uric acid, lactoferrin, vitamin $\mathrm{C}$, and vitamin E) in favour of oxidants, which contributes to the pathogenesis of several inflammatory lung diseases ${ }^{76}$. The development of such an imbalance in lung inflammation may activate redox-sensitive transcription factors such as nuclear factor-kappa B and activator protein-1, which regulate the genes for pro-inflammatory mediators and protective antioxidant genes ${ }^{77}$. Activation of inflammatory and structural cells result in an increased production of reactive oxygen species. Superoxide anions are generated by nicotinamide adenine dinucleotide phosphate oxidase and then converted to hydrogen peroxide by superoxide dismutases. Hydrogen peroxide is then degraded to water by catalases. Superoxide anions and hydrogen peroxide may generate the highly reactive hydroxyl radicals, leading to peroxidative damage of airway structures and formation of volatile thiobarbituric acid reactive substances. Hydrogen peroxide is less reactive than other reactive oxygen species, and because it is soluble, increased hydrogen peroxide in the airway equilibrates with air 9,12,78.

Exhaled hydrogen peroxide has potential as a marker of oxidative stress in the lungs. Exhaled hydrogen peroxide is less stable than other markers, and its concentration appears to be expiratory flow rate dependent ${ }^{79}$. Furthermore, symptomatic upper respiratory tract infection may act as a confounder in studies on hydrogen peroxide and chronic lower airway inflammation ${ }^{80}$. No significant circadian rhythm in hydrogen peroxide levels was reported in healthy subjects ${ }^{52^{*}}$. However, concentrations of exhaled hydrogen peroxide showed diurnal variation in both stable chronic obstructive pulmonary disease patients and healthy controls 54,81 . Hydrogen peroxide is measured in EBC by the spectrophotometric method or the fluorometric method with horseradish peroxidase ${ }^{82}$. Recently, some new techniques have been described: a fast chemiluminescent method for hydrogen peroxide measurement in EBC 83, on-line measurement of hydrogen peroxide based on a biosensor with electrochemical detection and a detection limit of $12.5 \mathrm{nmol}{ }^{84^{*}-86^{*}}$ and a sensitive $(0.02 \mu \mathrm{mol})$ fluorometrical method with a stable storage time of 40 days ${ }^{61}$.

Paediatric EBC data on hydrogen peroxide are summarised in Table 2.

Reference data for exhaled hydrogen peroxide have been described in a group of 93 healthy children ${ }^{35}$. There was no correlation between the levels of exhaled hydrogen peroxide and age, sex, or lung function in healthy children ${ }^{35}$. Hydrogen peroxide levels in a study on 102 healthy children was influenced by atmospheric nitric oxide ${ }^{73}$.

Exhaled hydrogen peroxide levels were elevated in asthmatic children compared to healthy controls 28,69 . Higher levels of hydrogen peroxide correlated with severity of asthma ${ }^{87^{*}}$. Besides diagnostic purposes, hydrogen peroxide may be used to monitor therapy. Little data are available on this topic. However, hydrogen peroxide levels were increased in 16 children with an acute infectious pulmonary exacerbation of cystic fibrosis, and significantly decreased in EBC during intravenous antibiotic treatment ${ }^{70}$. 
Table 2. Hydrogen peroxide in EBC of children, measured by fluorimetric assay (with horseradish peroxidase)

\begin{tabular}{llllll} 
& $\begin{array}{l}\text { Median value } \\
\text { patient group } \\
\text { (micromol) }\end{array}$ & $\begin{array}{l}\text { Median value } \\
\text { healthy controls } \\
\text { (micromol) }\end{array}$ & $\begin{array}{l}\text { P value } \\
\text { Reference }(\mu \mathrm{mol})\end{array}$ \\
\hline Asthma & $0.81(\dagger)$ & $0.25(\dagger)$ & 0.013 & 28 & - \\
\hline Asthma, stable & $0.54(\dagger)$ & - & - & 28 & - \\
\hline Asthma, acute & $1.50(\dagger)$ & - & $\begin{array}{l}\text { Lower limit of } \\
\text { detection }\end{array}$ \\
& & & $\begin{array}{l}\text { (vs. stable } \\
\text { asthma) }\end{array}$ & \\
\hline Asthma & 0.60 & 0.15 & $<0.05$ & 69 & 0.1 \\
\hline Asthma, no ICS & 0.80 & 0.15 & $<0.01$ & 69 & 0.1 \\
\hline Asthma, with ICS & 0.45 & 0.15 & n.s. & 69 & 0.1 \\
\hline Asthma, severe & $149.5(\ddagger)$ & $10.9(\ddagger)$ & $<0.001$ & $87^{*}$ & - \\
\hline CF, acute infective & 0.28 & - & - & 70 & 0.01 \\
\hline CF, after AB iv & 0.16 & - & 0.002 & 70 & 0.01 \\
& & & (vs. acute & \\
\hline Ventilated & 0.45 & - & infective) & \\
\hline Healthy & - & 0.13 & - & $88^{*}$ & 0.083 \\
\hline Healthy & - & $0.49(\S)$ & - & 35 & 0.01 \\
\hline Healthy & - & 0.51 & - & 73 & - \\
\hline
\end{tabular}

EBC : exhaled breath condensate

$\dagger: \mu \mathrm{mol} / \mathrm{l}$

$\ddagger: \mathrm{uM} / \mathrm{ml}$

$\S$ : nasally collected EBC

CF : cystic fibrosis

$A B$ iv : antibiotics intravenously

ICS : inhalation corticosteroids

n.s. : not significant

In mechanically ventilated children with various non-specified underlying conditions, hydrogen peroxide was detected in all EBC specimens, but did not correlate with the severity of illness ${ }^{88^{*}}$.

\section{Eicosanoids}

Eicosanoids are potent mediators of inflammation, which are derived from arachidonic acid. They include prostaglandins, thromboxane, isoprostanes, leukotrienes and lipoxins. Prostaglandins and thromboxane are formed through increased expression of inducible cyclo-oxygenase-2. Most prostaglandins and thromboxane have proinflammatory properties. Prostaglandin-E2 and Prostaglandin-I2 are anti-inflammatory. 
Leukotrienes are lipid mediators derived from arachidonic acid via the 5-lipoxygenase pathway. Leukotrienes are potent constrictors and proinflammatory mediators that contribute to the pathophysiology of asthma ${ }^{9}$. The cysteinyl-leukotrienes (leukotriene-C4, leukotrieneD4 and leukotriene-E4) are generated predominantly by mast cells and eosinophils. By contrast, leukotriene-B4 has potent chemotactic activity towards neutrophils 9,12.

Isoprostanes are formed by free radical-catalysed lipid peroxidation of arachidonic acid during oxidative stress 9,12,78. They are initially esterified in membrane phospholipids, from which they are cleaved by a phospholipase-A2 ${ }^{9}$. F2-isoprostanes are not only relatively stable and specific markers of lipid peroxidation, but also posses potent biological activity ${ }^{89}$. They can be mediators of the cellular effects of oxidant stress and are a reflection of complex interactions between the reactive nitrogen species and reactive oxygen species $8,9,89$. The most prevalent isoprostane in humans is 8-epi-PGF2-alpha also known as 8-isoprostane ${ }^{9}$.

Lipoxin-A4 and lipoxin-B4 have potential anti-inflammatory action in asthma, and lipoxin-A4 is detected in supernatant of induced sputum ${ }^{90}$.

Eicosanoids are measured by enzyme immunoassays, using commercially available detection kits. Recently, validation of measurement of 8-isoprostanes, prostaglandin-E2 and leukotriene-B4 in EBC by reverse-phase high-performance liquid chromatography

Table 3. 8-isoprostanes in EBC of children

\begin{tabular}{|c|c|c|c|c|c|c|}
\hline Disease & $\begin{array}{l}\text { Median } \\
\text { value } \\
\text { patient } \\
\text { group } \\
(\mathrm{pg} / \mathrm{ml})\end{array}$ & $\begin{array}{l}\text { Median } \\
\text { value } \\
\text { healthy } \\
\text { controls } \\
\text { (pg/ml) }\end{array}$ & $P$ value & Reference & Assay & $\begin{array}{l}\text { Lower limit } \\
\text { of } \\
\text { detection } \\
\text { (pg/ml) }\end{array}$ \\
\hline Asthma, acute & 12.00 & 2.60 & $<0.01$ & 75 & EIA & - \\
\hline Asthma, after OCS & 8.40 & 2.60 & $\begin{array}{l}<0.001 \\
(<0.05 \\
\text { vs acute) }\end{array}$ & 75 & EIA & - \\
\hline Asthma, no ICS & 9.34 & 3.81 & $<0.01$ & $95^{*}$ & EIA & 4 \\
\hline Asthma, with ICS & 6.73 & 3.81 & $<0.01$ & $95^{*}$ & EIA & 4 \\
\hline Asthma, no ICS & 61.90 & 33.60 & $<0.01$ & $101^{*}$ & RIA & - \\
\hline Asthma, with ICS & 64.30 & 33.60 & $<0.01$ & $101^{*}$ & RIA & - \\
\hline Asthma, with ICS & 47.20 & 34.20 & $<0.008$ & $99^{*}$ & RIA & - \\
\hline $\begin{array}{l}\text { EBC : exhaled breat } \\
\text { EIA : enzyme immu } \\
\text { ICS : inhalation cort } \\
\text { OCS : oral corticost } \\
\text { RIA : radio immuno }\end{array}$ & $\begin{array}{l}\text { densate } \\
\text { ay } \\
\text { roids }\end{array}$ & & & & & \\
\hline
\end{tabular}


Table 4. Cysteinyl-leukotrienes in EBC of children

\begin{tabular}{|c|c|c|c|c|c|c|}
\hline Disease & $\begin{array}{l}\text { Median } \\
\text { value } \\
\text { Patient } \\
\text { group } \\
(\mathrm{pg} / \mathrm{ml})\end{array}$ & $\begin{array}{l}\text { Median } \\
\text { value } \\
\text { healthy } \\
\text { controls } \\
\text { (pg/ml) }\end{array}$ & $P$ value & Reference & Assay & $\begin{array}{l}\text { Lower } \\
\text { limit of } \\
\text { detection } \\
(\mathrm{pg} / \mathrm{ml})\end{array}$ \\
\hline Asthma, mild intermittent & 19.90 & 18.50 & n.s. & 74 & ElAt & 15 \\
\hline Asthma, mild persistent & 27.90 & 18.50 & $<0.01$ & 74 & ElAt & 15 \\
\hline $\begin{array}{l}\text { Asthma, moderate } \\
\text { to severe }\end{array}$ & 31.50 & 18.50 & $<0.05$ & 74 & ElAt & 15 \\
\hline Asthma, mild & 19.40 & 17.20 & - & $96^{*}$ & ElAt & 17 \\
\hline Asthma, moderate & 22.90 & 17.20 & $<0.001$ & $96^{*}$ & ElAt & 17 \\
\hline Asthma, severe & 27.70 & 17.20 & - & $96^{*}$ & ElAt & 17 \\
\hline Asthma, allergic & 14.26 & - & & $102^{*}$ & EIA & \\
\hline $\begin{array}{l}\text { Asthma, after } 3 \text { months } \\
\text { HDM free }\end{array}$ & 4.60 & - & $\begin{array}{l}<0.01 \\
\text { (vs allergic } \\
\text { asthma) }\end{array}$ & $102^{*}$ & EIA & \\
\hline Asthma, no ICS & 12.30 & 4.90 & 0.01 & $97^{*}$ & ElAt & 17 \\
\hline Asthma, with ICS & 10.50 & 4.90 & 0.01 & $97^{*}$ & ElAt & 17 \\
\hline Asthma, no ICS & 30.50 & 15.90 & $<0.05$ & $100^{*}$ & EIA & - \\
\hline Asthma, with ICS & 31.80 & 15.90 & $<0.05$ & $100^{*}$ & EIA & - \\
\hline Asthma, acute & 12.70 & 4.30 & $<0.01$ & 75 & ElAt & 17 \\
\hline Asthma, after OCS & 5.20 & - & $\begin{array}{l}<0.01 \\
\text { (vs. acute } \\
\text { asthma) }\end{array}$ & 75 & ElAt & 17 \\
\hline Asthma & 14.70 & - & - & $106^{*}$ & ELISA & 4.5 \\
\hline $\mathrm{CF}$ & 9.30 & - & - & $106^{*}$ & ELISA & 4.5 \\
\hline$\overline{P C D}$ & 21.70 & 17.20 & - & $107^{*}$ & ElAt & 17 \\
\hline
\end{tabular}

EBC : exhaled breath condensate

n.s. : not significant

EIAt : enzyme immuno assay (Cayman Chemical, Ann Arbor, Michigan, USA)

HDM : house dust mite

ICS : inhalation corticosteroids

OCS : oral corticosteroids

ELISA : enzyme linked immuno sorbent assay (DPC Biermann, Bad-Neuheim, Germany)

CF : cystic fibrosis

$P C D$ : primary ciliary dyskinesia

or by gas chromatography/mass spectrometry has been reported ${ }^{12,91,92^{*}-93^{*}}$. Exhaled 8isoprostane and prostaglandin-E2 are not flow dependent in healthy subjects ${ }^{94^{*}}$. The EBC levels of prostaglandin-E2 and thromboxane-B2 in healthy subjects with or without nose clip are comparable ${ }^{44^{*}}$. 
Table 5. Leukotriene-B4 in EBC of children

\begin{tabular}{|c|c|c|c|c|c|c|}
\hline Disease & $\begin{array}{l}\text { Median } \\
\text { value } \\
\text { patient } \\
\text { group } \\
\text { (pg/ml) }\end{array}$ & $\begin{array}{l}\text { Median } \\
\text { value } \\
\text { healthy } \\
\text { controls } \\
\text { (pg/ml) }\end{array}$ & $P$ value & Reference & Assay & $\begin{array}{l}\text { Lower limit } \\
\text { of } \\
\text { detection } \\
\text { (pg/ml) }\end{array}$ \\
\hline Asthma, mild intermittent & 52.7 & 47.9 & n.s. & 74 & EIAT & 4.4 \\
\hline Asthma, mild persistent & 126.0 & 47.9 & $<0.0001$ & 74 & EIAt & 4.4 \\
\hline $\begin{array}{l}\text { Asthma, moderate } \\
\text { to severe }\end{array}$ & 131.9 & 47.9 & $<0.0001$ & 74 & EIAt & 4.4 \\
\hline Asthma, mild & 69.8 & 62.7 & - & $96^{*}$ & EIAT & 4 \\
\hline Asthma, moderate & 137.7 & 62.7 & $<0.001$ & $96^{*}$ & ElAt & 4 \\
\hline Asthma, severe & 137.5 & 62.7 & $<0.001$ & $96^{*}$ & EIAt & 4 \\
\hline Asthma, before IHV & 25.8 & - & & $103^{*}$ & - & - \\
\hline Asthma, after IHV & 35.5 & - & $\begin{array}{l}<0.05 \\
\text { (vs before) }\end{array}$ & $103^{*}$ & - & - \\
\hline Asthma, no ICS & 26.3 & 19.8 & n.s. & $100^{*}$ & EIA & - \\
\hline Asthma, with ICS & 24.8 & 19.8 & n.s. & $100^{*}$ & EIA & - \\
\hline Asthma & 58.0 & 37.8 & n.s. & $98^{*}$ & ElAt & \\
\hline PCD & 54.7 & 54.5 & - & $107^{*}$ & ElAt & 4 \\
\hline $\begin{array}{l}\text { EBC : exhaled breath cond } \\
\text { n.s. : not significant } \\
\text { EIAt : enzyme immuno as } \\
\text { IHV : isocapnic hyperventil } \\
\text { ICS : inhalation corticoster } \\
\text { PCD : primary ciliary dyski }\end{array}$ & $\begin{array}{l}\text { nsate } \\
\text { ay (Cayma } \\
\text { tion } \\
\text { ids } \\
\text { esia }\end{array}$ & Chemical, $A$ & Arbor, Mich & gan, USA) & & \\
\hline
\end{tabular}

Paediatric EBC data on eicosanoids are summarised in Tables 3-6.

In asthmatic children, elevated eicosanoids were found when compared with

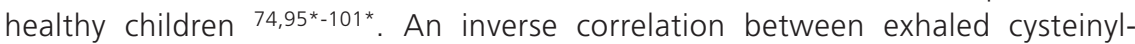
leukotrienes and leukotriene-B4 in children with mild persistent asthma was assessed, which may reflect the contrary effect of steroids on eosinophil and neutrophil survival 74 . No significant diurnal variation in cysteinyl-leukotriene levels was found in asthmatic children ${ }^{51^{*}}$. Reduced cysteinyl-leukotrienes were reported after 3 months of house dust mite avoidance in allergic asthmatic children ${ }^{102 *}$. After a course of oral steroid therapy, a reduction was seen in cysteinyl-leukotrienes and 8-isoprostanes of children with an asthma exacerbation ${ }^{75}$. Leukotriene-B4 was significantly increased after isocapnic hyperventilation with cold air in children with stable asthma, but not in the control group $103^{*}-104^{*}$. No correlation with spirometric measurements was found $74,96 *-99 *$ 
Table 6. Prostaglandin-E2 in EBC of children

\begin{tabular}{|c|c|c|c|c|c|c|}
\hline Disease & $\begin{array}{l}\text { Median } \\
\text { value } \\
\text { patient } \\
\text { group } \\
\text { (pg/ml) }\end{array}$ & $\begin{array}{l}\text { Median } \\
\text { value } \\
\text { healthy } \\
\text { controls } \\
\text { (pg/ml) }\end{array}$ & $P$ value & Reference & Assay & $\begin{array}{l}\text { Lower limit } \\
\text { of } \\
\text { detection } \\
\text { (pg/ml) }\end{array}$ \\
\hline PCD & 15.7 & 19.7 & $<0.05$ & $107^{*}$ & EIA & 15 \\
\hline Asthma, no ICS & 28.8 & 22.6 & n.s. & $101^{*}$ & RIA & - \\
\hline Asthma, with ICS & 24.0 & 22.6 & n.s. & $101^{*}$ & RIA & - \\
\hline Asthma, with ICS & 51.5 & 46.8 & n.s. & $99^{*}$ & RIA & - \\
\hline \multicolumn{7}{|c|}{ EBC : exhaled breath condensate } \\
\hline \multicolumn{7}{|c|}{ PCD : primary ciliary dyskinesia } \\
\hline \multicolumn{7}{|c|}{ EIA : enzyme immuno assay (Cayman Chemical, Ann Arbor, Michigan, USA) } \\
\hline \multicolumn{7}{|c|}{ ICS : inhalation corticosteroids } \\
\hline \multicolumn{7}{|c|}{ n.s. : not significant } \\
\hline \multicolumn{7}{|c|}{ RIA : radio immuno assay } \\
\hline
\end{tabular}

In children with severe atopic eczema but without asthma, increased cysteinylleukotrienes were found in EBC ${ }^{105^{*}}$.

In children with cystic fibrosis and primary ciliary dyskinesia, cysteinyl-leukotrienes were detected in EBC $106^{\star}-107^{*}$.

Decreased concentrations of prostaglandin-E2 were reported in children with primary ciliary dyskinesia, compared with healthy controls ${ }^{107^{*}}$. No differences were seen in the levels of leukotriene-B4 and cysteinyl-leukotrienes between these children ${ }^{107 *}$.

\section{Nitrogen-reactive species}

Nitrite/nitrate, S-nitrosothiols and 3-nitrotyrosine are nitrogen-reactive species. The reaction between nitric oxide and superoxide anions in the airways results in the formation of peroxynitrite, a reactive oxygen species. Peroxynitrite can be trapped by thiol-containing biomolecules such as cysteine and glutathione, to form S-nitrosothiols or can be oxidized to nitrate and nitrite $9,12,78$. Peroxynitrite reacts with tyrosine residues in proteins to form the stable end-product 3-nitrotyrosine, which is used as a diagnostic tool to identify involvement of nitric oxide-derived oxidants in various disease states $8,9,12$. The balance between nitrite/nitrate, S-nitrosothiols, and nitrotyrosine gives insight into nitric oxide synthesis and short- and long-term changes in nitric oxide production ${ }^{9,12}$.

The nitrite/nitrate balance is determined by colorimetric assay (based on the Griess reaction), by fluorometric assay (based on the 2,3-diaminonaphtalene reaction), or by an ionic chromatograph analyser 108-109,110*. Recently, a method based on gas 
Table 7. Nitrite in EBC of children

\begin{tabular}{|c|c|c|c|c|c|c|}
\hline Disease & $\begin{array}{l}\text { Median } \\
\text { value } \\
\text { patient } \\
\text { group } \\
\text { ( } \mu \mathrm{mol})\end{array}$ & $\begin{array}{l}\text { Median } \\
\text { value } \\
\text { healthy } \\
\text { controls } \\
\text { ( } \mu \mathrm{mol})\end{array}$ & $P$ value & Reference & Assay & $\begin{array}{l}\text { Lower limit } \\
\text { of } \\
\text { detection } \\
\text { ( } \mu \mathrm{mol})\end{array}$ \\
\hline Asthma, no ICS & 0.87 & 0.31 & 0.009 & $118^{*}$ & - & - \\
\hline Asthma, mild & 2.02 & 0.41 & $<0.05$ & 71 & $C$ & - \\
\hline Asthma, moderate & 3.51 & 0.41 & $<0.05$ & 71 & C & - \\
\hline $\mathrm{CF}$, mild & 2.16 & 0.41 & $<0.05$ & 71 & $C$ & - \\
\hline$\overline{\mathrm{CF}}$, moderate & 1.87 & 0.41 & $<0.05$ & 71 & $C$ & - \\
\hline $\mathrm{CF}$, severe & 2.13 & 0.41 & $<0.05$ & 71 & C & - \\
\hline $\mathrm{CF}$ & 3.30 & 1.00 & 0.018 & 68 & $C$ & 0.074 \\
\hline$\overline{C F}$ & 4.13 & 3.70 & n.s. & $33^{*}$ & C & - \\
\hline PCD & 2.40 & 1.80 & n.s. & $120^{*}$ & $\mathrm{~F}$ & - \\
\hline Cough & 0.75 & 0.41 & n.s. & 71 & C & - \\
\hline Healthy & - & 3.30 & - & 73 & $\mathrm{~F}$ & 0.1 \\
\hline \multicolumn{7}{|c|}{ EBC ; exhaled breath condensate } \\
\hline \multicolumn{7}{|c|}{ ICS : inhalation corticosteroids } \\
\hline \multicolumn{7}{|c|}{ C : colorimetric assay (Griess reaction) } \\
\hline \multicolumn{7}{|l|}{ CF : cystic fibrosis } \\
\hline \multicolumn{7}{|l|}{ n.s. : not significant } \\
\hline \multicolumn{7}{|c|}{ PCD : primary ciliary dyskinesia } \\
\hline \multicolumn{7}{|c|}{$\mathrm{F}$ : fluorimetric assay (2,3 di-amino-naphtalene) } \\
\hline
\end{tabular}

chromatography/mass spectrometry was developed that allows simultaneous quantification of nitrite and nitrate in various biological fluids ${ }^{111}$. Furthermore, a modification of the Griess method is described for use with EBC, with a detection limit of $0.640 \mu \mathrm{mol}{ }^{64^{\star}}$. Several methods are used for the detection of S-nitrosothiols and nitrotyrosine ${ }^{112-115}$. To quantitate low concentrations of free 3-nitrotyrosine in EBC, a mass-selective determination was developed and validated ${ }^{65^{*}}$.

Paediatric EBC data on nitrogen-reactive species are summarised in Tables 7 and 8.

In healthy children, nitrite values were not related to the levels of exhaled nitric oxide ${ }^{73}$.

Although, in 23 children with and without respiratory disease, expiratory flow patterns did not significantly alter mean total nitrite/nitrate levels in EBC, large intrasubject variation was found ${ }^{116^{*}}$. 
Table 8. 3-nitrotyrosine in $\mathrm{EBC}$ of children

\begin{tabular}{|c|c|c|c|c|c|c|}
\hline Disease & $\begin{array}{l}\text { Median } \\
\text { value } \\
\text { patient } \\
\text { group } \\
\text { (pg/ml) }\end{array}$ & $\begin{array}{l}\text { Median } \\
\text { value } \\
\text { healthy } \\
\text { controls } \\
\text { (pg/ml) }\end{array}$ & $P$ value & Reference & Assay & $\begin{array}{l}\text { Lower limit } \\
\text { of } \\
\text { detection } \\
\text { (pg/ml) }\end{array}$ \\
\hline Asthma, moderate & 13.5 & 5.3 & $<0.05$ & $119^{*}$ & EIA & - \\
\hline $\mathrm{CF}$ & 1.60 & 1.69 & n.s. & $117^{*}$ & EIA & - \\
\hline $\begin{array}{l}\text { EBC : exhaled breatl } \\
\text { EIA : enzyme immun } \\
\text { CF : cystic fibrosis } \\
\text { n.s. : not significant }\end{array}$ & $\begin{array}{l}\text { nsate } \\
\text { (Cayman }\end{array}$ & emical, Ar & Arbor, Mich & n, USA) & & \\
\hline
\end{tabular}

In children with cystic fibrosis, elevated levels of nitrite were found in EBC compared to controls 68,71 . There was no significant correlation between condensate nitrite values and age, lung function indices, chest radiograph score, or the use of inhaled steroids ${ }^{68}$. Nitrite levels were not correlated with the severity of cystic fibrosis ${ }^{68}$. In infants with cystic fibrosis, nitrite was measured using a copper baby-condensatesampler $3^{3{ }^{*}}$. However, no statistical difference in nitrite was found between infants with cystic fibrosis and healthy infants ${ }^{33^{*}}$. Nitrotyrosine levels did not differentiate between children with cystic fibrosis and healthy subjects, and there was no correlation with lung function ${ }^{117^{*}}$.

In asthmatic children, significantly elevated levels of nitrite were found in EBC compared to controls ${ }^{71,118^{*}}$. Nitrite levels were not correlated with age, family history of asthma, anti-inflammatory treatment, number of allergic sensitisations, or the severity of asthma ${ }^{71}$.

After treatment with inhaled corticosteroids, a significant reduction in nitrite was only observed in asthmatic patients with a clinical improvement ${ }^{118^{*}}$. Nitrotyrosine levels were increased in asthmatic children compared to normal children, but no correlation was observed with exhaled nitric oxide ${ }^{119^{*}}$.

In primary ciliary dyskinesia, levels of nitrite and nitrite/nitrate were not increased ${ }^{120^{*}}$.

\section{Other markers of oxidative stress}

A key feature in the pathophysiology of inflammatory lung diseases is the development of an imbalance between oxidants (reactive oxygen species) and anti-oxidants (glutathione), known as oxidative stress ${ }^{76}$.

Glutathione is formed by the selenium-dependent enzyme glutathione peroxidase and it is a vital intra- and extra-cellular protective antioxidant against oxidative/ nitrosative 
Table 9. Malondialdehyde and glutathione in $\mathrm{EBC}$ of children

\begin{tabular}{|c|c|c|c|c|c|}
\hline Mediator & Disease & $\begin{array}{l}\text { Median value } \\
\text { patient group } \\
\text { (nanomol) }\end{array}$ & $\begin{array}{l}\text { Median value } \\
\text { healthy controls } \\
\text { (nanomol) }\end{array}$ & $P$ value & Reference \\
\hline \multirow[t]{2}{*}{ Malondialdehyde } & $\begin{array}{l}\text { Asthma, } \\
\text { acute }\end{array}$ & 30.2 & 19.4 & 0.002 & 63 \\
\hline & $\begin{array}{l}\text { Asthma, } \\
\text { after OCS }\end{array}$ & 18.5 & & $\begin{array}{l}0.001 \\
\text { (vs.acute) }\end{array}$ & 63 \\
\hline \multirow[t]{2}{*}{ Glutathione } & $\begin{array}{l}\text { Asthma, } \\
\text { acute }\end{array}$ & 5.96 & 14.1 & $<0.0001$ & 63 \\
\hline & $\begin{array}{l}\text { Asthma, } \\
\text { after OCS }\end{array}$ & 8.44 & & $\begin{array}{l}0.04 \\
\text { (vs.acute) }\end{array}$ & 63 \\
\hline
\end{tabular}

EBC : exhaled breath condensate

OCS : oral corticosteroids

stresses, which play a key role in the control of proinflammatory processes in the lung 76,77 . Glutathione is important in immunomodulation, remodelling of the extracellular matrix, apoptosis and mitochondrial respiration ${ }^{77}$. Glutathione can be measured in EBC by modified high-performance liquid chromatography with fluorescence detection ${ }^{63}$.

Reactive oxygen species generated close to cell membranes deplete intracellular glutathione and oxidize membrane phospholipids (membrane lipid peroxidation), which may continue in a chain reaction ${ }^{77}$. Endogenously generated aldehydic lipid peroxidation products are malondialdehyde, $\alpha, \beta$-unsaturated aldehydes and saturated aldehydes (hexanal, heptanal, nonanal). Aldehydes are involved in many of the pathophysiologic effects associated with oxidative stress in cells and tissues ${ }^{77,121}$. Malondialdehyde is generated mainly by arachidonic acid and docosahexenoic acid. $\alpha, \beta$-unsaturated aldehydes are formed by lipid peroxidation of $\omega-6$ (arachidonic acid and linoleic acid) and $\omega-3$ (oleic acid) polyunsaturated fatty acids. Saturated aldehydes are breakdown products of oxidised linoleic acid and arachidonic acid, palmitoleic acid and oleic acid ${ }^{63}$. Malondialdehyde can be quantified as (volatile) thiobarbituric acid reactive substances, but the colorimetric assay lacks specificity ${ }^{63}$. Recently, malondialdehyde was measured by high-performance liquid chromatography separation and fluorescence detection (with a detection limit of $4.1 \mathrm{nmol}$ ), or after derivatization by liquid chromatography-tandem mass spectrometry ${ }^{62-63,122}$. In subjects with asthma and chronic obstructive pulmonary disease, the concentration of aldehydes in condensate was not affected by expiratory flow rates, sampling time, total exhaled air volume, and total condensate volume 63,122.

Paediatric EBC data on glutathione and malondialdehyde are summarised in Table 9.

In children with an asthma exacerbation, malondialdehyde levels were higher and glutathione levels were lower compared to healthy controls ${ }^{63}$. After a course of oral 
Table 10. Cytokines in EBC of children

\begin{tabular}{|c|c|c|c|c|c|c|c|}
\hline Cytokine & Disease & $\begin{array}{l}\text { Median } \\
\text { value } \\
\text { patient } \\
\text { group } \\
(\mathrm{pg} / \mathrm{ml})\end{array}$ & $\begin{array}{l}\text { Median } \\
\text { value } \\
\text { healthy } \\
\text { controls } \\
\text { (pg/ml) }\end{array}$ & $P$ value & Reference & Assay & $\begin{array}{l}\text { Lower limit } \\
\text { of } \\
\text { detection } \\
\text { (pg/ml) }\end{array}$ \\
\hline \multirow[t]{8}{*}{ IL-4 } & Atopy & 1.94 & - & - & $125^{*}$ & ELISA $†$ & 0.13 \\
\hline & $\begin{array}{l}\text { Asthma, } \\
\text { atopic }\end{array}$ & 7.68 & 1.34 & - & $124^{*}$ & $\mathrm{EIA}$ & - \\
\hline & $\begin{array}{l}\text { Allergic } \\
\text { rhinitis }\end{array}$ & 5.36 & 1.34 & - & $124^{*}$ & $\mathrm{EIA}$ & - \\
\hline & $\begin{array}{l}\text { Allergic } \\
\text { rhinitis }\end{array}$ & 1.78 & 1.34 & n.s. & $123^{*}$ & EIA & - \\
\hline & $\begin{array}{l}\text { Asthma, } \\
\text { atopic }\end{array}$ & 1.54 & 1.34 & n.s. & $123^{*}$ & EIA & - \\
\hline & $\begin{array}{l}\text { Asthma, } \\
\text { acute }\end{array}$ & 5.67 & - & $\begin{array}{l}\text { n.s. } \\
\text { (vs. atopic } \\
\text { asthma) }\end{array}$ & $123^{*}$ & EIA & - \\
\hline & $\begin{array}{l}\text { Asthma, } \\
\text { no ICS }\end{array}$ & 53.7 & 35.7 & $<0.05$ & 72 & ELISA & 20 \\
\hline & $\begin{array}{l}\text { Asthma, } \\
\text { with ICS }\end{array}$ & 37.5 & & $\begin{array}{l}<0.05 \\
\text { (vs. no ICS) }\end{array}$ & 72 & ELISA & 20 \\
\hline \multirow[t]{2}{*}{ IFN-g } & $\begin{array}{l}\text { Asthma, } \\
\text { no ICS }\end{array}$ & 3.7 & 5.1 & $<0.01$ & 72 & EIA§ & 0.5 \\
\hline & $\begin{array}{l}\text { Asthma, } \\
\text { with ICS }\end{array}$ & 4.1 & & $\begin{array}{l}\text { n.s. } \\
\text { (vs. no ICS) }\end{array}$ & 72 & EIA§ & 0.5 \\
\hline IL-8 & $\mathrm{CF}$ & 47 & 10 & n.s. & 68 & ELISAף & 0.5 \\
\hline
\end{tabular}

$E B C$ : exhaled breath condensate

IL : interleukin

ELISA : enzyme linked immuno-sorbent assay

$t$ : R\&D systems, Minneapolis, USA

EIA : enzyme immuno assay

n.s. : not significant

ICS : inhalation corticosteroids

¥ : Cayman Chemical, Ann Arbor, Michigan, USA

IFN-g : interferon gamma

$\S$ : Pierce Endogen, Rockfort, Illinois, USA

CF : cystic fibrosis

१ : home made

prednisone, malondialdehyde levels decreased, whereas glutathione levels increased ${ }^{63}$. No differences were observed among these marker levels obtained at different flow 
rates $^{63}$. No correlation was found between biomarker levels and spirometric values ${ }^{63}$. $\alpha, \beta$-unsaturated aldehydes were detectable only in a few EBC samples, but chemically stable saturated aldehydes were detectable in all EBC samples ${ }^{63}$

Furthermore, the observed bi-directional changes in malondialdehyde and glutathione levels in EBC of asthmatic children show that EBC analysis does not simply represents alterations of turbulent airflow and airway obstruction ${ }^{63}$

\section{Cytokines}

Cytokines are intercellular low molecular weight $(<80 \mathrm{kDa})$ immune regulatory peptides involved in controlling the local and/or systemic consequences of injury, inflammation, haematopoiesis, and tissue repair. Their effects start by binding to specific high-affinity cell surface receptors that cause alteration of gene expression in the target cells. An increasing number of cytokines are being described. They are categorised as T-cell derived lymphokines, proinflammatory cytokines, anti-inflammatory (inhibitory) cytokines and growth factors. Analysis of cytokines is performed by enzyme immunoassay, using (modified) commercially available detection kits.

Paediatric EBC data on cytokines are summarised in Table 10.

In cystic fibrosis, proinflammatory interleukin-8 was present in only $30 \%$ of the children with clinically stable disease ${ }^{68}$. Although the values were higher than in healthy controls, there was no statistically significant difference ${ }^{68}$.

In asthmatic children, significantly increased mean interleukin-4 levels and decreased mean interferon-gamma levels were found compared with normal children ${ }^{72}$. The levels of exhaled interleukin-4 were lower under steroid treatment ${ }^{72}$

In atopic children with stable asthma or allergic rhinitis, the concentrations of interleukin-4 were statistically not different from those in non-atopic controls ${ }^{123^{*}-124^{*}}$. After allergen exposure or asthma exacerbation, higher levels of interleukin-4 were found $123^{*}, 125^{*}$.

\section{Immunoglobulin E}

Immunoglobulin E was not demonstrated by nephelometric technique in EBC of children with allergic asthma ${ }^{32^{*}}$. However, by enzyme immunoassay, immunoglobulinE was detected in all samples of atopic children and controls with considerable overlap, values ranging from 20 to $230 \mathrm{IU} / \mathrm{ml}^{123^{*}-126^{\star}}$. After allergen exposure, an increase of immunoglobulin-E in EBC was found ${ }^{126^{*}}$.

\section{Eosinophilic Cationic Protein}

In EBC of children with asthma and healthy controls, eosinophilic cationic protein was detected in similar concentration ${ }^{127^{*}}$. 


\section{Acidity of EBC}

The degree of airway acidification or acidopnea may serve as a simple and inexpensive method to monitor respiratory inflammation. However, the measurement of the $\mathrm{pH}$ of EBC remains controversial because of methodological issues and the possible influence of salivary contamination $128-135,136^{*}-139^{*}$. Furthermore, the complex determinants of the $\mathrm{pH}$ of EBC need to be clarified. A direct comparison between the $\mathrm{pH}$ of $\mathrm{EBC}$ and in situ measurement of bronchial mucosal fluid $\mathrm{pH}$ in mechanically ventilated adults, showed significantly higher in situ $\mathrm{pH}$ measurements ${ }^{140^{*}}$. These results suggest different anatomo-pathophysiology, or may reflect that vaporization by itself may favour the lower $\mathrm{pH}$ of EBC $140^{*}$.

In asthmatic children, no significant correlation between EBC acidity, lung function, exhaled carbon monoxide and exhaled nitric oxide was found ${ }^{141^{*}}$.

In children with cystic fibrosis, the $\mathrm{pH}$ of EBC was decreased during infective exacerbations, but there was no significant difference between stable children with cystic fibrosis and healthy controls ${ }^{142^{*}}$. The reduced $\mathrm{pH}$ of EBC in children with cystic fibrosis was associated with a lower level of EBC ammonium ${ }^{143^{*}}$.

\section{Bacteria and inflammatory cells}

Reports on negative detection results are scanty, but their interpretation may guide further research developments.

No bacteria or cells were detectable in EBC of 14 cystic fibrosis patients, aged 728 years ${ }^{144^{*}}$. Cells could not be demonstrated in freshly obtained EBC of 11 atopic children, aged 6-15 years, as assessed by fluorescence activated cell sorter (own data).

\section{Pearls and pitfalls of EBC}

Assessment of inflammatory markers in EBC is a challenging new technique for the diagnosis and management of various lung diseases. The non-invasive character, the direct information on airway inflammation, the relatively easy collection procedure, and the general lack of appropriate techniques of pulmonary function testing in young children makes it particularly interesting and potentially useful.

The management of different types of chronic respiratory inflammation in childhood may improve by further developing EBC into an easy, reliable and 'daily practice' clinical tool which may provide us with characteristic profiles of different biomarkers for different stages of inflammatory lung disease. Hence, it may enlarge our understanding of the disease process and may provide the potential for more appropriate customised therapy ${ }^{10}$.

Nevertheless, the apparent simplicity of EBC must not be over-stated, as numerous methodological pitfalls are identified and several problems still have to be solved. 
Comparison and interpretation of data on this rapidly growing field of research is mainly hampered by the lack of standardization and the lack of specific high-sensitivity immunochemical or colorimetric assays (Tables 1-10). The application of proteomics, with high resolution two-dimensional gel electrophoresis and micro-analysis of protein spots, may allow the recognition of particular protein patterns in different disease and may result in the recognition of new diagnostic proteins or therapeutic targets $4,145 *$. Similarly, the use of fluorescence detection and mass spectrometry-related techniques, and of high-performance liquid chromatography, may offer advantages not only in terms of sensitivity, but also in terms of discriminative power and quantitative reliability ${ }^{63}$. The initiative of the European Respiratory Society to institute a task force on this topic is a first step towards a uniform technique of EBC.

Future efforts should be directed towards: (i) optimizing the EBC condenser system and the $E B C$ storage procedures; (ii) standardization of the measurement procedures of inflammatory markers in EBC; (iii) improving the sensitivity of the assays of inflammatory markers in EBC; (iv) validation or correlation of markers against more direct measurements of airway inflammation (biopsies) in groups with various inflammatory disorders and in healthy subjects; (v) reproducibility, normal variation (intra- and inter-day) and reference ranges (age dependent) of the inflammatory marker; (vi) evaluation of the sensitivity and specificity of the various markers or profiles of markers in differentiating inflammatory airway disorders; (vii) predictive value of the various exhaled inflammatory markers for early diagnosis and exacerbations of disease; and (viii) assessing the usefulness of EBC for the guiding of anti-inflammatory treatment, resulting in better outcome of disease.

In this way, it will become clear whether EBC is the challenging new technique, able to improve diagnosis and management of various chronic respiratory disorders in childhood. 


\section{References, abstracts are marked with an asterisk (*)}

1. Chung KF. Chronic inflammation in asthma. Eur Respir Rev 1998: 8: 999-1006.

2. Helms PJ. Issues in pediatric asthma. Pediatr Pulmonol 2001: S21: 49-56.

3. Hunt J. Exhaled breath condensate: an evolving tool for noninvasive evaluation of lung disease. J Allergy Clin Immunol 2002: 110: 28-34.

4. Kharitonov SA, Barnes PJ. Biomarkers of some pulmonary diseases in exhaled breath. Biomarkers 2002: 7: 1-32.

5. Montuschi P. Indirect monitoring of lung inflammation. Nat Rev Drug Discov 2002: 1: $238-242$.

6. Scheideler L, Manke HG, Schwulera U, Inacker O, Hämmerle H. Detection of nonvolatile macromolecules in breath. A possible diagnostic tool? Am Rev Respir Dis 1993: 148: 778-784.

7. Sterk PJ. Non-invasive monitoring of bronchial inflammation in asthma. Schweiz Med Wochenschr 1997: 127: 1686-1692.

8. Mutlu GM, Garey KW, Robbins RA, Danziger LH, Rubinstein I. Collection and analysis of exhaled breath condensate in humans. Am J Respir Crit Care Med 2001: 164: 731-737.

9. Kharitonov SA, Barnes PJ. Exhaled markers of pulmonary disease. Am J Respir Crit Care Med 2001: 163: 1693-1722.

10. Wilson N. Measurement of airway inflammation in asthma. Curr Opin Pulm Med 2002: 8: 25-32.

11. Kharitonov SA, Barnes PJ. Exhaled markers of inflammation. Curr Opin Allergy Clin Immunol 2001: 1: 217-224.

12. Montuschi P, Barnes PJ. Analysis of exhaled breath condensate for monitoring airway inflammation. Trends Pharmacol Sci 2002: 23: 232-237.

13. Antczak A, Gorski P. Markers of pulmonary diseases in exhaled breath condensate. Int J Occup Med Environ Health 2002: 15: 317-323.

14. Effros RM, Hoagland KW, Bosbous M, et al. Dilution of respiratory solutes in exhaled condensates. Am J Respir Crit Care Med 2002: 165: 663-669.

15. Griese M, Noss J, von Bredow C. Protein pattern of exhaled breath condensate and saliva. Proteomics 2002: 2: 690-696.

16. Von Pohle WR, Anholm JD, McMillan J. Carbon dioxide and oxygen partial pressure in expiratory water condensate are equivalent to mixed expired carbon dioxide and oxygen. Chest 1992: 101: 1601-1604.

17*. Dwyer TM. Expired breath condensate and the ultimate disposition of airway surface liquid. Am J Respir Crit Care Med 2001: 163: A406.

18*. Effros RM, Wahlen K, Bosbous M, et al. Dilution of respiratory fluids by exhaled water vapor. Am J Respir Crit Care Med 2002: 165: A342.

19. McFadden ER Jr. Respiratory heat and water exchange: physiological and clinical implications. J Appl Physiol 1983: 54: 331-336.

20*. Gessner C, Kuhn H, Engelmann L, Schauer J, Wirtz H. Increased pressure amplitude in mechanical ventilation leads to an increase in breath condensate volume to ventilation ratio. Eur Respir J 2001: 18: 481s.

21. Fairchild $\mathrm{Cl}$, Stampfer JF. Particle concentration in exhaled breath. Am Ind Hyg Assoc J 1987: 48: 948-949. 
22. Papineni RS, Rosenthal FS. The size of droplets in the exhaled breath of healthy human subjects. J Aerosol Med 1997: 10: 105-116.

23*. Khorovskaya LA, Sazonetz OI, Emanuel VL. Noninvasive laboratory investigation of lung secretion in bronchial asthma. Eur Respir J 2002: 20: 90s.

24*. Rickmann J, Dauletbaev N, Bratzke H, et al. Breath condensate reflects different compartments of respiratory tract depending on ventilation pattern. Am J Respir Crit Care Med 2001: 163: A407.

$25 *$. Rothe M, Becher $\mathrm{G}$. Influence of substances from mouth cavity on composition of exhaled breath condensate. Am J Respir Crit Care Med 2002: 165: A342.

26*. Machado RF, Janocha AJ, Laskowski D, et al. Analysis of the exhaled breath condensate protein profile. Am J Respir Crit Care Med 2003: 167: A446.

27. Kietzmann D, Kahl R, Müller M, Burchardi H, Kettler D. Hydrogen peroxide in expired breath condensate of patients with acute respiratory failure and with ARDS. Intensive Care Med 1993: 19: 78-81.

28. Dohlman AW, Black HR, Royall JA. Expired breath hydrogen peroxide is a marker of acute airway inflammation in pediatric patients with asthma. Am Rev Respir Dis 1993: 148: 955-960.

29. Horvath I, Donnely LE, Kiss A, et al. Combined use of exhaled hydrogen peroxide and nitric oxide in monitoring asthma. Am J Respir Crit Care Med 1998: 158: 1042-1046.

30. Ho LP, Innes JA, Greening AP. Nitrite levels in breath condensate of patients with cystic fibrosis is elevated in contrast to exhaled nitric oxide. Thorax 1998: 53: 680-684.

31. Becher G, Winsel K, Beck E Neubauer G, Stresemann E. Breathing condensate as noninvasive measure for mediators from the lower airways. Pneumologie 1997: 51: 456-459.

32*. Rosias PPR, Meilicke R, Pfannenstiel C, Dompeling E, Hendriks JJE, Jöbsis Q. Total IgE in exhaled air condensate of allergic asthmatic children. Eur Respir J 2001: 18: 40s.

33*. Horak FJr, Stöffler H, Höller B, et al. Measurement of nitrite in the breathing condensate of healthy infants and infants with cystic fibrosis. Am J Respir Crit Care Med 2002: 165: A485.

34. Griese $\mathrm{M}$, Latzin P, Beck J. A noninvasive method to collect nasally exhaled air condensate in humans of all ages. Eur J Clin Invest 2001: 31: 915-920.

35. Jöbsis Q, Raatgreep HC, Schellekens SL, Hop WCJ, Hermans PWM, de Jongste JC. Hydrogen peroxide in exhaled air of healthy children: reference values. Eur Respir $J$ 1998: 12: 483-485.

36. Baraldi E, Ghiro L, Piovan V, Carraro S, Zacchello F, Zanconato S. Safety and success of exhaled breath condensate collection in asthma. Arch Dis Child 2003: 88: 358-360.

37. Montuschi P, Corradi M, Ciabattoni G, Nightingale J, Kharitonov SA, Barnes PJ. Increased 8-isoprostane, a marker of oxidative stress, in exhaled condensate of asthma patients. Am J Respir Crit Care Med 1999: 160: 216-220.

38. Reinhold P, Langenberg A, Becher G, Rothe M. Breath condensate: a medium obtained by a noninvasive method for the detection of inflammation mediators of the lung. Berl Munch Tierarztl Wochenschr 1999: 112: 254-259.

39. Sznajder JI, Fraiman A, Hall JB, et al. Increased hydrogen peroxide in the expired breath of patients with acute hypoxemic respiratory failure. Chest 1989: 96: 606612 . 
40. Gessner C, Kuhn H, Seyfarth $\mathrm{HJ}$, et al. Factors influencing breath condensate volume. Pneumologie 2001: 55: 414-419.

41*. Gajdocsi R, Brindicci C, Cosio B, Paredi P, Barnes PJ, Kharitonov SA. Influence of breathing pattern on exhaled breath condensate collection. Eur Respir J 2002: 20: 174s.

42*. Moeller A, Franklin PJ, Hall GL, Stick SM. Limitations of breath condensates in infants. Am J Respir Crit Care Med 2003: 167: A978.

43. Weitzberg E, Lundberg JON. Humming greatly increases nasal nitric oxide. Am J Respir Crit Care Med 2002: 166: 144-145.

44*. Vass G, Huszar E, Barat E, Horvath I, Kollai M. Measurement of prostaglandin E2 and thromboxane B2 in exhaled breath condensate in healthy volunteers. Eur Respir $\mathrm{J}$ 2002: 20: 510 s.

45. Vass G, Huszar E, Barat E, et al. Comparison of nasal and oral inhalation during exhaled breath condensate collection. Am J Respir Crit Care Med 2003: 167: 850-855.

46*. Becher G, Rothe M. Standardisation of breath condensate sampling for airway diagnostic. Eur Respir J 2001: 18: 68s.

47*. Leadbetter K, Ho LP, Cunningham S. Breath condensate collection in children is well tolerated and not contaminated by saliva when collected using the Jaeger Ecoscreen. Eur Respir J 2002: 20: 527s.

48*. Vaughan JW, Hunt J. Exhaled breath condensate sampling: colder is not necesarily better. Eur Respir J 2002: 20: 175s.

49*. Schulz C, Dressler D, Engelhart K, Bernhard J. Influence of environmental components on exhaled oxygen species. Am J Respir Crit Care Med 2002: 165: A342.

50. Corradi M, Alinovi R, Goldoni M, et al. Biomarkers of oxidative stress after controlled human exposure to ozone. Toxicol Lett 2002: 134: 219-225.

51*. Shahid SK, Kharitonov SA, Csoma Zs, Bush A, Wilson N, Barnes PJ. Reproducibility of cysteinyl-leukotriene measurement in exhaled breath condensate in children. Eur Respir J 2001: 18: 39s.

52*. Lehmann C, Becher G, Rothe M. Biosensor measurement of hydrogen peroxide in exhaled breath condensate in healthy subjects. Eur Respir J 2002: 20: 175s.

53*. Kozyrev A, Dotsenko E, Goncharova V, Zhdanov V. Serotonin excretion by lung in asthmatic patients. Eur Respir J 2002: 20: 112s.

54. Van Beurden WJC, Dekhuijzen PNR, Harff GA, Smeenk FWJM. Variability of exhaled hydrogen peroxide in stable COPD patients and matched healthy controls. Respiration 2002: 69: 211-216.

55*. Carey KW, Neuhauser MM, Mody A, Kumar B, Danziger LH, Rubinstein I. Circadian variation in inflammatory mediators, $\mathrm{pH}$, and collection volume in exhaled breath condensate of healthy volunteers. Am J Respir Crit Care Med 2001: 163: A64.

56*. Hunt J, Vaughan J. Utility of rapid (two-minute) exhaled breath condensate collection for ammonia and pH measurements. Am J Respir Crit Care Med 2002: 165: A532.

57. Hyde RW. I don't know what you guys are measuring but you sure are measuring it. A fair criticism of measurements of exhaled condensates. Am J Respir Crit Care Med 2002: 165: 561-562.

58*. Effros RM, Biller J, Sun F, Foss B. Elevated glucose concentrations in respiratory droplets of cystic fibrosis patients. Eur Respir J 2002: 20: 527s-528s. 
59*. Bondesson E, Wollmer P, Jansson LT. Exhaled breath condensate: large variation in the recovery of an inhaled radioactive tracer. Am J Respir Crit Care Med 2003: 167: A424.

60*. Effros RM, Bosbous M, Foss BE, Dunning M, Biller J. Exhalation filtration: a new method for collecting respiratory solutes. Am J Respir Crit Care Med 2003: 167: A977.

61. van Beurden WJ, Harff GA, Dekhuijzen PN, van den Bosch MJ, Creemers JP, Smeenk FW. An efficient and reproducible method for measuring hydrogen peroxide in exhaled breath condensate. Respir Med 2002: 96: 197-203.

62. Larstad M, Ljungkvist G, Olin AC, Toren K. Determination of malondialdehyde in breath condensate by high-performance liquid chromatography with fluorescence detection. J Chromtogr B Analyt Technol Biomed Life Sci 2002: 766: 107-114.

63. Corradi M, Folesani G, Andreoli R, et al. Aldehydes and glutathione in exhaled breath condensate of children with asthma exacerbation. Am J Respir Crit Care Med 2003: 167: 395-399.

64*. Dziedzic B, Mazanowska-Gajdowicz J, Walczewska A, Nowak D. Application of Griess method for NO2/NO3 measurement in expired breath condensate. Eur Respir J 2002: 20: 92s.

65*. Larstad M, Soderling AS, Olin AC, Caidahl K, Toren K. Mass-selective determination of free 3-nitrotyrosine in breath condensate. Eur Respir J 2002: 20: 484s.

66. Sidorenko Gl, Zborovskii El, Levina DI. Surface-active properties of the exhaled air condensate (a new method of studying lung function). Ter Arkh 1980: 52: 65-68.

67*. Tate S, Baker A, Colie DDS. Exhaled breath condensate as a surrogate marker of LPSinduced inflammatory lung disease: correlation with bronchoalveolar lavage. First ERS Lung Science Conference, Taormina, Italy, March, 2003. PP12, p.59.

68. Cunningham S, McColm JR, Pei Ho L, Greening AP, Marshall TG. Measurement of inflammatory markers in the breath condensate of children with cystic fibrosis. Eur Respir J 2000: 15: 955-957.

69. Jöbsis Q, Raatgreep HC, Hermans PWM, de Jongste JC. Hydrogen peroxide in exhaled air is increased in stable asthmatic children. Eur Respir J 1997: 10: 519-521.

70. Jöbsis Q, Raatgreep HC, Schellekens SL, Kroesbergen A, Hop WCJ, de Jongste JC. Hydrogen peroxide and nitric oxide in exhaled air of children with cystic fibrosis during anitbiotic treatment. Eur Respir J 2000: 16: 95-100.

71. Formanek W, Inci D, Lauener RP, Wildhaber JH, Frey U, Hall GL. Elevated nitrite in breath condensates of children with respiratory disease. Eur Respir J 2002: 19: 487491.

72. Shahid SK, Kharitonov SA, Wilson NM, Bush A, Barnes PJ. Increased interleukin-4 and decreased interferon-gamma in exhaled breath condensate of children with asthma. Am J Respir Crit Care Med 2002: 165: 1290-1293.

73. Latzin P, Griese M. Exhaled hydrogen peroxide, nitrite and nitric oxide in healthy children: decrease of hydrogen peroxide by atmospheric nitric oxide. Eur J Med Res 2002: 30: 353-358.

74. Csoma Zs, Kharitonov SA, Balint B, Bush A, Wilson NM, Barnes PJ. Increased leukotrienes in exhaled breath condensate in childhood asthma. Am J Respir Crit Care Med 2002: 166: 1345-1349. 
75. Baraldi E, Carraro S, Alinovi R, et al. Cysteinyl leukotrienes and 8-isoprostane in exhaled breath condensate of children with asthma exacerbations. Thorax 2003: 58: 505-509.

76. Barnes PJ, Chung KF, Page CP. Inflammatory mediators of asthma: an update. Pharmacol Rev 1998: 50: 515-596.

77. Rahman I, MacNee W. Oxidative stress and regulation of glutathione in lung inflammation. Eur Respir J 2000: 16: 534-554.

78. Dworski R. Oxidant stress in asthma. Thorax 2000: 55: S51-S53.

79. Schleiss MB, Holz O, Behnke M, Richter K, Magnussen H, Jörres RA. The concentration of hydrogen peroxide in exhaled air depends on expiratory flow rate. Eur Respir $J$ 2000: 16: 1115-1118.

80. Jobsis R, Schellekens SL, Fakkel-Kroesbergen A, Raatgreep RHC, de Jongste JC. Hydrogen peroxide in breath condensate during a common cold. Mediators Inflamm 2001: 10: 351-354.

81. Nowak D, Kalucka S, Bialasiewicz P, Krol M. Exhalation of hydrogen peroxide and TBARs by healthy subjects. Free Radic Biol Med 2001: 30: 178-186.

82. Horvath I, MacNee W, Kelly FJ, et al. Haemoxygenase-1 induction and exhaled markers of oxidative stress in lung diseases, summary of the ERS Research Seminar in Budapest, Hungary, September, 1999. Eur Respir J 2001: 18: 420-430.

83. Zappacosta B, Persichilli S, Mormile F, et al. A fast chemiluminescent method for hydrogen peroxide measurement in exhaled breath condensate. Clin Chim Acta 2001: 310: 187-191.

84*. Lehmann C, Rothe M, Becher G. A new method for rapid measurement of hydrogen peroxide in exhaled breath condensate. Am J Respir Crit Care Med 2002: 165: A53.

85*. Becher G, Schmid G, Lehmann C, Dietze S, Rothe M. Possible use of exhaled breath condensate for continuous monitoring of lung inflammation in artificial ventilation. Eur Respir J 2002: 20: 85s.

86*. Gajdocsi R, Brindicci C, Essilfie-Quaye S, Barnes PJ, Kharitonov SA. On-line H2O2 assessment is a useful tool in standardizing exhaled breath condensate collection according to ventilation parameters. Am J Respir Crit Care Med 2003: 167: A221.

87*. Doniec Z, Gawel J, Tomalak W, Kurzawa R. Evaluation of hydrogen peroxide in breath condensate in children with bronchial asthma. Eur Respir J 2002: 20: $143 \mathrm{~s}$.

88*. Grabska I, Sarniak A, Krol M, Nowak D, Langer K, Krajewski W. Hydrogen peroxide in expired breath condensate does not relate to severity in mechanically ventilated children. Eur Respir J 2002: 20: 532s.

89. Cracowski JL, Durand T, Bessard G. Isoprostanes as a biomarker of lipid peroxidation in humans: physiology, pharmacology and clinical implications. Trends Pharmacol Sci 2002: 23: 360-366.

90. Bonnans C, Vachier I, Chavis C, Godard P, Bousquet J, Chanez P. Lipoxins are potential endogenous anti-inflammatory mediators in asthma. Am J Respir Crit Care Med 2002: 165: 1531-1535.

91. Carpenter CT, Price PV, Christman BW. Exhaled breath condensate isoprostanes are elevated in patients with acute lung injury or ARDS. Chest 1998: 114: 1653-1659.

92*. Montuschi P, Ragazzoni E, Valente $S$, et al. Validation of eicosanoid measurements in exhaled breath condensate. Eur Respir J 2002: 20: 422s-423s. 
93*. Montuschi P, Ragazzoni E, Valente S, Corbo G, Ciabattoni G. Validation of eicosanoid measurements in exhaled breath condensate. Am J Respir Crit Care Med 2002: 165: A805.

94*. Montuschi P, Varone F, Valente S, et al. Measurements of exhaled prostanoids: reproducibility and flow-dependence. Am J Respir Crit Care Med 2003: 167: A752.

95*. Shahid SK, Kharitonov SA, Csoma Zs, Bush A, Wilson N, Barnes PJ. Exhaled 8isoprostane as a marker of airway inflammation in asthmatic children. Eur Respir $J$ 2001: 18: 39s.

96*. Csoma Zs, Kharitonov SA, Shahid SK, et al. Leukotrienes in exhaled breath condensate of children with asthma. Eur Respir J 2001: 18: 39s.

97*. Zanconato S, Piovan V, Ghiro L, et al. Cysteinyl-leukotrienes as markers of airway inflammation in exhaled breath condensate of asthmatic children. Eur Respir J 2002: 20: $412 \mathrm{~s}$.

98*. Artlich A, Reineck P, Hoeser C, Huls G, Lindemann H. Atopic asthma: leukotriene metabolites in breath condensate and in urine. Eur Respir J 2002: 20: 412s.

99*. Montuschi P, Ghiro L, Piovan V, et al. Increased exhaled 8-isoprostane in childhood asthma. Eur Respir J 2002: 20: 141s.

100*. Mondino C, Koch PL, Pistelli R, et al. Leukotrienes in exhaled breath condensate in childhood asthma. Am J Respir Crit Care Med 2003: 167: A445.

101*. Montuschi P, Mondino C, Pistelli R, et al. Prostanoids in exhaled breath condensate in childhood asthma. Am J Respir Crit Care Med 2003: 167: A978.

102*. Bodini A, Peroni DG, Baraldi E, et al. Cysteinyl-leukotrienes in exhaled breath condensate are reduced after mite avoidance in allergic asthmatic children. Eur Respir J 2002: 20: 412s.

103*. Vogelberg C, Hirsch T, Rosen-Wolff A, Leupold W. Effect of isocapnic hyperventilation with cold air on breath condensate volume and LTB4-concentration in breath condensate. Eur Respir J 2002: 20: 411s.

104*. Mainz J, van Egmond-Froehlich A, Riede M, Zintl F. Collection of exhaled breath condensate during isocapnic hyperventilation increases LTB4 in asthma and CF patients with elevated IgE. Am J Respir Crit Care Med 2003: 167: A978.

105*. Linkosalo L, Holm K, Kaila M, Laitinen J, Lehtimaki L, Moilanen E. Exhaled bronchial $\mathrm{NO}$ and cysteinyl-leukotrienes in breath condensate in atopic children. Eur Respir $J$ 2002: 20: 412s.

106*. Rosias PPR, Pfannenstiel C, Dompeling E, Hendriks JJE, Jöbsis Q. Cysteinylleukotrienes in breath condensate of children with chronic inflammatory lung diseases. Am J Respir Crit Care Med 2002: 165: A485.

107*. Csoma Zs, Kharitonov SA, Shahid SK, et al. Eicosanoids in exhaled breath condensate of children with primary ciliary dyskinesia. Eur Respir J 2001: 18: 180s.

108. Green LC, Wagner DA, Glogowski J, Skipper PL, Wishnok JS, Tannenbaum SR. Analysis of nitrate, nitrite and [15N]nitrate in biological fluids. Anal Biochem 1982: 126: 131-138.

109. Misko TP, Shilling RJ, Salvemini D, Moore WM, Currie MG. A fluorometric assay for the measurement of nitrite in biological samples. Ann Biochem 1993: 214: 11-16.

110*. Corradi M, Saglia S, Majori M, Zanini A, Pesci A, Cuomo A. A new technique for measurement of nitrate in breath condensate. Am J Respir Crit Care Med 2000: 161: A395. 
111. Tsikas D. Simultaneous derivatization and quantification of the nitric oxide metabolites nitrite and nitrate in biological fluids by gas chromatography / mass spectrometry. Anal Chem 2000: 72: 4064-4072.

112. Vukomanovic DV, Hussain A, Zoutman DE, Marks GS, Brien JF, Nakatsu K. Analysis of nanomolar S-nitrosothiol concentrations in physiological media. J Pharmacol Toxicol Method 1998: 39: 235-240.

113. Hou Y, Wang J, Arias F, Echegoyen L, Wang PG. Electrochemical studies of Snitrosothiols. Bioorg Med Chem Lett 1998: 8: 3065-3070.

114. Wink DA, Kim S, Coffin D, et al. Detection of S-nitrosothiols by fluorometric and colorimetric methods. Methods Enzymol 1999: 301: 201-211.

115. Stamler JS, Loscalzo J. Capillary zone electrophoretic detection of biological thiols and their S-nitrosated derivates. Anal Chem 1992: 64: 779-785.

116*. Franklin PJ, Moeller A, Hall GL, Stick SM. Measuring total nitrite/nitrate in exhaled breath condensate: methodological issues. Am J Respir Crit Care Med 2003: 167: A977.

117*. MacGregor G, Tate S, Davis M, et al. Nitrotyrosine levels of exhaled breath condensate in cystic fibrosis adults and children. Am J Respir Crit Care Med 2002: 165(8): A278.

118*. Petrovski FI, Salnikov AV, Petrovskaia IA, Ogorodova LM, Serebrov VYu. Nitrite levels in breath condensate of children with bronchial asthma. Eur Respir J 2001: 18: 269s.

119*. Csoma Zs, Kharitonov SA, Balint B, Wilson N, Bush A, Barnes PJ. 3-Nitrotyrosine levels in exhaled condensate in childhood asthma. Am J Respir Crit Care Med 2001: 163: A47.

120*. Csoma Zs, Kharitonov SA, Shahid SK, et al. Nitric oxide metabolites in exhaled breath condensate of children with primary ciliary dyskinesia. Eur Respir J 2001: 18: 180s.

121. Rahman I, van Schadewijk AAM, Crowter AJL, et al. 4-Hydroxy-2-nonenal, a specific lipid peroxidation product, is elevated in lungs of patients with chronic obstructive pulmonary disease. Am J Respir Crit Care Med 2002: 166: 490-495.

122. Corradi M, Rubinstein I, Andreoli R, et al. Aldehydes in exhaled breath condensate of patients with chronic obstructive pulmonary disease. Am J Respir Crit Care Med 2003: 167: 1380-1386.

123*. Sourovenko TN, Zgeleznova LV, Nevzorova VA. Interleukin-4 and IgE level in exhaled air condensate of the atopy patients. Eur Respir J 2002: 20: 509s-510s.

$124 *$. Sourovenko TN, Zgeleznova LV. Association between house dust mite level in homes of atopic children and interleukin-4 and IgE in expired air condensate. Eur Respir J 2002: 20: $536 \mathrm{~s}$.

125*. Sourovenko TN, Kochetkova EA, Geltser BI. Interleukin-4 and NO metabolites in the exhaled air condensates of atopic children as a predictor of asthma development. Eur Respir J 2001: 18: 38s.

126*. Sourovenko TN, Ovchinnikova OV, Geltser BI. Nitric oxide metabolites and total IgE in exhaled air condensate of the patients with bronchial asthma and allergen exposure. Eur Respir J 2002: 20: 604s.

127*. Severien C, Artlich A, Graf A, Pürschl S, Jonas S, Becher G. Eosinophil cationic protein in breathing condensate of asthmatic and healthy children. Eur Respir J 1999: 14: 34s.

128. Hunt JF, Erwin E, Palmer L, et al. Expression and activity of pH-regulatory glutaminase in the human airway epithelium. Am J Respir Crit Care Med 2002: 165: 101-107. 
129. Kostikas K, Papatheodorou G, Ganas K, Psathakis K, Panagou P, Loukides S. pH in expired breath condensate of patients with inflammatory airway diseases. Am J Respir Crit Care Med 2002: 165: 1364-1370.

130. Hunt JF, Fang K, Malik R, et al. Endogenous airway acidification: implications for asthma pathophysiology. Am J Respir Crit Care Med 2000: 161: 694-699.

131. Effros RM. Endogenous airway acidification: implications for asthma pathology. Am J Respir Crit Care Med 2001: 163: 293-294.

132. Gaston B, Hunt JF. How acidopneic is my patient? A new question in the pulmonary laboratory. Am J Respir Crit Care Med 2002: 165: 1349-1350.

133. Tate S, MacGregor G, Davis M, Innes JA, Greening AP. Airways in cystic fibrosis are acidified: detection by exhaled breath condensate. Thorax 2002: 57: 926-929.

134. Effros RM, Gaston BM, Hunt JF. Do low exhaled condensate NH4+ concentrations in asthma reflect reduced pulmonary production? Am J Respir Crit Care Med 2003: 167(1): 91-92.

135. McShane D, Davies JC, Davies MG, Bush A, Geddes DM, Alton EWFW. Airway surface $\mathrm{pH}$ in subjects with cystic fibrosis. Eur Respir J 2003: 21: 37-42.

136*. Ojoo JC, Kastelik JA, Morice AH, Redington AE. Elevated exhaled nitric oxide without acidification of exhaled breath condensate in patients with mild asthma. Eur Respir J 2002: 20: 506s-507s.

137*. Vaughan J, Gaston B, Hunt J. Exhaled breath condensate pH and ammonia levels are not dependent on airway CO2 tension. Am J Respir Crit Care Med 2002: 165: A14.

138*. Vaughan JW, Ngamtrakulpanit L, Smith AF, et al. Exhaled breath condensate pH is stable over time with minimal interday and intraday variability in healthy subjects. Am J Respir Crit Care Med 2003: 167: A446.

139*. MacGregor G, Ellis S, Andrews J, et al. Exhaled breath ammonium lower in asthmatic children. Am J Respir Crit Care Med 2003: 167: A977.

140*. Lange T, Gessner C, Hammerschmidt S, Engelmann L, Schauer J, Wirtz H. Comparison of exhaled breath condensate $\mathrm{pH}$ with $\mathrm{pH}$ measured in situ in patients with ARDS/ALI. Eur Respir J 2002: 20: 84s.

141*. Van lersel M, Rosias PPR, Jöbsis Q, Pennings HJ, Hendriks JJE, Dompeling E. The relationship between control of childhood asthma, $\mathrm{NO}$ and $\mathrm{CO}$ in exhaled air, acidity of and cytokines in exhaled breath condensate. Am J Respir Crit Care Med 2002: 165: A486.

142*. Cain D, MacGregor G, Ho LP, Innes JA, Greening A, Cunningham S. Breath condensate is acidified during infective exacerbations in children with cystic fibrosis. Eur Respir J 2002: 20: 527s.

143*. MacGregor G, Cain D, Ellis S, et al. Low ammonium levels in exhaled breath condensate in cystic fibrosis adults and children. Am J Respir Crit Care Med 2003: 167: A916.

144*. Huels G, Bittner-Dersch P, Gartner U, Schuler D, Sziegoleit A, Lindemann H. Bacterial contamination and cell count in exhaled breath condensate of patients with cystic fibrosis. Eur Respir J 2000: 16: 209s.

145*. Gessner C, Dihazi H, Brettschneider S, et al. Analysis of exhaled breath condensate proteom by matrix assisted laser desorption/ioniosation - time of flight (MALDI-TOF). Am J Respir Crit Care Med 2003: 167: A742. 


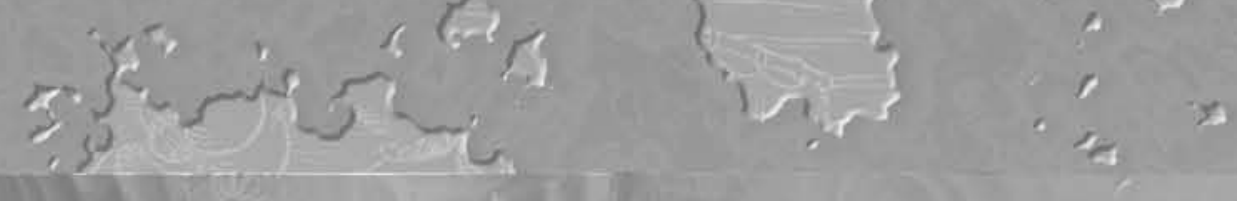

4

$x+\frac{2}{3}=$

$2 \sum^{2}$

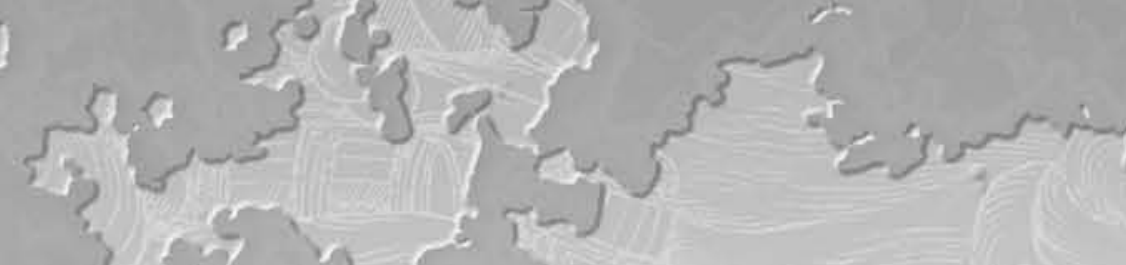

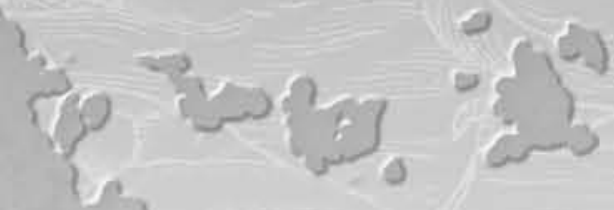

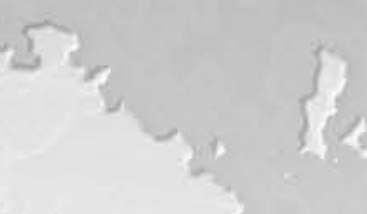

a 


\section{CHAPTER 3}

\section{CHILDHOOD ASTHMA:}

\section{EXHALED MARKERS OF AIRWAY INFLAMMATION,}

ASTHMA CONTROL SCORE AND LUNG FUNCTION TESTS.

Rosias PPR, Dompeling E, Dentener MA, Pennings HJ, Hendriks JHE, Van lersel MPA, Jöbsis Q.

Pediatric Pulmonology 2004; 38: 107-114. 


\section{Abstract}

Exhaled markers of airway inflammation become increasingly important in the management of childhood asthma. The aims of the present study are: (i) to compare exhaled markers of inflammation (nitric oxide, carbon monoxide, acidity of breath condensate), with conventional asthma measures (lung function tests, asthma control score) in childhood asthma; and (ii) to investigate the detectability of albumin, Creactive protein, interleukin-6, interleukin-8, tumor necrosis factor-alpha, soluble intercellular adhesion molecule-1 and soluble tumor necrosis factor-receptor-75 in exhaled breath condensate (EBC) of asthmatic children.

Thirty-two children with mild to moderate persistent asthma, and healthy controls aged 6-12 years were studied. We measured exhaled nitric oxide and carbon monoxide, and subsequently EBC was collected. Inflammatory mediators in EBC were measured using enzyme-linked immunosorbent assay. Respiratory symptoms and asthma control were assessed using the asthma control questionnaire of Juniper et al. Exhaled nitric oxide showed a significant correlation with exhaled carbon monoxide ( $r$ $=0.59, p<0.05)$ and forced expiratory volume in 1 second $\left(\mathrm{FEV}_{1}\right)(r=-0.59, p<0.05)$, but not with asthma control questionnaire score $(r=0.48, p=0.06)$.

Exhaled carbon monoxide was correlated with pre-bronchodilator $\mathrm{FEV}_{1}(r=-0.45$, $p<0.05)$, but not with asthma control score $(r=0.18, p=0.35)$. Acidity of EBC was significantly lower in asthmatic children than in healthy controls $(p<0.05)$, but did not correlate with any of the conventional asthma measures. We were not able to demonstrate the presence of C-reactive protein, interleukin-6, interleukin-8, tumor necrosis factor-alpha, soluble intercellular adhesion molecule- 1 and soluble tumor necrosis factor-receptor-75 in EBC. Albumin was found in two EBC samples of asthmatic children.

We conclude that exhaled nitric oxide had a better correlation with lung function parameters and asthma control than exhaled carbon monoxide and acidity of EBC, in mild to moderate persistent childhood asthma. However, exhaled nitric oxide, carbon monoxide, and deaerated acidity of EBC did not differ between asthmatic children and controls, possibly because of a too homogeneous and well-controlled study population. To further evaluate the clinical utility of exhaled markers in monitoring childhood asthma, more studies are required on a wider range of asthma severity, and, preferably, with repeated measurements of markers and of asthma control. 


\section{Introduction}

Asthma is a chronic lung disorder characterised by airway inflammation, variable but reversible airway obstruction, and episodic wheezing, coughing or dyspnoea 1,2. Noninvasive assessment of inflammatory markers in exhaled air and exhaled breath condensate (EBC) of asthmatic children becomes increasingly important ${ }^{3,4}$. Airway inflammation leads to increased expression of inducible nitric oxide synthase type 2 , and consequently, to an increase of exhaled nitric oxide. Indeed, exhaled nitric oxide of asthmatic patients is elevated, and shows a dose-dependent decrease during treatment with inhaled corticosteroids 5,6. A close correlation was found between exhaled nitric oxide and the percentage of eosinophils in bronchoalveolar lavage fluid in asthmatic children ${ }^{7}$. Furthermore, exhaled nitric oxide may be useful to assess clinical heterogeneity in children with moderate and difficult asthma ${ }^{8-10}$. Increased levels of exhaled carbon monoxide, by upregulation of the enzyme heme-oxygenase1 through oxidative stress and inflammatory cytokines, were described in asthmatic patients ${ }^{11,12}$. Recently, the acidity $(\mathrm{pH})$ of EBC was suggested as a new marker of inflammation in adult asthmatic patients: the $\mathrm{pH}$ of de-aerated $\mathrm{EBC}$ was approximately two log orders lower in patients with acute asthma, than in healthy control subjects 13. However, only a few studies compared these different exhaled markers of inflammation with such conventional asthma measures as lung function tests, reversibility of airway obstruction, respiratory symptoms, and asthma control. It is unknown which exhaled marker of airway inflammation is best related with conventional asthma measures.

Furthermore, data on inflammatory markers in EBC of asthmatic patients are increasing ${ }^{3}$. However, various other inflammatory parameters have not yet been evaluated in EBC. Many cytokines play a critical role in orchestrating, perpetuating and amplifying the inflammatory response in asthma ${ }^{14}$. Tumor necrosis factor-alpha and interleukin-6 are involved in many inflammatory diseases. Interleukin- 6 is released in asthma, has growth-regulatory effects on many cells and is involved in T-cell activation, growth and differentiation. It is a terminal differentiation factor for B cells, and an important cofactor in interleukin-4 dependent immunoglobulin-E synthesis. Interleukin6 may also have anti-inflammatory effects ${ }^{15}$. Interleukin- 8 appears to possess chemotactic activity for primed eosinophils, however it's major action is neutrophil chemoattraction and activation. Interleukin-8 may be a marker of severe asthma ${ }^{15}$. Interleukin-8 levels in bronchoalveolar lavage fluid of asthmatic children were not only strongly correlated with neutrophil counts, but also increased with more asthma symptoms ${ }^{16}$. Tumor necrosis factor-alpha may have an important amplifying effect in asthmatic inflammation. The effects of tumor necrosis factor-alpha are very similar to those of interleukin-1beta, which is an important growth factor for T-helper type 2 cells in response to antigen-primed antigen-presenting cells ${ }^{15}$. Tumor necrosis factor-alpha interacts with two cell surface receptors, tumor necrosis factor-receptor-55 and tumor necrosis factor-receptor-75. Soluble receptors may act as inhibitors of the effects of tumor necrosis factor-alpha. Tumor necrosis factor-receptor-75 is the principal receptor released by human alveolar macrophages and monocytes in the presence of interferon- 
gamma ${ }^{15}$. Adhesion molecule interactions regulate the migration of inflammatory cells from the circulation into the lungs. The intercellular adhesion molecule-1 was demonstrated to mediate leukocyte rolling on inflamed pulmonary endothelium, and was shown to mediate capillary sequestration in inflamed lungs ${ }^{17}$. Soluble intercellular adhesion molecule-1 levels were significantly increased in bronchoalveolar lavage fluid from asthmatic children compared with control children, and these soluble intercellular adhesion molecule-1 levels correlated with disease activity ${ }^{18}$.

The aims of the present study in asthmatic and healthy children were: (i) to compare exhaled markers of airway inflammation (exhaled nitric oxide, exhaled carbon monoxide, and acidity of EBC) with conventional asthma measures (lung function tests and asthma control score); and (ii) to investigate the detectability of albumin, C-reactive protein, interleukin-6, interleukin-8, tumor necrosis factor-alpha, soluble intercellular adhesion molecule-1, and soluble tumor necrosis factor-receptor75 in EBC of asthmatic children.

\section{Subjects and Methods}

\section{Subjects}

In total, 32 nonsmoking children aged 6-16 years were selected for this study (23 asthmatic children and 9 healthy controls). The asthmatic children were recruited from our outpatient clinic.

Inclusion criteria were: (i) doctor-diagnosed asthma for at least 1 year, with a history of at least two of the following: recurrent wheeze, chest tightness, shortness of breath, and/or cough; and (ii) mild or moderate persistent asthma requiring, for at least 6 months, daily treatment with inhaled corticosteroids ${ }^{19}$.

Exclusion criteria were: (i) clinical evidence of a respiratory infection in the 4 weeks prior to the study; and (ii) comorbidities such as severe mental retardation, congenital anomalies of the respiratory tract, or congenital cardiac defects. Allergy, defined as at least one positive radio-allergo-sorbent test (greater than or equal to class 2), was not an obligatory criterium for the diagnosis of asthma. The 9 healthy controls had no history of allergic rhinitis, asthma or eczema. All parents gave written informed consent. The study was approved by the Medical Ethics Committee of the University of Maastricht.

\section{Lung function tests}

Bronchodilator medication was stopped prior to lung function testing: short-acting bronchodilators at least 8 hours before the test, and long-acting bronchodilators at least 36 hours before. Dynamic spirometry was performed by means of a pneumotachograph (Masterlab Jaeger, Würzberg, Germany), with measurement of the forced expiratory volume in 1 second $\left(\mathrm{FEV}_{1}\right)$ and the forced vital capacity, according to the standards of the European Respiratory Society ${ }^{20}$. The highest values of three forced expiratory manoeuvres were used for data analysis. The bronchodilating 
response was assessed 15 minutes after administration of $400 \mu \mathrm{g}$ salbutamol (Airomir ${ }^{\circledR}$ ) through a spacer $\left(\operatorname{Volumatic}^{\circledR}\right)$. The bronchodilating response was expressed as the relative increase of $\mathrm{FEV}_{1}$ compared to the predicted value of the $\mathrm{FEV}_{1}$.

\section{Nitric oxide in exhaled air}

Exhaled nitric oxide was measured by means of the $\mathrm{NIOX}^{\circledR}$ (Aerocrine, Solna, Sweden) according to the criteria of the American Thoracic Society ${ }^{21}$. After inhalation of nitric oxide-free air to total lung capacity, the child exhaled slowly, keeping a constant flow rate at $50 \mathrm{ml} / \mathrm{sec}$, guided by a balloon meter. In this way, a nitric oxide plateau was created for at least 3 seconds. Automatic control of exhaled flow rate by a dynamic flow restrictor was carried out by the apparatus, in order to achieve a constant flow rate of $50 \mathrm{ml} / \mathrm{sec}$. The fractional exhaled nitric oxide concentration was determined by averaging the nitric oxide levels during the nitric oxide-plateau for 5-8 seconds of exhalation. The mean fractional exhaled nitric oxide concentration of three consecutive measurements was used for analysis.

\section{Carbon monoxide in exhaled air}

Exhaled carbon monoxide was measured by a modified electrochemical analyser (EC50-MICRO smokerlyzer CO monitor, Bedfont Scientific Ltd, UK), sensitive to carbon monoxide from 0-1000 parts per million by volume with a resolution of 1 part per million. Prior to the start of this study, the analyser was calibrated with a mixture of 50 part per million carbon monoxide in air. Subjects were asked to inhale maximally and hold their breath for 20 seconds before exhaling rapidly into a disposable mouthpiece ${ }^{22}$. This procedure was repeated three times, with 1 minute of normal breathing between each manoeuvre. The mean value was used for analysis 22 .

\section{Exhaled breath condensate}

EBC was collected on ice, while the children were wearing a noseclip and breathed quietly through a mouthpiece, connected to a two-way nonrebreathing valve and a cooled $\left(0^{\circ} \mathrm{C}\right)$ double-jacketed $30 \mathrm{~cm}$-long borosilicate glass tube ${ }^{23}$. In order to prevent salivary contamination of EBC samples, the two-way valve and tubing were used as a saliva gravity trap. Acidification of the condensate was measured immediately after collection, using a portable pH-meter (Radiometer, type PHM201, Lyon, France) ${ }^{13}$. A stable $\mathrm{pH}$ was achieved by deaeration of the condensate with nitrogen at a flow rate of $250-500 \mathrm{ml} / \mathrm{min}$ for 10 minutes. The remaining condensate was frozen rapidly by submerging the microtubes in isopentane at $-24^{\circ} \mathrm{C}$, and was subsequently stored at $-75^{\circ} \mathrm{C}$ to $-80^{\circ} \mathrm{C}$. Inflammatory mediators were measured in EBC using sandwich enzyme-linked immunosorbent assay, as reported previously ${ }^{24-29}$. The time interval between the collection of EBC and the measurement of mediators was not longer than 2 months.

In short, for detection of soluble tumor necrosis factor-receptor-55 and soluble tumor necrosis factor-receptor-75, monoclonal antibody MR1-1 and monoclonal antibody MR2-2 were used for coating. Specific biotin labelled polyclonal rabbit antihuman soluble tumor necrosis factor-receptor immunoglobulin-G were used as 
detector reagents ${ }^{24}$. Monoclonal antibody $5^{\mathrm{E}} 1$ was used as coating for the interleukin6 enzyme-linked immunosorbent assay, and biotinylated polyclonal rabbit anti-human interleukin-6 immunoglobulin-G was used for detection ${ }^{25}$. Interleukin-8 was coated by the interleukin-8 monoclonal antibody HM.5, and detected by biotinylated polyclonal rabbit anti-human interleukin-8 immunoglobulin-G ${ }^{26}$. Tumor necrosis factor-alpha measurement was performed by coating with anti-human tumor necrosis factor-alpha monoclonal antibody 61E71, and detection was done with rabbit antihuman tumor necrosis factor-alpha ${ }^{27}$. Enzyme-linked immunosorbent assay for soluble intercellular adhesion molecule-1 consisted of monoclonal antibody HM2 as coatings reagent, and biotinylated $\mathrm{HM} 1$ for detection ${ }^{28}$. For detection of human albumin, plates were coated with monoclonal antibody HM17. Albumin was detected with a horseradish peroxidase-labeled polyclonal rabbit anti-human albumin immunoglobulin G (Cappel; Organon Teknika Corporation, West Chester, PA) ${ }^{29}$. The $\mathrm{C}$-reactive protein concentration was measured by using a polyclonal enzyme-linked immunosorbent assay, for which antibodies and standard were obtained from Dako A/S (Glostrup, Denmark). Sensitivity of the assays was $40 \mathrm{pg} / \mathrm{ml}$ for both soluble tumor necrosis factor-receptors; $20 \mathrm{pg} / \mathrm{ml}$ for interleukin-6, interleukin-8, and tumor necrosis factor-alpha; $3 \mathrm{ng} / \mathrm{ml}$ for soluble intercellular adhesion molecule-1; $8 \mathrm{ng} / \mathrm{ml}$ for albumin; and $50 \mathrm{pg} / \mathrm{ml}$ for C-reactive protein.

Immunoassay plates (NUNC Immuno Plate Maxisorp, Roskilde Denmark) were used for enzyme-linked immunosorbent assays. Biotinylated samples were detected using streptavidin-peroxidase conjugate, obtained from Zymed Laboratories Inc. (San Fransisco, CA). The substrate used was 3,3',5,5'-tetramethylbenzidine (KPL, Gaithersburg, MD). Absorbence was measured spectro-photo-metrically at $450 \mathrm{~nm}$ using a micro-enzymelinked immunosorbent assay autoreader.

\section{Asthma control and symptoms}

Respiratory symptoms and the degree of asthma control were measured in a standardised way by the Asthma Control Questionnaire of Juniper et al 30. The validity of the Dutch translation has been checked, and appeared to be excellent.

\section{Power analysis and statistics}

A number of 22 subjects is necessary to assess clinically relevant correlations between exhaled markers of airway inflammation and conventional measures of asthma severity with a correlation coefficient of 0.60 , a power of $90 \%$, and an alpha of 0.05 . Differences between normally distributed parameters were tested with the unpaired Student's t-test, and non-normally distributed parameters with the Mann-Whitney test. Relationships between exhaled markers of airway inflammation, lung function tests and asthma control questionnaire score, were determined by Spearman correlation coefficients. $\mathrm{P}<0.05$ was considered statistically significant. 


\section{Results}

\section{Characteristics of the study population}

No difference in age, height, weight and postbronchodilator FEV 1 were found between asthmatic children and healthy controls (Table 1). As expected, asthmatic subjects had a significantly higher asthma control questionnaire score, and a lower prebronchodilator $\mathrm{FEV}_{1}$ than healthy controls (Table 1). The mean EBC collection time was 30 minutes in the asthmatic and healthy control groups. The mean volume of collected condensate was $2.6 \mathrm{ml}(\mathrm{SD}, 0.5)$ in the asthmatic children, $2.9 \mathrm{ml}(\mathrm{SD}, 0.3)$ in the control group, and $2.7 \mathrm{ml}(\mathrm{SD}, 0.5)$ in the total study population.

Table 1. Characteristics of study population

\begin{tabular}{|c|c|c|}
\hline & Healthy controls & Asthmatic children \\
\hline Number & 9 & 23 \\
\hline atopic / non-atopic & - & $16 / 7$ \\
\hline mild / moderate & - & $13 / 10$ \\
\hline ICS dose $(\mu \mathrm{g})$ & - & $400(456)$ \\
\hline Age (years) & $9.4(1.0)$ & $10.6(2.8)$ \\
\hline Weight (kg) & $33.6(10.2)$ & $35.4(12.3)$ \\
\hline Height (m) & $1.41(0.15)$ & $1.42(0.14)$ \\
\hline Pre-FEV 1 (\% pred) & $104.6(6.9)$ * & $96.4(16.2)$ \\
\hline Post-FEV 1 (\% pred) & $107.6(6.6)$ & $103.2(16.7)$ \\
\hline Reversibility (\% pred) & $3.0(3.8)$ & $6.8(8.4)$ \\
\hline ACQ score & 0 ** & $9.7(8.2)$ \\
\hline
\end{tabular}

ICS beclomethasone dipropionate or equivalent

Pre-FEV 1 prebronchodilator forced expiratory volume in 1 second, in \% predicted

Post-FEV 1 postbronchodilator forced expiratory volume in 1 second, in \% predicted

ACQ score asthma control questionnaire score

1 median and (standard deviation)

${ }^{*} p=0.053$, unpaired Student's t-test

${ }^{* *} p<0.0001$, unpaired Student's t-test

\section{Exhaled nitric oxide, exhaled carbon monoxide, and acidity of EBC}

Between asthmatic children and healthy controls, no significant differences in exhaled nitric oxide and exhaled carbon monoxide were found (Table 2). Only the not deaerated $\mathrm{pH}$ of EBC in the asthmatic group (median, 6.49) was significantly lower than in the healthy control group (median, 6.64) (unpaired Student's t-test, $\mathrm{p}<0.05$ ).

\section{Albumin, C-reactive protein, and cytokines in EBC}

In all EBC samples, C-reactive protein was less than 50 pg/ml; interleukin-6, interleukin8, and tumor necrosis factor-alpha were less than $20 \mathrm{pg} / \mathrm{ml}$; soluble intercellular adhesion molecule- 1 was less than $3 \mathrm{ng} / \mathrm{ml}$, and soluble tumor necrosis factor- 
Table 2. Noninvasive markers of airway inflammation (exhaled nitric oxide, exhaled carbon monoxide, and $\mathrm{pH}$ of exhaled breath condensate) in asthmatic children and healthy controls

\begin{tabular}{lll} 
& Healthy controls & Asthmatic children \\
\hline eNO $(\mathrm{ppb})$ & $15.6(8.1)$ & $23.1(5.0)$ \\
eCO (ppm) & $2.1(0.7)$ & $2.3(0.3)$ \\
pH-dea & $8.11(0.07)$ & $8.14(0.06)$ \\
pH-nondea & $6.64(0.05)^{*}$ & $6.49(0.05)$ \\
\hline
\end{tabular}

eNO exhaled nitric oxide, in parts per billion

eCO exhaled carbon monoxide, in parts per million

$\mathrm{pH}$-dea deaerated $\mathrm{pH}$ of exhaled breath condensate

$\mathrm{pH}$-nondea nondearated $\mathrm{pH}$ of exhaled breath condensate

1 median and (standard error of the mean)

${ }^{*} \mathrm{p}<0.05$, unpaired Student's t-test

receptor-75 was less than $40 \mathrm{pg} / \mathrm{ml}$. Albumine was detected in two samples of asthmatic children, with a concentration of 116 and $243 \mathrm{ng} / \mathrm{ml}$, respectively. The highest value was found in a child with unstable disease. Albumin was not detected in EBC samples of the healthy control group.

Relationship between exhaled nitric oxide, exhaled carbon monoxide, acidity of EBC, lung function tests, and asthma control questionnaire score

In the total study population, exhaled nitric oxide showed significant correlations with

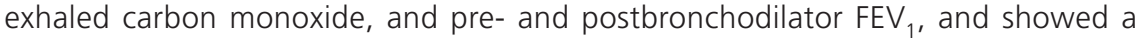
nonsignificant correlation with asthma control score (Table 3). Figure 1 shows the

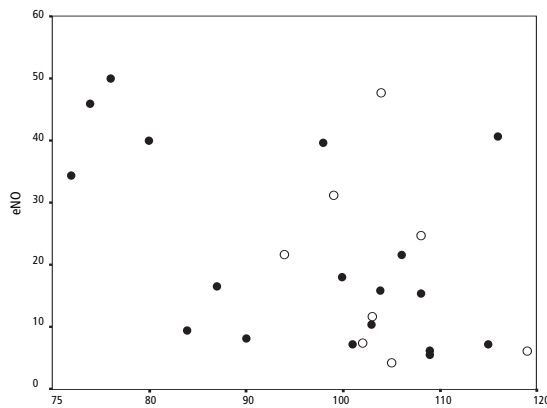

a Forced Expiratory Volume in1 second

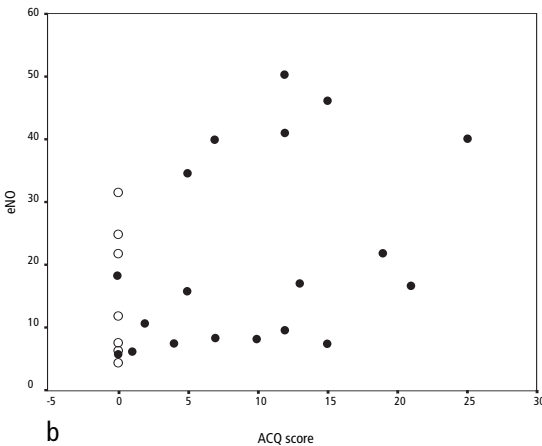

$\mathrm{b}$

ACQ score

Figure 1. Scatterplots of (a) exhaled nitric oxide and prebronchodilator $\mathrm{FEV}_{1}(r=-0.59, p<0.05)$, and (b) exhaled nitric oxide and asthma control questionnaire score $(r=0.48, p=0.06)$.

eNO exhaled nitric oxide, in parts per billion

ACQ score asthma control questionnaire score

(०) healthy control children

$(\bullet \quad$ asthmatic children 
Table 3. Spearman correlation coefficients between conventional asthma measures ( $F E V_{1}$ and asthma control questionnaire score), and noninvasive markers of airway inflammation (exhaled nitric oxide, exhaled carbon monoxide, and $\mathrm{pH}$ of exhaled breath condensate) in total study population ( $n=32$ )

\begin{tabular}{llllllll} 
& eNO & eCO & pH-nondea & pH-dea & pre-FEV & post-FEV $_{1}$ & ACQ \\
\hline eNO & - & $0.59^{*}$ & -0.23 & 0.20 & $-0.59^{*}$ & $-0.67^{* *}$ & $0.48 \dagger$ \\
eCO & $\mathbf{0 . 5 9 *}$ & - & $-0.41^{*}$ & -0.13 & $-0.45^{*}$ & -0.33 & 0.18 \\
pH-nondea & -0.23 & $-0.41^{*}$ & - & $0.68^{* *}$ & 0.10 & 0.07 & -0.25 \\
pH-dea & 0.20 & -0.13 & $0.68^{* *}$ & - & -0.25 & -0.25 & 0.08 \\
pre-FEV $_{1}$ & $-0.59^{*}$ & $-0.45^{*}$ & 0.10 & -0.25 & - & $0.86^{* *}$ & -0.26 \\
post-FEV $_{1}$ & $-0.67^{* *}$ & -0.33 & 0.07 & -0.25 & $0.86^{* *}$ & - & -0.16 \\
ACQ & $0.48^{* * *}$ & 0.18 & -0.25 & 0.08 & -0.26 & -0.16 & - \\
\hline
\end{tabular}

eNO exhaled nitric oxide

eCO exhaled carbon monoxide

$\mathrm{pH}$-nondea nondearated pH of exhaled breath condensate

$\mathrm{pH}$-dea deaerated $\mathrm{pH}$ of exhaled breath condensate

pre-FEV 1 prebronchodilator forced expiratory volume in 1 second

post-FEV 1 postbronchodilator forced expiratory volume in 1 second

ACQ score asthma control questionnaire score

${ }^{*} p<0.05$

${ }^{* *} p<0.01$

$* * * p=0.06$

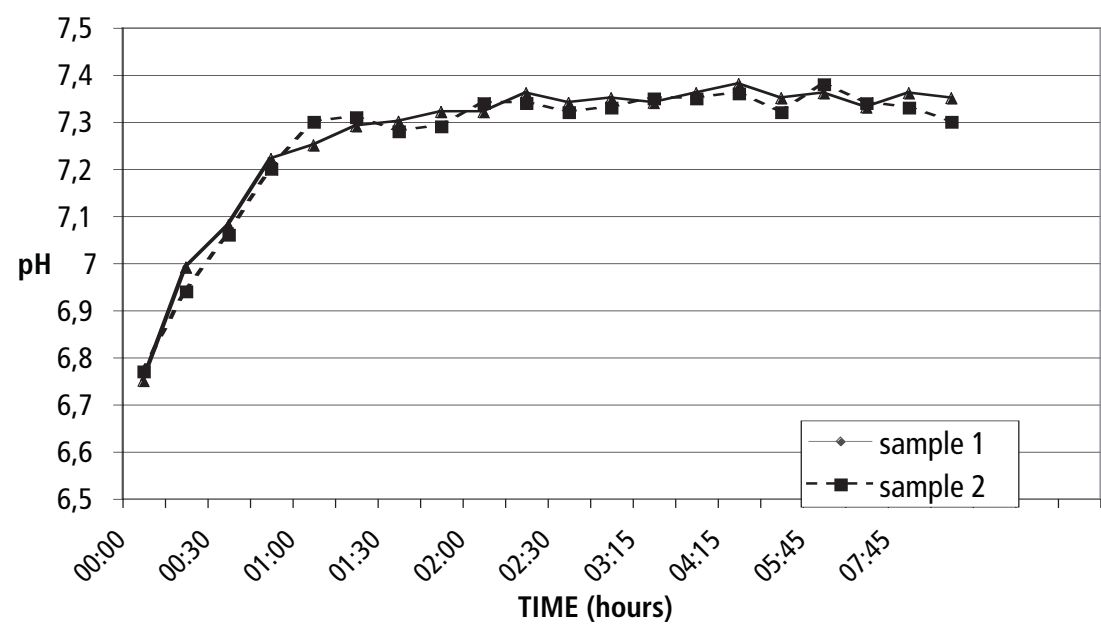

Figure 2. Nondeaerated $\mathrm{pH}$ of exhaled breath condensate with time (hours) in 2 subjects of the study population. 
correlations found between exhaled nitric oxide and prebronchodilator FEV $1(r=-0.59$, $p<0.05)$, and exhaled nitric oxide and asthma control score $(r=0.48, p=0.06)$. Exhaled carbon monoxide was significantly correlated with prebronchodilator $\mathrm{FEV}_{1}$ and nondeaerated $\mathrm{pH}$ of EBC. Although the nondeaerated $\mathrm{pH}$ of EBC was significantly lower in asthmatics than in controls, it only correlated with exhaled carbon monoxide, and not with $\mathrm{FEV}_{1}$, asthma control score, and exhaled nitric oxide. When correlations were analysed in asthmatics separately, comparable results were found. Deaeration of EBC did not influence the correlations of $\mathrm{pH}$ with the other variables. There was a substantial increase of $\mathrm{pH}$ levels of nondeaerated EBC samples over time (Figure 2). This effect in $\mathrm{pH}$ was almost 0.5 units in the first hour after EBC collection.

\section{Discussion}

Noninvasive assessment of inflammatory markers in exhaled air and EBC is a growing research field ${ }^{3,4}$. This is the first study in a paediatric population comparing exhaled inflammatory markers (exhaled nitric oxide, exhaled carbon monoxide, and acidity of EBC) with lung function tests and asthma control score. Exhaled nitric oxide showed higher correlations with conventional measures of asthma, than did exhaled carbon monoxide, and $\mathrm{pH}$ of EBC: exhaled nitric oxide did correlate with pre- and postbronchodilator $\mathrm{FEV}_{1}$, and with asthma control score. Exhaled nitric oxide levels were significantly related to exhaled carbon monoxide levels, but exhaled carbon monoxide was less related to lung function parameters and symptoms than exhaled nitric oxide. Although the $\mathrm{pH}$ of EBC was lower in asthmatics than in healthy control children, the acidity was not related to any other parameter. It was not possible to demonstrate C reactive protein, interleukin-6, interleukin-8, tumor necrosis factor-alpha, soluble intercellular adhesion molecule-1, and soluble tumor necrosis factor-receptor-75 in EBC.

Significant correlations between exhaled nitric oxide and lung function parameters were described in asthma previously, both cross-sectionally 5,31 and longitudinally 5,32. However, several other studies found no relationship between exhaled nitric oxide and lung function tests ${ }^{33,34}$. In our study, a significant correlation existed between exhaled nitric oxide and lung function tests. However, the percentage of variance in exhaled nitric oxide by changes in lung function $\left(=r^{2}\right)$ was less than $45 \%$, indicating that exhaled nitric oxide and lung function tests probably reflect different aspects of the airway pathophysiology 35,36 .

With respect to exhaled carbon monoxide and lung function parameters, we found a significant but moderate correlation between exhaled carbon monoxide and prebronchodilator $\mathrm{FEV}_{1}$. Conflicting results are reported in the adult literature ${ }^{37,38}$. In childhood asthma, however, no significant correlation was found between exhaled carbon monoxide and $\mathrm{FEV}_{1}$ 12,22,39. The different correlations of exhaled nitric oxide and carbon monoxide with conventional asthma measures may be due to the differences in standardization and methodology. Extensive recommendations on standardization of measurements are formulated for exhaled nitric oxide, but not for 
exhaled carbon monoxide 21,40 . Comparable to exhaled nitric oxide, it may be that exhaled carbon monoxide is flow-dependent, and that ambient air carbon monoxide levels may disturb exhaled carbon monoxide measurements. Ambient air carbon monoxide levels were not recorded in our study.

Our data suggest that exhaled nitric oxide has a better correlation with lung function parameters and asthma control in childhood asthma, than exhaled carbon monoxide. This view is supported by other recent findings ${ }^{39}$. Before oral prednisone therapy, both exhaled nitric oxide and carbon monoxide were elevated in 30 children with an asthma exacerbation, compared with healthy controls ${ }^{39}$. After steroid treatment, exhaled nitric oxide, but not exhaled carbon monoxide, significantly improved ${ }^{39}$.

We did not find a significant difference for exhaled nitric oxide or carbon monoxide, between asthmatic children and healthy controls. Several explanations are possible. (i) Maintenance treatment with inhaled corticosteroids is known to rapidly decrease exhaled nitric oxide levels, and may also decrease exhaled carbon monoxide 6,41,42. All asthmatic children in our study were on long term inhalation corticosteroids. Inclusion of a group of steroid-free asthmatic children, would have facilitated interpretation of the influence of inhaled corticosteroids on exhaled markers. (ii) Most children had mild to moderate persistent asthma with fairly well-controlled disease, which may lower exhaled nitric oxide and also exhaled carbon monoxide levels 22,34

Our data showed lower $\mathrm{pH}$ of EBC in asthmatic children than in healthy controls, which corresponds to the results of others in adults 13,43 . However, this potential marker of inflammation was not correlated with lung function tests and asthma control at all. We demonstrated a substantial increase of $\mathrm{pH}$ level with time for nondeaerated samples of EBC, averaging about 0.5 units in the first hour after collection. Deaeration of EBC samples did not improve correlation of $\mathrm{pH}$ of $\mathrm{EBC}$ with conventional asthma measures. The influence of deaeration on the $\mathrm{pH}$ of $\mathrm{EBC}$ needs further clarification.

Albumin was detected in two EBC samples of asthmatic children, of which one had unstable disease. Furthermore, albumin was not detected in EBC of the healthy controls. In asthmatic subjects, albumin was demonstrated in induced sputum ${ }^{44}$. Albumin may reach the epithelial lining fluid by microvascular leakage in the airway epithelium ${ }^{44}$. Therefore, the detection of albumin in EBC may be related to airway inflammation in asthma.

We were not able to demonstrate the presence of C-reactive protein, interleukin-6, interleukin-8, tumor necrosis factor-alpha, soluble intercellular adhesion molecule-1, and soluble tumor necrosis factor-receptor-75 in EBC samples of our children. Possibly the detection limit of the assays used was not low enough to measure the concentration of these substances in EBC. Alternatively, the concentrations of these inflammatory mediators in EBC may have been adequately down-regulated by the long-term 
treatment with inhaled corticosteroids used by our asthmatic children. On the other hand, these mediators may not be present in EBC of asthmatic children, because these cytokines are not derived from T-helper type 2 cells, in contrast to interleukin-4 and interleukin-5, which are more specific to allergic airway inflammation. Until now, interleukin-8 has only been demonstrated in EBC of children with cystic fibrosis, but not in asthma ${ }^{45}$. The lower detection limit of the interleukin-8 assay used by Cunningham and co-workers was $0.5 \mathrm{pg} / \mathrm{ml}$, which is more sensitive than the limit of $20 \mathrm{pg} / \mathrm{ml}$ used in our study ${ }^{45}$. So far, soluble intercellular adhesion molecule-1, soluble tumor necrosis factor-receptor-75, tumor necrosis factor-alpha, and C-reactive protein have not been found in EBC of asthmatic patients. We recommend the use of assays with the lowest possible detection limit for measurement of inflammatory markers in EBC. Methodological standardizations of EBC collection systems, procedures, preservation methods, and analysis are needed, as recently reported ${ }^{46}$.

A limitation of our study may be the relatively small number of subjects. However, the power analysis showed that 22 subjects were sufficient to assess a clinically relevant correlation of 0.60 between exhaled inflammatory markers and conventional measures of asthma severity, with a power of $90 \%$, and an alpha of 0.05 . Therefore, the number of subjects was sufficient to answer the aims of this study.

Asthmatic heterogeneity implicates a variable degree of chronic airway inflammation, airway hyperresponsiveness, reversible airway obstruction, and potential but irreversible structural remodeling of the airways ${ }^{47}$. Moreover, asthmatic airway inflammation is not necessarily correlated with airway calibre $8,34,36$, and many inflammatory and structural changes may begin early in life ${ }^{47,48}$. Hence, a discordant pattern of generally low correlations between measures of airway inflammation, clinical parameters of disease severity, and physiological variables such as spirometric measurement of airflow obstruction, as shown in our study, may not be surprising at an early stage 35,49-51. Childhood asthma management should include noninvasive integrated monitoring of all of these aspects: disease severity, disease control, airflow obstruction, airway hyperresponsiveness, airway inflammation, and airway remodeling.

In the present study, exhaled nitric oxide showed better correlations with conventional asthma measures. However, this does not imply that exhaled nitric oxide is the 'ideal' parameter of asthmatic inflammation. Pragmatically, the question remains whether exhaled nitric oxide is sensitive and specific enough to discriminate (some or all) asthmatic children from children with other chronic lung diseases, to guide adjustment of a maintenance dose of inhaled corticosteroids, to predict asthmatic exacerbations, and to improve and individualize the care for asthmatic children. Furthermore, the analysis of EBC is still hampered by the lack of methodological standardization. Numerous methodological pitfalls await further investigation, before clinical studies will help to evaluate the diagnostic and monitoring capacity in children with various chronic inflammatory lung diseases. Basically, at present it is not possible to make a judgement of whether EBC markers have value or not. 
In conclusion, exhaled nitric oxide had a better correlation with lung function parameters and asthma control than did exhaled carbon monoxide and $\mathrm{pH}$ of $\mathrm{EBC}$ in mild to moderate persistent childhood asthma. However, exhaled nitric oxide, exhaled carbon monoxide, and deaerated $\mathrm{pH}$ of EBC did not differ between asthmatic children and healthy controls. Albumin was detected in two condensate samples of asthmatic children, but C-reactive protein, interleukin-6, interleukin-8, tumor necrosis factoralpha, soluble intercellular adhesion molecule-1, and soluble tumor necrosis factorreceptor-75 were not found in EBC of asthmatic and healthy children. Methodological standardisation of EBC is mandatory. To further evaluate the clinical utility of exhaled markers in monitoring childhood asthma, more studies are required on a wider range of asthma severity, and preferably, with repeated measurements of markers and of asthma control.

\section{Acknowledgements}

We thank the children and parents of the outpatient clinic of the Department of Paediatrics of our hospital, who participated in this study. We would like to thank Mr. H. Schouten for his statistical advice. 
Chapter 3 


\section{References}

1. National Asthma Education and Prevention Program Expert Panel Report. Guidelines for the diagnosis and management of asthma, update on selected topics-2002. J Allergy Clin Immunol 2002; 110(5).

2. Standards for diagnosis and care of patients with chronic obstructive pulmonary disease (COPD) and asthma. Am Rev Respir Dis 1987; 136: 225-244.

3. Kharitonov SA, Barnes PJ. Exhaled markers of pulmonary disease. Am J Respir Crit Care Med 2001; 163: 1693-1722.

4. Gibson PG, Henry RL, Thomas P. Noninvasive assessment of airway inflammation in children: induced sputum, exhaled nitric oxide and breath condensate. Eur Respir J 2000; 16: 1008-1015.

5. Kharitonov SA, Barnes PJ. Clinical aspects of exhaled nitric oxide. Eur Respir J 2000; 16: 781-792.

6. Kharitonov SA, Donnelly LE, Montuschi P, Corradi M, Collins JV, Barnes PJ. Dosedependent onset and cessation of action of inhaled budesonide on exhaled nitric oxide and symptoms in mild asthma. Thorax 2002; 57: 889-896.

7. Warke TJ, Fitch PS, Brown V, Taylor R, Lyons JDM, Ennis M, Shields MD. Exhaled nitric oxide correlates with airway eosinophils in childhood asthma. Thorax 2002; 57: 383387.

8. La Grutta S, Gagliardo R, Mirabella F, Pajno GB, Bonsignore G, Bousquet J, Bellia V, Vignola AM. Clinical and biological heterogeneity in children with moderate asthma. Am J Respir Crit Care Med 2003; 167: 1490-1495.

9. Payne DNR, Adcock IM, Wilson NM, Oates T, Scallan M, Bush A. Relationship between exhaled nitric oxide and mucosal eosinophilic inflammation in children with difficult asthma, after treatment with oral prednisolone. Am J Respir Crit Care Med 2001; 164: 1376-1381.

10. Payne DNR, Wilson NM, James A, Hablas H, Agrafioti C, Bush A. Evidence for different subgroups of difficult asthma in children. Thorax 2001; 56: 345-350.

11. Donnelly LE, Barnes PJ. Expression of heme oxygenase in human airway epithelial cells. Am J Respir Cell Mol Biol 2001; 24: 295-303.

12. Yilmaz O, Ozturk F, Bakirtas A, Cengizlier R, Turktas I. Exhaled carbon monoxide levels in children with bronchial asthma. Pediatric Asthma Allergy Immunol 2003; 16 : 155-162.

13. Hunt JF, Fang K, Malik R, Snyder A, Malhotra N, Platts-Mills TA, Gaston B. Endogenous airway acidification. Implications for asthma pathophysiology. Am J Respir Crit Care Med 2000; 161: 694-699.

14. Chung KF, Barnes PJ. Cytokines in asthma. Thorax 1999; 54: 825-857.

15. Barnes PJ, Chung KF, Page CP. Inflammatory mediators of asthma: an update. Pharmacol Rev 1998; 50: 515-596.

16. Marguet C, Dean TP, Basuyau JP, Warner JO. Eosinophil cationic protein and interleukin-8 levels in bronchial lavage fluid from children with asthma and infantile wheeze. Pediatr Allergy Immunol 2001; 12: 27-33.

17. Tang ML, Fiscus LC. Important roles for L-selectin and ICAM-1 in the development of allergic airway inflammation in asthma. Pulm Pharmacol Ther 2001; 14: 203-210. 
18. Marguet C, Dean TP, Warner JO. Soluble intercellular adhesion molecule-1 (sICAM1) and interferon-gamma in bronchoalveolar lavage fluid from children with airway diseases. Am J Respir Crit Care Med 2000; 162: 1016-1022.

19. Global Strategy for Asthma Management and Prevention NHLBI/WHO Workshop Report. National Institutes of Health, december 1995. National Heart Lung and Blood Institute, Publication no. 95-3659

20. Tammeling GJ, Quanjer PH, on behalf of the Report Working Party. Standardized lung function testing. Eur Respir J 1993; 6(suppl.16).

21. American Thoracic Society. Recommendations for standardized procedures for the online and offline measurements of exhaled lower respiratory nitric oxide and nasal nitric oxide in adults and children. Am J Respir Crit Care Med 1999; 160: 2104-2117.

22. Uasuf CG, Jatakanon A, James A, Kharitonov SA, Wilson NM, Barnes PJ. Exhaled carbon monoxide in childhood asthma. J Pediatr 1999; 135: 569-574.

23. Jöbsis Q, Raatgreep HC, Hemans PWM, de Jongste JC. Hydrogen peroxide in exhaled air is increased in stable asthmatic children. Eur respir J 1997; 10: 519-521.

24. Leeuwenberg JF, Jeunhomme TM, Buurman WA. Slow release of soluble TNF receptors by monocytes in vitro. J Immunol 1994; 152: 4036-4043.

25. Dentener MA, Bazil V, Von Asmuth EJ, Ceska M, Buurman WA. Involvement of CD14 in lipopolysaccharide-induced tumor necrosis factor-alpha, IL-6 and IL-8 release by human monocytes and alveolar macrophages. J Immunol 1993; 150: 2885-2891.

26. Bouma MG, Stad RK, van den Wildenberg FA, Buurman WA. Differential regulatory effects of adenosine on cytokine release by activated human monocytes. J Immunol 1994; 153: 4159-4168.

27. Engelberts I, Moller A, Schoen GJ, van der Linden CJ, Buurman WA. Evaluation of measurement of human TNF in plasma by ELISA. Lymphokine Cytokine Res 1991; 10: 69-76.

28. Bouma MG, Laan MP, Dentener MA, Buurman WA. Analysis of soluble adhesion molecules. In: Johnstone AP, Turner MW. Immunochemistry 2: A practical approach. Oxford: Oxford University Press; 1997. p181.

29. Vernooy JH, Küçükaycan M, Jacobs JA, Chavannes NH, Buurman WA, Dentener MA, Wouters EF. Local and systemic inflammation in patients with chronic obstructive pulmonary disease; soluble tumor necrosis factor receptors are increased in sputum. Am J Respir Crit Care Med 2002; 166: 1218-1224.

30. Juniper EF, O'Bryne PM, Guyatt GH, Ferrie PJ, King DR. Development and validation of a questionnaire to measure asthma control. Eur Respir J 1999; 14: 902-907.

31. Piacentini GL, Bodini A, Costella S, Suzuki Y, Zerman L, Peterson CG, Boner AL. Exhaled nitric oxide, serum ECP and airway responsiveness in mild asthmatic children. Eur Respir J 2000; 15: 839-843.

32. Spallarossa D, Battistini E, Silvestri M, Sabatini F, Biraghi MG, Rossi GA. Timedependent changes in orally exhaled nitric oxide and pulmonary functions induced by inhaled corticosteroids in childhood asthma. J Asthma 2001; 38: 545-553.

33. Narang I, Ersu R, Wilson NM, Bush A. Nitric oxide in chronic airway inflammation in children: diagnostic use and pathophysiological significance. Thorax 2002; 57: 586589. 
34. Covar RA, Szefler SJ, Martin RJ, Sundstrom DA, Silkoff PE, Murphy J, Young DA, Spahn JD. Relations between exhaled nitric oxide and measures of disease activity among children with mild-to-moderate asthma. J Pediatr 2003; 142: 469-475.

35. Henderson AC, Ingenito EP, Atileh H, Israel E, Suki B, Lutchen KR. How does airway inflammation modulate asthmatic airway constriction? An antigen challenge study. J Appl Physiol 2003; 95: 873-882.

36. Sterk PJ. Non-invasive monitoring of bronchial inflammation in asthma. Schweiz Med Wochenschr 1997; 127: 1686-1692.

37. Paredi P, Leckie MJ, Horvath I, Allegra L, Kharitonov SA, Barnes PJ. Changes in exhaled carbon monoxide and nitric oxide levels following allergen challenge in patients with asthma. Eur Respir J 1999; 13: 48-52.

38. Yamaya M, Hosoda M, Ishizuka S, Monma M, Matsui T, Suzuki T, Sekizawa K, Sasaki $\mathrm{H}$. Relation between exhaled carbon monoxide levels and clinical severity of asthma. Clin Exp Allergy 2001; 31: 417-422

39. Zanconato S, Scollo M, Zaramella C, Landi L, Zacchello F, Baraldi E. Exhaled carbon monoxide levels after a course of oral prednisone in children with asthma exacerbation. J Allergy Clin Immunol 2002; 109: 440-445.

40. Baraldi E, de Jongste JC, on behalf of the Task Force. Measurement of exhaled nitric oxide in children, 2001. Eur Respir J 2002; 20: 223-237.

41. Ece A, Gurkan F, Haspolat K, Derman O, Kirbas G. Passive smoking and expired carbon monoxide concentrations in healthy and asthmatic children. Allergol Immunopathol 2000; 28: 255-260.

42. Beck-Ripp J, Griese M, Arenz S, Köring C, Pasqualoni B, Bufler P. Changes of exhaled nitric oxide during steroid treatment of childhood asthma. Eur Respir J 2002; 19: 1015-1019.

43. Kostikas K, Papatheodorou G, Ganas K, Psathakis K, Panagou P, Loukides S. pH in expired breath condensate of patients with inflammatory airway diseases. Am J Respir Crit Care Med 2002; 165: 1364-1370.

44. Van Rensen ELJ, Hiemstra PS, Rabe KF, Sterk PJ. Assessment of microvascular leakage via sputum induction. Am J Respir Crit Care Med 2002; 165: 1275-1279.

45. Cunningham S, McColm JR, Pei Ho L, Greening AP, Marshall TG. Measurement of inflammatory markers in the breath condensate of children with cystic fibrosis. Eur Respir J 2000; 15: 955-957.

46. Rosias PR, Dompeling E, Hendriks HJE, Heijnens JWCM, Donckerwolcke RAMG, Jöbsis Q. Exhaled breath condensate in children: pearls and pitfalls. Pediatr Allergy Immunol 2004; 15: 4-19.

47. Jeffery P. Inflammation and remodeling in the adult and child with asthma. Pediatr Pulmonol 2001; S21: 3-16.

48. Barbato A, Turato G, Baraldo S, Bazzan E, Calabrese F, Tura M, Zuin R, Beghé B, Maestrelli P, Fabbri LM, Saetta M. Airway inflammation in childhood asthma. Am J Respir Crit Care Med 2003; 168: 798-803.

49. Zeiger RS, Dawson C, Weiss S. Relationships between duration of asthma and asthma severity among children in the Childhood Asthma Management Program (CAMP). J Allergy Clin Immunol 1999; 103: 376-387. 
50. Fish JE, Peters SP. Asthma severity: histopathologic correlations. Drugs Today (Barc) 1999; 35: 585-594.

51. Magnussen H. Inhalation therapy for bronchial asthma: strategies and targets. Curr Opin Pulm Med 2003; 9(Suppl.1): S3-7. 


\section{CHAPTER 4.1}

\section{Exhaled Breath Condensate:}

\section{A SPACE OdYSSEY,}

\section{WHERE NO ONE HAS GONE BEFORE ...}

Rosias P, Robroeks C, Hendriks J, Dompeling E, Jöbsis Q.

European Respiratory Journal 2004; 24: 189-190. 


\section{Exhaled breath condensate: a space odyssey, where no one has gone before ...}

\section{Letter to the Editor of the European Respiratory Journal:}

We read with great interest the editorial of Rahman ${ }^{1}$ on the reproducibility of oxidative stress biomarkers in breath condensate. As a consequence, we would like to share some of our thoughts, as ultimately, we all may want to walk on planet Mars. However, this does not mean that we are already able to lift off, as many methodological problems first need to be properly addressed.

Similarly, exhaled breath condensate (EBC) is an interesting noninvasive technique to explore inflammatory lung diseases, where no one has gone before... Many methodological issues are still waiting to be solved, as recently reviewed ${ }^{2}$. Indeed, the development of EBC is currently hampered by many conflicting reports on biomarker reproducibility. As clearly stated, one of the main obstacles consists of current analytical problems, due to limitations of sensitivity and specificity of the assays used to date ${ }^{3}$.

However, the statement that "now with the use of EcoScreen, collection of EBC is being standardised in many leading laboratories" may be misleading, as it suggests that "this would no longer be a confounding factor contributing to the variations in biomarkers in EBC" 1. We want to clearly point out that the EBC collection method still remains a possible confounding factor and an important source of biomarker variability, because standardisation involves applying more than one identical collection technique. To our knowledge, there is no scientific evidence that the EcoScreen condenser would be the most valid technique to collect EBC for the measurement of inflammatory mediators in condensate. In fact, the key issue is not the reproducibility of a certain biomarker, but the reproducibility of a certain biomarker for a certain condenser system ${ }^{2}$. We compared the influence of different inner condenser coatings on the detection of human albumin and 8-isoprostane in EBC ${ }^{4}$. Our data show a much greater efficiency of condenser systems with a borosilicate glass or silicone coating, compared with the EcoScreen, or condensers with aluminium, polyproylene and teflon coating. This implicates that the Ecoscreen may not be the most valid apparatus, at least not for some biomarkers.

Although the need for clear-cut methodological recommendations is incontestable, one has to recognise that we are not yet able to give such recommendations. Further research on the reproducibility of biomarkers with different condenser systems is urgently needed. 


\section{References}

1. Rahman I. Reproducibility of oxidative stress biomarkers in breath condensate: are they reliable? Eur Respir J 2004; 23: 183-184.

2. Rosias PPR, Dompeling E, Hendriks HJE, Heijnens JWCM, Donckerwolcke RAMG, Jöbsis Q. Exhaled breath condensate in children: pearls and pitfalls. Pediatr Allergy Immunol 2004; 15: 4-19.

3. Van Hoydonck PGA, Wuyts WA, Vanaudenaerde BM, Schouten EG, Dupont LJ, Temme EHM. Quantitative analysis of 8-isoprostane and hydrogen peroxide in exhaled breath condensate. Eur Respir J 2004; 23: 189-192.

4. Rosias PPR, Vernooy JHJ, Dentener MA, et al. The inner coating of condenser systems influences the detection of human albumin in exhaled breath condensate. Eur Respir J 2003; 22: Suppl. 45, 280s. 


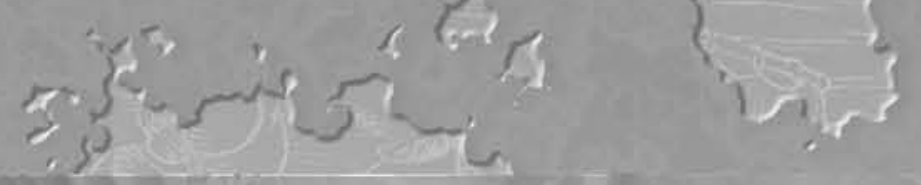

,

$$
\begin{aligned}
& \text { दर } \\
& +\quad 1 \frac{\pi}{F}
\end{aligned}
$$

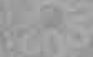

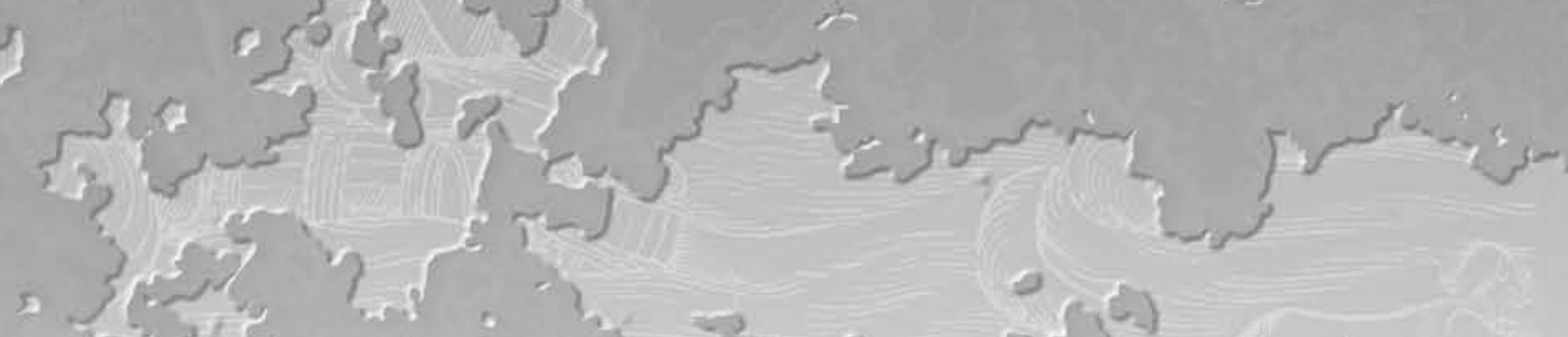
औरत :

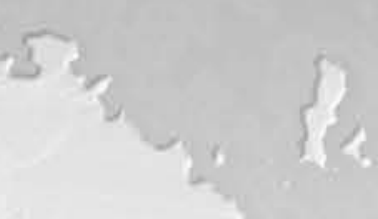

7

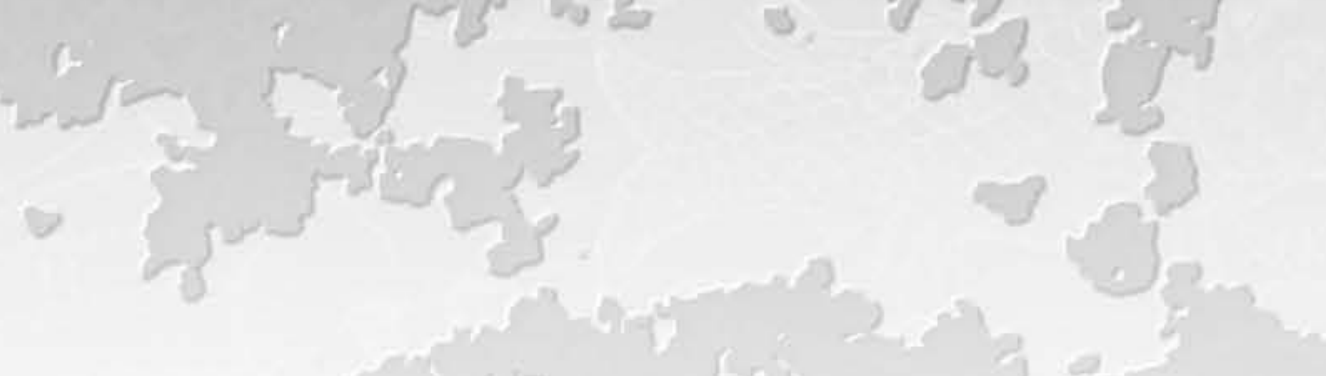
$x+3 x^{2}+x^{2}+3=1$ 


\section{CHAPTER 4.2}

\section{Breath Condenser Coatings Affect}

MEASUREMENT OF Biomarkers

in Exhaled Breath Condensate
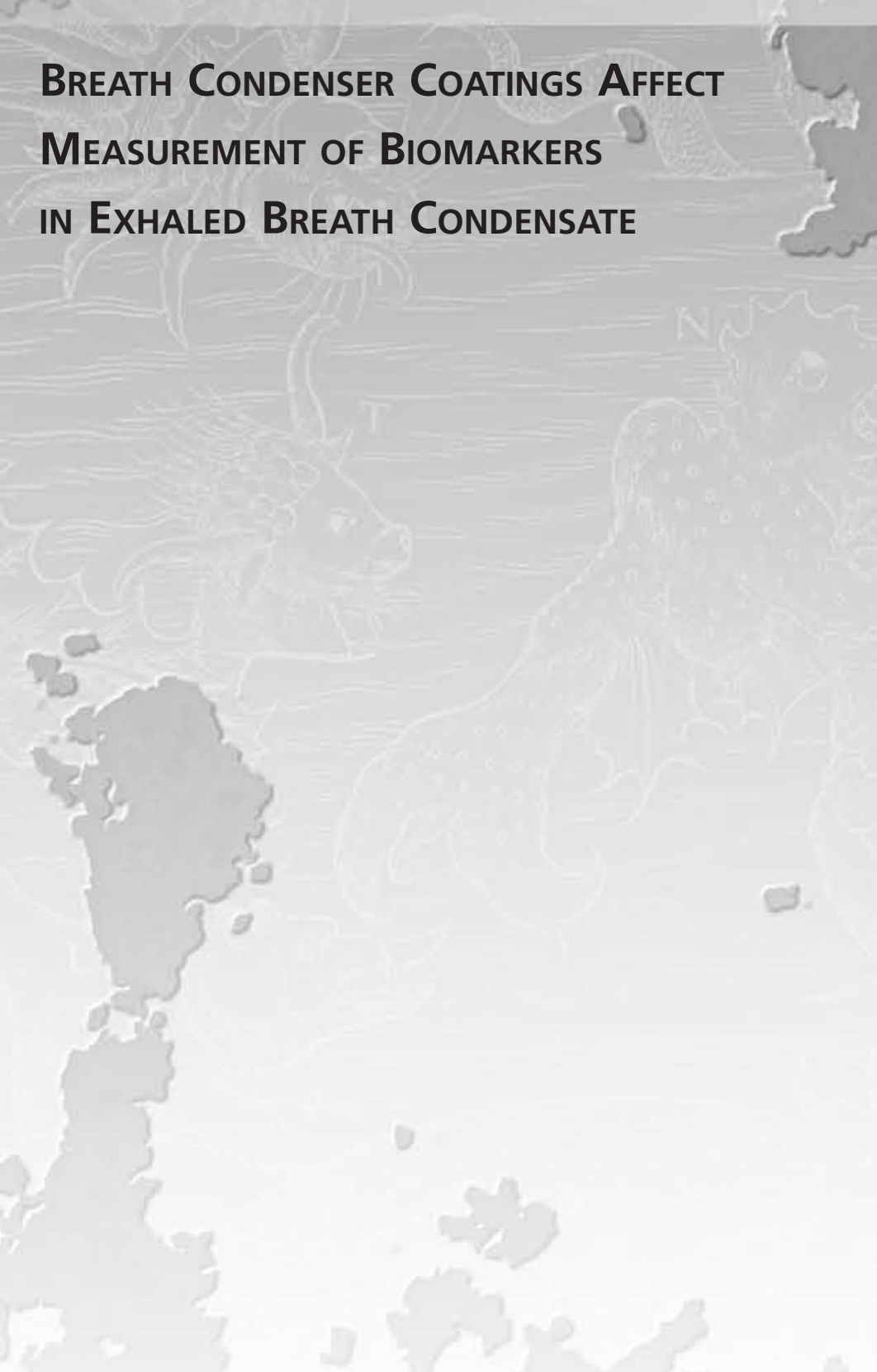

Rosias PP, Robroeks CM, Niemarkt HJ, Kester AD, Vernooy JH, Suykerbuyk J, Teunissen

J, Heynens J, Hendriks HJ, Jöbsis Q, Dompeling E.

European Respiratory Journal 2006; 28: 1036-1041. 


\section{Abstract}

Exhaled breath condensate collection is not yet standardised and biomarker measurements are often close to lower detection limits. In the current study, it was hypothesised that adhesive properties of different condenser coatings interfere with measurements of eicosanoids and proteins in breath condensate.

In vitro, condensate was derived from a collection model using two test solutions (8-isoprostane and albumin) and five condenser coatings (silicone, glass, aluminium, polypropylene, and Teflon). In vivo, condensate was collected using these five coatings and the EcoScreen ${ }^{\circledR}$ condenser to measure 8-isoprostane, and three coatings (silicone, glass, EcoScreen ${ }^{\circledR}$ ) to measure albumin.

In vitro, silicone and glass coatings had significantly higher albumin recovery compared with the other coatings. A similar trend was observed for 8-isoprostane recovery. In vivo, median (interquartile range) 8-isoprostane concentrations were significantly higher using silicone $(9.2(18.8) \mathrm{pg} / \mathrm{mL})$ or glass $(3.0(4.5) \mathrm{pg} / \mathrm{mL})$ coating, compared with aluminium $(0.5(2.4) \mathrm{pg} / \mathrm{mL})$, polypropylene $(0.5(0.5) \mathrm{pg} / \mathrm{mL})$, Teflon $(0.5(0.0) \mathrm{pg} / \mathrm{mL})$, and $\mathrm{EcoScreen}^{\circledR}(0.5(2.0) \mathrm{pg} / \mathrm{mL})$. Albumin in vivo was mainly detectable using glass coating.

In conclusion, a condenser with silicone or glass coating is more efficient for measurement of 8-isoprostane or albumin in exhaled breath condensate, than Ecoscreen ${ }^{\circledR}$, aluminium, polypropylene or Teflon. Guidelines for exhaled breath condensate standardisation should include the most valid condenser coating to measure a specific biomarker.
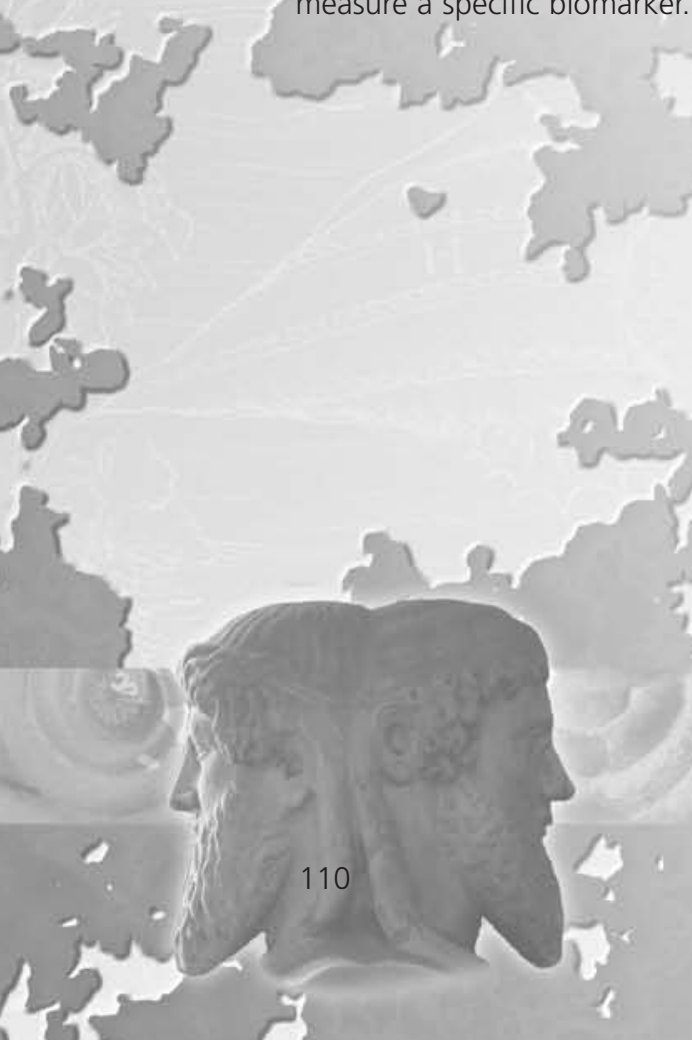


\section{Introduction}

The collection of exhaled breath condensate (EBC) has been rediscovered as a simple and noninvasive technique to measure mediators of airway inflammation. EBC consists not only of water vapor, but also contains aerosolised respiratory fluid droplets released from the respiratory epithelial lining fluid. These fluid droplets contain traces of nonvolatile solutes, which can be recovered in EBC samples ${ }^{1}$. EBC is collected by guiding and cooling exhaled air of a tidally breathing subject in a condenser system. EBC does not affect the airways; in contrast to bronchial biopsy, bronchoalveolar lavage and induced sputum. It can be obtained with minimal risk and minimal inconvenience for both adults and children ${ }^{2}$. Although the American Thoracic Society and European Respiratory Society Task Force on EBC recently published general methodological recommendations on the collection of EBC, there are still some methodological pitfalls and unresolved questions ${ }^{3-4}$. The most commonly used condensers are the Ecoscreen ${ }^{\circledR}$ (Erich Jaeger, GmbH, Hochberg, Germany), RTube ${ }^{\circledR}$ (Respiratory Research Inc., Charlottesville, VA, USA), and home-made glass or Teflon devices.

Two important groups of inflammatory biomarkers in EBC of adults and children are eicosanoids and cytokines ${ }^{3-10}$. Eicosanoids, such as 8-isoprostane, are formed by lipid peroxidation of arachidonic acid during oxidative stress ${ }^{11}$. 8-Isoprostane (molecular weight 354 Dalton) can be measured in EBC of adults and children, although reproducibility remains controversial ${ }^{12-13}$. Cytokines are low molecular weight $(<80.000$ Dalton) proteins involved in mediating inflammation and tissue repair. Reports on the detection of cytokines in EBC are incidental, with the exception of a report on interleukin- 6 by Carpagnano and co-workers ${ }^{14}$. Albumin, a protein with a similar molecular weight (66.000 Dalton), was demonstrated in induced sputum and $\mathrm{EBC}$ in asthmatic subjects ${ }^{15-16}$.

The reported mean biomarker values in EBC are usually situated in the lower range of detection ${ }^{3,6}$. It may be that the biomarker concentration in the epithelial lining fluid is intrinsically low, or that only minor amounts are released from the lining fluid into exhaled air. An alternative explanation may be that adhesive properties of different inner condenser coatings interfere with the detection of various inflammatory markers in $\mathrm{EBC}{ }^{13,17}$.

The aim of this study was to investigate the influence of different inner condenser coating surfaces (silicone, borosilicate glass, aluminium, polypropylene, Teflon, and EcoScreen ${ }^{\circledR}$ with a Teflon-like coating) on the measurement of 8-isoprostane and albumin in EBC using both an in vitro and in vivo approach. 


\section{Methods \\ In vitro studies}

In close collaboration with the department of Instrument Development Engineering \& Evaluation of the University of Maastricht (Maastricht, the Netherlands), an in vitro EBC collection model was developed consisting of a rechargeable condenser system connected in series with an ultrasonic nebuliser (Ultra-Neb ${ }^{T M} 2000$, DeVilbiss) and a ventilator (Servo-900C, Siemens) (figure 1A). The rechargeable condenser system consisted of a fixed 30-cm metal outer cylinder (diameter $4 \mathrm{~cm}$ ) (Felix Philips Maatmetaal $\mathrm{BV}$, Maastricht, the Netherlands) connected to a counter current circulating ice-water pump at $0^{\circ} \mathrm{C}$, and an exchangeable inner cylinder (diameter $2 \mathrm{~cm}$ ), as shown in figure 1B. The exchangeable inner cylinder was available in five different coatings: silicone, borosilicate glass, aluminium, polypropylene and Teflon. The borosilicate glass tubes
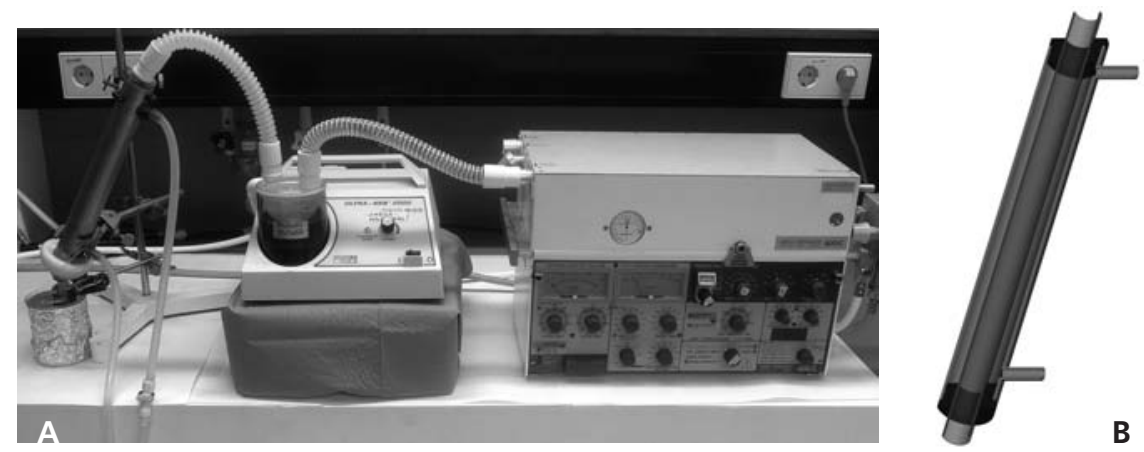

1A. In vitro exhaled breath condensate collection model consisting of a rechargeable condenser system, connected in series with an ultrasonic nebuliser and a ventilator. The nebuliser could be filled with a test solution of a known concentration of 8-isoprostane or human albumin. The nebulised test solution is propelled by the ventilator through the condenser system.
1B. Schematic representation of the rechargeable condenser tube system, which consisted of a fixed $30 \mathrm{~cm}$ metal outer cylinder (diameter $4 \mathrm{~cm}$ ), connected to a counter-current circulating ice-water pump, and an exchangeable inner cylinder (diameter $2 \mathrm{~cm}$ ). The exchangeable inner cylinder was available in five different coatings: silicone, borosilicate glass, aluminium, polypropylene, and Teflon. The outer surface of this inner cylinder was in direct contact with the counter-current circulating ice-water, while its inner surface was in direct contact with the exhaled breath or the volatile substances derived from the nebuliser and propelled by the ventilator.

Figure 1A-1B. The rechargeable exhaled breath condenser system

were manufactured by Louwers Glass and Ceramic Technologies (Hapert, the Netherlands). Identical glass tubes were coated internally with silicone by Imbreglon BV (Beuningen, the Netherlands). The aluminium tubes were manufactured by Felix Philips Maatmetaal BV. Identical aluminium tubes were coated internally with Tempcoat $1011 \mathrm{~F}$ (Teflon) by Imbreglon BV. The polypropylene tubes were produced by Applikon BV 
(Schiedam, the Netherlands). The outer surface of the inner cylinder was in direct contact with the counter current circulating ice-water, while its inner surface was in direct contact with the exhaled breath or the volatile substances derived from the nebuliser and propelled by the ventilator. The nebuliser was filled with a biomarker test solution (42 pg/mL 8-isoprostane or $0.1 \mathrm{mg} / \mathrm{mL}$ albumin in a $22 \mathrm{~mL}$ saline $0.9 \%$ solution), which was nebulised and propelled by a ventilator through the condenser system, simulating tidal breathing for 15 minutes (ventilator settings: inspiration time $33 \%$, respiratory frequency $20 /$ minute, tidal volume $200 \mathrm{~mL}$ ). The construction of the collection device only allowed contact between the propelled air/exhaled breath and one specific type of inner coating that was chosen at that moment (figure 1B). The condensate was collected at the open end of the condenser device directly into vials. For each coating, 15 experiments were performed (see the power analysis in the Statistics section). After each experiment, the coated tubes were rinsed repeatedly with bi-distilled water and subsequently dried at room air for at least 24 hours. Multiple coated tubes of each type were available to allow a smooth continuation of the experiments, without any delay due to the drying of the coated tube that was used in the preceding test. The biomarker condensate recovery percentage was defined as the ratio of biomarker concentration in condensate, to biomarker concentration in the test solution.

\section{In vivo 8-isoprostane study}

As 8-isoprostane has been detected in EBC of healthy subjects, the influence of condenser coatings on 8-isoprostane measurements in vivo was studied in 28 healthy volunteers (see the power analysis in the Statistics section). Standardised questionnaires from the International Study of Asthma and Allergies in Childhood (ISAAC) were completed to exclude the presence of respiratory infections, asthma or allergic disease 18. Each subject was asked to breathe tidally, while wearing a nose-clip, into a mouthpiece connected to a two-way non-rebreathing valve that was in turn connected by tubing to the condenser. The two-way valve and tubing also served as a saliva trap. In this way, each subject exhaled during 15 minutes along each of the five coatings in random order, as well as along the EcoScreen ${ }^{\circledR}$, a commercial condenser system with a modified Teflon coating.

\section{In vivo albumin study}

In contrast to 8-isoprostane, the in vivo albumin study was planned in asthmatic children, as the chance on positive albumin detections is larger in a disease population 16. EBC was collected in 40 asthmatic children. Inclusion criteria were doctor-diagnosed mild or moderate persistent asthma requiring daily inhaled corticosteroids for at least 6 months ${ }^{19}$. Exclusion criteria were clinical evidence of respiratory infection 4 weeks prior to study, and co-morbidity (mental retardation, respiratory tract anomalies, or cardiac defects). In contrast to the in vivo 8-isoprostane study, the asthmatic children in the albumin study were only asked to exhale tidally along one type of coating (silicone or glass or EcoScreen ${ }^{\circledR}$ ), to allow parallel group comparison. Children were randomly allocated to one out of three coating groups. 


\section{Sample processing}

Immediately after collection, the condensate samples were snap-frozen at $-78^{\circ} \mathrm{C}$ using dry ice and subsequently stored at $-80^{\circ} \mathrm{C}$ until analysis. A reaction mixture of the immunoassay was not added to the condensate samples before storage. In order to maintain optimal condensate sample preservation, for subsequent 8-isoprostane and albumin measurement, samples were analysed within 6 to 8 weeks of storage at $-80^{\circ} \mathrm{C}$. Samples were only defrosted once, at the time of analysis. All isoprostane and albumin concentrations were determined in duplicate by specific enzyme immunoassay (Cayman Chemical ${ }^{\circledR}$, Ann Arbor, MI, USA) and sandwich enzyme-linked immunosorbent assay, respectively ${ }^{16}$. The lower limit of detection was 2.45 and $32 \mathrm{pg} / \mathrm{mL}$, respectively.

\section{Statistics}

The condensate recovery percentage of a specific coating was the primary outcome measure of the in vitro experiments. Mean values and standard deviations of recovery percentages were calculated. A comparison between the five different coatings and between the two biomarkers in vitro was made by means of univariate analysis of variance (ANOVA). Power analysis demonstrated a required number of 15 experiments in each group, in order to detect a relevant difference between coatings of $25 \%$ with a power of $90 \%$, an alpha of 0.05 and a standard deviation of $20 \%$ (the standard deviation in the first set of 10 experiments was $20 \%$ ).

In the in vivo studies, the number of positive detections, median and mean values, standard deviations (based on the first 15 subjects) and interquartile ranges were calculated. Power calculation showed that 23 patients are needed to detect a $10 \%$ difference in biomarker concentration with a power of $90 \%$, an alpha of 0.05 , and a standard deviation of $14 \%$ (paired t-test). Due to a number of negative detections, the Wilcoxon paired signed-rank test was used to compare data within subjects. A sample with negative detection is not considered as a missing value, because it actually informs us that the measurement of a marker was below the detection limit. Therefore, the negative detection is given an arbitrary value of 0.5 .

\section{Ethics}

All subjects gave written informed consent. The study was approved by the Medical Ethics Committee of the University Hospital of Maastricht.

\section{Results}

\section{in vitro study of albumin and 8-isoprostane}

Albumin was detected in $93 \%$ of condensate samples (figure 2). Overall, the mean albumin recovery in condensate was only $52 \%$ using this experimental model. The albumin recovery percentages varied from $22.9 \%$ using a Teflon coating, to 69.4 and $94.7 \%$ using a glass and silicone coating, respectively. The albumin recovery percentage was significantly higher using the silicone and glass coating compared with the other coatings ( $p=0.03$, ANOVA). No other statistically significant differences were present. 


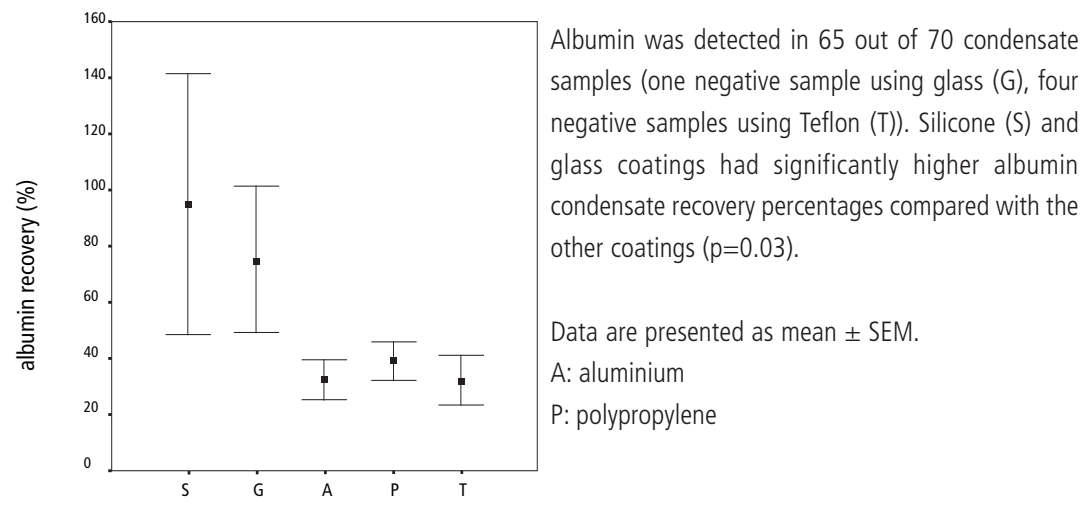

Figure 2. In vitro albumin condensate recovery percentages using five different condenser coatings.

Isoprostane was detected in 77 out of 78 condensate samples (figure 3). The isoprostane recovery percentages varied from $93.1 \%$ using an aluminium coating to 102.7 and $105.6 \%$ using a glass and silicone coating, respectively, which did not reach statistical significance (ANOVA, F-test, $\mathrm{p}=0.09$ ). Overall, the mean 8-isoprostane recovery in condensate was close to $100 \%$, which was significantly higher than the overall albumin recovery percentage of $52 \%$ (ANOVA, $p=0.0001$ ).

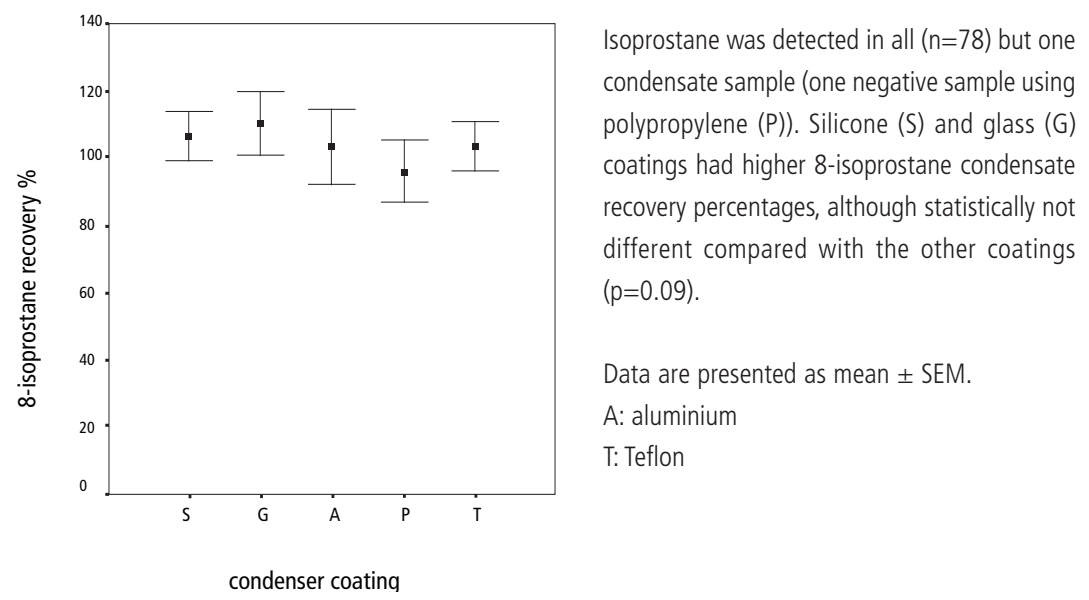

Figure 3. In vitro 8-isoprostane condensate recovery percentages using five different condenser coatings.

\section{In vivo study of 8-isoprostane}

Subject characteristics are shown in table 1. Isoprostane was detected in $41 \%$ of condensate samples (figure 4). For each coating, the number of positive / negative isoprostane detections in EBC was 23 / 5 (silicone), 15 / 13 (glass), 11 / 17 (aluminium), $7 / 21$ (polypropylene), $5 / 23$ (Teflon) and $8 / 20$ (EcoScreen ${ }^{\circledR}$ ). The median 8-isoprostane concentrations in $\mathrm{EBC}$ in 28 healthy subjects ranged from $0.5 \mathrm{pg} / \mathrm{mL}$ for aluminium 


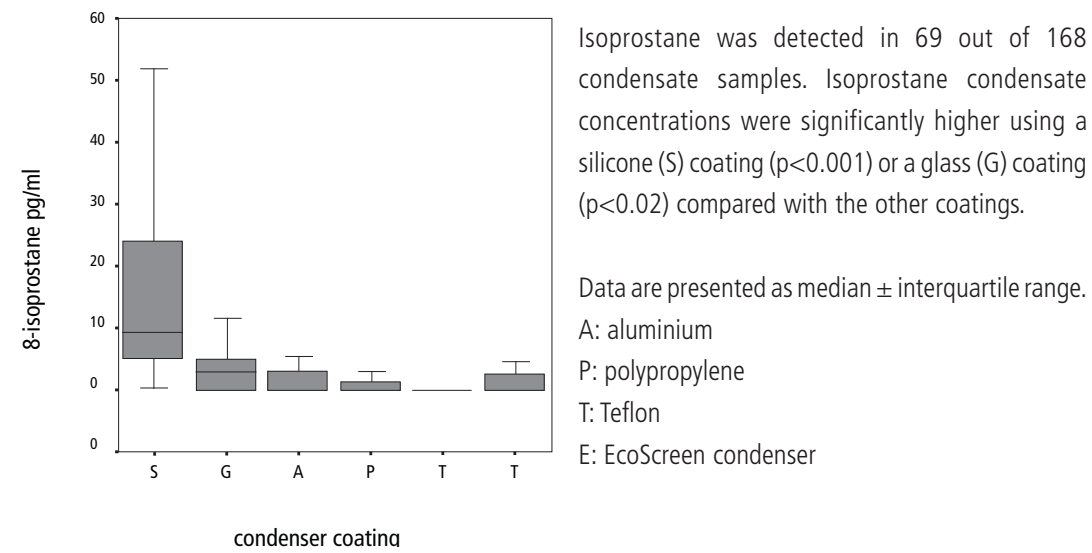

Figure 4. In vivo 8-isoprostane condensate concentrations in 28 healthy volunteers using six different condenser coatings.

(interquartile range 0.5-2.9), polypropylene (0.5-1.0), Teflon (0.5-0.5) and the EcoScreen ${ }^{\circledR}(0.5-2.5)$, to $3.0 \mathrm{pg} / \mathrm{mL}(0.5-5.0) \mathrm{pg} / \mathrm{mL}$ and 9.2 (5.1-23.9) pg/mL for the glass and silicone coating, respectively. Condensate 8-isoprostane concentrations were significantly higher using silicone coating compared with each of the other coatings $(p<0.001$, Wilcoxon signed-rank test). Similarly, glass coating was better than polypropylene, Teflon and the EcoScreen ${ }^{\circledR}$ ( $p<0.02$, Wilcoxon test). The 8-isoprostane concentrations obtained with aluminium, polypropylene, Teflon and the EcoScreen ${ }^{\circledR}$ did not differ from each other $(p=0.763$, Friedman test). As median values and interquartile ranges in smokers and nonsmokers were comparable, smoking was not a confounder in this study.

\section{In vivo study of albumin}

Subject characteristics are shown in table 1. Albumin was detected in 8 out of 40 condensate samples $(0.04-0.24 \mu \mathrm{g} / \mathrm{mL})$. Positive detections were almost exclusively found with a glass coating: 7 out of 13 samples using a glass coating, 1 out of 14 samples using the EcoScreen ${ }^{\circledR}$, and none out of 13 samples using a silicone coating

Table 1. Subject characteristics.

\begin{tabular}{lll} 
& $\begin{array}{l}\text { Healthy subjects } \\
8 \text {-isoprostane study }\end{array}$ & $\begin{array}{l}\text { Asthmatic subjects } \\
\text { albumin study }\end{array}$ \\
\hline Subjects & 28 & 40 \\
Male & 10 & 27 \\
Smoking & 5 & 0 \\
Atopic & 0 & 36 \\
Age yrs & $26(20-57)$ & $11(5-17)$ \\
\hline &
\end{tabular}


$(p<0.008$, Chi-square test). Disease stability, lung function and atopic status were not confounding factors, as these characteristics were equally distributed across the three coating groups (data not shown).

\section{Discussion}

Both in vitro and in vivo, the present study demonstrates a significant influence of the different inner condenser coatings on the measurement of eicosanoid and protein biomarkers in EBC. In particular, silicone and glass coatings were superior to aluminium, polypropylene and Teflon with respect to the recovery of both 8-isoprostane and albumin in EBC in vitro and in vivo.

A careful MEDLINE online database search for all available studies on 8-isoprostane in EBC, demonstrates data in line with the results of our study. When considering an identical assay (enzyme- or radio-immunoassay), higher 8-isoprostane concentrations were reported using a glass coating compared with the EcoScreen ${ }^{\circledR}$. In vivo using the EcoScreen ${ }^{\circledR}$, present 8-isoprostane concentrations (median (range) 3.5 (2.5-4.8) $\mathrm{pg} / \mathrm{mL}$ ) were comparable to the values reported by Van Hoydonck et al (4.6 (3.9-7.7) $\mathrm{pg} / \mathrm{mL}$ ). Specific data on detectability of isoprostane in EBC are scarce. The current study reports $41 \%$ of detectability in volunteers, which is in agreement with the findings (36\%) of Van Hoydonck et al in smokers 20.

In vitro, the overall mean albumin condensate recovery percentage was 52\%, compared with $100 \%$ isoprostane recovery. This suggests a more difficult condensate recovery of protein biomarkers, which is supported by the present limited number of positive albumin detections in vivo. Also, the relatively few positive studies on cytokines or proteins in $E B C$ versus several positive reports on 8-isoprostane and leukotrienes in $E B C$ may suggest that the recovery of proteins in $E B C$ is less easily than of eicosanoids. Recently, Tufvesson and Bjermer also showed that the detection of eicosanoids and cytokines in EBC in asthmatic subjects may be facilitated by coating of all collection surfaces with Tween 20 and bovine serum albumin, respectively, combined with vacuum-centrifugation of condensate samples ${ }^{21}$. Moreover, 30 -fold differences in condensate levels of interleukin-4 in asthmatic children were found using different condenser systems and enzyme immunoassays ${ }^{22-24}$. The latter finding indicates that variability of biomarker levels in condensate may also be attributed to intrinsic analytical problems of currently used immunoassays, as illustrated recently for thromboxane-A2 metabolite measurements in EBC ${ }^{24}$.

In vitro, the mean 8-isoprostane condensate recovery percentages did not differ significantly between the condenser coatings $(p=0.09)$. An explanation may be the higher overall mean condensate recovery of isoprostane, in contrast to albumin, which may illustrate a different behavior of these biomarkers during the expiratory phase of the EBC collection. In turn, this may be a reflection of difficulties experienced by molecules with a higher molecular weight, in their transition from respiratory fluid 
droplets and exhaled air, to condensate. Conversely, overload in the 8-isoprostane in vitro tests seems unlikely when considering that the absolute amount in the test tubes must have been very close to concentrations found in vivo. Hence, it may be that the nebuliser set-up is producing 8-isoprostane aerosols that are more effectively condensed as compared to the real EBC in vivo. Therefore, further studies on the optimal condenser coating should always include in vivo experiments.

The EcoScreen ${ }^{\circledR}$ is a commonly used and commercially available condenser system with distinctive physical characteristics. In contrast to the current authors' collection system and the RTube ${ }^{\circledR}$, which collect EBC in the liquid phase, the EcoScreen ${ }^{\circledR}$ collects EBC mainly as ice, which may be associated with more drastic freeze-thaw cycles that can affect the molecules collected ${ }^{23,25}$. The EcoScreen ${ }^{\circledR}$ is a condenser system based on a modified inner Teflon coating. The 8-isoprostane EBC concentrations were similar for the EcoScreen ${ }^{\circledR}$ and the Teflon coating, suggesting no significant influence from the specific physical characteristics of the EcoScreen ${ }^{\circledR}$ condenser device in vivo.

A different design of the in vivo 8-isoprostane and albumin study was chosen, although ideally both study parts should have had a similar design. However, considerations in support of differing designs were decisive: (i) subjects with asthma are more likely to have positive albumin detection in EBC than healthy controls ${ }^{16}$; and (ii) a 90 minutes $E B C$ collection period, like in the in vivo 8-isoprostane study, was neither realistic nor feasible in the asthmatic children of the in vivo albumin study. Therefore, a between-subject (parallel groups), rather than an intra-subject, comparison of condenser coatings was chosen for the in vivo albumin study.

Standardisation of the EBC collection method implicates more than applying one identical collection technique. It implicates the development of a condenser system with the highest and least varying recovery percentages. Optimalisation of condensate recovery percentages may lead to an improvement of biomarker reproducibility. Therefore, the current authors recommend the use of a condenser system with an inner glass or silicone coating for the measurement of 8-isoprostane and albumin in EBC. The reproducibility of measurements by using different condenser coatings should be evaluated in vivo.

An explanation for this superiority of glass and silicone coatings may be that water acts as a bipolar vehicle. The $\mathrm{pH}$ of exhaled breath ranges from 6.50 to 7.80 , whereas the isoelectrical point of human albumin is situated at $\mathrm{pH} 4.80^{3,26}$. In other words, at higher $\mathrm{pH}$ values (such as reported in EBC) albumin acts as a negatively charged molecule. Therefore, the negatively charged albumin in exhaled breath may be repulsed by glass that is also negatively charged. This may promote the recovery of albumin in EBC. In contrast, the same albumin molecule may be attracted by aluminum metal ions that are positively charged. This may hamper the recovery of albumin in EBC in this case. Furthermore, 8-isoprostane acts in an extremely hydrophobic manner and will stick to neutral surfaces (such as Teflon) in the presence of aqueous solutions, to lipids and to detergents. 
Not only adhesive and electrical properties of the condensation equipment may affect whether a compound is collected in EBC, but also issues such as the length of the condensation tube, thermal conduction of the coating, and solute solubility, volatility, and its dissociation constant $(\mathrm{pKa}=-\log \mathrm{Ka})$.

Finally, these findings in 8-isoprostane and albumin do not necessarily hold for all other biomarkers. Every biomarker has its own chemical and physical characteristics. Currently, one may speculate that most eicosanoids act in a similar way. Likewise, small proteins such as cytokines may act differently from eicosanoids, but similarly when compared one cytokine to another.

The present authors conclude that a condenser system with a silicone or glass coating is more efficient for the measurement of 8-isoprostane or albumin in EBC, compared with the EcoScreen ${ }^{\circledR}$, or condensers with aluminium, polypropylene or Teflon coating. The increased efficiency of the borosilicate glass and silicone coatings may be due to less adhesive properties resulting in more biomarker recovery in the condensate. To establish methodological standardisation of the collection of EBC, the most valid and inert condenser coating has to be applied for the measurement of a specific inflammatory biomarker.

\section{Acknowledgement}

The authors wish to thank: Mieke Dentener and Roy Cloots of the department of Respiratory Medicine, University Hospital of Maastricht, for their technical support in the analysis of the albumin condensate samples; M'hamed Hadfoune of the General Surgery, Nutrition and Toxicology Research Institute Maastricht, Maastricht University, for his technical support in the analysis of the 8-isoprostane condensate samples; Paul Laeven of the department of Instrument Development Engineering \& Evaluation, University of Maastricht, for his technical support in the development of the rechargeable condenser system; Jildou Sijbrandij of the department of Epidemiology, University of Maastricht, for her statistical support; and last but not least the volunteers for their participation. 


\section{References}

1. Scheideler L, Manke HG, Schwulera U, Inacker O, Hämmerle H. Detection of nonvolatile macromolecules in breath. A possible diagnostic tool? Am Rev Respir Dis 1993; 148: 778-784.

2. Baraldi E, Ghiro L, Piovan V, Carraro S, Zacchello F, Zanconato S. Safety and success of exhaled breath condensate collection in asthma. Arch Dis Child 2003; 88: 358-360.

3. Rosias PPR, Dompeling E, HJE Hendriks, JWCM Heijnens, RAMG Donckerwolcke, Q Jöbsis. Exhaled breath condensate in children: pearls and pitfalls. Pediatr Allergy Immunol 2004; 15: 4-19.

4. Horváth I, Hunt J, Barnes PJ on behalf of the ATS/ERS Task Force. Exhaled breath condensate: methodological recommendations and unresolved questions. Eur Respir J 2005; 26: 523-548.

5. Mutlu GM, Garey KW, Robbins RA, Danziger LH, Rubinstein I. Collection and analysis of exhaled breath condensate in humans. Am J Respir Crit Care Med 2001; 164: 731-737.

6. Kharitonov SA, Barnes PJ. Exhaled markers of pulmonary disease. Am J Respir Crit Care Med 2001; 163: 1693-1722.

7. Montuschi P, Barnes PJ. Analysis of exhaled breath condensate for monitoring airway inflammation. Trends Pharmacol Sci 2002; 23: 232-237.

8. Hunt J. Exhaled breath condensate: an evolving tool for non-invasive evaluation of lung disease. J Allergy Clin Immunol 2002; 110: 28-34.

9. Antczak A, Gorski P. Markers of pulmonary diseases in exhaled breath condensate. Int J Occup Med Environ Health 2002; 15: 317-323.

10. Jöbsis Q, Rosias PPR. Analysis of exhaled breath condensate in children. In: Montuschi $\mathrm{P}$, ed. New perspectives in monitoring lung inflammation: analysis of exhaled breath condensate. CRC Press, London / New York / Washington DC, 2005; pp.105-111.

11. Wood LG, Gibson PG, Garg ML. Biomarkers of lipid peroxidation, airway inflammation and asthma. Eur Respir J 2003; 21: 177-186.

12. Montuschi P, Ragazzoni E, Valente S, Corbo G, Mondino C, Ciappi G, Ciabattoni G. Validation of 8-isoprostane and prostaglandin E2 measurements in exhaled breath condensate. Inflamm Res 2003; 52: 502-507.

13. Rahman I. Reproducibility of oxidative stress biomarkers in breath condensate: are they reliable? Eur Respir J 2004; 23: 183-184.

14. Carpagnano GE, Resta O, Foschino-Barbaro MP, Spanevello A, Stefano A, Di Gioia G, Serviddio G, Gramiccioni E. Exhaled interleukin-6 and 8-isoprostane in chronic obstructive pulmonary disease: effect of carbocysteine lysine salt monohydrate (SCMC-Lys). Eur J Pharmacol 2004; 505: 169-175.

15. Van Rensen ELJ, Hiemstra PS, Rabe KF, Sterk PJ. Assessment of microvascular leakage via sputum induction. Am J Respir Crit Care Med 2002; 165: 1275-1279.

16. Rosias PPR, Dompeling E, Dentener MA, Pennings HJ, Hendriks JJE, Van lersel MPA, Jöbsis Q. Childhood asthma: exhaled markers of airway inflammation, asthma control score and lung function tests. Pediatr Pulmonol 2004; 38: 107-114.

17. Rosias PPR, Robroeks C, Hendriks J, Dompeling E, Jöbsis Q. Exhaled breath condensate: a space odyssey, where no one has gone before. Eur Respir J 2004; 24: 189-190. 
18. Asher MI, Keil U, Anderson HR, Beasley R, Crane J, Martinez F, Mitchell EA, Pearce N, Sibbald B, Stewart AW, Strachan D, Weiland SK, Wiliams HC. International study of asthma and allergies in childhood (ISAAC): rationale and methods. Eur Respir $J$ 1995; 8: 483-491.

19. Global Strategy for Asthma Management and Prevention NHLBI/WHO Workshop report. National Heart Lung and Blood Institute, Bethesda, MD. National Institutes of Health; 1995. Publication No. 95-3659.

20. Van Hoydonck PGA, Wuyts WA, Vanaudenaerde BM, Schouten EG, Dupont LJ, Temme EHM. Quantitative analysis of 8-isoprostane and hydrogen peroxide in exhaled breath condensate. Eur Respir J 2004; 23: 189-192.

21. Tufvesson E, Bjermer L. Methodological improvements for measuring eicosanoids and cytokines in exhaled breath condensate. Respir Med 2006; 100: 34-38.

22. Shahid SK, Kharitonov SA, Wilson NM, Bush A, Barnes PJ. Increased interleukin-4 and decreased interferon-gamma in exhaled breath condensate of children with asthma. Am J Respir Crit Care Med 2002; 165: 1290-1293.

23. Leung TF, Wong GWK, Ko FWS, Li CY, Yung E, Lam CWK, Fok TF. Analysis of growth factors and inflammatory cytokines in exhaled breath condensate from asthmatic children. Int Arch Allergy Immunol 2005; 137: 66-72.

24. Huszár É, Szabó Z, Jakab Á, Barta I, Herjavecz I, Horváth I. Comparative measurement of thromboxane A2 metabolites in exhaled breath condensate by different immunoassays. Inflamm Res 2005; 54: 350-355.

25. Leung TF, Li CY, Lam CWK, Au CSS, Yung E, Chan IHS, Wong GWK, Fok TF. The relation between obesity and asthmatic airway inflammation. Pediatr Allergy Immunol 2004; 15: 344-350.

26. Komatsu T, Oguro Y, Teramura Y, Takeoka S, Okai J, Anraku M, Otagiri M, Tsuchida E. Physicochemical characterization of cross-linked human serum albumin dimer and its synthetic heme hybrid as an oxygen carrier. Biochim Biophys Acta 2004; 1675: 21-31. 


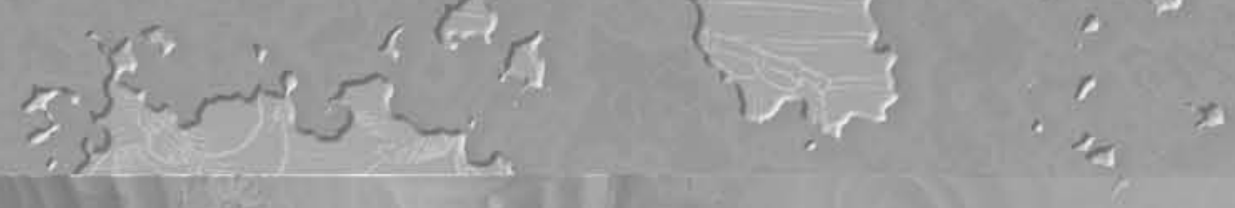

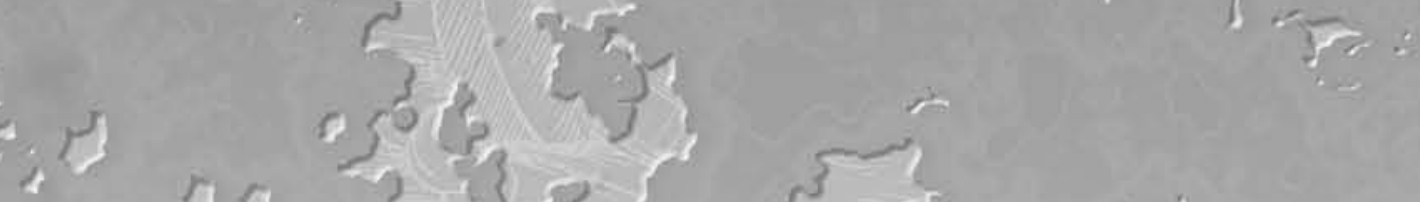

$$
\begin{aligned}
& \text { - } \frac{1}{3} \ln ^{2} \\
& \text { I I P }
\end{aligned}
$$

$\frac{3}{3}$

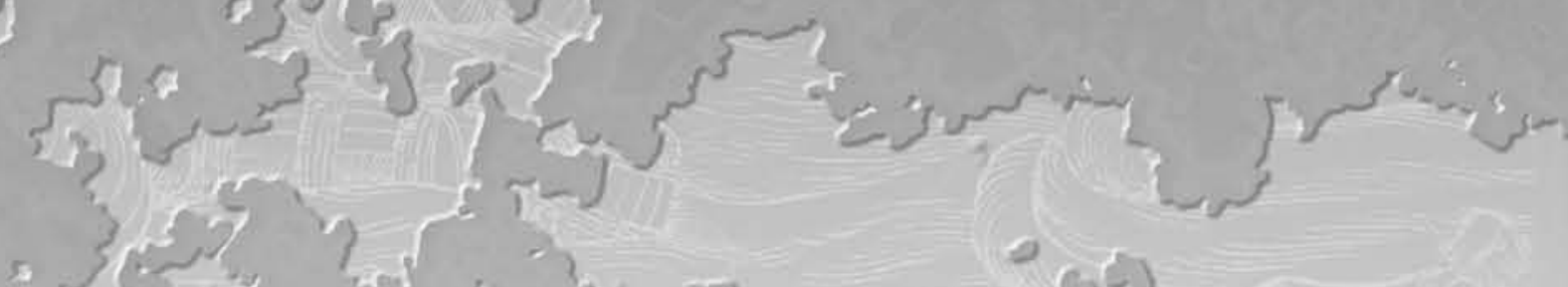

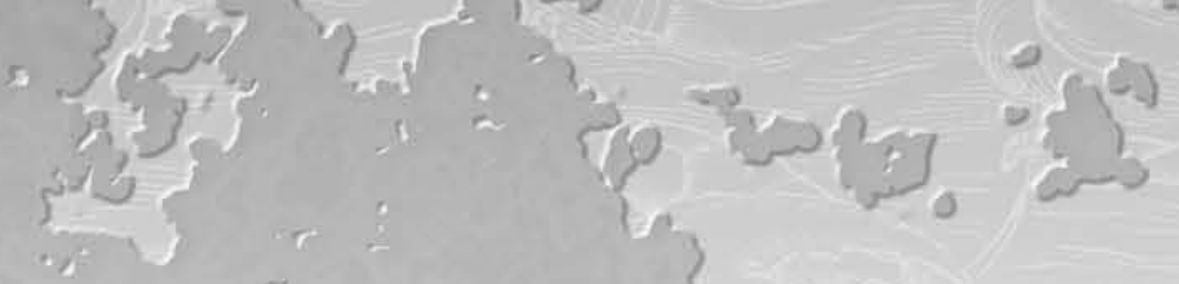

$2 \pi-40$

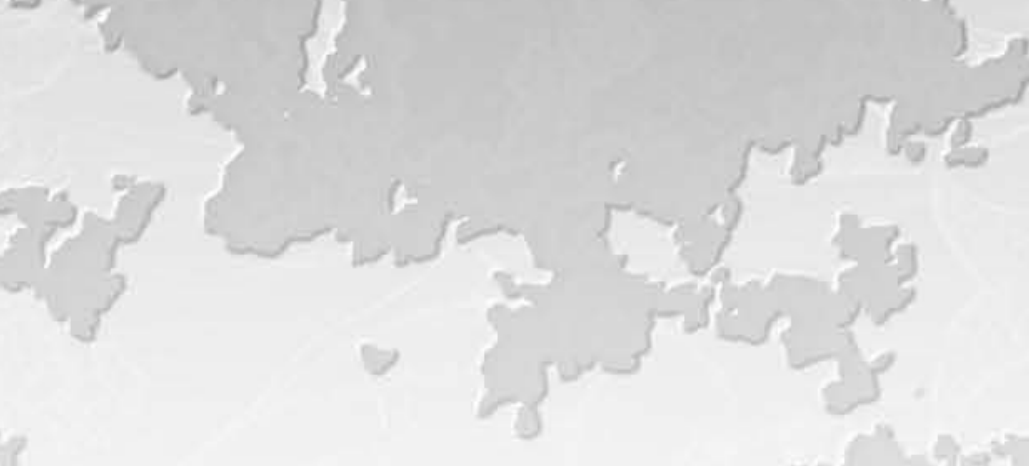

7

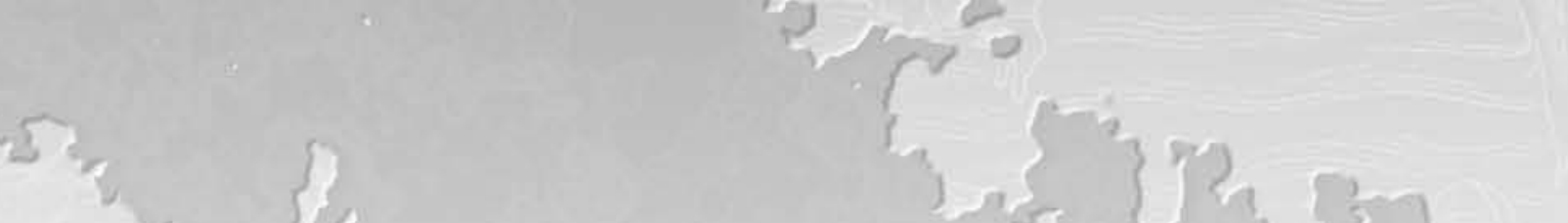<smiles>CCCCCCCCCCCC</smiles>

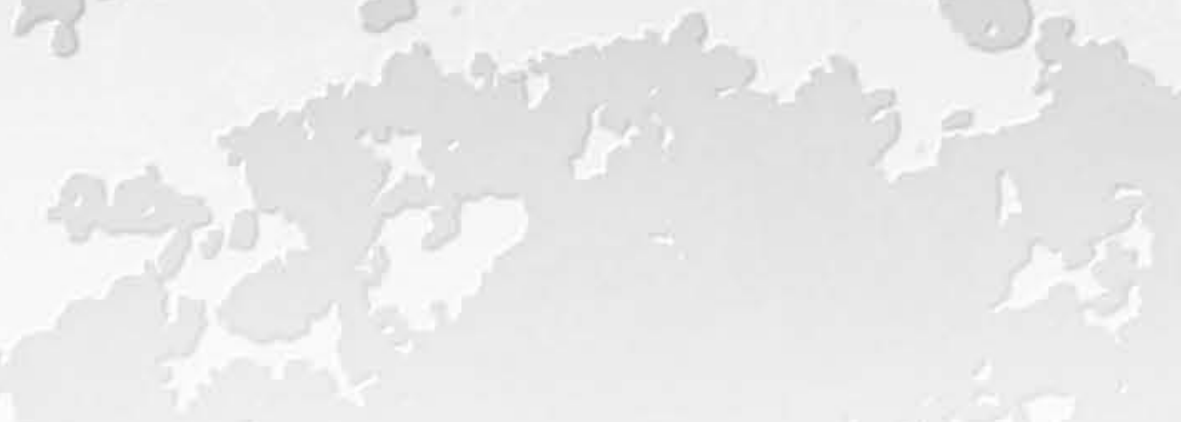




\section{CHAPTER 5}

\section{BIOMARKER REPRODUCIBILITY}

in Exhaled Breath Condensate Collected

\section{WITH DifFERENT CONDENSERS}

Rosias PP, Robroeks CM, Kester AD, den Hartog GJ, Wodzig WK, Rijkers GT, Zimmermann LJ, van Schayck CP, Jöbsis Q, Dompeling E.

European Respiratory Journal; in press. 


\section{Introduction}

The collection of exhaled breath condensate $(E B C)$ is a non-invasive, safe technique to obtain direct samples from the lower respiratory tract, without disturbing an ongoing inflammation ${ }^{1-3}$. Analysis of EBC reveals the presence of inflammatory markers such as eicosanoids, hydrogen peroxide, and cytokines ${ }^{1-3}$. Although the American Thoracic Society and European Respiratory Society Task Force on EBC published general methodological recommendations on the collection and analysis of EBC, there are still some unresolved methodological pitfalls, as illustrated by the use of various nonstandardised collection systems ${ }^{1-3}$.

Optimal condensate collection, and optimal biomarker detection and measurement in EBC are reciprocal prerequisites for any standardisation. However, current condensation systems are suboptimal, with relatively short-measured, open ended designs and loss of noncondensed exhaled breath, as reflected by variable EBC volumes and biomarker reproducibility ${ }^{1}$. Logically, modification by using guided breath flows, enlarged condensation surface, and optimised condensate recovery may improve condensation. Moreover, current designs have different inner coatings, featuring different adhesive interactions with exhaled markers ${ }^{4}$. Recently, loss of biomarker within the sampling system was demonstrated, in vitro and in vivo, for 8-isoprostane and albumin, at the expense of nonglass condenser systems, and in favour of glass and silicone condensers 4. To assess clinical relevance, a study on the reproducibility of these biomarker measurements in vivo, using different condenser coatings including glass, is needed ${ }^{4}$. Furthermore, conventional biomarker assays are not always suitable for use in even large sample volumes of condensate, a bio fluid highly 'diluted' by water vapour ${ }^{5}$, whereas new analytical techniques are rapidly emerging and may offer new perspectives ${ }^{6-7}$. Recently, multiplexed cytometric bead array was used in children to simultaneously measure different cytokines in only $50 \mu \mathrm{L}$ condensate samples, however, the detection level did not reach $50 \%{ }^{6}$. Liquid bead-based multiplexing XMAP ${ }^{\circledR}$ technology (Luminex Corporation, Austin, USA), based on flow cytometry and (faster) liquid microspheres reaction kinetics, is less laborious, highly sensitive and specific, allows simultaneous measurements in small sample sizes, and improves interarray reproducibility ${ }^{7}$. Therefore, we hypothesised that optimised condensate collection with minimal adhesive properties, improves the reproducibility of different measurements in EBC.

The aim of the present study is to assess the effect of four different condensers (glass, silicone, EcoScreen ${ }^{\circledR}$, and a new, optimised glass condenser) on the reproducibility of breath condensate volume, and the detection, concentration and reproducibility of inflammatory biomarkers, including hydrogen peroxide, 8-isoprostane, interleukin-2, interleukin-4, interleukin-5, interleukin-6, interleukin-8, interleukin-10, interleukin-13, and tumor necrosis factor-alpha, in EBC in healthy nonasthmatic adults. 


\section{Methods \\ Study subjects}

We recruited 30 eligible healthy nonasthmatic adult volunteers (table 1) among medical students and staff at the University Hospital Maastricht, based on the following criteria: each volunteer was able to breath tidally into a mouthpiece for at least 15 minutes; exclusion criteria were: history of asthma, upper or lower airway infection, and use of antibiotics, corticosteroids, cromoglycate, nedocromil, theophylline or leukotrien-antagonist. Nonasthmatic healthy adults were chosen to eliminate possible confounding factors attributable to heterogeneous disease expression and/or variability of disease control.

Table 1. Subject characteristics of healthy nonasthmatic adult volunteers $(n=30)$.

\begin{tabular}{ll} 
male : female ratio & $19: 11$ \\
age (in years) & $23(14)$ \\
weight (in kg)* & $75(25)$ \\
height (in cm)* & $180(14)$ \\
non smoking & 28 \\
history of eczema and/or hay-fever & 6 \\
\hline & \\
* median and (interquartile range) &
\end{tabular}

\section{Study design}

To assess within-day, between-day and between-week reproducibility, each volunteer was asked to perform four tests: on the first day in the morning (test 1) and afternoon (test 2), the day after at the same time as test 1 (test 3), and one week later at the same time (test 4). In turn, each test consisted of four sequential EBC collections, using ad random different types of condenser.

\section{Exhaled breath condensate collection}

EBC was collected using one of the following condensers: the commercial Teflon-like EcoScreen ${ }^{\circledR}$, a condenser with exchangeable inner cylinder of silicone or glass, as described previously ${ }^{4}$, and a new, optimised glass condenser that was developed in close collaboration with the Department of Instrument Development Engineering \& Evaluation of the Maastricht University (patent number EP 07102586), as extensively described in figure 1. Briefly, the inclined condensation surface is enlarged (using a length of $90 \mathrm{~cm}$ ), condensate recovery is optimised (using a downwards moveable plunger), and breath flows are turbinately directed towards the condenser wall (by the plunger's multiple breath channels).

To perform one EBC collection, each subject was asked to exhale tidally, while using a nose clip, through a mouthpiece and two-way nonrebreathing valve connected with the condenser, during a fixed period of 15 minutes. 

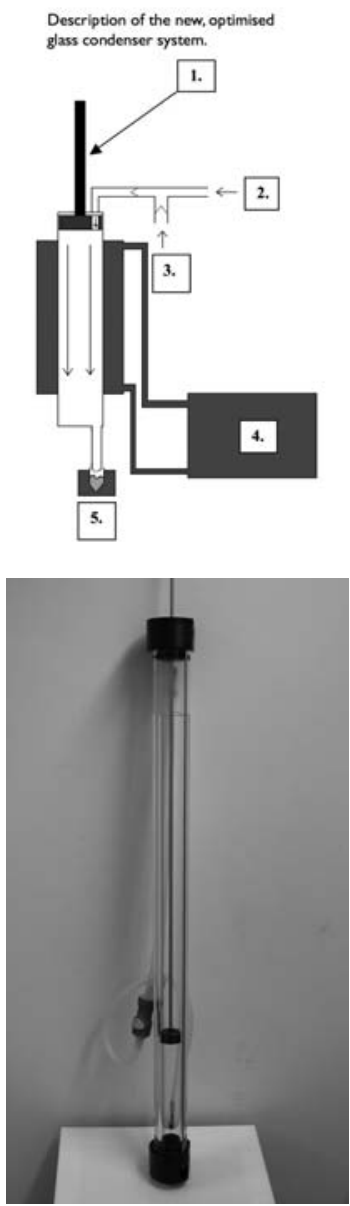

Figure $1 \mathrm{~A}, 1 \mathrm{~B}$, and $1 \mathrm{C}$.

\section{A}

1. inclined glass condenser with a tube length of $90 \mathrm{~cm}$ (to enlarge the condensation surface), and downwards moveable plunger (to optimise condensate recovery from the inner condenser wall), with tangential and axial breath flow channels (to turbinately direct the tidally exhaled breath flows towards the cooled inner condenser wall)

2. swan-neck tubing (serving as gravitational saliva trap) and two-way nonrebreathing valve, connected to a mouthpiece

3. entrance of inspired room air

4. cooling unit consisting of a counter-current circulating ice-water pump

5. removable, cooled glass sample vial (to collect exhaled breath condensate)

B

Photograph of the glass condenser tube with plunger in situ.

c

Photographic detail of the glass condenser tube with downwards moveable plunger in situ. The plunger has three tangential and axial breath flow channels (to turbinately direct the tidally exhaled breath flows towards the cooled inner condenser wall).

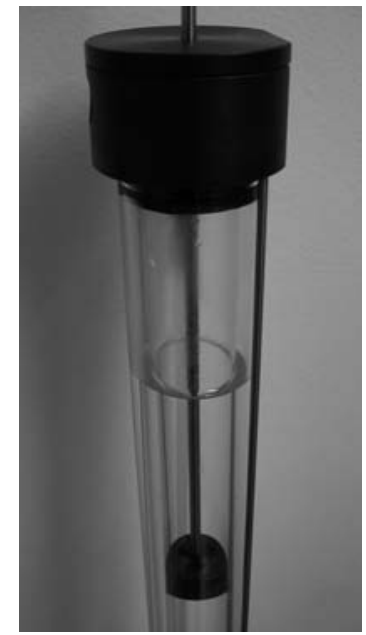

The new optimised glass condenser system.

\section{Condensate sample processing}

Immediately after collection, condensate samples were snap-frozen at $-78^{\circ} \mathrm{C}$ using dry ice and stored at $-80^{\circ} \mathrm{C}$. Analysis was performed within three months from sampling time.

Hydrogen peroxide was measured in $50 \mu \mathrm{LEBC}$, in duplicate by spectrophotometer (Perkin Elmer ${ }^{\circledR}$ UV-VIS Lambda 10 Spectrometer, Shelton/Norwalk, Connecticut, USA) with a lower detection limit of $0.05 \mu \mathrm{M}$, as described previously ${ }^{8}$.

Isoprostane was measured in 100 $\mathrm{LLBC}$, by specific enzyme immunoassay (Cayman Chemical ${ }^{\circledR}$, Ann Arbor, Michigan, USA), that was modified to reach a lower limit of detection of $1.0 \mathrm{pg} / \mathrm{mL}$. The standard curve of this assay ranged from $250 \mathrm{pg} / \mathrm{mL}$ to $1.95 \mathrm{pg} / \mathrm{mL}$. We were able to report 8-isoprostane values as low as $1.0 \mathrm{pg} / \mathrm{mL}$, as a logit/log transformation was used. Isoprostane recovery experiments were performed, 
and coefficients of variation of the absorption signals were assessed. When spiking for the lower 8 -isoprostane values of $3.9 \mathrm{pg} / \mathrm{mL}$ and $7.8 \mathrm{pg} / \mathrm{mL}$, an isoprostane recovery of $92 \%$ (coefficient of variation of concentration 16\%), and $95 \%$ (coefficient of variation of concentration 15\%) were found, respectively. A coefficient of variation (of absorption signals) below $15 \%$ was considered highly acceptable. Hence, the corresponding coefficient of variation of concentrations may be higher. Therefore, the coefficients of variation found in the 8-isoprostane recovery experiments using these low values, were considered good. Standard curves, patient samples and quality control samples of $2.5 \mathrm{pg} / \mathrm{mL}$ and $10 \mathrm{pg} / \mathrm{mL}$ isoprostane were assayed in triplicate. Intra-assay variation of standard curves, patient samples and quality control samples should be less than 15\%, otherwise all samples measured in that assay were excluded and reanalysed. Finally, in all accepted samples, 8-isoprostane concentrations were determined from mean absorption signal intensities.

Cytokines were measured in $50 \mu \mathrm{LEBC}$, using the liquid bead-based multiplexing $\mathrm{XMAP}^{\circledR}$ technology (Luminex Corporation, Austin, USA). Multiplex immunoassay was performed as described previously ${ }^{7,9-10}$. The corresponding lower limits of cytokine and chemokine detection were: interleukin-2 (1.0pg/mL), interleukin-4 (1.2pg/mL), interleukin-5 $(1.2 \mathrm{pg} / \mathrm{mL})$, interleukin-6 $(0.4 \mathrm{pg} / \mathrm{mL})$, interleukin-8 $(1.1 \mathrm{pg} / \mathrm{mL})$, interleukin-10 (1.2pg/mL), interleukin-13 $(1.0 \mathrm{pg} / \mathrm{mL})$, and tumor necrosis factor-alpha $(1.3 \mathrm{pg} / \mathrm{mL})$. Measurement and data analysis were performed using the Bioplex 100 system and Bioplex Manager software version 3.0 (Bio-Rad Laboratories, Hercules, CA). All multiplex immunoassays were performed in 96 well format $1.2 \mu \mathrm{m}$ filter bottom plates (Millipore, Amsterdam, The Netherlands) and a 12 point standard curve in duplicate was included on every plate. In order to minimise interassay variation, positive and negative control samples were included. As far as possible, EBC samples from one donor series of experiments were run on one plate. Three EBC samples were spiked with 100 or $10 \mathrm{pg} / \mathrm{mL}$ cytokines (interleukin-2, interleukin-4, interleukin-5, interleukin-6, interleukin-8, interleukin-10, interleukin-13, and tumor necrosis factoralpha), and measured them in quadruplicate. The mean coefficient of variation of these cytokine measurements was $12.2 \%$. The recovery of $100 \mathrm{pg} / \mathrm{mL}$ spiked cytokine was $103 \%$ (range from 71 to $129 \%$ ). At $10 \mathrm{pg} / \mathrm{mL}$, the mean recovery was somewhat lower at $89 \%$ (range from $64 \%$ in interleukin-13, to $111 \%$ in interleukin-4). It was concluded that there was a slight matrix effect of $E B C$, but this did not result in an overestimation of cytokine measurements.

\section{Statistics}

Statistical calculations were performed using SPSS 11.5 (SPSS Inc, Chicago, USA). Not normally distributed data were expressed as median and interquartile range. Normally distributed data were expressed as mean and standard error. To estimate variance within a single method of measurement (coating), coefficient of variation (= (standard deviation/mean) $\times 100 \%$ ) were used. The coefficient of variation was calculated as the mean of individual coefficients of variation, calculated over the two or four relevant measurements. Within-subjects, coefficients of variation were used as data distribution was normal. When the distribution of individual coefficients of variation was not 
normal, the nonparametric Friedman test was used to see if these coefficients of variation were different between coatings. To test for differences among normally distributed repeated measures, analysis of variance (ANOVA) was used. The Chisquare test was used to evaluate statistically the differences between proportions for four groups in a data set. Condensate samples with biomarker concentration below the lower detection limit, in strictu sensu negative detections, were not considered as missing values, because they actually informed us that marker concentrations were below the lower detection limit. Therefore, these negative detections were given an arbitrary value between zero and the lower detection limit: $0.025 \mu \mathrm{M}$ for hydrogen peroxide, $0.1 \mathrm{pg} / \mathrm{mL}$ for 8 -isoprostane, and $0.1 \mathrm{pg} / \mathrm{mL}$ for cytokines. Samples were defined missing if the EBC volume, yielded after 15 minutes collection time, was zero, or insufficient to analyse.

\section{Power calculation}

Ideally, power calculations should be based on the expected changes in biomarker concentrations and on their variability. However, these changes in biomarker concentrations and their variability were unknown. In fact, the objective of this study was to answer this question. Therefore, we took the uncertainty of the estimated variability as a basis for power calculations. For each of the estimated variances (within-day, between-day and between-week) we have data from 30 volunteers. Using standard results for the variance of a chi-square random variable, we infer that, with 30 subjects, the relative confidence limits (relative to the observed value of the variance) will be 0.634 and 1.807 . For the standard deviation this implies relative limits of 0.80 and $1.34{ }^{11}$.

\section{Ethics}

All parents gave written informed consent. The study was approved by the Medical Ethics Committee of the University Hospital of Maastricht.

\section{Results \\ EBC volume}

In 5 out of 480 manoeuvres, we were not able to collect condensate due to erroneously connected tubing. EBC collection by the optimised glass condenser yielded significantly more median condensate volume, compared to the other condensers $(p=0.001$, Friedman) (table 2). Within-day, between-day, between-week and overall reproducibility of EBC volume (expressed as coefficient of variation) were comparable in the new condenser and EcoScreen ${ }^{\circledR}(p=0.715$, Chi-square), but was significantly better compared to silicone and glass ( $p<0.028$, Chi-square).

\section{Hydrogen peroxide measurements in EBC}

Overall, $29 \%$ of hydrogen peroxide measurements were missing (table 3). Significantly more positive hydrogen peroxide detections were found using the optimised glass condenser, compared to silicone and glass ( $p<0.050$, Chi-square). Median hydrogen peroxide concentrations and reproducibility (expressed as coefficient of variation) did 
Table 2. Volume of exhaled breath condensate, and reproducibility (expressed as coefficients of variation) in four different condenser systems.

\begin{tabular}{llllll} 
EBC & Silicone & Glass & New & EcoScreen & p-value \\
\hline missings & $4 / 120$ & $0 / 120$ & $1 / 120$ & $0 / 120$ & - \\
volume * $_{\text {CVin-day * }}$ & $525(319)$ & $712(297)$ & $2025(1056)$ & $1237(759)$ & $0.001 \dagger$ \\
CVbe-day * $^{*}$ & $28(27)$ & $21(19)$ & $11(15)$ & $9(21)$ & $0.002 \dagger$ \\
CVbe-week * $^{*}$ & $35(36)$ & $30(26)$ & $11(26)$ & $13(23)$ & $0.027 \dagger$ \\
CVoverall * $^{*}$ & $37(22)$ & $26(28)$ & $15(22)$ & $15(21)$ & $0.003 \dagger$ \\
\hline
\end{tabular}

EBC exhaled breath condensate

New optimised glass condenser

missings number of failed EBC collections, after 15 minutes, to total number of tests

volume volume of $\mathrm{EBC}$, in $\mu \mathrm{L}$

CV coefficient of variation, in percentage

in-day within day

be-day between day

be-week between week

* $\quad$ expressed as median (interquartile range)

$\dagger \quad$ Friedman test

Table 3. Hydrogen peroxide measurements in exhaled breath condensate: detection, concentration, and reproducibility (expressed as coefficients of variation) in four different condenser systems.

\begin{tabular}{llllll}
$\mathrm{H}_{2} \mathrm{O}_{2}$ & Silicone & Glass & New & EcoScreen & p-value \\
\hline missings & $59 / 120$ & $49 / 120$ & $10 / 120$ & $23 / 120$ & - \\
detections & $52 / 9$ & $62 / 9$ & $77 / 33$ & $75 / 22$ & $0.003 \ddagger$ \\
conc * & $2.6(2.7)$ & $2.1(2.3)$ & $1.8(1.6)$ & $2.2(2.5)$ & $0.286 \ddagger$ \\
CVin-day * & $17(25)$ & $12(28)$ & $46(71)$ & $13(21)$ & $0.271 \ddagger$ \\
CVbe-day * & $22(33)$ & $30(42)$ & $30(118)$ & $16(52)$ & $0.821 \ddagger$ \\
CVbe-week * & $18(46)$ & $26(42)$ & $32(44)$ & $12(32)$ & $0.256 \ddagger$ \\
CVoverall * & $23(25)$ & $29(21)$ & $24(52)$ & $22(13)$ & $0.080 \ddagger$ \\
\hline
\end{tabular}

$\mathrm{H}_{2} \mathrm{O}_{2}$ hydrogen peroxide

New optimised glass condenser

missings number of missing measurements to total number of tests

detections number of positive to negative detections

conc concentration of $\mathrm{H}_{2} \mathrm{O}_{2}$ in $\mathrm{EBC}$, in $\mu \mathrm{M}$

$\mathrm{CV}$ coefficient of variation, in percentage

in-day within day

be-day between day

be-week between week

* $\quad$ expressed as median (interquartile range)

$\dagger \quad$ Chi-square test

$\ddagger \quad$ Friedman test 
not significantly differ between the four condensers $(p=0.286$ and $p>0.080$, respectively, Friedman).

\section{8-Isoprostane measurements in EBC}

Overall, $13 \%$ of 8 -isoprostane measurements were missing (table 4). Significantly more positive 8-isoprostane detections were found using the optimised glass condenser, compared to silicone and glass ( $p<0.023$, Chi-square). The median concentration of 8-isoprostane was significantly higher using the new condenser compared with the other three condensers ( $p=0.001$, Friedman). Statistically, 8isoprostane reproducibility (expressed as coefficient of variation) did not significantly differ between the four condensers ( $p>0.151$, Friedman).

Table 4. Isoprostane measurements in exhaled breath condensate: detection, concentration, and reproducibility (expressed as coefficients of variation) in four different condenser systems.

\begin{tabular}{llllll} 
8-IP & Silicone & Glass & New & EcoScreen & p-value \\
\hline missings & $27 / 120$ & $16 / 120$ & $9 / 120$ & $10 / 120$ & - \\
detections & $89 / 4$ & $98 / 6$ & $110 / 1$ & $109 / 1$ & $0.001 \ddagger$ \\
conc * & $2.0(2.2)$ & $2.9(2.3)$ & $3.6(2.7)$ & $2.5(1.8)$ & $0.001 \ddagger$ \\
CVin-day * & $6(29)$ & $20(55)$ & $23(35)$ & $24(29)$ & $0.297 \ddagger$ \\
CVbe-day * & $31(65)$ & $26(57)$ & $23(32)$ & $15(32)$ & $0.559 \ddagger$ \\
CVbe-week * & $22(42)$ & $22(57)$ & $15(31)$ & $25(28)$ & $0.954 \ddagger$ \\
CVoverall * & $31(57)$ & $48(55)$ & $29(22)$ & $26(26)$ & $0.151 \ddagger$ \\
\hline
\end{tabular}

$\begin{array}{ll}\text { 8-IP } & \text { 8-isoprostane } \\ \text { New } & \text { optimised glass condenser } \\ \text { missings } & \text { number of missing measurements to total number of tests } \\ \text { detections number of positive to negative detections } \\ \text { conc } & \text { concentration of } 8-\mathrm{IP} \text { in EBC, in } \mathrm{pg} / \mathrm{ml} \\ \mathrm{CV} & \text { coefficient of variation, in percentage } \\ \text { in-day } & \text { within day } \\ \text { be-day } & \text { between day } \\ \text { be-week } & \text { between week } \\ * & \text { expressed as median (interquartile range) } \\ \dagger & \text { Chi-square test } \\ \ddagger & \text { Friedman test }\end{array}$

\section{Cytokine measurements in EBC}

Overall, $20 \%$ of cytokine measurements were missing (table 5.a). Overall, the levels of cytokine detection using xMAP's technology were: interleukin-2 (68\%), interleukin$4(97 \%)$, interleukin-5 (73\%), interleukin-6 (46\%), interleukin-8 (46\%), interleukin10 (61\%), interleukin-13 (70\%) and tumor necrosis factor-alpha (64\%). The optimised glass condenser had significantly more positive detections of interleukin-2, interleukin4, interleukin-5, interleukin-13 and tumor necrosis factor-alpha, compared to silicone 
Table 5.a. Number of positive to negative detections of cytokines in exhaled breath condensate, collected with four different condenser systems.

\begin{tabular}{llllll} 
detections & Silicone & Glass & New & EcoScreen & p-value * \\
\hline missings & $49 / 120$ & $37 / 120$ & $1 / 120$ & $10 / 120$ & - \\
IL-2 & $50 / 21$ & $60 / 23$ & $82 / 37$ & $68 / 42$ & 0.001 \\
IL-4 & $69 / 2$ & $81 / 2$ & $113 / 6$ & $108 / 2$ & 0.001 \\
IL-5 & $58 / 13$ & $65 / 18$ & $87 / 32$ & $70 / 40$ & 0.001 \\
IL-6 & $41 / 30$ & $45 / 38$ & $48 / 71$ & $43 / 67$ & 0.811 \\
IL-8 & $44 / 27$ & $45 / 38$ & $44 / 75$ & $44 / 66$ & 0.999 \\
IL-10 & $54 / 17$ & $57 / 26$ & $63 / 56$ & $61 / 49$ & 0.654 \\
IL-13 & $53 / 18$ & $58 / 25$ & $88 / 31$ & $71 / 39$ & 0.001 \\
TNF-alpha & $52 / 19$ & $57 / 26$ & $72 / 47$ & $65 / 45$ & 0.050 \\
\hline
\end{tabular}

detections number of positive to negative detections

New optimised glass condenser

missings number of missing measurements to total number of tests

IL interleukin

TNF tumor necrosis factor

* Chi-square test

Table 5.b. Concentration of cytokine measurements in exhaled breath condensate, collected with four different condenser systems.

\begin{tabular}{lllllc} 
conc & Silicone & Glass & New & EcoScreen & p-value \\
\hline missings & $49 / 120$ & $37 / 120$ & $1 / 120$ & $10 / 120$ & - \\
$\mathrm{IL}-2{ }^{*}$ & $1.9(5.0)$ & $1.6(4.4)$ & $1.2(3.5)$ & $1.6(4.0)$ & 0.494 \\
$\mathrm{IL}-4 \dagger$ & $5.8(0.3)$ & $5.1(0.3)$ & $4.7(0.3)$ & $5.4(0.3)$ & 0.129 \\
$\mathrm{IL}-5{ }^{*}$ & $4.4(13.8)$ & $3.0(12.1)$ & $3.2(11.4)$ & $3.1(12.1)$ & 0.544 \\
$\mathrm{IL}-6$ * & $0.9(4.3)$ & $0.9(4.5)$ & $0.7(3.8)$ & $0.6(4.4)$ & 0.113 \\
$\mathrm{IL}-8$ * & $2.0(4.6)$ & $2.1(4.0)$ & $2.7(4.8)$ & $2.1(3.9)$ & 0.341 \\
$\mathrm{IL}-10 \dagger$ & $1.5(0.3)$ & $1.6(0.9)$ & $1.4(0.8)$ & $1.3(0.7)$ & 0.872 \\
$\mathrm{IL}-13 \dagger$ & $6.6(1.1)$ & $6.6(1.1)$ & $6.3(0.7)$ & $5.9(0.8)$ & 0.946 \\
TNF-alpha $\dagger$ & $2.1(0.4)$ & $2.0(0.4)$ & $1.8(0.3)$ & $1.7(0.3)$ & 0.876
\end{tabular}

conc concentration in $\mathrm{EBC}$, in $\mathrm{pg} / \mathrm{ml}$

New optimised glass condenser

missings number of missing measurements to total number of tests

IL interleukin

TNF tumor necrosis factor

* $\quad$ expressed as median (interquartile range), Friedman test

$\dagger \quad$ expressed as mean (standard error), analysis of variance 
and glass ( $p<0.050$, Chi-square), and more interleukin- 5 and interleukin-13 detections, compared to EcoScreen ${ }^{\circledR}(p<0.021$, Chi-square). Cytokine concentrations were not significantly different between the four condenser types ( $p>0.113$, Friedman or ANOVA, respectively) (table 5.b). Reproducibility (expressed as coefficient of variation) of cytokine measurements did not significantly differ, neither overall (table 5.c), nor within-day, between-day and between-week (data not shown). Best range of overall coefficients of variation was found for the measurement of interleukin-6 (11-14\%), interleukin-8 (2-15\%), interleukin-10 (11-30\%) and tumor necrosis factor-alpha (8$22 \%)$. When coefficients of variation were evaluated using the positive values only (without negative and/or arbitrary values), also no differences between condensers were found (data not shown).

Table 5.c. Overall reproducibility (expressed as coefficients of variation) of cytokine measurements in exhaled breath condensate, collected with four different condenser systems.

\begin{tabular}{llllll} 
CV overall & Silicone & Glass & New & EcoScreen & p-value \\
\hline missings & $49 / 120$ & $37 / 120$ & $1 / 120$ & $10 / 120$ & - \\
$\mathrm{IL}-2 \dagger$ & $80(12)$ & $75(11)$ & $84(10)$ & $70(11)$ & 0.802 \\
$\mathrm{IL}-4 \dagger$ & $33(7)$ & $32(6)$ & $36(5)$ & $26(4)$ & 0.494 \\
$\mathrm{IL}-5 \dagger$ & $74(13)$ & $71(12)$ & $73(11)$ & $81(13)$ & 0.941 \\
$\mathrm{IL}-6$ * & $12(77)$ & $12(68)$ & $14(78)$ & $11(69)$ & 0.690 \\
$\mathrm{IL}-8$ * & $15(28)$ & $12(21)$ & $2(18)$ & $9(25)$ & 0.766 \\
$\mathrm{IL}-10$ * & $30(48)$ & $17(48)$ & $16(39)$ & $11(53)$ & 0.719 \\
IL-13 $\dagger$ & $51(11)$ & $68(12)$ & $73(10)$ & $63(10)$ & 0.574 \\
TNF-alpha * & $17(45)$ & $22(64)$ & $19(62)$ & $8(68)$ & 0.878 \\
\hline
\end{tabular}

CV coefficient of variation, in percentage

New optimised glass condenser

missings number of missing measurements to total number of tests

IL interleukin

TNF tumor necrosis factor

* $\quad$ expressed as median (interquartile range), Friedman test

$\dagger \quad$ expressed as mean (standard error), analysis of variance

\section{Discussion}

We demonstrated that EBC volume, and the detection of biomarkers were significantly influenced by the condenser system, in favour of the new glass condenser, whereas biomarker reproducibility was not influenced by the type of condenser. The proposed optimised glass condenser yielded significantly more condensate volume compared to the silicone, glass and EcoScreen ${ }^{\circledR}$ condensers. Reproducibility of EBC volume was comparable for the new condenser and EcoScreen ${ }^{\circledR}$, and was significantly better compared to the other two condenser types. 
In EBC collected with this new condenser, significantly more positive hydrogen peroxide, 8-isoprostane, interleukin-2, interleukin-4, interleukin-5, interleukin-13 and tumor necrosis factor-alpha detections were found, supporting improved sampling of EBC. Moreover, 8-isoprostane concentrations were significantly increased in EBC yielded by the new condenser, compared to the other three condensers, which is in accordance with former findings ${ }^{4}$. On the other hand, reproducibility of hydrogen peroxide, 8-isoprostane, and cytokine measurements in EBC did not significantly differ between the four condensers, suggesting no significant influence of the type of condenser coating on reproducibility. In literature and to date, no formal study addressing this issue has been published, although reproducibility using other analytical techniques has been reported ${ }^{12-14}$, and/or could not be calculated due to small number of subjects ${ }^{15-17}$.

Variations in biomarker measurements in EBC may be attributed to variations in the dilution and/or quality of condensate that is influenced by different collection techniques and procedures, sample processing and storage conditions, and/or sensitivity of the analytical techniques used ${ }^{17}$. The levels of the highly volatile hydrogen peroxide in EBC may be susceptible to different cooling temperatures during collection ${ }^{18}$, circadian rhythm ${ }^{19}$, flow dependency ${ }^{20}$, different methods of measurement with widely varying values (even in healthy subjects) close to lower detection limits 3,17,2122 , and high chemical reactivity with salivary and exhaled compounds by which (some) hydrogen peroxide is consumed over time during collection and storage 3,17,22. Isoprostanes are relatively stable end-products of in vivo arachidonate peroxidation, and are measured in EBC by immunoassay, that may be influenced by cross reactivity with closely related substances ${ }^{17}$. Other confounding factors may be age, diets rich in antioxidants, and smoking habits ${ }^{17}$.

The use of coefficients of variation is not always the ideal way of expressing variability: when mean values are low, coefficients of variation can be abnormally high. Therefore, we also expressed our results as standard deviations and intraclass correlation coefficients. When using both of these alternative expression methods, results were comparable: no difference in biomarker variability between condensers was found (data not shown). Furthermore, biomarker levels were assessed in condensate originating from healthy adults, and thus, may have been more pronounced in a steroid naïve population with documented chronic respiratory inflammation, and comparable levels of disease control. Hence, one may expect increased mean concentrations, and lowered coefficients of variation in diseased subjects. On the other hand, with these very low concentrations of cytokines and 8isoprostane, we cannot rule out an influence of analytical variability.

Cytokines were simultaneously measured by xMAP's technology in small $50 \mu \mathrm{L} E B C$ samples. The overall level of detection was $46-97 \%$, that was much better compared to cytometric bead array in small samples in children $(<50 \%)$, and in large 1000$2000 \mu \mathrm{L}$ lyophilisated samples in adults (3-100\%) 6,23-26. When compared with conventional (solid-phase) immunoassays, multiplexed immunoassays detect bioactive 
and inactive molecules, have a growing analytical range, are rapid (hours instead of days), have good precision (coefficient of variation: 10-15\%), are not interfered by drugs, and have simple protocols ${ }^{7}$.

Currently, different nonstandardised techniques to collect EBC are in use ${ }^{1-3}$. All systems are based on the cooling of exhaled breath, whereas their design may vary from immersed plastic tubing, over glass distilling columns, to commercial systems, such as the lamellar Teflon-like EcoScreen ${ }^{\circledR}$ condenser (Erich Jaeger GmbH, Hoechberg, Germany), the hand-held disposable polypropylene RTube ${ }^{\mathrm{TM}}$ (Respiratory Inc., Charlottesville, Virginia, USA), and the thermostatically-controlled polyethylene TurboDeccs (ItalChill, Parma, Italy) ${ }^{1-3,27}$. These designs implicate relatively short-measured and open-ended systems that tolerate the needless loss of noncondensed exhaled breath, whether initially, or after a prolonged collection time. Moreover, also biomarkers may be lost within these collection systems, as recently demonstrated for 8-isoprostane and albumin measurements, in vitro and in vivo, in nonglass condensers (including EcoScreen $\left.{ }^{\circledR}\right)^{4}$. This superiority of glass coatings may be mainly related to the behaviour of water as bipolar vehicle ${ }^{4}$. Three other studies report the influence of sampling systems on biomarkers in EBC ${ }^{28-30}$. Tufvesson et al proposed to coat EcoScreen ${ }^{\circledR}$ collection surfaces with bovine serum albumin and Tween-20, to measure cytokines and eicosanoids, respectively ${ }^{28}$. However, they also reported possible false-positive (eicosanoid) results, and the need of sample concentration, by vacuum-centrifugation, prior to analysis ${ }^{28}$. Soyer et al found significantly higher cysteinyl leukotrienes and eotaxin using EcoScreen ${ }^{\circledR}$, compared to RTube ${ }^{\mathrm{TM}}$, due to susceptibility of precooled RTube $^{\mathrm{TM}}$ sleeves to (increased) ambient temperatures during collection, and due to different materials that could affect sample recovery ${ }^{29}$. Prieto et al compared RTube ${ }^{\mathrm{TM}}$ and $\mathrm{EcoScreen}{ }^{\circledR}$, and reported that EBC pH values are dependent on the collection device used ${ }^{30}$. Furthermore, the EcoScreen ${ }^{\circledR}$ has been associated with deposition of frozen condensate on its lamellar walls. For all the above mentioned reasons, we developed an optimised glass condenser system. The new glass condenser had an improved condensation process and condensate recovery, using an inclined and enlarged condensation surface, with a condensate sweeping plunger, having tangentially and axially guiding breath flow channels.

In the present study, these improvements resulted in significantly increased EBC volumes, and increased biomarker detections with the new glass condenser, compared to silicone, glass and EcoScreen ${ }^{\circledR}$. This suggests both an improved condensation process, and an increased opportunity to perform a broad spectrum of analyses. Moreover, the optimised glass and EcoScreen ${ }^{\circledR}$ condenser were both significantly associated with less variation in the generated EBC volume, compared to the other condensers. Hereby, reducing a possible confounding influence of the variable quantity of EBC collected over a given time, and even within individuals.

Optimisation of EBC collection, using the modified new glass condenser with statistically equivalent coefficients of variation compared to the commercial EcoScreen ${ }^{\circledR}$, and optimisation of EBC analysis, using rapid, multiplexed measurement 
of cytokines in small EBC sample sizes, may all together open a window of opportunities, even in strained collection procedures, such as in young or dyspnoeic subjects (with less sustained efforts to cope with sampling procedures), by allowing the search for, and identification of, particular profiles of different exhaled markers, involved in the regulation of chronic respiratory inflammation, for diagnostic and monitoring purposes.

In conclusion, the optimised glass condenser yielded significantly more EBC volume, with good reproducibility. Furthermore, significantly more positive detections of hydrogen peroxide, 8-isoprostane, interleukin-2, interleukin-4, interleukin-5, interleukin-13 and tumor necrosis factor-alpha were found in EBC collected with the new condenser, hereby offering an increased capacity to analyse for complex biomarker profiles. Moreover, concentrations of 8-isoprostane were significantly increased using the optimised glass condenser, compared to the other three condensers. However, reproducibility of biomarker measurements in EBC was not influenced by the type of condenser.

\section{Acknowlegdement}

The authors wish to thank Joelle Suykerbuyk, for her technical support in the collection of EBC; Mia Meers, for her technical support in the measurement of 8-isoprostane (Dept of Clinical Chemistry, University Hospital Maastricht, the Netherlands); Nathalie van Uden, for her technical support in the measurement of cytokines (Dept of Immunology, University Medical Centre Wilhelmina Children's Hospital, Utrecht, the Netherlands); and last but not least the volunteers for their participation. 


\section{References}

1. Rosias PPR, Dompeling E, Hendriks JJE, Heijnens JWCM, Donckerwolcke RAMG, Jöbsis Q. Exhaled breath condensate in children: pearls and pitfalls. Pediatr Allergy Immunol 2004; 15: 4-19.

2. Jöbsis Q, Rosias PPR. Analysis of exhaled breath condensate in children. In: New perspectives in monitoring lung inflammation. Montuschi P, editor. Taylor \& Francis Publishers, London, 2004. (ISBN 0415324653)

3. Horváth I, Hunt J, Barnes PJ, on behalf of the ATS / ERS Task Force, Exhaled breath condensate: methodological recommendations and unresolved questions. Eur Respir J 2005; 26: 523-548.

4. Rosias PP, Robroeks CM, Niemarkt HJ, Kester AD, Vernooy JH, Suykerbuyk J, Teunissen J, Heynens J, Hendriks HJ, Jöbsis Q, Dompeling E. Breath condenser coatings affect measurement of biomarkers in exhaled breath condensate. Eur Respir J 2006; 28: 1036-1041.

5. Huszar E, Szabo Z, Jakab A, Barta I, Herjavecz I, Horvath I. Comparative measurement of thromboxane A2 metabolites in exhaled breath condensate by different immunoassays. Inflamm Res 2005; 54: 350-355.

6. Robroeks CMHHT, Jöbsis Q, Damoiseaux JGMC, Heijmans PHM, Rosias PPR, Hendriks HJE, Dompeling E. Cytokines in exhaled breath condensate of children with asthma and cystic fibrosis. Ann Allergy Asthma Immunol 2006; 96: 349-355.

7. de Jager W, Rijkers GT. Solid-phase and bead-based cytokine immunoassay: a comparison. Methods 2006; 38: 294-303.

8. Dekhuijzen PN, Aben KK, Dekker I, Aarts LP, Wielders PN, van Herwaarden CL, Bast A. Increased exhalation of hydrogen peroxide in patients with stable and unstable chronic obstructive pulmonary disease. Am J Resp Crit Care Med 1996; 154: 813-816.

9. de Jager W, Prakken BJ, Bijlsma JW, Kuis W, Rijkers GT. Improved multiplex immunoassay performance in human plasma and synovial fluid following removal of interfering heterophilic antibodies. J Immunol Methods 2005; 300: 124-135.

10. de Jager W, te Velthuis H, Prakken BJ, Kuis W, Rijkers GT. Simultaneous detection of 15 human cytokines in a single sample of stimulated peripheral blood mononuclear cells. Clin Diagn Lab Immunol 2003; 10: 133-139.

11. Rosner B. Fundamentals of Biostatistics. $6^{\text {th }}$ Edn. Dixbury Press, Belmont, CA, 2006; p.200.

12. Brooks WM, Lash $H$, Kettle AJ, Epton MJ. Optimising hydrogen peroxide measurement in exhaled breath condensate. Redox Rep 2006; 11: 78-84.

13. Gerritsen WB, Zanen P, Bauwens AA, van den Bosch JM, Haas FJ. Validation of a new method to measure hydrogen peroxide in exhaled breath condensate. Respir Med 2005; 99: 1132-1137.

14. Gonzalez-Reche LM, Musiol AK, Muller-Lux A, Kraus T, Goen T. Method optimization and validation for the simultaneous determination of arachidonic acid metabolites in exhaled breath condensate by liquid chromatography-electrospray ionization tandem mass spectrometry. J Occup Med Toxicol 2006, doi:10.1186/1745-6673-1-5. 
15. Van Hoydonck PG, Wuyts WA, Vanaudenaerde BM, Schouten EG, Dupont L, Temme EH. Quantitative analysis of 8-isoprostane and hydrogen peroxide in exhaled breath condensate. Eur Respir J 2004; 23: 189-192.

16. Kharitonov SA. Exhaled markers of inflammatory lung diseases: ready for routine monitoring? Swiss Med Wkly 2004; 134: 175-192.

17. Rahman I, Biswas SK. Non-invasive biomarkers of oxidative stress: reproducibility and methodological issues. Redox Rep 2004; 9: 125-143.

18. Goldoni M, Caglieri A, Andreoli R, Poli D, Manini P, Vettori MV, Corradi M, Mutti A. Influence of condensation temperature on selected exhaled breath parameters. $B M C$ Pulmonary Medicine 2005, doi: 10.1186/1471-2466-5-10.

19. Nowak D, Kalucka $\mathrm{S}$, Bialasiewicz $\mathrm{P}$, Krol M. Exhalation of $\mathrm{H}_{2} \mathrm{O}_{2}$ and thiobarbituric acid reactive substances (TBARs) by healthy subjects. Free Radic Biol Med 2001; 30: 178-186.

20. Schleiss MB, Holz O, Behnke M, Richter K, Magnussen H, Jorres RA. The concentration of hydrogen peroxide in exhaled air depends on expiratory flow rate. Eur Respir $J$ 2000; 16: 1115-1118.

21. Rahman I. Reproducibility of oxidative stress biomarkers in breath condensate: are they reliable? Eur Respir J 2004; 23: 183-184.

22. American Thoracic Society. Workshop Proceedings: Exhaled nitric oxide and nitric oxide oxidative metabolism in exhaled breath condensate. Proc Am Thorac Soc 2006; 3: $131-145$.

23. Sack U, Scheibe R, Wötzel M, Hammerschmidt S, Kuhn H, Emmrich F, Hoheisel G, Wirtz H, Gessner C. Multiplex analysis of cytokines in exhaled breath condensate. Cytometry A 2006; 69: 169-172.

24. Gessner C, Scheibe R, Wötzel M, Hammerschmidt S, Kuhn H, Engelmann L, Hoheisel G, Gillissen A, Sack U, Wirtz H. Exhaled breath condensate cytokine patterns in chronic obstructive pulmonary disease. Respir Med 2005; 99: 1229-1240.

25. Matsunaga K, Yanagisawa S, Ichikawa T, Ueshima K, Akamatsu K, Hirano T, Nakanishi M, Yamagata T, Minakata Y, Ichinose M. Airway cytokine expression measured by means of protein array in exhaled breath condensate: correlation with physiologic properties in asthmatic patients. J Allergy Clin Immunol 2006; 118: 84-90.

26. Schumann C, Triantafilou K, Krueger S, Hombach V, Triantafilou M, Becher G, Lepper PM. Detection of erythropoietin in exhaled breath condensate of nonhypoxic subjects using a multiplex bead array. Mediators Inflamm 2006, doi:10.1155/MI/2006/18061.

27. Caglieri A, Goldoni M, Acampa O, Andreoli R, Vettori MV, Corradi M, Apostoli P, Mutti $A$. The effect of inhaled chromium on different exhaled breath condensate biomarkers among chrome-plating workers. Environ Health Perspect 2006; 114 : 542-546.

28. Tufvesson E, Bjermer L. Methodological improvements for measuring eicosanoids and cytokines in exhaled breath condensate. Respir Med 2006; 100: 34-38.

29. Soyer OU, Dizdar EA, Keskin O, Lilly C, Kalayci O. Comparison of two methods for exhaled breath condensate collection. Allergy 2006; 61: 1016-1018.

30. Prieto L, Ferrer A, Palop J, Domenech J, Llusar R, Rojas R. Differences in exhaled breath condensate $\mathrm{pH}$ measurements between samples obtained with two commercial devices. Respir Med 2007, doi: 10.1016/j.rmed.2007.02.023. 


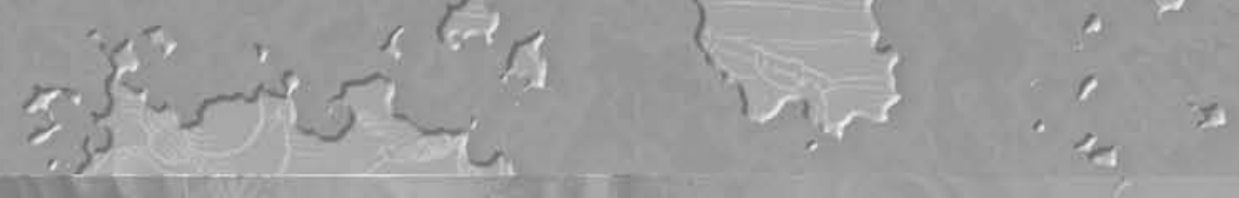

4

$$
\begin{aligned}
& \text { क } \\
& \text { i 1 } 95
\end{aligned}
$$

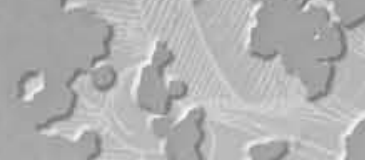

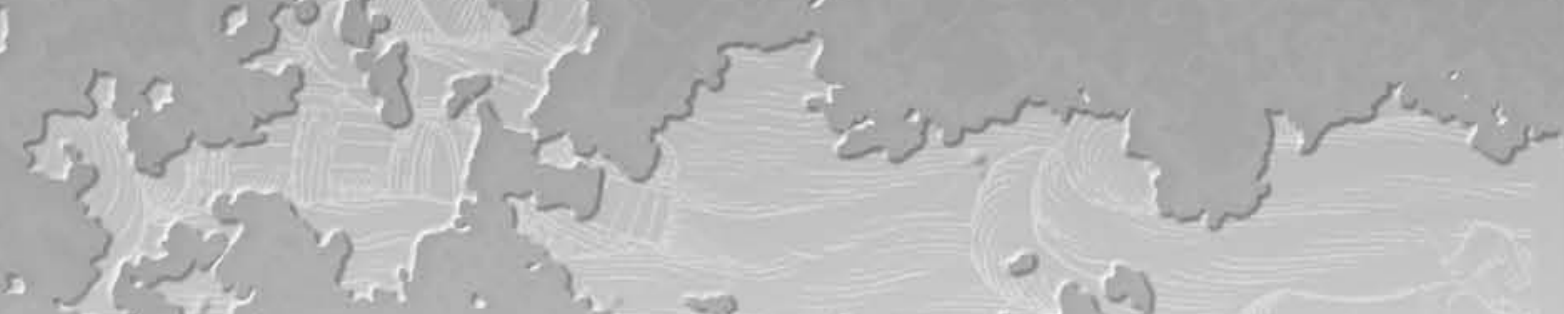

मुड़ी जन : का कर

$52,\{8$

i)

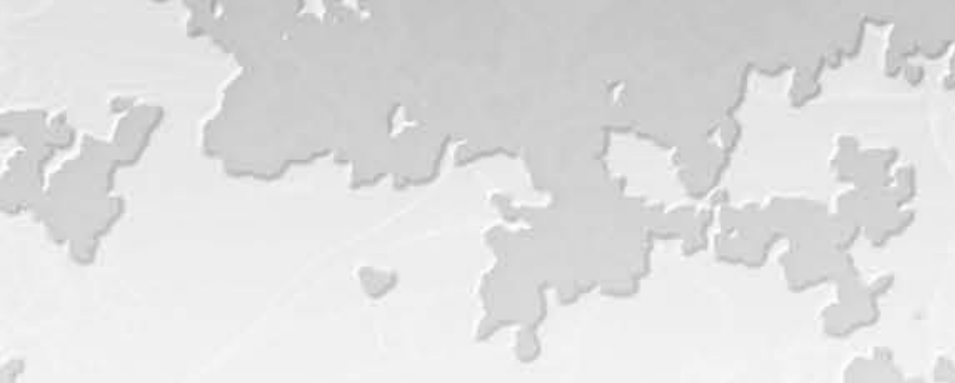

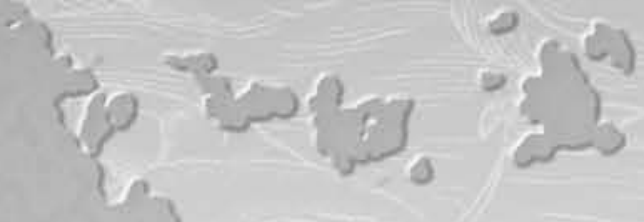

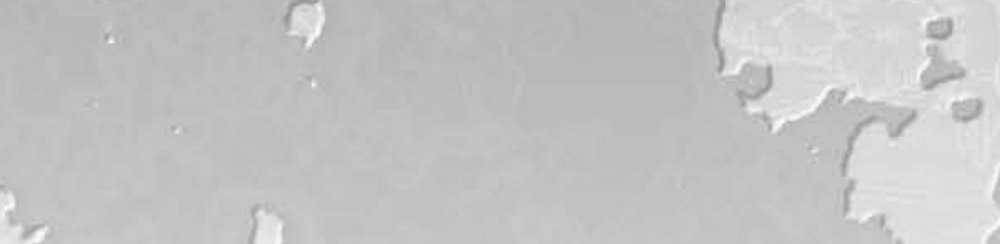




\section{CHAPTER 6}

\section{Free Radicals in Exhaled Breath Condensate in}

Cystic Fibrosis and Healthy Subjects

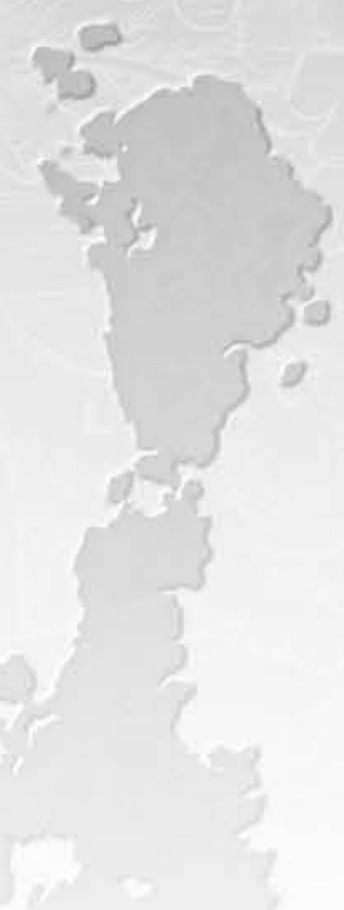

Rosias PPR, den Hartog GJM, Robroeks CMHHT, Bast A, Donckerwolcke RAMG, Heynens JWCM, Suykerbuyk J, Hendriks HJE, Jöbsis Q, Dompeling E. Free Radical Research 2006; 40: 901-909. 


\section{Abstract}

Many markers of airway inflammation and oxidative stress can be measured noninvasively in exhaled breath condensate. However, no attempt has been made to directly detect free radicals using electron paramagnetic resonance spectroscopy.

Condensate was collected in 14 children with cystic fibrosis and seven healthy subjects. Free radicals were trapped by 5,5-dimethyl-1-pyrroline-N-oxide. Electron paramagnetic resonance spectra were recorded using a Bruker $E M X^{\circledR}$ spectrometer. Secondly, to study the source of oxygen centered radical formation, catalase or hydrogen peroxide was added to the condensate.

Radicals were detected in 18 out of 21 condensate samples. Analysis of spectra indicated that both oxygen and carbon centered radicals were trapped. Within-subject reproducibility was good in all but one subject. Quantitatively, there was a trend towards higher maximal peak heights of both oxygen and carbon centered radicals in the children with cystic fibrosis. Catalase completely suppressed the signals in condensate. Addition of hydrogen peroxide resulted in increased radical signal intensity.

Detection of free radicals in exhaled breath condensate of children with cystic fibrosis and healthy subjects is feasible using EPR spectroscopy. 


\section{Introduction}

The collection of exhaled breath condensate (EBC) is a simple and noninvasive technique to measure mediators of airway inflammation. EBC consists not only of water vapor, but also contains aerosolized respiratory fluid droplets released from the respiratory epithelial lining fluid. These fluid droplets contain traces of nonvolatile solutes, which can be recovered in EBC samples ${ }^{1}$. EBC is collected by guiding and cooling exhaled air of a tidally breathing subject through a condenser system. The collection of EBC does not disturb the airways, in contrast to bronchial biopsy, bronchoalveolar lavage and induced sputum, and thus, can be obtained with minimal risk and inconvenience in both adults and children ${ }^{2}$. Many inflammatory mediators, such as 8-isoprostane, have been demonstrated in EBC of adults and children with chronic inflammatory lung diseases ${ }^{3-12}$.

Oxidative stress appears to play an important role in several inflammatory lung diseases, including asthma and cystic fibrosis. Oxidative stress is defined as an imbalance between oxidants (reactive oxygen species, and reactive nitrogen species) and antioxidants (superoxide dismutase, catalase, glutathione, uric acid, lactoferrin, vitamin C, vitamin E) in favor of oxidants ${ }^{13}$. By virtue of their unpaired electrons, many reactive oxygen species are unstable compounds, capable of initiating widespread oxidative events. Increased production of reactive oxygen species has been directly linked to protein, DNA and lipid oxidation, which may cause direct lung injury or induce a variety of cellular responses, through the generation of secondary metabolic reactive species ${ }^{14}$.

The measurement of F2-isoprostanes is currently the most reliable approach to assess oxidative stress status in vivo ${ }^{11}$. In EBC, 8-isoprostane can be measured in both adults and children, although reproducibility remains controversial 11-12,15-16. On the other hand, spin trapping is the only direct method for the detection of free radicals ${ }^{14,17}$. Reactive oxygen and nitrogen species can be detected by electron paramagnetic resonance spectroscopy using various spin traps, e.g. 5,5-dimethyl-1-pyrroline N-oxide (DMPO) $14,18,19$.

However, as the increased production of radicals appears to play an important role in inflammatory lung diseases, as far as we know, no attempt has been made to detect free radicals in EBC. The aim of this study was the detection of free radicals in EBC of children with cystic fibrosis using electron paramagnetic resonance spectroscopy.

\section{Materials and methods Study subjects}

EBC was collected in 14 children with cystic fibrosis, routinely attending the cystic fibrosis centre of the Maastricht University Hospital, and seven healthy controls (including one adult). Cystic fibrosis was defined as a positive quantitative sweat test in conjunction with chronic airway obstruction and/or recurrent infections of the airways and/or exocrine pancreatic insufficiency and maldigestion. Children with cystic 
fibrosis were clinically stable at the time of the assessment. Healthy subjects were asked to complete a standardized questionnaire of the International Study of Asthma and Allergies in Childhood (ISAAC) in order to exclude the presence of asthma or allergic disease ${ }^{20}$. The subject characteristics are shown in Table I. The study was approved by the medical ethical committee of the University of Maastricht.

Table I. Subject characteristics.

\begin{tabular}{|c|c|c|}
\hline & Cystic fibrosis & Healthy subjects \\
\hline Number of subjects & 14 & 7 \\
\hline Age (years) & $14(6-17)^{*}$ & $13(9-25)^{*}$ \\
\hline Male / female ratio & $9 / 5$ & $4 / 3$ \\
\hline Weight $(\mathrm{kg})$ & $38(18-60)^{*}$ & $44(37-85)^{*}$ \\
\hline Height $(\mathrm{cm})$ & $153(114-176)^{*}$ & $164(144-179)^{*}$ \\
\hline $\mathrm{FEV}_{1}$ (\%predicted) & $66(31-108)^{*}$ & - \\
\hline Use of corticosteroids & 4 & 0 \\
\hline Use of antibiotics & 4 & 0 \\
\hline
\end{tabular}

\section{Collection of exhaled breath condensate}

Each subject was asked to exhale tidally, while wearing a nose clip, through a mouthpiece connected to a two-way non-rebreathing valve and a cooled $\left(0^{\circ} \mathrm{C}\right)$ double-jacketed 50 $\mathrm{cm}$ borosilicate glass tube as shown in figure 1 and described previously ${ }^{3,10}$. In order to prevent salivary contamination of EBC samples, the two-way valve and tubing were used as a saliva gravity trap. Condensate was collected at the open end of the glass condenser, as shown in figure 1, directly into vials containing spin trap (DMPO) (Table II). Thus, no resistance was created during exhalation. Each vial was wrapped in aluminum paper to

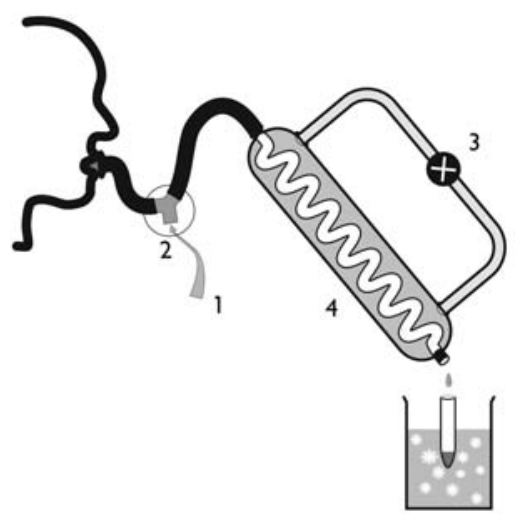

The subject breaths tidally and inhales room air (1) through a two-way nonrebreathing valve (2). Exhaled air is guided by the tubing through a double-wall glass condenser (4), which is cooled by a counter-current circulating ice-water pump (3). The two-way non-rebreathing valve (2) and tubing also serve as a saliva trap.

Figure 1. Schematic representation of the exhaled breath condensate collection device. 
protect DMPO against daylight. The condensate collection continued until the minimal required volume of EBC was obtained necessary to perform one test (Table II). Samples were analyzed immediately. Four different test conditions were applied, as shown in Table II. Test 1-4 were performed to study DMPO-condensate samples under different volumes and concentrations of EBC and DMPO (Table II).

Table II. Specific test conditions.

\begin{tabular}{lllll} 
& CF & Healthy & EBC & DMPO \\
\hline Test 1 & 2 & 1 & $1 \mathrm{~mL}$ & $1 \mathrm{~mL}(50 \mathrm{mM})$ \\
Test 2 & 4 & - & $0.5 \mathrm{~mL}$ & $0.5 \mathrm{~mL}(100 \mathrm{mM})$ \\
Test 3 & 5 & 6 & $0.5 \mathrm{~mL}$ & $0.25 \mathrm{~mL}(100 \mathrm{mM})$ \\
Test 4 & 3 & - & $0.3 \mathrm{~mL}$ & $0.25 \mathrm{~mL}(100 \mathrm{mM})$ \\
\hline
\end{tabular}

CF number of cystic fibrosis patients

Healthy number of healthy subjects

EBC volume of collected exhaled breath condensate

DMPO volume and (concentration) of spin trap (5,5-dimethyl-1-pyrroline $\mathrm{N}$-oxide)

\section{Electron paramagnetic resonance spectroscopy}

Electron paramagnetic resonance spectra of the DMPO trapped radicals were recorded at room temperature using a Bruker $E M X^{\circledR}$ electron paramagnetic resonance spectrometer (Bruker Biospin GmbH, Karlsruhe, Germany). The experimental conditions were as follows: Klystron frequency $9.85 \mathrm{GHz}$, microwave power $30 \mathrm{~mW}$, field

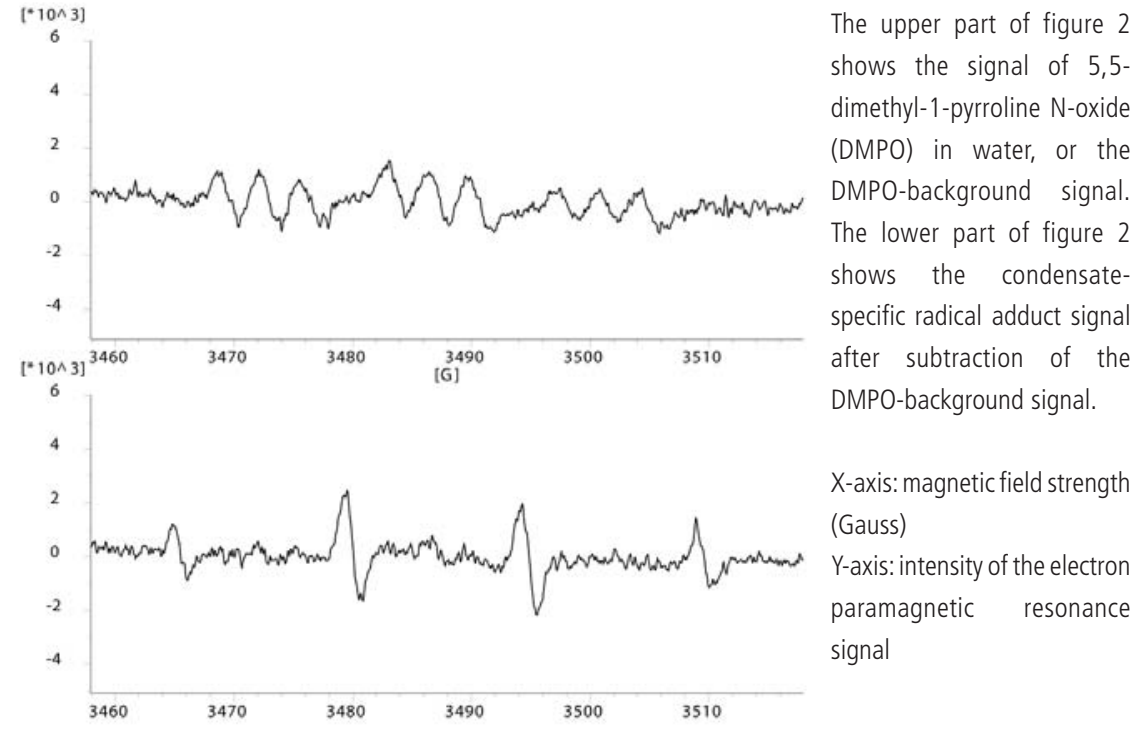

Figure 2. The DMPO-background signal and the condensate-specific radical adduct signal. 
modulation amplitude $2 \mathrm{G}$ at $100 \mathrm{kHz}$ frequency, time constant $40.96 \mathrm{msec}$ and $1.0 \mathrm{x}$ $10^{6}$ gain, and a sweep width of $60 \mathrm{G}$. Each sample was scanned 50 times. The signal of DMPO in $\mathrm{H}_{2} \mathrm{O}$ was subtracted from the DMPO-condensate signal to obtain condensate-specific spectra (Figure 2).

Within-subject reproducibility of the electron paramagnetic resonance signals was assessed in five subjects by measuring electron paramagnetic resonance spectra in EBC collected with a one-hour interval. The results were expressed as coefficients of variation (CV $=[S D /$ mean $] \times 100 \%)$.

In order to quantify the method, we assigned to each electron paramagnetic resonance signal an arbitrary unit derived from it's maximal peak height, as illustrated in figure 3.

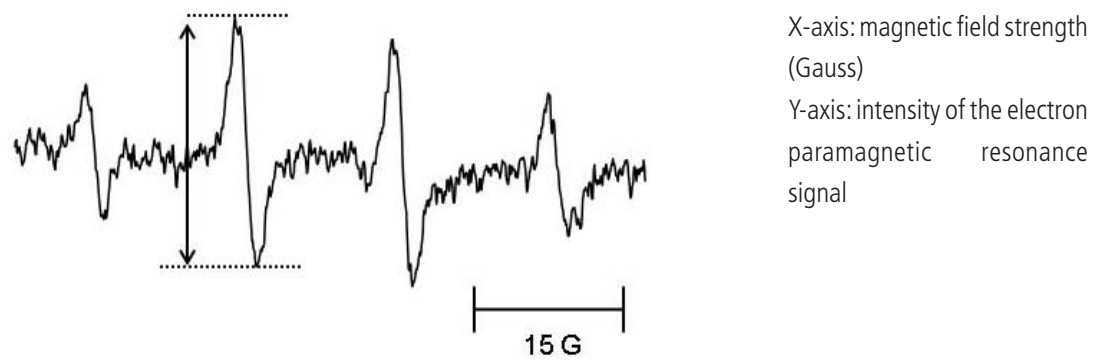

Figure 3. Quantification of electron paramagnetic resonance spectra in exhaled breath condensate by assessing maximal peak height in arbitrary units.

Additionally, test $A$ and $B$ were designed to study the source of oxygen centered radical formation. In test $A$, catalase (50 $\mu \mathrm{L}$ of a $5000 \mathrm{U} / \mathrm{mL}$ catalase solution) was added to the DMPO vials of test three. Catalase converts hydrogen peroxide in water and oxygen. Therefore, catalase was expected to reduce free radical signals derived from hydrogen peroxide. In test $\mathrm{B}$, hydrogen peroxide $(2 \mu \mathrm{L}$ of a $9.7 \mathrm{M}$ hydrogen peroxide solution) was added to the DMPO vials of test four. When hydrogen peroxide is considered to be the main source of free radical generation, hydrogen peroxide should amplify free radical signals.

Finally, saliva and sputum were investigated on the presence of free radical signals, in order to exclude free radical contamination by these biofluids.

\section{Results}

The median duration of EBC collection was 16.5 minutes (range 13-18 minutes). As shown in Table III, optimal capture of free radical adducts was obtained using 0.25$0.50 \mathrm{~mL}$ DMPO $(100 \mathrm{mM})$ and $0.5 \mathrm{~mL}$ condensate. Free radical adduct signals were detected in 18 out of 21 DMPO-condensate samples of children with cystic fibrosis and healthy controls (Table III). 
Table III. Detection of oxygen ( 0 ) and carbon (C) centered radical adduct signals in exhaled breath condensate of children with cystic fibrosis and healthy controls.

\begin{tabular}{lllllll} 
& \multicolumn{3}{l}{ Cystic Fibrosis } & \multicolumn{3}{l}{ Healthy Controls } \\
\hline & 0 & $\mathrm{C}$ & 0 or C & 0 & $\mathrm{C}$ & 0 or C \\
\hline Test 1 & $1 / 2$ & $0 / 2$ & $1 / 2$ & $0 / 1$ & $0 / 1$ & $0 / 1$ \\
Test 2 & $1 / 4$ & $3 / 4$ & $4 / 4$ & - & - & - \\
Test 3 & $5 / 5$ & $3 / 5$ & $5 / 5$ & $6 / 6$ & $4 / 6$ & $6 / 6$ \\
Test 4 & $2 / 3$ & $0 / 3$ & $2 / 3$ & - & - & - \\
Total & & & $12 / 14$ & & & $6 / 7$ \\
\hline
\end{tabular}

0 number of oxygen centered radical adduct signals to number of subjects

C number of carbon centered radical adduct signals to number of subjects

0 or $\mathrm{C}$ number of free radical adduct signals to number of subjects

Total total number of free radical adduct signals to total number of subjects

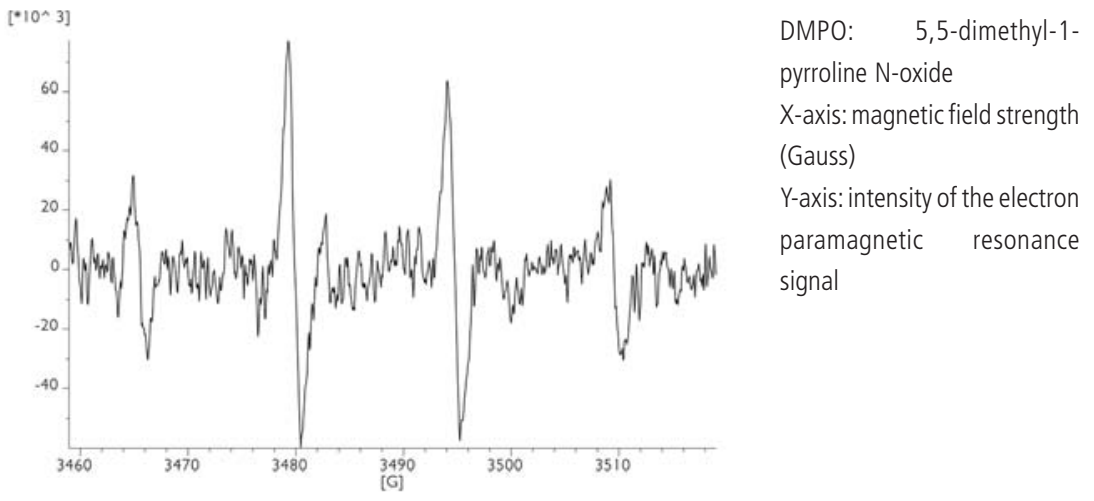

Figure 4A. Oxygen (1:2:2:1) centered radical adduct signal in the mixture of condensate and spin trap (DMPO).

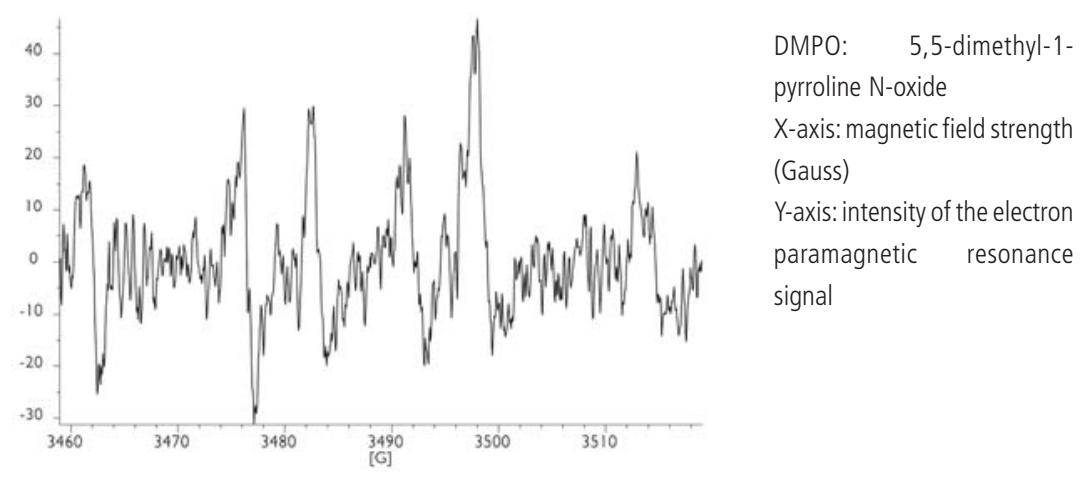

Figure 4B. Carbon (1:1:1:1:1:1) centered radical adduct signal in the mixture of condensate and spin trap (DMPO). 
Analysis of electron paramagnetic resonance spectra indicated that both oxygen and carbon centered radicals were trapped by DMPO, as shown in Figure 4A and 4B respectively.

Within-subject reproducibility of electron paramagnetic resonance spectra in EBC was good in four subjects (coefficients of variation ranged from five to twelve percent) (figure 5). However, in one subject the coefficient of variation was $87 \%$.

\section{within-subject reproducibility}

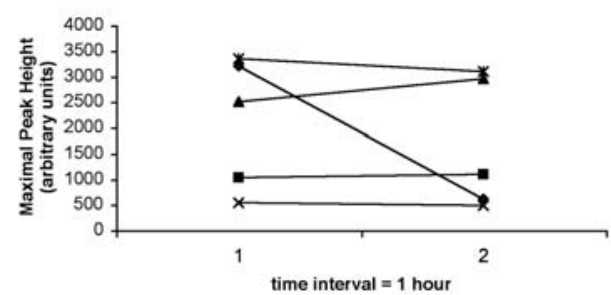

Within-subject reproducibility was assessed in five subjects by measuring electron paramagnetic resonance spectra in exhaled breath condensate that was collected twice with $1 \mathrm{hr}$ time interval. The coefficients of variation were $87,5,12,8$ and $5 \%$ respectively.

Figure 5. Within-subject reproducibility of electron paramagnetic resonance spectra in exhaled breath condensate.

Quantitative results expressed as maximal peak height (in arbitrary units) of both oxygen and carbon centered radicals in children with cystic fibrosis and healthy controls had a normal distribution and are shown in figure 6. The maximal peak heights of oxygen as well as carbon centered radical adduct signals seemed higher in the cystic fibrosis group compared with the healthy controls. However, the difference in oxygen and carbon centered radicals failed to reach statistical significance $(p=0.828$ and $p=0.253$ respectively, Student's t-test).

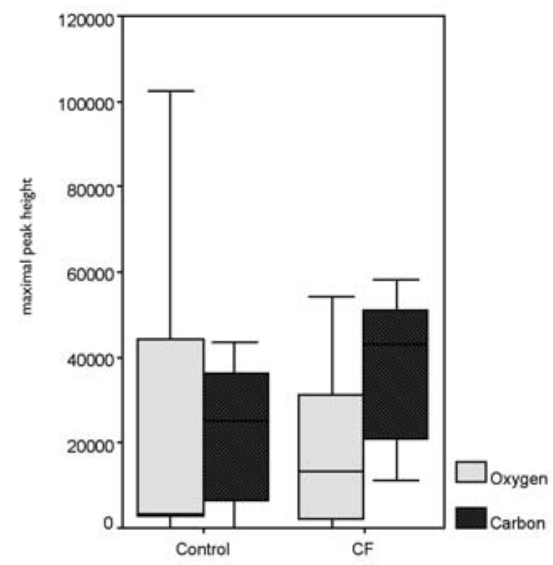

The maximal peak height of oxygen centered radical adduct signals (oxygen) and carbon centered radical adduct signals (carbon) did not differ significantly between the children with cystic fibrosis (CF) and healthy control group ( $p=0.828$ and $p=0.253$ respectively, t-test).

Figure 6. Quantitative results expressed as maximal peak height (in arbitrary units) of both oxygen and carbon centered radical adduct signals in exhaled breath condensate in children with cystic fibrosis and healthy controls. 
Catalase completely suppressed most oxygen centered radical adduct signals in EBC of children with cystic fibrosis (four out of five) and healthy controls (three out of six) (Figure 7A). On the other hand, addition of hydrogen peroxide resulted in a substantial increase of oxygen centered radical adduct signals in EBC of children with cystic fibrosis (two out of three) (Figure 7B).

Saliva contained little or no free radicals (three out of four samples were negative). It was not possible to detect free radicals in sputum $(n=1)$ due to its viscosity.

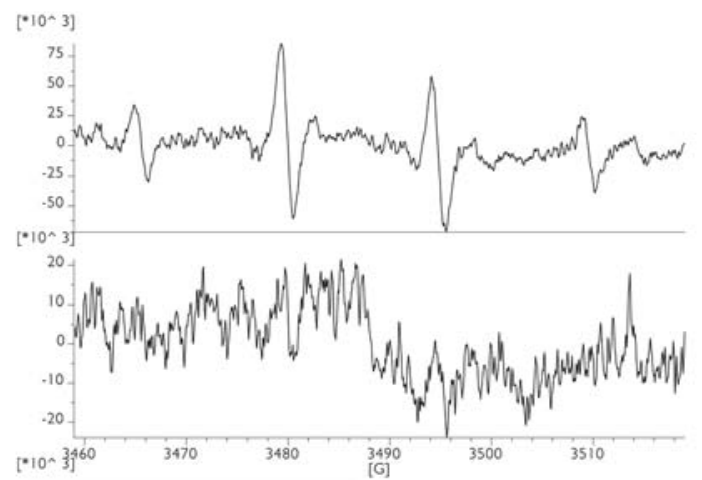

The upper part of figure 7A shows an oxygen centered radical adduct signal in the mixture of condensate and spin trap (5,5-dimethyl-1-pyrroline $\mathrm{N}$ oxide, or DMPO). The lower part of figure 7A shows that subsequent addition of catalase results in suppression of the oxygen centered radical adduct signal.

$X$-axis: magnetic field strength (Gauss)

Y-axis: intensity of the electron paramagnetic resonance signal

Figure 7A. Suppression of oxygen centered radical adduct signal in the mixture of condensate, spin trap (DMPO) and catalase.

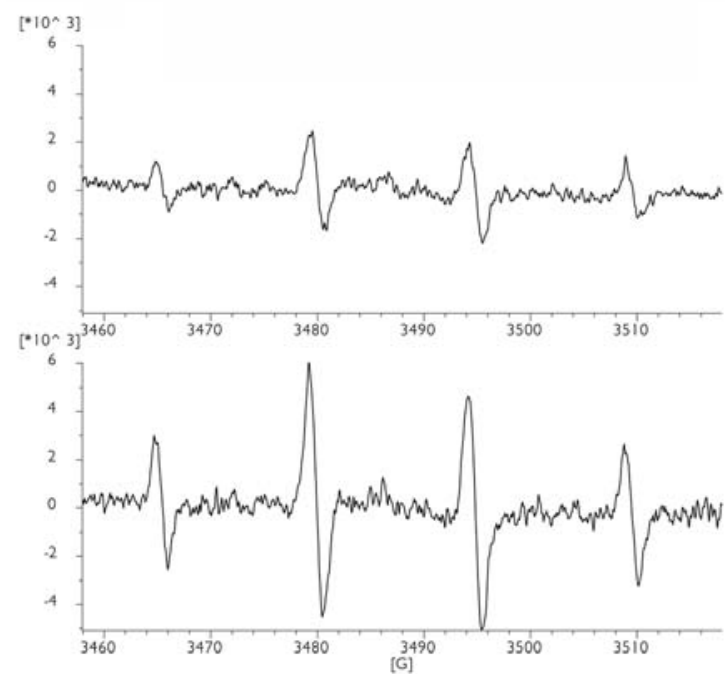

The upper part of figure 7B shows an oxygen centered radical adduct signal in the mixture of condensate and spin trap (5,5-dimethyl-1-pyrroline $\mathrm{N}$ oxide, or DMPO). The lower part of figure $7 \mathrm{~B}$ shows that subsequent addition of hydrogen peroxide results in amplification of the oxygen centered radical adduct signal.

$X$-axis: magnetic field strength (Gauss)

Y-axis: intensity of the electron paramagnetic resonance signal

Figure 7B. Amplification of oxygen centered radical adduct signal in the mixture of condensate, spin trap (DMPO) and hydrogen peroxide. 


\section{Discussion}

The presence of oxidative stress in children with cystic fibrosis was assessed by direct measurement of free radicals in EBC using electron paramagnetic resonance spectroscopy. Oxygen as well as carbon centered radicals were trapped by DMPO in EBC in children with cystic fibrosis and healthy controls. Quantification demonstrated a difference that failed to reach statistical significance. Short-term reproducibility was good, except in one subject. Furthermore, most oxygen centered radical adduct signals were completely suppressed by catalase, while signal amplification by hydrogen peroxide was observed, indicating that hydrogen peroxide is a main source for the generation of free radicals in EBC.

Although within-subject reproducibility was good in four subjects, reproducibility was questionable in one subject, maybe as a consequence of physical exertion between the two tests.

Our quantitative approach using maximal peak height of an electron paramagnetic resonance signal in EBC did not show a statistical significant difference in oxygen or carbon centered radicals, between the cystic fibrosis children and healthy controls. However, there was a trend towards higher maximal peak heights of both oxygen and carbon centered radicals in the cystic fibrosis group, that may reach statistical significance in a larger study population.

Various indirect biomarkers of oxidative stress in condensate of subjects with chronic respiratory inflammation are known, as recently reviewed ${ }^{3,14}$. Currently, comparative reports on the direct measurement of free radicals in EBC are, to our knowledge, not available.

Oxidative stress appears to play an important role in several inflammatory lung diseases. It is defined as an imbalance between oxidants (reactive oxygen species, reactive nitrogen species) and antioxidants (e.g. catalase) in favor of oxidants ${ }^{13}$. Chronic inflammatory lung diseases, such as asthma and cystic fibrosis, are characterized by the activation of epithelial cells and resident macrophages, and the recruitment and activation of neutrophils, eosinophils, monocytes and lymphocytes ${ }^{14}$. The activation of macrophages, neutrophils and eosinophils results in the generation of reactive oxygen species ${ }^{14}$. Lung epithelial cells also release reactive oxygen species, and when this occurs these substances stimulate inflammatory cells directly, thereby amplifying lung inflammatory and oxidant events ${ }^{14,21}$.

By virtue of their unpaired electrons, oxygen species are reactive compounds, that cause widespread oxidative events ${ }^{14}$. One such species, the superoxide anion, is rapidly reduced to hydrogen peroxide by superoxide dismutase ${ }^{14}$. The combination of hydrogen peroxide with transition metal ions yields the hydroxyl radical ${ }^{14}$. Reactive oxygen and nitrogen species can also be generated intracellular from several sources, including mitochondrial respiration, the NADPH oxidase system and xanthine/xanthine 
oxidase, leading to cell necrosis or apoptosis ${ }^{14}$. When generated close to cell membranes, the reactive oxygen species oxidize membrane phospholipids (lipid peroxidation) ${ }^{14}$. This initiates a chain reaction, which in turn leads to the generation and accumulation of lipid peroxidation products such as malondialdehyde, F2isoprostanes, 4-hydroxy-2-nonenal and acrolein ${ }^{14}$. The peroxidative breakdown of polyunsaturated fatty acids within the membrane impairs function, inactivates membrane-bound receptors and enzymes and increases tissue permeability and cell fragility ${ }^{14}$. In addition to their cytotoxic properties, lipid peroxides are increasingly recognized as being important in redox-sensitive signal transduction pathways, especially those activated during an inflammatory response $14,22,23$.

To study the source of the formation of oxygen centered radicals, two additional tests (test $A$ and $B$ ) were performed. Test $A$ shows the absence of a radical adduct signal in the mixture condensate, catalase and spin trap (in seven out of eleven samples), which suggests that hydrogen peroxide may play an important role in the generation of oxygen centered radicals measured in EBC after spin trapping. Increased concentrations of hydrogen peroxide in EBC have been demonstrated in patients with asthma and cystic fibrosis ${ }^{3}$. In sixteen children with cystic fibrosis, Jöbsis et al reported increased hydrogen peroxide levels in EBC, and a significant decrease of these levels during intravenous antibiotic treatment ${ }^{24}$. Test $B$ demonstrates an increased formation of most oxygen centered radicals (in two out of three samples), after addition of hydrogen peroxide. These amplified electron paramagnetic resonance signals suggests that EBC may contain compounds that enable the formation of radicals from hydrogen peroxide, such as transition metal ions and/or compounds that reduce these ions to their Fenton active states. Griese and co-workers found higher concentrations of zinc in EBC in cystic fibrosis patients, compared to healthy controls ${ }^{25}$. Zinc is known as a redox-active metal that may generate both hydrogen peroxide and hydroxyl radicals by Fenton reaction ${ }^{26}$.

Carbon centered radicals may originate from various sources, such as fatty acids, alkane, ethanol or carbohydrates. However, we are not able to exclude with certainty whether free radicals are formed in situ in the collection vial. A possible explanation for the presence of carbon centered radicals, in the absence of oxygen centered radicals, may be that carbon-containing molecules react with hydroxyl radicals. By consequence, carbon containing molecules become carbon centered radicals and the former hydroxyl radical is no longer an oxygen centered radical. Similarly, hydroxyl radicals may be formed in situ from hydrogen peroxide in the presence of certain compounds such as transition metals. In order to reduce the risk of in situ free radical formation, one may develop a collecting device that allows direct contact between exhaled air and a DMPO containing filter. Spin trapping remains highly dependent on the spin trap used and the antioxidant status of the condensate ${ }^{27}$. Furthermore, the outcome of electron paramagnetic resonance results is not only influenced by the amount of free radicals trapped by constituent compounds of the EBC and the presence of some electrolyte ions, such as sodium and potassium, but also influenced by the spin trap-free radical interaction (each free radical has a specific affinity for a given spin trap) ${ }^{27}$. 
Finally, as most saliva samples were negative, free radicals in $E B C$ do not likely result from contamination with this biofluid. This suggests that free radicals in EBC may originate from the lower respiratory tract, providing further support that EBC reflects the epithelial lining fluid.

Free radicals were also present in condensate of healthy subjects. This may not be surprising, considering that the lung normally exists in an oxygen rich environment which makes it susceptible to oxidative stress, and considering that electron paramagnetic resonance spectroscopy allows direct but semi-quantitative measurement of free radicals ${ }^{14,28}$. We did not find free radicals in three out of 21 condensate samples, including one healthy control, one child with cystic fibrosis on longterm prednison treatment, and one child with cystic fibrosis on antibiotics. Corticosteroids may have an antioxidant effect by decreasing the numbers as well as the oxidative and chemotactic responses of neutrophils, whereas antibiotics may have a certain role in reducing oxidative stress by reducing infection and thereby lung inflammation ${ }^{29}$.

We aimed at assessing the potential use of electron paramagnetic resonance spectroscopy in the detection of free radicals in EBC in children with cystic fibrosis and healthy subjects. Future studies should include a larger number of subjects and a wider range of disease severity, with repeated measurements of conventional markers and free radicals in EBC.

Other disturbing factors may include counteracting effects of exercise, dietary components, diurnal rhythm, duration of EBC collection and analysis, partial exposition of DMPO to daylight, environmental temperature and inhaled air particles of diverse origin $27,30,31$.

As we report on a more direct and noninvasive assessment of oxidative stress, one may speculate on clinical implications. However, the future challenge is to define the source of free radical formation, and to extend our understanding of the discriminative power of electron paramagnetic resonance spectroscopy in the detection of (exacerbations of) chronic lung disease, monitoring of disease severity, and disease progression.

We conclude that detection of free radicals in EBC of children with cystic fibrosis and healthy subjects is feasible using electron paramagnetic resonance spectroscopy. Furthermore, it is likely that hydrogen peroxide is crucial for the generation of oxygen centered radicals detected in EBC. Moreover, EBC may also contain compounds that enable radical formation.

\section{Acknowledgements}

The authors wish to thank the patients and healthy volunteers for their participation in this study. 


\section{References}

1. Scheideler L, Manke HG, Schwulera U, Inacker O, Hämmerle H. Detection of nonvolatile macromolecules in breath. A possible diagnostic tool? Am Rev Respir Dis 1993; 148: 778-784.

2. Baraldi E, Ghiro L, Piovan V, Carraro S, Zacchello F, Zanconato S. Safety and success of exhaled breath condensate collection in asthma. Arch Dis Child 2003; 88: 358360.

3. Rosias PPR, Dompeling E, HJE Hendriks, JWCM Heijnens, RAMG Donckerwolcke, Q Jöbsis. Exhaled breath condensate in children: pearls and pitfalls. Pediatr Allergy Immunol 2004; 15: 4-19.

4. Mutlu GM, Garey KW, Robbins RA, Danziger LH, Rubinstein I. Collection and analysis of exhaled breath condensate in humans. Am J Respir Crit Care Med 2001; 164: 731737.

5. Kharitonov SA, Barnes PJ. Exhaled markers of pulmonary disease. Am J Respir Crit Care Med 2001; 163: 1693-1722.

6. Montuschi P, Barnes PJ. Analysis of exhaled breath condensate for monitoring airway inflammation. Trends Pharmacol Sci 2002; 23: 232-237.

7. Montuschi P. Indirect monitoring of lung inflammation. Nat Rev Drug Discov 2002; 1: $238-242$.

8. Hunt J. Exhaled breath condensate: an evolving tool for noninvasive evaluation of lung disease. J Allergy Clin Immunol 2002; 110: 28-34.

9. Antczak A, Gorski P. Markers of pulmonary diseases in exhaled breath condensate. Int J Occup Med Environ Health 2002; 15: 317-323.

10. Rosias PPR, Dompeling E, Dentener MA, Pennings HJ, Hendriks JJE, Van lersel MPA, Jöbsis Q. Childhood asthma: exhaled markers of airway inflammation, asthma control score and lung function tests. Pediatr Pulmonol 2004; 38: 107-114.

11. Montuschi P, Barnes PJ, Roberts II LJ. Isoprostanes: markers and mediators of oxidative stress. FASEB J 2004; 18: 1791-1800.

12. Montuschi P, Corradi M, Ciabattoni G, Nightingale J, Kharitonov SA, Barnes PJ. Increased 8-isoprostane, a marker of oxidative stress, in exhaled breath condensate of asthma patients. Am J Respir Crit Care Med 1999; 160: 216-220.

13. Barnes PJ, Chung KF, Page CP. Inflammatory mediators of asthma: an update. Pharmacol Rev 1998; 50: 515-596.

14. Rahman I, Kelly F. Biomarkers in breath condensate: a promising new non-invasive technique in free radical research. Free Radic Res 2003; 37: 1253-1266.

15. Rahman I. Reproducibility of oxidative stress biomarkers in breath condensate: are they reliable? Eur Respir J 2004; 23: 183-184.

16. Rosias P, Robroeks C, Hendriks J, Dompeling E, Jöbsis Q. Exhaled breath condensate: a space odessey, where no one has gone before... Eur Respir J 2004; 24: 189-190.

17. Janzen EG. Spin trapping. Methods Enzymol 1984; 105: 188-198.

18. Buettner GR, Mason RP. Spin-trapping methods for detecting superoxide and hydroxyl free radicals in vitro and in vivo. Methods Enzymol 1990; 186: 127-133.

19. Berliner LJ, Khramtsov V, Fujii H, Clanton TL. Unique in vivo applications of spin traps. Free Radic Biol Med 2001; 30: 489-499. 
20. Asher MI, Keil U, Anderson HR, Beasley R, Crane J, Martinez F, Mitchell EA, Pearce N, Sibbald B, Stewart AW, Strachan D, Weiland SK, Wiliams HC. International study of asthma and allergies in childhood (ISAAC): rationale and methods. Eur Respir $J$ 1995; 8: 483-491.

21. Rochelle LG, Fischer BM, Adler KB. Concurrent production of reactive oxygen and nitrogen species by airway epithelial cells in vitro. Free Radic Biol Med 1998; 24: 863868.

22. Uchida K, Shiraishi M, Naito Y, Torii N, Nakamura Y, Osawa T. Activation of stress signaling pathways by the end product of lipid peroxidation. J Biol Chem 1999; 274: 2234-2242.

23. Parola M, Bellomo G, Robino G, Barrera G, Dianzani MU. 4-Hydroxynonenal as a biological signal: molecular basis and pathophysiological implications. Antioxid Redox Signal 1999; 1: 255-284.

24. Jöbsis Q, Raatgreep HC, Schellekens SL, Kroesbergen A, Hop WCJ, de Jongste JC. Hydrogen peroxide and nitric oxide in exhaled air of children with cystic fibrosis during antibiotic treatment. Eur Respir J 2000; 16: 95-100.

25. Griese M, Noss J, Schramel P. Elemental and ion composition of exhaled air condensate in cystic fibrosis. J Cyst Fibros 2003; 2: 136-142.

26. Jiménez Del Río M, Vélez-Pardo C. Transition metal-induced apoptosis in lymphocytes via hydroxyl radical generation, mitochondria dysfunction, and caspase-3 activation: an in vitro model for neurodegeneration. Arch Med Res 2004; 35: 185-193.

27. Rahman I, Biswas SK. Non-invasive biomarkers of oxidative stress: reproducibility and methodological issues. Redox Rep 2004; 9: 125-143.

28. Caramori G, Papi A. Oxidants and asthma. Thorax 2004; 59: 170-173.

29. Repine JE, Bast A, Lankhorst I, and the Oxidative Stress Study Group. Oxidative stress in chronic obstructive pulmonary disease. Am J Respir Crit Care Med 1997; 156: 341 357.

30. Hubbard R, Fogarty A. The developing story of antioxidants and asthma. Thorax 2004; 59: 3-4.

31. Crapo JD. Oxidative stress as an initiator of cytokine release and cell damage. Eur Respir J 2003; 22(S44): 4s-6s. 
-35,

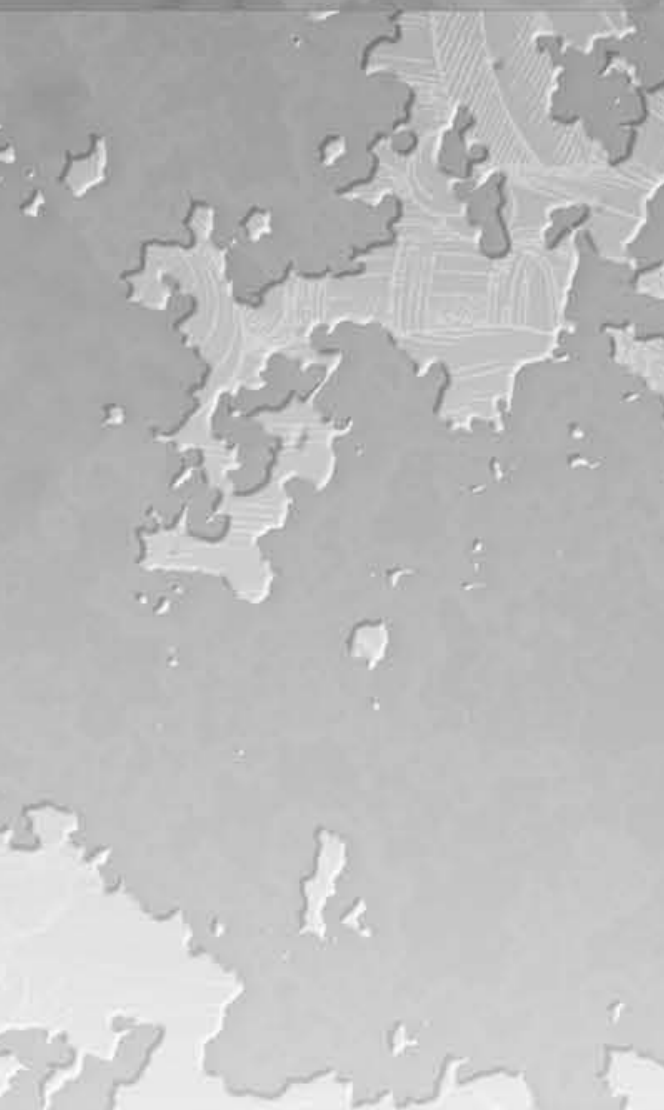

$$
\begin{aligned}
& \text { द. } \\
& +3 \frac{2}{5}
\end{aligned}
$$

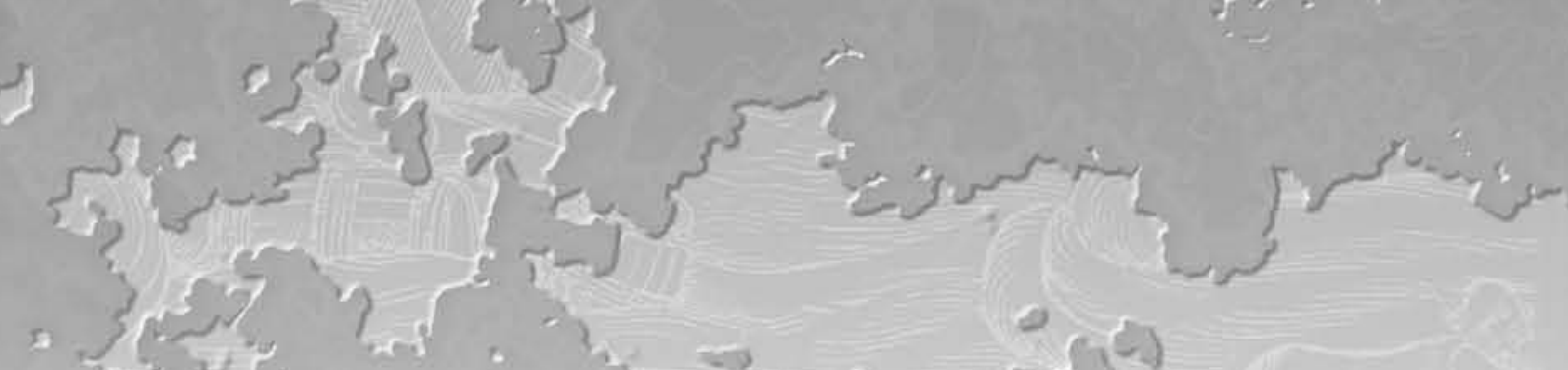

is

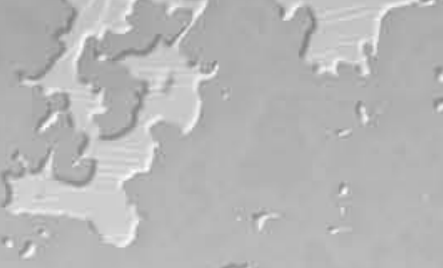

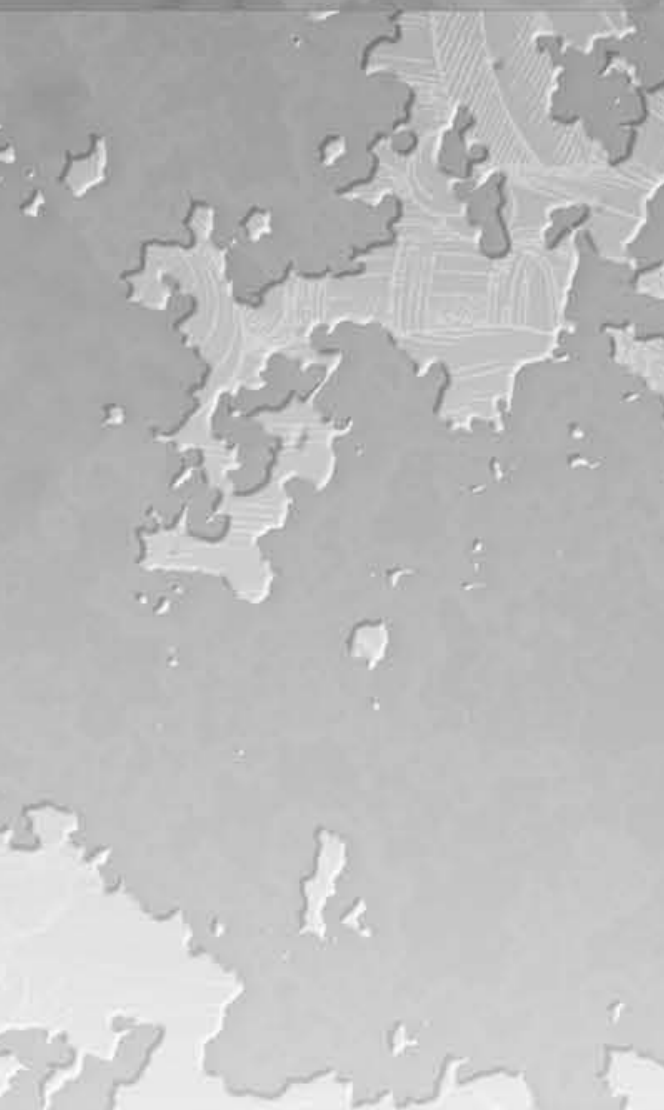

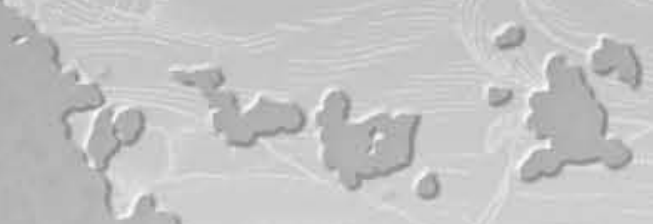

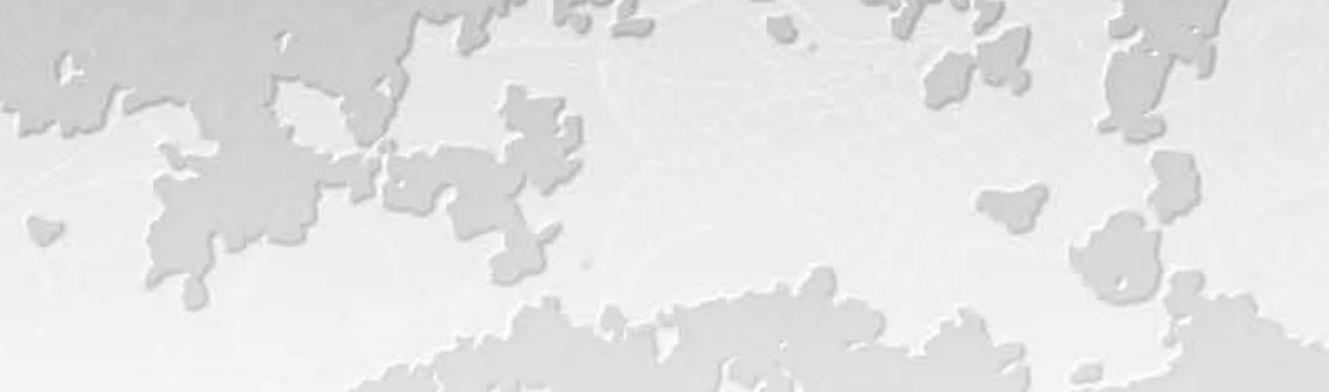

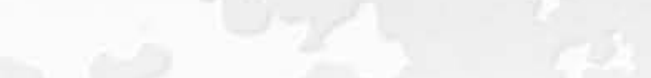




\section{CHAPTER 7}

\section{BIOMARKERS IN EXHALED BREATH CONDENSATE}

INDICATE PRESENCE AND SEVERITY

\section{OF CYSTIC FIBROSIS IN CHILDREN}

Robroeks CMHHT, Rosias PPR, van Vliet D, Jöbsis Q, Yntema J-BL, Brackel HJL, Damoiseaux JGMC, den Hartog GJM, Wodzig WKWH, Dompeling E.

Pediatric Allergy and Immunology; in press. 


\section{Abstract}

Chronic airway inflammation is present in cystic fibrosis. Noninvasive inflammometry may be useful in disease management. The aim of the present cross-sectional study in children with cystic fibrosis was to investigate: (i) the ability of fractional exhaled nitric oxide and other exhaled inflammatory markers (exhaled breath condensate acidity, nitrite, nitrate, hydrogen peroxide, 8-isoprostane, and Th1/Th2 cytokines) to indicate (exacerbations of) cystic fibrosis; and (ii) the ability of these noninvasive inflammatory markers to indicate disease severity in cystic fibrosis.

In 98 children (48 cystic fibrosis / 50 controls) exhaled nitric oxide was measured using the $\mathrm{NIOX}^{\circledR}$. Subsequently, exhaled breath condensate was collected and analysed, and lung function tests were performed by means of dynamic spirometry.

In cystic fibrosis, condensate interferon-gamma and nitrite concentrations were significantly higher, and exhaled nitric oxide levels were significantly lower, compared to controls $(3.3( \pm 0.3) \mathrm{pg} / \mathrm{mL}, 2.2( \pm 0.2) \mu \mathrm{M}, 10.0( \pm 1.2) \mathrm{ppb}$, versus $2.6( \pm 0.2) \mathrm{pg} / \mathrm{mL}$, $1.4( \pm 0.1) \mu \mathrm{M}, 15.4( \pm 1.4) \mathrm{ppb}$, respectively). Using multivariate logistic regression models, the presence of cystic fibrosis was best indicated by combined condensate 8isoprostane, nitrite and interferon-gamma (sensitivity $78 \%$, specificity $83 \%$; area under receiver operating characteristic curve $0.906, p<0.001$ ). An exacerbation of cystic fibrosis was best indicated by condensate 8-isoprostane and nitrite (sensitivity $40 \%$, specificity $97 \%$, area under receiver operating characteristic curve 0.838 , $\mathrm{p}=0.009$ ). Most indicative biomarkers of cystic fibrosis severity were exhaled nitric oxide, and condensate acidity (sensitivity $96 \%$, specificity $67 \%$; area under receiver operating characteristic curve $0.751, p=0.008$ ).

In this cross-sectional study in children, the combination of different exhaled inflammatory markers could indicate the presence of cystic fibrosis disease, exacerbation, and severity. Longitudinal data are necessary to further confirm the role of these exhaled markers in the management of cystic fibrosis in children. 


\section{Introduction}

Cystic fibrosis is an autosomal recessive disorder, caused by genetic mutations in the cystic fibrosis transmembrane conductance regulator protein. This results in impaired or absent transport of chloride through cell-membranes, with impaired mucociliary clearance, and viscous mucus in the airways. Moreover, defective mucociliary action results in inability of the airways to clear bacteria, e.g. Pseudomonas aeruginosa ${ }^{1}$. Chronic airway infection, inflammation and oxidative stress are the characteristics of cystic fibrosis disease, which are mainly due to neutrophilic immune responses ${ }^{2}$. Pulmonary disease is the leading cause of morbidity and mortality in patients with cystic fibrosis ${ }^{3}$.

Currently, monitoring of pulmonary disease in cystic fibrosis is based on clinical features and pulmonary function tests. However, these tests may not reflect the onset, origin or severity of airway inflammation ${ }^{4}$. The noninvasive assessment of inflammatory markers in exhaled breath condensate (EBC) may be a promising tool in patients with chronic lung diseases ${ }^{4-6}$. In cystic fibrosis, noninvasive inflammatory markers may be helpful in the early detection of cystic fibrosis lung disease in infants, the prediction and follow-up of an exacerbation, and the evaluation of treatment effects.

Several research groups detected altered inflammatory markers, such as leukotriene-B4, interleukin-6, and free radicals, in EBC of patients with cystic fibrosis, compared to controls ${ }^{7-10}$. Jöbsis et al showed increased exhaled hydrogen peroxide concentrations during cystic fibrosis exacerbations ${ }^{8}$. Recently, the presence of interleukin-4, interleukin-10, tumor necrosis factor-alpha, and interferon-gamma was demonstrated in EBC of patients with cystic fibrosis ${ }^{10}$. However, study populations were often small, and data on noninvasive markers in cystic fibrosis limited and inconsistent. In addition, the relationships between noninvasive inflammatory markers, and the severity or exacerbations of cystic fibrosis disease, are still unknown. Therefore, we assessed different inflammatory markers in EBC in almost 100 children with cystic fibrosis and controls, comparing the ability of these markers to indicate (exacerbations of) cystic fibrosis, and/or disease severity. Because of oxidative stress and airway inflammation, hydrogen peroxide, 8-isoprostane, and nitrite/nitrate are upregulated in the airways of cystic fibrosis patients, and acidity is increased. Conversely, fractional exhaled nitric oxide levels have shown to be lower in cystic fibrosis.

The aim of the present cross-sectional study in children with cystic fibrosis was to investigate: (i) the ability of fractional exhaled nitric oxide and other exhaled inflammatory markers (condensate acidity, nitrite, nitrate, hydrogen peroxide, 8-isoprostane, and Th1/Th2 cytokines) to indicate (exacerbations of) cystic fibrosis; and (ii) the ability of these noninvasive inflammatory markers to indicate disease severity in cystic fibrosis. 


\section{Methods \\ Study subjects}

We included 48 children with cystic fibrosis, and 50 control children without a history of lung disease or atopy. Informed consent was obtained from all subjects. The study was approved by the Medical Ethics Committee of the University Hospital of Maastricht.

\section{Cystic fibrosis population}

Children known with cystic fibrosis were recruited from the outpatient clinics. Cystic fibrosis disease was defined as a combination of typical clinical features (persistent pulmonary problems, meconium ileus, failure to thrive, steatorrhoe), and an abnormal sweat test (chloride $>60 \mathrm{mM}$ ). An exacerbation of cystic fibrosis was diagnosed by the paediatric pulmonologist based on a significant increase in cystic fibrosis related symptoms, and/or a decrease of at least $10 \%$ in forced expiratory volume in one second, or forced vital capacity compared to previous measurements ${ }^{11}$. Height and weight were expressed as Z-scores (age and gender specific standard deviation scores). Cystic fibrosis severity was assessed using the Shwachman-Kulczycki score.

\section{Control population}

Control children without lung disease were recruited from the outpatient clinic of the University Hospital Maastricht. The reasons of consultation were constipation and enuresis nocturna. All children completed the questionnaire from the International Study of Asthma and Allergies in Childhood (ISAAC) to exclude children with a (history of) airway or allergy complaints, or asthmatic disease ${ }^{12}$.

\section{Exclusion criteria}

Exclusion criteria were: (i) diseases that may interfere with the results of the study (upper airway infection, heart disease, anatomic abnormalities of the airways, and other chronic inflammatory diseases, such as Crohns disease and rheumatoid arthritis); (ii) mental retardation; (iii) inability to perform the EBC collection procedure; (iv) active smoking; and (v) use of the following medication: papaverin, sodium nitroprusside, angiotensinconverting enzyme inhibitors, oxymetazoline, L-arginine, or nitric oxide synthase inhibitors.

\section{Design and Measurements}

The design of this study was cross-sectional. At first, fractional exhaled nitric oxide was measured. Subsequently, EBC was collected, and lung function was measured by means of dynamic spirometry. All tests were performed within one hour.

\section{Nitric oxide in exhaled air}

Fractional exhaled nitric oxide was measured using a $\mathrm{NIOX}^{\circledR}$ chemiluminescence analyser (Aerocrine, Solna, Sweden). Measurements were assessed according to the recommendations of the American Thoracic Society and European Respiratory Society for children ${ }^{6}$. The mean nitric oxide value of the plateau reached during the last 3 seconds of exhalation, was used to obtain the fractional exhaled nitric oxide value of that measurement ${ }^{6}$. The mean fractional exhaled nitric oxide of three measurements was used for analysis. 
In 14 patients with cystic fibrosis, fractional exhaled nitric oxide was measured using the offline method, because there was not a $\mathrm{NIOX}^{\circledR}$ analyser available in these clinics. The first 4 seconds of exhaled air were discarded and during the next 4 seconds, exhaled air was collected in an inert balloon. Fractional exhaled nitric oxide levels were analysed on the $\mathrm{NIOX}^{\circledR}$ chemiluminescence analyser within 8 hours ${ }^{13}$. The exhalation flow rate during these measurements was $50 \mathrm{~mL} / \mathrm{sec}$.

\section{Exhaled breath condensate}

EBC was collected using a home-made $50-\mathrm{cm}$ double-wall borosilicate glass condenser, continuously cooled by circulating ice water $\left(1^{\circ} \mathrm{C}\right)$, as described previously $5,10,14$. Subjects were asked to breath tidally for 30 minutes through a mouthpiece, while wearing a nose-clip. The mouthpiece was connected to a two-way non-rebreathing valve (Hans Rudolph Inc, series 1420, Kansas City,USA), which also served as a gravitational saliva trap. In addition, children were allowed to swallow saliva during EBC collection.

The acidity of the EBC was measured immediately after collection (Radiometer ${ }^{\circledR}$, type PHM201, Radiometer Nederland BV, Zoetermeer, the Netherlands). Samples were not deaerated ${ }^{14}$. Subsequently, the EBC samples were frozen and stored at $-80^{\circ} \mathrm{C}$ in $1 \mathrm{~mL}$ Eppendorf ${ }^{\circledR}$ tubes.

In EBC, nitrite and nitrate concentrations were assessed using a fluorimetric assay (Cayman Chemical, Ann Arbor, USA) ${ }^{15}$. To measure 8-isoprostane in EBC, an enzyme immunoassay was used (Cayman Chemical, Ann Arbor, USA), which was modified in order to lower the detection limit from $5.0 \mathrm{pg} / \mathrm{mL}\left(80 \% \mathrm{~B} / \mathrm{B}_{0}\right)$ to $0.5 \mathrm{pg} / \mathrm{mL}$. Standard curves, patient samples and quality control samples of $2.5 \mathrm{pg} / \mathrm{mL}$ and $10 \mathrm{pg} / \mathrm{mL}$, were assayed in triplicate. The coefficients of variation of the absorption signal were assessed. Intra-assay variation of standard curves, patient samples and quality control samples should be less than $15 \%$, otherwise all samples measured in that assay were excluded and re-analysed. Finally, in all accepted samples, 8-isoprostane concentrations were determined from mean absorption signal intensities.

Hydrogen peroxide measurements in EBC were based on a method previously described by Dekhuijzen et al ${ }^{16}$. Briefly, EBC was mixed with $0.4 \mathrm{M}$ citrate buffer, horseradish peroxidase solution $(50 \mathrm{U} / \mathrm{mL})$, and tetramethylbenzidine $(20 \mathrm{mM})$, and incubated for 20 minutes at room temperature. Subsequently, the sample was mixed with sulphuric acid $(2 \mathrm{M})$. The tetramethylbenzidine oxidation product, as a measure of the amount of hydrogen peroxide, was determined spectrometrically at 450nm using a Perkin Elmer UV-VIS Spectrometer Lambda 10 (Norwalk, CT, USA).

Cytokines (interleukin-2, interleukin-4, interleukin-5, interleukin-10, tumor necrosis factor-alpha, and interferon-gamma) were assessed in $50 \mu \mathrm{L}$ samples of EBC with flow cytometry (multiplexed cytometric bead array (CBA), BD Bioscience ${ }^{\circledR}$, San Diego, USA), as described previously ${ }^{10}$. 


\section{Lung function tests}

Bronchodilator medication was stopped prior to lung function testing: shortacting bronchodilators for at least 8 hours, and longacting bronchodilators at least for 36 hours. Dynamic spirometry was performed by means of the Flowscreen ${ }^{\circledR}$ (Jaeger ${ }^{\circledR}$, Wuerzburg, Germany). The lung function parameters were assessed according to European Respiratory Society standards. The highest values of one of three correct performed manoeuvres were used for analysis. Recorded parameters were: forced expiratory volume in one second, and forced vital capacity. In addition, in the cystic fibrosis population, residual volume, total lung capacity, and intrathoracic gas volume were assessed by body plethysmography (Jaeger ${ }^{\circledR}$, Würzberg, Germany). The reversibility on a bronchodilator was determined 15 minutes after inhalation of $400 \mu \mathrm{g}$ salbutamol. Reversibility was defined as an increase in measured forced expiratory volume in one second of at least $9 \%$ of predicted value.

\section{Statistical analysis}

Statistical calculations were performed using SPSS 11.5 (SPSS Inc., Chicago, USA). Data were expressed as mean \pm standard error of the mean, or as median (interquartile range) values for normal, or not normal distributed continuous variables, respectively. Comparison between groups was performed using the chi-square for categorical variables, the Student's t-tests for normal distributed parameters, and, Mann Whitney $\mathrm{U}$-test was used when the distribution of the parameters was considered not normal. P-values $<0.05$ were considered statistically significant.

At first, the influence of separate inflammatory markers was tested in univariate logistic regression analyses. Thereafter, the different inflammatory markers were combined in multivariate logistic regression models with cystic fibrosis disease, cystic fibrosis exacerbation, and cystic fibrosis severity as dependent binary variables. Age, height, weight, forced expiratory volume in one second as per centage of predicted value, and the forced expiratory volume in one second to vital capacity ratio were introduced in the model as covariates, but were removed if $p$-values exceeded 0.10 , in order to keep the degrees of freedom as high as possible. The stepwise backward method was applied to reduce the number of independent variables, and to assess which inflammatory markers were most predictive: only inflammatory markers with a p-value $<0.05$ were kept in the final models. Based on these models, receiver operating characteristic curves were obtained. EBC samples with negative detections were not considered as missings, because they actually inform us that the measurements of inflammatory markers were below the lower detection limit. Therefore, the negative detections were given an arbitrary value between the lower detection limit and zero.

\section{Power analysis}

The standard error of the sensitivity and the specificity of an inflammatory marker will be less than $5 \%$, given a population of 50 children with cystic fibrosis and 50 controls, and an assumed sensitivity of $70 \%$. This was considered sufficiently accurate for the purpose of this study. 


\section{Results \\ Population characteristics}

Two of the 48 patients with cystic fibrosis were older than 18 (21 and 25 years, respectively). Children with cystic fibrosis $(n=48)$ were older, smaller, weighed less and had more airway obstruction compared to controls $(n=50)$ (Table $1 ; p<0.05)$. Exacerbation was diagnosed in $13 \%$ of the cystic fibrosis patients. 24 Patients were treated with prophylactic antibiotics. All of these patients were receiving antibiotics orally (trimethoprim/sulphamethoxazol 17\%, azitromycin 27\%, amoxicillin/clavulanic acid $4 \%$, and flucloxacillin 2\%). In addition, 11 patients received inhaled antibiotics (8 (17\% tobramycin, and 6 (13\%) colistin). Therapeutic antibiotic treatment was given to the six patients with an exacerbation (orally: azitromycin 2(4\%), ciprofloxacin 2(4\%), amoxicillin/clavulanic acid 1(2\%), and, intravenously: tobramycin 3(6\%), ceftazidim $1(2 \%)$, piperacillin/tazobactam $1(2 \%))$.

\section{Collection of EBC and FeNO measurements}

The mean EBC volume collected was $3.1 \pm 0.2 \mathrm{~mL}$ and $3.0 \pm 0.2 \mathrm{~mL}$ in the cystic fibrosis population and control population, respectively. No side effects were reported during or following exhaled nitric oxide measurements and EBC collection.

\section{Detection of inflammatory markers}

Detections of inflammatory markers in EBC are shown in Table 2. Nitrite, nitrate, hydrogen peroxide, and 8-isoprostane were measured in all EBC samples. The level of cytokine detection in EBC ranged up to $42 \%$, and $20 \%$ in children with cystic fibrosis, and healthy controls, respectively. It was not possible to detect interleukin-5. Interferon-gamma and interleukin-4 were detected significantly more often in EBC samples of cystic fibrosis patients ( $42 \%$, and $13 \%$ respectively), compared to samples originating from healthy controls ( $20 \%$, and $2 \%$ respectively; Chi-square test, $p<0.05)$.

\section{Concentration of inflammatory markers}

Mean concentrations of interferon-gamma and nitrite were significantly higher in the cystic fibrosis group $(3.3 \pm 0.3 \mathrm{pg} / \mathrm{mL}$, and $2.2 \pm 0.2 \mu \mathrm{M}$, respectively) compared to controls $(2.6 \pm 0.2 \mathrm{pg} / \mathrm{mL}$, and $1.4 \pm 0.1 \mu \mathrm{M}$, respectively; Student's t-test, $\mathrm{p}<0.05)$ (Table 2). In contrast, fractional exhaled nitric oxide was significantly lower in children with cystic fibrosis (10.0 $\pm 1.2 \mathrm{ppb})$, compared to control children (15.4 \pm 1.4 ppb; $\mathrm{p}<0.05)$. No influence was present of inhaled corticosteroids, use of antibiotics, or presence of atopy.

\section{Cystic fibrosis disease}

Multivariate logistic regression models showed that EBC 8-isoprostane, nitrite, and interferon-gamma, and forced expiratory volume in one second, were all significant indicators for cystic fibrosis disease (Table 3 ). The model including exhaled markers only, had a sensitivity of $78 \%$, a specificity of $92 \%$, and a area under the receiver operating characteristic curve of 0.906 (Figure 1A). 
Table 1. Clinical characteristics of the study population*

\begin{tabular}{|c|c|c|c|}
\hline & $\begin{array}{l}\text { cystic fibrosis } \\
(n=48)\end{array}$ & & $\begin{array}{c}\text { controls } \\
(n=50)\end{array}$ \\
\hline age (yrs) & $13.0 \pm 0.6$ & $t$ & $10.0 \pm 0.4$ \\
\hline height (cm) & $148 \pm 3$ & & $142 \pm 2$ \\
\hline Z-score height \# & $-1.0 \pm 0.2$ & $\dagger$ & $0.1 \pm 0.2$ \\
\hline Z-score weight \| & $-1.0 \pm 0.1$ & $\dagger$ & $0.5 \pm 0.2$ \\
\hline sexe (male / female) & $27 / 21$ & & $27 / 23$ \\
\hline $\mathrm{FEV}_{1} \%$ predicted & $76 \pm 4$ & $\dagger$ & $102 \pm 2$ \\
\hline $\mathrm{FEV}_{1} / \mathrm{NC}(\%)$ & $77 \pm 2$ & $\dagger$ & $88 \pm 1$ \\
\hline TLC \% predicted & $104 \pm 2$ & & NA \\
\hline RV \% predicted & $174 \pm 10$ & & NA \\
\hline ITVG \% predicted & $123 \pm 4$ & & NA \\
\hline reversibility $\S$ & $23 \%$ & & NA \\
\hline cystic fibrosis exacerbation & $6(13 \%)$ & & NA \\
\hline atopy ** & $17(36 \%)$ & & NA \\
\hline \multicolumn{4}{|l|}{ positive sputum cultures: } \\
\hline - Pseudomonas aeruginosa & $23(58 \%)$ & & NA \\
\hline - Staphylococcus aureus & $29(60 \%)$ & & NA \\
\hline - Haemophilus influenzae & $14(29 \%)$ & & NA \\
\hline - Haemophilus parainfluenzae & $3(6 \%)$ & & NA \\
\hline - Aspergillus fumigatus & $17(35 \%)$ & & NA \\
\hline - Candida albicans & $6(13 \%)$ & & NA \\
\hline - Hemolytic Streptococcus group A or B & $8(17 \%)$ & & NA \\
\hline \multicolumn{4}{|l|}{ therapy: } \\
\hline - rhDNase & $25(52 \%)$ & & NA \\
\hline - antacids & $24(50 \%)$ & & NA \\
\hline - corticosteroids & $13(27 \%)$ & & NA \\
\hline - therapeutic antibiotics & $7(15 \%)$ & & NA \\
\hline - prophylactic antibiotics & $24(50 \%)$ & & NA \\
\hline
\end{tabular}

$\mathrm{FEV}_{1}$, forced expiratory volume in one second; FVC, forced vital capacity; ITVG, intrathoracic gas volume; NA, not applicable; rhDNase, recombinant human desoxyribonuclease; RV, residual volume; TLC, total lung capacity; VC, vital capacity.

* data are shown as mean \pm SEM, except indicated otherwise

\# standard deviation of height corrected for age and sex, according to Dutch standard values

|| standard deviation of weight corrected for age and sex, according to Dutch standard values $\S$ defined as an increase in $\mathrm{FEV}_{1}$ after $400 \mu \mathrm{g}$ salbutamol of $9 \%$ of predicted or more † significantly different from controls $(p<0.05)$

** defined as total IgE level exceeds $20 \mathrm{kU} / \mathrm{L}$, and/or positive Phadiatop, and/or positive radioallergosorbent test 
Table 2. Concentrations, and number of positive detections of inflammatory markers in exhaled breath condensate.

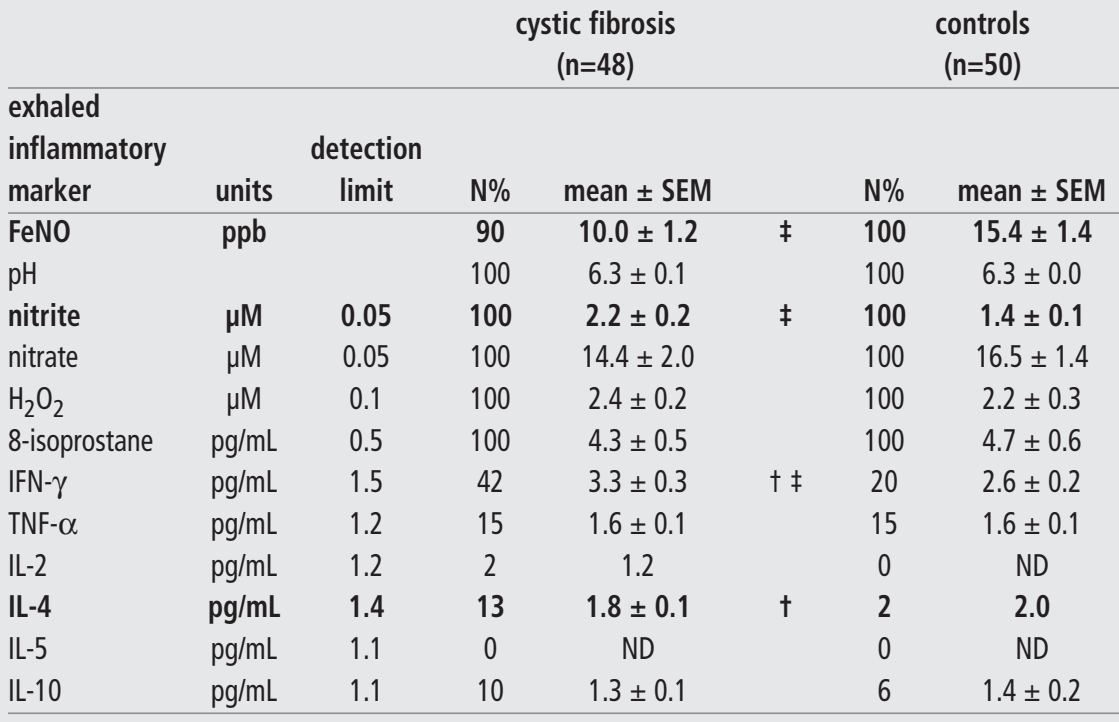

FeNO, fractional exhaled nitric oxide; $\mathrm{H}_{2} \mathrm{O}_{2}$, hydrogen peroxide; IFN- $\gamma$, interferon-gamma; IL, interleukin; $\mathrm{ND}$, not detectable; $\mathrm{pH}$, condensate acidity; SEM, standard error of the mean; TNF- $\alpha$, tumor necrosis factor-alpha.

$\mathrm{N} \%$ number of positive detections, as percentage of samples above detection limit $\dagger p<0.05$ positive detections of cystic fibrosis versus controls

$\ddagger p<0.05$ concentrations of inflammatory markers in cystic fibrosis versus controls

Table 3. Multivariate logistic regression model to indicate the presence of cystic fibrosis disease.

\begin{tabular}{lccc} 
& $\mathrm{p}(-\mathbf{2 L L})$ & $\boldsymbol{B} \pm \mathrm{SE}$ & $\mathrm{OR}(\mathrm{Cl} 95 \%)$ \\
\hline 8-isoprostane & 0.02 & $-0.08 \pm 0.76$ & $0.92(0.88-0.98)$ \\
nitrite & 0.03 & $0.75 \pm 0.37$ & $2.11(1.35-3.25)$ \\
IFN- $\gamma$ & 0.02 & $0.74 \pm 0.35$ & $2.10(1.17-2.54)$ \\
FEV $_{1} \%$ predicted & $<0.01$ & $-0.07 \pm 0.02$ & $0.93(0.89-0.97)$
\end{tabular}

$\beta$, coefficient of the predictor variables; $\mathrm{Cl}$, confidence interval; $\mathrm{FEV}_{1}$, forced expiratory volume in one

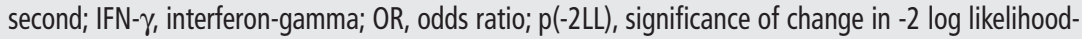
ratio; $\mathrm{SE}$, standard error. 


\section{Cystic fibrosis exacerbation}

Six $(13 \%)$ of the cystic fibrosis population had an exacerbation, based on an increase in symptoms, and/or decrease in lung function parameters. In the sputum of these patients, the following micro-organisms were cultured: Pseudomonas aeruginosa (100\%), Staphylococcus aureus (67\%), Haemophilus influenzae (33\%), Aspergillus fumigatus (83\%), Candida albicans (17\%), Hemolytic Streptococcus group A or B (17\%). In a multivariate analysis, 8-

Figure 1A. Receiver operating characteristic (ROC) curve of the multivariate backward logistic regression model of exhaled breath condensate 8isoprostane, nitrite and interferon-gamma, to indicate the presence of cystic fibrosis (CF) disease.

The area under the curve is 0.906 . The maximum sensitivity is $78 \%$, with a specificity $92 \%$.

$$
\begin{aligned}
& 0=\text { Controls } \\
& 1=\text { Cystic fibrosis }
\end{aligned}
$$

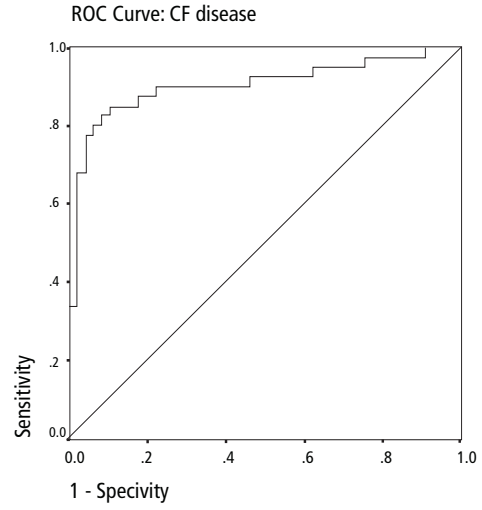

Table 4. Multivariate logistic regression model to indicate cystic fibrosis exacerbation.

\begin{tabular}{lccc} 
& $\mathbf{p}(-2 \mathrm{LL})$ & $\mathbf{B} \pm \mathrm{SE}$ & $\mathrm{OR}(\mathrm{Cl} 95 \%)$ \\
\hline 8-isoprostane & 0.03 & $-0.42 \pm 0.21$ & $0.70(0.44-0.99)$ \\
nitrite & 0.01 & $-1.34 \pm 0.65$ & $0.26(0.07-0.93)$
\end{tabular}

The definition of poor cystic fibrosis lung disease control was based on the presence or severity of symptoms, and decrease in lung function parameters.

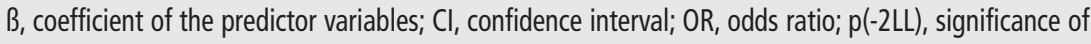
change in -2 log likelihood-ratio; SE, standard error.

Figure 1B. Receiver operating characteristic (ROC) curve of the multivariate backward logistic regression model of exhaled breath condensate 8isoprostane and nitrite, to indicate cystic fibrosis (CF) exacerbation.

The area under the curve is 0.838 . The maximum sensitivity is $40 \%$, with a specificity $97 \%$.

$0=$ Stable $\mathrm{CF}$

$1=\mathrm{CF}$ exacerbation

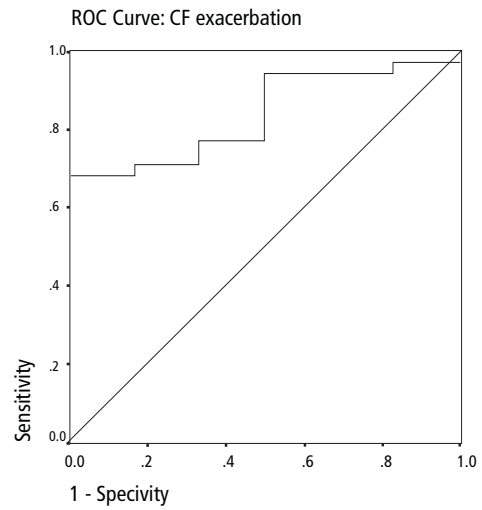


isoprostane and nitrite indicated a cystic fibrosis exacerbation (Table 4). However, sensitivity was only $40 \%$, with a corresponding specificity of $97 \%$ (area under the receiver operating characteristic curve of $0.838, p=0.009$ ) (Figure 1B). Correction for age, gender, presence of atopy, lung function parameters, or use of antibiotics, did not influence the results.

\section{Cystic fibrosis severity}

In this part of the analysis, the cystic fibrosis severity classes were reduced to two groups, according to the Shwachman-Kulczycki score: group $1(n=15)$ consisted of patients with no excellent severity status, whereas group $2(n=33)$ consisted of children with an excellent status. In the multivariate logistic regression model, fractional exhaled nitric oxide, EBC acidity, and forced expiratory volume in one second to vital capacity ratio were significant markers to indicate cystic fibrosis severity (Table 5). The model including exhaled markers only, had a sensitivity of $96 \%$, and a specificity of $67 \%$ (area under the receiver operating characteristic curve of $0.751, p=0.008$ ) (Figure 1C).

Table 5. Multivariate logistic regression model to indicate cystic fibrosis lung disease severity.

\begin{tabular}{lccc} 
& $\mathbf{p}(-2 \mathrm{LL})$ & $\boldsymbol{B} \pm \mathrm{SE}$ & OR $(\mathrm{Cl} 95 \%)$ \\
\hline FeNO & 0.01 & $-0.19 \pm 0.09$ & $0.83(0.70-0.98)$ \\
pH & 0.01 & $-6.04 \pm 2.66$ & $0.02(0.00-0.44)$ \\
FEV ${ }_{1}$ NC $\%$ & $<0.01$ & $0.19 \pm 0.08$ & $1.21(1.03-1.41)$ \\
\hline
\end{tabular}

Cystic fibrosis severity was classified using the Shwachman-Kulczycki score.

$B$, coefficient of the predictor variables; $\mathrm{Cl}$, confidence interval; FeNO, fractional exhaled nitric oxide; $\mathrm{FEV}_{1}$, forced expiratory volume in one second; $\mathrm{OR}$, odds ratio; $\mathrm{p}(-2 \mathrm{LL})$, significance of change in -2 log likelihood-ratio; pH, condensate acidity; SE, standard error; VC, vital capacity.

Figure 1C. Receiver operating characteristic (ROC) curve of the multivariate backward logistic regression model of fractional exhaled nitric oxide, and exhaled breath condensate acidity, to indicate cystic fibrosis (CF) lung disease severity.

Cystic fibrosis severity was classified using the Shwachman-Kulczycki score. The area under the curve is 0.751 . The maximum sensitivity is $96 \%$ with a specificity $67 \%$.

$0=$ Not excellent CF status

$1=$ Excellent CF status

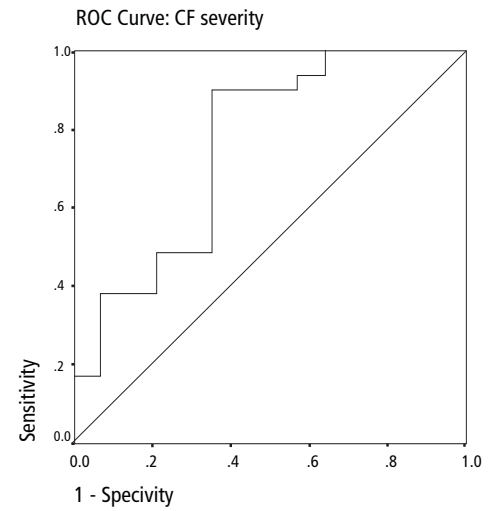




\section{Discussion}

This study is based on a relatively large study population of 98 children, of whom 48 children with cystic fibrosis, and simultaneous measurement of several exhaled inflammatory biomarkers, as well as conventional (noninvasive) disease measures, in order to allow a comparison between inflammatory markers, and to assess relationships with cystic fibrosis exacerbation and disease severity. The presented data show that different profiles of noninvasive inflammatory markers in exhaled air and breath condensate are able to reflect different aspects of cystic fibrosis disease in children with good sensitivity and specificity: (i) EBC 8-isoprostane, nitrite and interferon-gamma concentrations were able to indicate the presence of cystic fibrosis disease; (ii) EBC 8-isoprostane and nitrite indicated cystic fibrosis exacerbation; and (iii) cystic fibrosis lung disease severity was assessed by fractional exhaled nitric oxide and EBC acidity.

To our knowledge, no comparable studies on noninvasive profiles of inflammatory markers in children with cystic fibrosis have (yet) been published. However, several of these markers have been studied separately. In the cystic fibrosis population, fractional exhaled nitric oxide levels were reduced when compared with control population, which is in accordance with available data in literature ${ }^{8,17-25}$. Furthermore, we found significantly higher concentrations of nitrite in EBC originating from children with cystic fibrosis, compared to controls. These results are similar to the findings of Formanek et al, Cunningham et al, as well as Ho, Ojoo and Tate et al in young adults with cystic fibrosis 17-18,26-28. Lower fractional exhaled nitric oxide levels and higher nitrite concentrations in the cystic fibrosis population may be explained by several hypotheses ${ }^{17,29}$. On one hand, the viscous mucus in cystic fibrosis airways may impair diffusion of gaseous nitric oxide into the airway lumen, which may result in conversion of nitric oxide into nitrite ${ }^{18}$. On the other hand, decreased expression of inducible nitric oxide synthase II in epithelial cells may result in low fractional exhaled nitric oxide levels in children with cystic fibrosis $25,30-33$.

Interferon-gamma and interleukin-4 were detected more often in EBC samples originating from children with cystic fibrosis, and interferon-gamma condensate concentrations were higher in this group, compared to controls. This is in accordance with the findings of Wojnarowski et al, which demonstrated increased transcription of interferon-gamma and interleukin-4 in bronchial biopsies from children with cystic fibrosis, whereas normal controls did not express these cytokines ${ }^{34}$. Immunoregulatory effects of interferon-gamma on various cells, are extensive and diverse ${ }^{35-36}$. Interferongamma and interleukin-4 upregulate class II molecules on macrophages and dendritic cells. Thereby, the antigen presenting capacity of epithelial and endothelial cells, among others, is being induced ${ }^{36}$. Moreover in cystic fibrosis, defensive mechanisms to antigens are impaired, and by consequence, additional mechanisms need to be addressed to resolve ongoing inflammatory processes and infections ${ }^{37}$. Interleukin-5 was not detected in any EBC sample, which is in agrrement with the findings of Armstrong et al in bronchoalveolar lavage fluid, and may be related to the presence 
of proteases in cystic fibrosis airways ${ }^{38}$. In general, cytokine concentrations in EBC were relatively low, and close to the detection limits of the assays. Previously, we reported that interferon-gamma, interleukin-2, interleukin-4, and interleukin-10 were detected in $8-25 \%$ of the samples originating from children with cystic fibrosis, whereas tumor necrosis factor-alpha and interleukin-5 were not detected ${ }^{10}$. In literature, no other comparative data on multiplexed cytometric bead array in small EBC sample sizes in children with cystic fibrosis are yet available.

EBC acidity, and concentrations of 8-isoprostane and hydrogen peroxide did not differ between cystic fibrosis and control populations, which is in accordance with the results of Jöbsis et al, and $\mathrm{Ho}$ et al ${ }^{8,39}$. On the other hand, other research groups demonstrated lower EBC pH levels and higher 8-isoprostane concentrations in children with cystic fibrosis ${ }^{40-42}$. This discrepancy may be attributed to the mild to moderate cystic fibrosis severity in this study population, as, in the multivariate models, condensate 8-isoprostane was a significant indicator of cystic fibrosis disease and exacerbation, while EBC $\mathrm{pH}$ significantly contributed to the indication model of cystic fibrosis severity.

Several limitations of this study on noninvasive measurements of inflammatory biomarkers in children have to be acknowledged. At first, the cystic fibrosis population mainly consisted of patients with mild to moderate disease, whereas no subjects were actually categorised into a severe disease category. Therefore, results cannot be generalised to the latter type of patients. Secondly, not all cytokines were detected in all EBC samples. However, the lack to detect (some) cytokines does not necessarily implicate that they are not present, as the used detection method may lack sufficient sensitivity, and as there is an overall agreement that cytokines are involved in the pathophysiology of cystic fibrosis. Therefore, a sample with negative detection was not considered as a missing value, as it actually informed us that the measurement of an inflammatroy marker was below the lower detection limit. Thirdly, and obviously, the clinical relevance of these findings for the individual child at long term level remains yet to be determined. Although the presented data may suggest that the combined use of exhaled inflammatory markers may be helpful in the management of cystic fibrosis disease, longitudinal study designs are needed to assess whether these markers are able to: (i) indicate the early onset of cystic fibrosis lung disease in young children, (ii) detect exacerbations in an early stage, and (iii) monitor disease exacerbations and treatment effects.

Finally, the presented findings emphasise the importance of evaluating different profiles of different exhaled inflammatory markers, for their 'synergistic' ability to reflect different aspects of chronic lung disease, as current disease management is mainly based on symptoms and deterioration of lung function parameters, which may not appropriately reflect ongoing inflammatory processes, and as a single inflammatory marker may not be able to properly reflect (an aspect of) an evolving chronic inflammatory process. In future, inflammatory markers in EBC may be a valuable additional tool to detect and monitor inflammatory activity in patients with cystic fibrosis, which ultimately may improve quality of live in children with cystic fibrosis. 
In conclusion, this cross-sectional study in children demonstrated that different profiles of noninvasive inflammatory markers, such as condensate 8-isoprostane, nitrite, interferon-gamma, acidity, and fractional exhaled nitric oxide, were able to indicate the presence of cystic fibrosis disease, disease exacerbation, and/or cystic fibrosis lung disease severity, with good sensitivity and specificity. Longitudinal data are necessary to further confirm the role of these exhaled markers in the management of cystic fibrosis in children.

\section{Acknowledgements}

This project was funded with a grant from AstraZeneca, and from the Dutch Cystic Fibrosis Foundation.

The authors wish to thank the patients and their parents for their participation in this study. 


\section{References}

1. Ratjen F, Doring G. Cystic fibrosis. Lancet 2003; 361: 681-689.

2. Brown RK, Wyatt $H$, Price JF, Kelly FJ. Pulmonary dysfunction in cystic fibrosis is associated with oxidative stress. Eur Respir J 1996; 9: 334-339.

3. FitzSimmons SC. The changing epidemiology of cystic fibrosis. Curr Probl Pediatr 1994; 24: 171-179.

4. Kharitonov SA, Barnes PJ. Exhaled markers of pulmonary disease. Am J Respir Crit Care Med 2001; 163: 1693-1722.

5. Rosias P, Dompeling E, Hendriks H, Heijnens J, Donckerwolcke R, Jöbsis Q. Exhaled breath condensate in children: Pearls and pitfalls. Pediatr Allergy Immunol 2004; 15 : 4-19.

6. American Thoracic Society. ATS/ERS recommendations for standardized procedures for the online and offline measurement of exhaled lower respiratory nitric oxide and nasal nitric oxide, 2005. Am J Respir Crit Care Med 2005; 171: 912-930.

7. Carpagnano GE, Barnes PJ, Geddes DM, Hodson ME, Kharitonov SA. Increased leukotriene B4 and interleukin- 6 in exhaled breath condensate in cystic fibrosis. Am J Respir Crit Care Med 2003; 167: 1109-1112.

8. Jöbsis Q, Raatgeep HC, Schellekens SL, Kroesbergen A, Hop WC, de Jongste JC. Hydrogen peroxide and nitric oxide in exhaled air of children with cystic fibrosis during antibiotic treatment. Eur Respir J 2000; 16: 95-100.

9. Rosias P, Den Hartog G, Robroeks C, Bast A, Donckerwolcke R, Heynens J, Suykerbuyk J, Hendriks H, Jöbsis Q, Dompeling E. Free radicals in exhaled breath condensate in cystic fibrosis and healthy subjects. Free Radic Res 2006; 40: 901-909.

10. Robroeks C, Jöbsis Q, Damoiseaux J, Heijmans P, Rosias P, Hendriks H, Dompeling E. Cytokines in exhaled breath condensate of children with asthma and cystic fibrosis. Ann Allergy Asthma Immunol 2006; 96: 349-355.

11. Rosenfeld M, Emerson J, Williams-Warren J, Pepe M, Smith A, Montgomery AB, Ramsey B. Defining a pulmonary exacerbation in cystic fibrosis. J Pediatr 2001; 139: 359-365.

12. Montuschi P. Indirect monitoring of lung inflammation. Nat Rev Drug Discov 2002; 1: $238-242$.

13. Pijnenburg M, Lissenberg E, Hofhuis W, Ghiro L, Ho WC, Holland WP, de Jongste JC. Exhaled nitric oxide measurements with dynamic flow restriction in children aged 48 yrs. Eur Respir J 2002; 20: 919-924.

14. Rosias P, Dompeling E, Dentener M, Pennings H, Hednriks H, Van lersel M, Jöbsis Q. Childhood asthma: exhaled markers of airway inflammation, asthma control score, and lung function tests. Pediatr Pulmonol 2004; 38: 107-114.

15. Misko TP, Schilling RJ, Salvemini D, Moore WM, Currie MG. A fluorometric assay for the measurement of nitrite in biological samples. Anal Biochem 1993; 214: 11-16.

16. Dekhuijzen PN, Aben KK, Dekker I, Aarts LP, Wielders PL, van Herwaarden CL, Bast A. Increased exhalation of hydrogen peroxide in patients with stable and unstable chronic obstructive pulmonary disease. Am J Respir Crit Care Med 1996; 154: 813816. 
17. Ojoo JC, Mulrennan SA, Kastelik JA, Morice AH, Redington AE. Exhaled breath condensate $\mathrm{pH}$ and exhaled nitric oxide in allergic asthma and in cystic fibrosis. Thorax 2005; 60: 22-26.

18. Ho LP, Innes JA, Greening AP. Nitrite levels in breath condensate of patients with cystic fibrosis is elevated in contrast to exhaled nitric oxide. Thorax 1998; 53: 680684.

19. Ho LP, Innes JA, Greening AP. Exhaled nitric oxide is not elevated in the inflammatory airways diseases of cystic fibrosis and bronchiectasis. Eur Respir J 1998; 12: 12901294.

20. Dotsch J, Demirakca S, Terbrack HG, Huls G, Rascher W, Kuhl PG. Airway nitric oxide in asthmatic children and patients with cystic fibrosis. Eur Respir J 1996; 9: $2537-$ 2540 .

21. Grasemann H, Michler E, Wallot M, Ratjen F. Decreased concentration of exhaled nitric oxide (NO) in patients with cystic fibrosis. Pediatr Pulmonol 1997; 24: 173-177.

22. Lundberg JO, Nordvall SL, Weitzberg E, Kollberg H, Alving K. Exhaled nitric oxide in paediatric asthma and cystic fibrosis. Arch Dis Child 1996; 75: 323-326.

23. Thomas SR, Kharitonov SA, Scott SF, Hodson ME, Barnes PJ. Nasal and exhaled nitric oxide is reduced in adult patients with cystic fibrosis and does not correlate with cystic fibrosis genotype. Chest 2000; 117: 1085-1089.

24. Elphick HE, Demoncheaux EA, Ritson S, Higenbottam TW, Everard ML. Exhaled nitric oxide is reduced in infants with cystic fibrosis. Thorax 2001; 56: 151-152.

25. Franklin PJ, Hall GL, Moeller A, Horak F, Jr., Brennan S, Stick SM. Exhaled nitric oxide is not reduced in infants with cystic fibrosis. Eur Respir J 2006; 27: 350-353.

26. Cunningham S, McColm JR, Ho LP, Greening AP, Marshall TG. Measurement of inflammatory markers in the breath condensate of children with cystic fibrosis. Eur Respir J 2000; 15: 955-957.

27. Formanek W, Inci D, Lauener RP, Wildhaber JH, Frey U, Hall GL. Elevated nitrite in breath condensates of children with respiratory disease. Eur Respir J 2002; 19: 487491.

28. Tate S, MacGregor G, Davis M, Innes JA, Greening AP. Airways in cystic fibrosis are acidified: detection by exhaled breath condensate. Thorax 2002; 57: 926-929.

29. de Winter-de Groot KM, van der Ent CK. Nitric oxide in cystic fibrosis. J Cyst Fibros 2005; 4 Suppl 2: 25-29.

30. Grasemann H, Ratjen F. Cystic fibrosis lung disease: the role of nitric oxide. Pediatr Pulmonol 1999; 28: 442-448.

31. Meng QH, Springall DR, Bishop AE, Morgan K, Evans TJ, Habib S, Gruenert DC, Gyi $\mathrm{KM}$, Hodson ME, Yacoub MH, Polak JM. Lack of inducible nitric oxide synthase in bronchial epithelium: a possible mechanism of susceptibility to infection in cystic fibrosis. J Pathol 1998; 184: 323-331.

32. Kelley TJ, Drumm ML. Inducible nitric oxide synthase expression is reduced in cystic fibrosis murine and human airway epithelial cells. J Clin Invest 1998; 102: 12001207.

33. Moeller A, Horak F, Jr., Lane C, Knight D, Kicic A, Brennan S, Franklin P, Terpolilli J, Wildhaber JH, Stick SM. Inducible NO synthase expression is low in airway epithelium from young children with cystic fibrosis. Thorax 2006; 61: 514-520. 
34. Wojnarowski C, Frischer T, Hofbauer E, Grabner C, Mosgoeller W, Eichler I, Ziesche R. Cytokine expression in bronchial biopsies of cystic fibrosis patients with and without acute exacerbation. Eur Respir J 1999; 14: 1136-1144.

35. IJzermans JN, Marquet RL. Interferon-gamma: a review. Immunobiology 1989; 179: 456-473.

36. Chung KF, Barnes PJ. Cytokines in asthma. Thorax 1999; 54: 825-857.

37. Watt AP, Courtney J, Moore J, Ennis M, Elborn JS. Neutrophil cell death, activation and bacterial infection in cystic fibrosis. Thorax 2005; 60: 659-664.

38. Armstrong DS, Hook SM, Jamsen KM, Nixon GM, Carzino R, Carlin JB, Robertson CF, Grimwood K. Lower airway inflammation in infants with cystic fibrosis detected by newborn screening. Pediatr Pulmonol 2005; 40: 500-510.

39. Ho LP, Faccenda J, Innes JA, Greening AP. Expired hydrogen peroxide in breath condensate of cystic fibrosis patients. Eur Respir J 1999; 13: 103-106.

40. Carpagnano GE, Barnes PJ, Francis J, Wilson N, Bush A, Kharitonov SA. Breath condensate $\mathrm{pH}$ in children with cystic fibrosis and asthma: a new noninvasive marker of airway inflammation? Chest 2004; 125: 2005-2010.

41. Bodini A, D'Orazio C, Peroni D, Corradi M, Folesani G, Baraldi E, Assael BM, Boner A, Piacentini GL. Biomarkers of neutrophilic inflammation in exhaled air of cystic fibrosis children with bacterial airway infections. Pediatr Pulmonol 2005; 40: 494499.

42. Montuschi P, Kharitonov SA, Ciabattoni G, et al. Exhaled 8-isoprostane as a new noninvasive biomarker of oxidative stress in cystic fibrosis. Thorax 2000; 55: 205-209. 


\section{CHAPTER 8}

\section{New Method to Collect Exhaled Breath}

Condensate, AND to Assess Airway

\section{Inflammation in Wheezing Preschool ChildRen}

Rosias PPR, Robroeks CM, van de Kant KD, Rijkers GT, Zimmermann L, van Schayck CP, Heynens JW, Jöbsis Q, Dompeling E. 


\section{Abstract}

Exhaled breath condensate is a promising noninvasive method to assess respiratory inflammation in adults and children. So far, condensate collection is mainly feasible in children aged 4 years and over, and condensate analysis is hampered by insufficiently sensitive bioassays. We hypothesised that a new optimised glass condenser, combined with an ultrasensitive multiplexed assay, enables adequate collection, and cytokine measurements in exhaled breath condensate in preschool children.

To assess feasibility and efficacy of a new method of exhaled breath condensate collection in 70 nonsedated preschool children; and to assess cytokine concentrations in condensate (interleukin-4, interleukin-5, interleukin-6, interleukin-8, interleukin-10, interleukin-12p70, interleukin-13, tumor necrosis factor-alpha) in preschool children with atopic asthma, recurrent viral wheeze, and healthy controls.

The overall success rate of condensate collection was $83 \%$. Median condensate volume was $400 \mu \mathrm{L}$. The detection of cytokines was succesful in $95-100 \%$ of samples. In the asthmatic group, tumor necrosis factor-alpha concentrations were significantly decreased, and the ratio's of interleukin-5 to tumor necrosis factor-alpha, and interleukin-13 to tumor necrosis factor-alpha were higher, compared to nonasthmatic children.

Noninvasive assessment of cytokines in exhaled breath condensate in preschool children is possible, by using a new optimised glass condenser system in combination with the ultrasensitive multiplexed liquid bead array analysis. This new method may help to discriminate between wheezing phenotypes in these children.
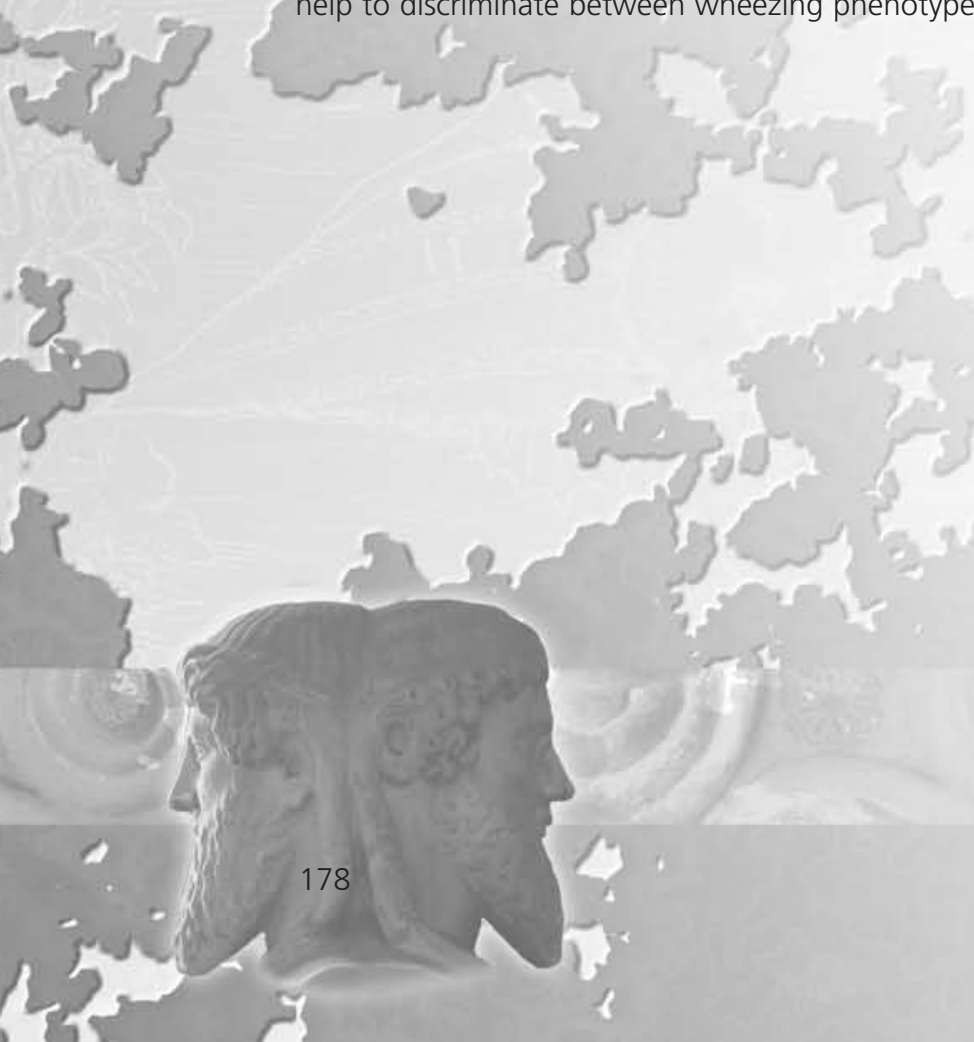


\section{Introduction}

Preschool wheezing is reported in no less than $30 \%$ of children, and may indicate a trivial cold, as well as an ongoing chronic lung inflammation, such as asthma ${ }^{1-2}$. Atopic asthma is associated with a cytokine pattern compatible with predominant activation of the T-helper cell type 2 mediated immune response ${ }^{3}$. However, in the developing preschool child, accurate assessment of different wheezing phenotypes is currently difficult ${ }^{1-8}$. Moreover, proper diagnosis is hampered by the current lack of a reliable routine technique to assess different types of respiratory inflammation in preschool children.

Ideally, such a technique would be noninvasive, rapid and easy to perform, without any risks, successful at any age, standardised, sensitive, specific and highly reproducible. The collection of exhaled breath condensate $(E B C)$ is a noninvasive technique to obtain direct samples from the lower respiratory tract, without disturbing an ongoing inflammation ${ }^{9-11}$. In children, analysis of EBC reveals the presence of various types of inflammatory biomarkers, including cytokines ${ }^{9-15}$.

General methodological recommendations on EBC collection are published ${ }^{11}$. So far, the collection of EBC was mainly feasible in children aged four years and over ${ }^{11,16}$. In preschool children, feasibility is substantially hampered by the need for procedural sedation, or, in nonsedated preschool children, by relatively too long EBC sampling times (from a toddler's point of view). Also, suboptimal condensate analysis due to the use of immunoassays with questionable reproducibility, that often require relatively too large sample volumes, contributes to this problem ${ }^{10,17-21}$.

Recently, the efficacy of different open-ended EBC collection systems was compared, and a condenser with silicone or glass coating was found to be more efficient for the measurement of 8-isoprostane or albumin in exhaled breath condensate, than EcoScreen ${ }^{\circledR}$, aluminum, polypropylene or Teflon ${ }^{\mathrm{TM}} 17$.

Taken together, this has led us to make the following methodological adjustments for the purpose of this study: (i) the collection of EBC using an optimised closed glass condenser system; and (ii) the simultaneous measurement of cytokines in the resulting EBC by means of $x M A P^{\circledR}$ technology, an ultrasensitive multiplexed liquid bead array that requires only small sample volumes. We hypothesised that the combination of these methodological adjustments enhances the feasibility and efficacy of EBC collection and analysis in preschool children with and without wheezing.

Therefore, the aims of the present study were: (i) to assess the feasibility and efficacy of EBC collection in nonsedated preschool children, using a modified, closed, glass condenser, and (ii) to assess cytokine profiles (interleukin-4, interleukin-5, interleukin-6, interleukin-8, interleukin-10, interleukin-12p70, interleukin-13, and tumor necrosis factor-alpha) in EBC using multiplexed $\mathrm{XMAP}{ }^{\circledR}$ technology in preschool children with different wheezing phenotypes. 


\section{Methods \\ Study subjects}

Eligible preschool children were recruited at the paediatric outpatient department of the Maasland Hospital of Sittard and the University Hospital of Maastricht. According to parent-completed questionnaires, medical documents, and information of the responsible paediatric pulmonologist, children were allocated to one of the following study groups:

1. The doctor's diagnosed atopic asthma group characterised by: (i) recurrent wheezing, (ii) not 'exclusively' triggered by viral infections, (iii) with a documented history of a favourable corticosteroid effect, (iv) positive family history of atopy in the first degree (parent or sibling with astma, hay fever, food allergy, or eczema), and ( $v$ ) atopy (positive Phadiatop or radioallergo-sorbent test class $\geq 2$, and/or elevated blood level of total immunoglobulin-E,). Current corticosteroid maintenance therapy was not an obligatory criterion.

2. The viral-triggered recurrent wheeze group characterised by: (i) recurrent wheezing, (ii) 'exclusively' triggered by viral infections, (iii) without a documented history of steroid therapy, or with documented history of no favourable corticosteroid effect, and (iv) without corticosteroid maintenance therapy in the preceding three months. Lack of atopy was not an obligatory criterion.

3. The healthy control group characterised by: (i) the absence of recurrent wheezing, and (ii) without a history of corticosteroid maintenance therapy. Lack of atopy was not an obligatory criterion.

4. The unclassifiable recurrent wheeze group consisted of infants and toddlers with recurrent wheezing, but not eligible for the asthmatic or viral wheeze group. They participated only in the feasibility study.

Overall exclusion criteria were cardiac disease, anatomic or congenital defects of the airways or lungs, syndromes, systemic disease, and/or mental retardation. Presumed inability to use a face mask did not preclude participation into this study. Subject characteristics are shown in Table 1.

\section{Exhaled breath condensate collection}

This cross sectional study design comprised one attempt, between wheezing episodes, to collect EBC in a preschool child. Precedingly, parents received thorough instructions on the collection procedure by one of the coaching childhood asthma nurses, and were asked to bring along the child's favourite cartoon, cd-song, booklet, and/or puppet.

EBC was collected using a modified closed glass condenser system that was developed in close collaboration with the Department of Instrument Development Engineering \& Evaluation of the Maastricht University (patent number EP 07102586). The EBC collection system consisted of an inclined and closed glass condenser with a tube length of $90 \mathrm{~cm}$ (to enlarge the condensation surface to $1046 \mathrm{~cm}^{2}$ ), a downwards moveable plunger (to optimise condensate recovery from the inner wall of the condenser), with tangential and axial breath flow channels (to turbunately direct the tidal breath flows towards the cooled 
Table 1. Characteristics of 70 preschool children, allocated to one of the four study groups, based on parent-completed questionnaires and available medical documents.

\begin{tabular}{lllll} 
Study group & Asthma & Viral & Control & Unclassifiable \\
\hline Number & 23 & 22 & 20 & 5 \\
Age in months A & $31(19) \mathrm{C}$ & $28(16) \mathrm{C}$ & $13(18) \mathrm{C}$ & $25(15)$ \\
$\quad$ range & $11-47$ & $5-47$ & $2-41$ & $14-47$ \\
Male / female ratio & $13 / 10$ & $17 / 5$ & $12 / 8$ & $2 / 3$ \\
Weight in kg A & $14(3) \mathrm{D}$ & $13(2) \mathrm{D}$ & $11(5) \mathrm{D}$ & $12(3)$ \\
Z-score weight A & $0(1.4)$ & $0(2.5)$ & $0(1.1)$ & $0(1.0)$ \\
Height in cm A & $95(14)$ & $94(17)$ & $85(23)$ & $92(15)$ \\
Z-score height A & $0.0(1.5)$ & $-0.3(2.1)$ & $0.5(2.1)$ & $-1.0(2.0)$ \\
Elevated IgE / Pos RAST B & $23(100)$ & $4(18)$ & $0(0)$ & $2(40)$ \\
Current use of steroids B & $15(65)$ & - & - & $5(100)$ \\
Inhaled steroid dose B & $400(100)$ & - & - & $400(200)$
\end{tabular}

Asthma, doctor's diagnosed atopic asthma group; Control, healthy control group;

Elevated IgE, elevated blood level of total immunoglobulin-E; Pos RAST, positive radioallergo-sorbent test $\geq$ class 2; Unclassifiable, unclassifiable recurrent wheezing group; Viral, viral-triggered recurrent wheezing group.

Amedian (interquartile range); Babsolute number (percentage); $C p=0.012$ (multiple comparisons, Hochberg correction); $\mathrm{Dp}=0.046$ (multiple comparisons, Hochberg correction).

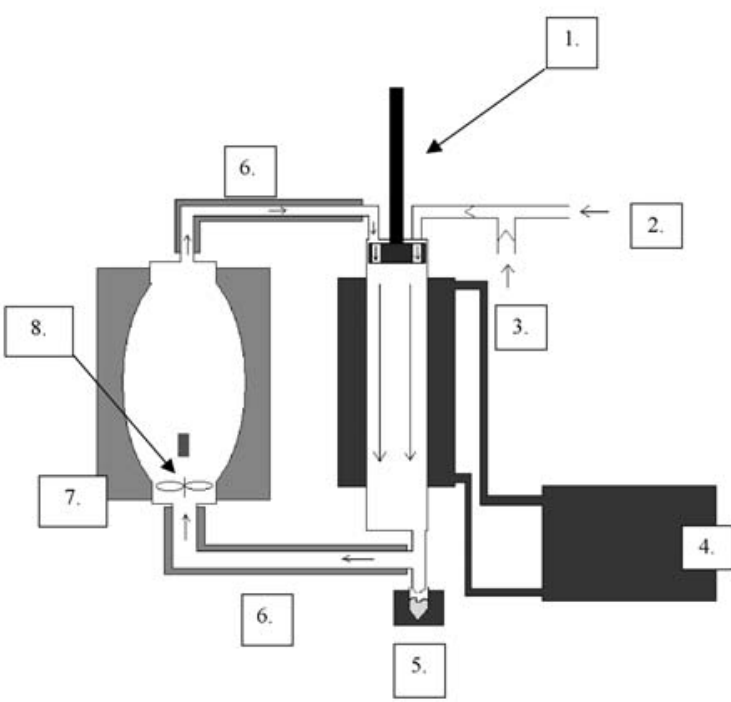

1. inclined and closed glass condenser, and downwards moveable plunger with tangential and axial breath flow channels.

2. swan-neck tubing, two-way nonrebreathing valve, and face mask with separated nose and mouth cavity. 3. entrance of inspired room air 4. cooling unit consisting of a countercurrent circulating ice-water pump 5. removable glass sample vial, to collect exhaled breath condensate 6. heated (at $37^{\circ} \mathrm{C}$ ) tubing, to guide the residual noncondensed exhaled breath 7. humidity sensor and heated (at $37^{\circ} \mathrm{C}$ ) inert Tedlar ${ }^{\mathrm{TM}}$ gas sample bag 8. small ventilator system to recirculate the residual noncondensed exhaled breath back into the condenser system.

Figure 1. Schematic representation of the new closed glass condenser system, that enabled condensate collection in preschool children before and after breath recirculation. 
inner condenser wall), and a unique breath recirculation system, heated at $37^{\circ} \mathrm{C}$ (Figure 1). The breath recirculation system consisted of heated tubing (to guide the residual noncondensed exhaled breath, and to avoid condensation outside the condenser tube), a humidity sensor, a heated inert Tedlar ${ }^{\mathrm{TM}}$ gas sample bag (to collect all residual noncondensed exhaled breath), and a small ventilator system to recirculate the residual noncondensed exhaled breath back into the cooled condenser system (to allow secondary condensation of exhaled breath) (Figure 1).

The child exhaled tidally, as long as possible, through a face mask which separated exhaled air from nose and mouth cavity, and with two-way nonrebreathing valve (8900 pediatric sizes oro-nasal masks, Hans Rudolph Inc., Kansas City, Missouri, USA), connected to the glass condenser system by means of a swan-neck tubing (serving as gravitational saliva trap). During this condensation process, the formerly lost noncondensed exhaled breath was separately being collected in the gradually inflating inert Tedlar ${ }^{\mathrm{TM}}$ gas sample bag. When the child ceased the procedure, EBC was collected by pushing the plunger downwards. Subsequently, the plunger was pulled up again, and the separately collected exhaled breath was recirculated from the Tedlar ${ }^{\mathrm{TM}}$ gas sample bag back into the condenser system, to perform a secondary breath condensation. The recirculation was stopped when the degree of humidity was $\leq 22 \%$.

To improve the toddler's coping with distress from the unfamiliar procedure, they were distracted while breathing tidally through a facemask. We primarily combined strict parental cooperation, with an age appropriate cartoon, that was already started prior to entrance. In case of imminent failure to cope, a more active strategy was used on parent's advice, including children's stories, puppetry, and/or children's songs.

EBC collection was defined successful when at least $60 \mu \mathrm{L}$ condensate was produced, comprising the minimal required volume of $50 \mu \mathrm{L}$ to perform one multiplexed cytokine analysis, and an additional $10 \mu \mathrm{L}$ to compensate for loss due to sample handling.

After each procedure, the nondisposable parts of the condenser were disconnected, rinsed repeatedly with bi-distilled water, and subsequently dried at room air for at least 24 hours.

\section{Condensate sample processing}

Immediately after collection, condensate samples were snap-frozen at $-78^{\circ} \mathrm{C}$ using dry ice and stored at $-80^{\circ} \mathrm{C}$. Analysis was performed within three months from sampling time. Cytokines in EBC were measured in duplicate using a liquid bead array multiplexing system or $\mathrm{xMAP}^{\circledR}$ technology (Luminex Corporation, Austin, USA). Multiplex immunoassay was performed as described previously, to measure the following cytokines (with corresponding lower limits of detection): interleukin-4 (1.2 pg/mL), interleukin-5 (1.2 pg/mL), interleukin-6 $(2.4 \mathrm{pg} / \mathrm{mL})$, chemokine interleukin-8 $(2.9 \mathrm{pg} / \mathrm{mL})$, interleukin$10(2.3 \mathrm{pg} / \mathrm{mL})$, interleukin-12p70 (1.2 pg/mL), interleukin-13 $(1.0 \mathrm{pg} / \mathrm{mL})$, and tumor necrosis factor-alpha $(1.3 \mathrm{pg} / \mathrm{mL})^{22-24}$. Measurement and data analysis were performed 
using the Bioplex 100 system and Bioplex Manager software version 3.0 (Bio-Rad Laboratories, Hercules, CA). All multiplex immunoassays were performed in 96 well format $1.2 \mu \mathrm{m}$ filter bottom plates (Millipore, Amsterdam, The Netherlands) and a 12 point standard curve in duplicate was included on every plate. In order to minimise interassay variation, positive and negative control samples were included.

In earlier experiments, the short-term intrasubject variability of cytokine measurements in EBC was determined in 59 older children (18 asthmatics, 21 children with cystic fibrosis, and 20 healthy controls), aged 6 to 16 years. The coefficient of variation was $17.9 \%$ for interleukin-4, 11.9\% for interleukin-5, $13.0 \%$ for interleukin$6,6.1 \%$ for interleukin-8, 14.9\% for interleukin-10, 26.9\% for interleukin-12p70, $22.6 \%$ for interleukin-13, and $15.8 \%$ for tumor necrosis factor-alpha 25 .

\section{Statistics}

Statistical calculations were performed using SPSS 11.5 (SPSS Inc, Chicago, USA). Normally distributed data were expressed as mean and standard error. The Student's t-test was used to test for differences among dependent, paired or repeated samples. Pearson's correlation coefficients were used to assess the degree of association between two normally distributed variables. Analysis of variance (ANOVA) was used to test for differences among normally distributed variables for more than two study groups.

Not normally distributed data were expressed as median with interquartile ranges $(\mathrm{IQR})$. The Wilcoxon signed rank test was used to test for differences among not normally distributed paired data, whereas the Mann-Whitney $U$ test was used for unpaired data. Spearman's rank correlation coefficients were used to assess the degree of association between two not normally distributed variables. The KruskalWallis test was used to test for differences among non-normal variables for more than two study groups. The Hochberg correction for multiple comparisons was applied. The Chi-square test was used to evaluate the distribution of categorical variables (number of occurrences) in four study groups.

\section{Power Calculation}

Assuming a success rate of $80 \%$, the standard error of feasibility is $5.1 \%$ using $n=60$ subjects. This was considered sufficiently accurate for the purpose of this study.

\section{Ethics}

The study was approved by the Medical Ethics Committee of the University Hospital of Maastricht and the Maasland Hospital Sittard. All parents gave written informed consent.

\section{Results}

\section{Feasibility of EBC collection}

A total number of 70 preschool children participated. Feasibility of the new EBC collection method in preschool children is shown in Table 2. 
Table 2. Feasibility of exhaled breath condensate collection, before and after breath recirculation (BR), in 70 preschool children.

\begin{tabular}{|c|c|c|c|c|c|}
\hline Study group & Asthma & Viral & Control & Unclass. & $p$ value \\
\hline Number & 23 & 22 & 20 & 5 & - \\
\hline Age $A$ & $31(19)^{C}$ & $28(16)^{C}$ & $13(18)^{C}$ & $25(15)$ & - \\
\hline \multicolumn{6}{|l|}{ Before BR } \\
\hline Duration A & $11(9) \mathrm{D}$ & $12(6)^{D}$ & $6(6) \mathrm{D}$ & $14(1)$ & $0.004 \mathrm{~F}$ \\
\hline Volume A & $200(250) \mathrm{E}$ & $300(280) \mathrm{E}$ & $0(245) \mathrm{E}$ & $300(100)$ & $0.031 \mathrm{~F}$ \\
\hline Success rate $B$ & $15(65)$ & $20(91)$ & $6(30)$ & $4(80)$ & - \\
\hline \multicolumn{6}{|l|}{ After BR } \\
\hline Volume A & 367 (620) & 340 (362) & 130 (417) & 575 (287) & $0.385^{F}$ \\
\hline \multicolumn{6}{|l|}{ Total } \\
\hline Volume $\mathrm{A}$ & $300(500)$ & $410(400)$ & 295 (357) & 800 (150) & $0.351^{\mathrm{F}}$ \\
\hline Success rate $B$ & 17 (74) & $21(95)$ & $15(75)$ & $5(100)$ & $<0.001 \mathrm{G}$ \\
\hline
\end{tabular}

After BR, after breath recirculation; Age, in months; Asthma, doctor's diagnosed atopic asthma group; Before BR, before breath recirculation; Control, healthy control group; Duration, duration of condensate collection in minutes; Success, exhaled breath condensate collection was defined successful when at least $60 \mu \mathrm{L}$ of condensate was yielded; Total, before and after breath recirculation; Unclass., unclassifiable recurrent wheezing group, excluded for statistical analysis for reasons of disproportionality; Viral, viral-triggered recurrent wheezing group; Volume, condensate volume in $\mu \mathrm{L}$. Amedian (interquartile range); Babsolute number (percentage); $C_{p}=0.012$ (multiple comparisons, Hochberg correction); $\mathrm{D} p \leq 0.012$ (multiple comparisons, Hochberg correction); $\mathrm{E}_{\mathrm{p}}=0.039$ (multiple comparisons, Hochberg correction); $\mathrm{F}$ analysis of variance (ANOVA); ${ }^{\mathrm{G}}$ chi square test.

Before breath recirculation, the median duration of $\mathrm{EBC}$ collection was 10 minutes (IQR 9), the median EBC volume was $200 \mu \mathrm{L}$ (IQR 270), and the success rate was $64 \%$ in these preschool children. After breath recirculation, the median EBC volume was 225 $\mathrm{L}$ (IQR 495).

In total, the median EBC volume was $400 \mu \mathrm{L}$ (IQR 450). The success rate of EBC collection was $83 \%$ in these preschool children, but differed significantly between the four study groups ( $p<0.001$, Chi square).

In the healthy group, the median duration of EBC collection was 6 minutes, and median EBC volume before breath recirculation was zero $\mu \mathrm{L}$, whereas both were significantly decreased compared to the asthmatic and viral wheeze group ( $p<0.031$, ANOVA).

A younger age was significantly correlated with less duration of EBC collection time ( $R=0.481, p<0.001$, Spearman correlation coefficient). A duration of $E B C$ collection time of 10 minutes or more, was associated with successful EBC collection before breath recirculation. 
Table 3. Distractive measures for preschool children during the exhaled breath condensate collection procedure.

\begin{tabular}{llllll} 
Study group & Asthma & Viral & Control & Unclass. & total (\%) \\
\hline Number & 23 & 22 & 20 & 5 & $70(100)$ \\
Success & 17 & 21 & 15 & 5 & $58(83)$ \\
Not started & 1 & 1 & 2 & 0 & $4(6)$ \\
Distraction by: & & & & & \\
Parent & 19 & 17 & 17 & 4 & $57(86)$ \\
Cartoon & 20 & 14 & 11 & 5 & $50(76)$ \\
Book & 10 & 5 & 5 & 4 & $24(36)$ \\
Puppet & 5 & 3 & 2 & 0 & $10(15)$ \\
Song & 0 & 6 & 2 & 0 & $8(12)$ \\
\hline
\end{tabular}

Asthma, doctor's diagnosed atopic asthma group; Control, healthy control group; Success, exhaled breath condensate collection was defined successful when at least $60 \mu \mathrm{L}$ of condensate was yielded; Unclass., unclassifiable recurrent wheezing group; Viral, viral-triggered recurrent wheezing group.

Table 3 shows the distractive measures used during EBC collection. Four children refused to start due to sudden anxiety, associated with insufficient parental stimulation and/or recent ear-nose-throat surgery (adenoidectomy, and/or tonsillectomy, and/or myringotomy with insertion of tympanostomy tube). Distraction was mainly achieved by combined parental cooperation and cartoon watching. The Hans Rudolph face mask was applied in 60 children, whereas five preferred the babyhaler ${ }^{\circledR}$ and one the nebuchamber ${ }^{\circledR}$ face mask. Two collection procedures were not successful due to leakage of exhaled breath from defective TedlarTM gas sample bags. No adverse effects on respiration, nor other side-effects, were seen during the collection procedures.

\section{Cytokine measurements before and after breath recirculation}

Table 4 shows the detection and concentration of interleukin-4, interleukin-5, interleukin6, interleukin-8, interleukin-10, interleukin-12p70, interleukin-13, and tumor necrosis factor-alpha in EBC collected before, as well as after breath recirculation, in 45 preschool children. The detection of cytokines in EBC was successful in 95 to $100 \%$ of the collected $50 \mu \mathrm{L}$ condensate samples. There was no statistical difference between cytokine concentrations before and after breath recirculation ( $p>0.117$, Wilcoxon).

\section{Cytokines in subgroups with and without wheeze}

For further cytokine analysis between the different study groups, the separately collected condensate samples before as well as after breath recirculation in each subject, were considered as one donor series. Between the asthmatic $(n=17)$, viral wheeze $(n=21)$ and healthy $(n=15)$ group, the median cytokine concentrations of interleukin-4, interleukin5, interleukin-6, interleukin-8, interleukin-10, interleukin-12p70, and interleukin-13 did not differ (data not shown), whereas the median concentration of tumor necrosis factor-alpha was significantly decreased in the asthmatic group (median 38.8pg/mL in 
Table 4. Detection (\%) and concentration $(\mathrm{pg} / \mathrm{mL})$ of cytokines in exhaled breath condensate collected before and after breath recirculation (BR) in 45 preschool children.

\begin{tabular}{llllll} 
EBC & \multicolumn{2}{l}{ before $\mathrm{BR}$} & \multicolumn{2}{l}{ after BR } & p value C \\
\hline & $\%$ A & $\mathrm{pg} / \mathrm{mL}^{\mathbf{B}}$ & $\% \mathrm{~A}$ & $\mathrm{pg} / \mathrm{mL}^{\mathbf{B}}$ & \\
\hline IL-4 & 100 & $2.1(0.7)$ & 100 & $2.2(0.9)$ & 0.346 \\
IL-5 & 98 & $16.7(1.6)$ & 97 & $16.7(1.6)$ & 0.278 \\
IL-6 & 96 & $3.3(0.9)$ & 95 & $2.9(0.4)$ & 0.611 \\
IL-8 & 100 & $3.9(1.0)$ & 100 & $4.4(1.1)$ & 0.117 \\
IL-10 & 98 & $4.7(0.7)$ & 100 & $4.7(0.5)$ & 0.455 \\
IL-12p70 & 100 & $3.4(0.4)$ & 100 & $3.4(0.3)$ & 0.301 \\
IL-13 & 100 & $8.5(1.8)$ & 100 & $8.5(1.4)$ & 0.603 \\
TNF-alpha & 96 & $40.9(5.8)$ & 95 & $40.9(6.1)$ & 0.746 \\
\hline
\end{tabular}

after BR, after breath recirculation; before BR, before breath recirculation; EBC, exhaled breath condensate.

Adetection in percentage; ${ }^{B}$ median concentration (interquartile range) in $\mathrm{pg} / \mathrm{mL}$; ${ }^{C}$ Wilcoxon signed rank test.

asthma, $42.9 \mathrm{pg} / \mathrm{mL}$ in viral wheeze, and $40.9 \mathrm{pg} / \mathrm{mL}$ in healthy controls, respectively) $(p=0.030$, Kruskal Wallis). A weak correlation existed between age and cytokine concentrations $(-0.120<R<0.392$, Spearman).

Table 5. Cytokine profile in exhaled breath condensate in 53 doctor's diagnosed atopic asthmatic (AA) and nonasthmatic (nonA) preschool children.

\begin{tabular}{llll} 
EBC & AA & nonA & p-value \\
\hline Number & 17 & 36 & - \\
TNF-alpha A & $38.8(4.3)$ & $41.7(3.4)$ & 0.019 \\
IL-5 / TNF-alpha A & $0.45(0.05)$ & $0.40(0.06)$ & 0.032 \\
IL-13 / TNF-alpha A & $0.24(0.06)$ & $0.20(0.03)$ & 0.049 \\
IL-4 A & $2.1(0.6)$ & $2.0(0.7)$ & NS \\
IL-5 A & $17.1(2.0)$ & $16.9(1.6)$ & NS \\
IL-6 A & $3.2(0.7)$ & $3.1(0.7)$ & NS \\
IL-8 A & $4.1(1.0)$ & $4.0(0.5)$ & NS \\
IL-10 A & $4.7(1.0)$ & $4.9(0.5)$ & NS \\
IL-12p70 A & $3.5(0.7)$ & $3.4(0.2)$ & NS \\
IL-13 A & $8.8(1.5)$ & $8.5(1.8)$ & NS
\end{tabular}

AA, doctor's diagnosed atopic asthma group; EBC, exhaled breath condensate; nonA, nonasthmatic preschool children consisting of the viral-triggered recurrent wheezing group and healthy group; NS, not significant.

Amedian (interquartile range); ${ }^{B}$ Mann Whitney $\mathrm{U}$ test. 
In atopic asthmatic children, inhaled corticosteroids did in general not influence cytokine levels in EBC, with one exception: tumor necrosis factor-alpha concentrations were significantly lowered in children with inhaled corticosteroid therapy, compared to steroid naïve children (median $37.1 \mathrm{pg} / \mathrm{mL}$ versus $41.7 \mathrm{pg} / \mathrm{mL}$, respectively) $(p=0.013$, Mann Whitney U).

When asthmatic and nonasthmatic (viral wheeze and healthy) children were compared, tumor necrosis factor-alpha concentrations in the asthmatic group (median $38.8 \mathrm{pg} / \mathrm{mL}, \mathrm{IQR} 4.3$ ) were significantly decreased versus nonasthmathic children

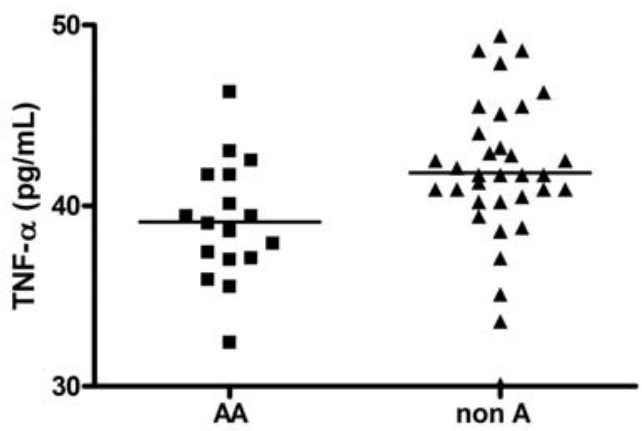

A

Tumor necrosis factor-alpha concentration in $E B C$ was significantly decreased in the AA group (median $38.8 \mathrm{pg} / \mathrm{mL}$, IQR 4.3), compared to the nonA group (median 41.7pg/mL, IQR 3.4) $(\mathrm{p}=0.019$, Mann Whitney U test).

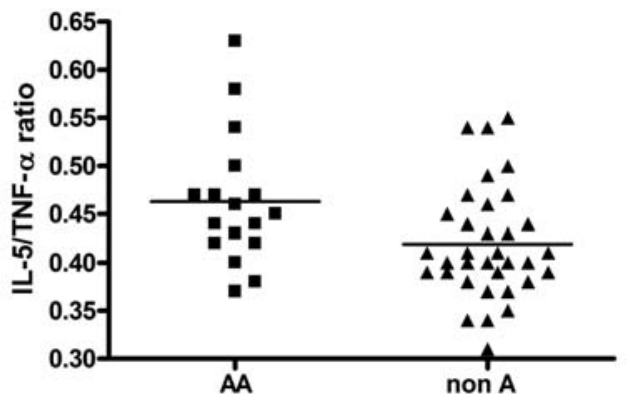

\section{B}

The interleukin-5 to tumor necrosis factor-alpha ratio in EBC was significantly increased in the AA group (median 0.45, IQR 0.05) compared to the nonA group (median 0.40, IQR $0.06)(p=0.032$, Mann Whitney U test).

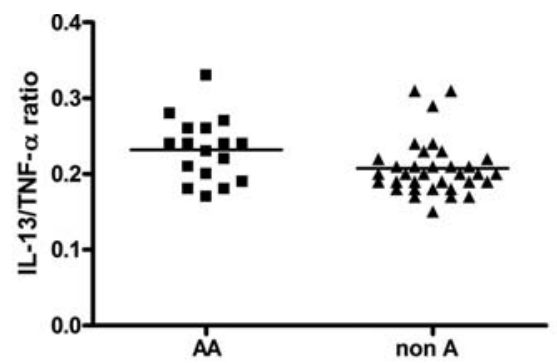

\section{C}

The interleukin-13 to tumor necrosis factor-alpha ratio in $E B C$ was significantly increased in the AA group (median 0.24, IQR 0.06) compared to the nonA group (median 0.20, IQR $0.03)(p=0.049$, Mann Whitney U test).

Figure 2A- 2B-2C. Th2/Th1 cytokine profiles in exhaled breath condensate (EBC) in doctor's diagnosed atopic asthmatic (AA) and nonasthmatic (nonA) preschool children.

AA, doctor's diagnosed atopic asthma group; EBC, exhaled breath condensate; IL, interleukin; IQR, interquartile range; nonA, nonasthmatic preschool children consisting of the viral-triggered recurrent wheezing group and healthy group; Th, T-helper cell; TNF- $\alpha$, tumor necrosis factor-alpha. 
(median 41.7pg/mL, IQR 3.4) ( $\mathrm{p}=0.019$, Mann Whitney U) (Table 5, Figure 2a). The ratios of interleukin-5 to tumor necrosis factor-alpha, and interleukin-13 to tumor necrosis factor-alpha in the asthmatic group (median 0.45, IQR 0.05, and median 0.24 , IQR 0.06, respectively) were significantly higher compared to nonasthmatic children (median 0.40, IQR 0.06, and median 0.20, IQR 0.03, respectively) ( $p=0.032$, and $p=0.049$, respectively, Mann Whitney $\mathrm{U}$ ) (Table 5, Figures 2b-2c).

\section{Discussion}

We demonstrated the feasibility and efficacy of EBC collection and analysis in preschool children with and without wheezing, using a novel closed glass condenser with breath recirculation system, and using multiplexed liquid bead array: (i) the overall success rate of the new EBC collection method was $83 \%$, with a median EBC volume of $400 \mu \mathrm{L}$; (ii) the detection of cytokine profiles in $50 \mu \mathrm{L} \mathrm{EBC}$ was successful in 95 to $100 \%$ of the collected samples; (iii) similar cytokine concentrations were found in EBC collected before as well as after breath recirculation; and (iv) in the atopic asthmatic group tumor necrosis factor-alpha concentrations in EBC were significantly decreased, whereas interleukin-5 to tumor necrosis factor-alpha, and interleukin-13 to tumor necrosis factor-alpha ratio's were significantly increased, compared to preschool children with viral wheeze and healthy controls.

We simultaneously introduced novel techniques to optimise the condensation process (Figure 1), and to improve small condensate sample analysis, in nonsedated preschool children with and without recurrent wheezing. Cumulatively, this new collection method with breath recirculation resulted in an overall success rate of $83 \%$, compared to $64 \%$ when using the 'usual' (before breath recirculation) procedure. Overall, the median total volume of EBC was $400 \mu \mathrm{L}$ in this study. In the literature, Moeller et al proposed a method to collect, both orally and nasally, a median EBC volume of $282 \mu \mathrm{L}$, using two disposable Plastipack syringes, in tidal breathing infants, however, during sedated sleep and without assessment of markers in the collected condensate ${ }^{19}$. Griese et al presented a nasal polypropylene collection system with air suction pump, to measure hydrogen peroxide and 8-isoprostane, and reported $85 \mu \mathrm{L}$ min $^{-1}$ of nasally collected EBC in healthy children aged 4 weeks to 18 years, however, with contamination by nasal secretions ${ }^{26-27}$. The correlation between age and duration of EBC collection is in accordance with the significantly increased volume of collected EBC with age, reported by both Griese et al, and Moeller et al ${ }^{19,25}$. Irrespective of the duration of EBC collection, breath recirculation allowed condensation of the totally exhaled breath volume within the closed glass system, in contrast to maximally $30 \%$ using the open-ended nasal suction system of Griese et al ${ }^{26-27}$. Hence, our concept of breath recirculation enabled not only the collection of an increased volume of EBC, but also, in the younger toddlers, with limited cooperation in time (often less than 10 minutes), breath recirculation was often crucial to yield a minimal but sufficient volume of condensate. 
Furthermore, cytokine concentrations in EBC collected before and after breath recirculation did not differ significantly, demonstrating that concentrations were not affected by the breath recirculation process, and illustrating an efficiency to generate additional and equivalent condensate.

In the literature, vastly different, nonstandardised EBC collection techniques are available, including the immersion of plastic tubing in an ice-filled bucket, a doublewall glass distilling column with counter-current ice-water pump, an ice-filled and double-chambered glass container, the commercial EcoScreen ${ }^{\circledR}$ (Erich Jaeger GmbH, Hoechberg, Germany), RTube ${ }^{\mathrm{TM}}$ (Respiratory Inc., Charlottesville, Virginia, USA), and Turbo-Deccs (ItalChill, Parma, Italy) ${ }^{9-11,28-29}$. All systems are based on the principle of constantly cooling exhaled air, whereas the handheld plastic RTube ${ }^{\mathrm{TM}}$, placed in a precooled sleeve, is highly susceptible to (higher) ambient temperatures during collection 9-11,30. Moreover, these systems have an open ended and relatively short measured design, resulting in the variable loss of noncondensed exhaled breath, as condensation does not immediately occur, and/or does not continue once the condensation surface is completely saturated.

Additionally, exhaled biomarkers may be lost in different EBC sampling systems, due to adhesive interactions between condenser coatings and exhaled biomarkers 17,31 . Therefore, Tufvesson et al proposed to coat the EcoScreen ${ }^{\circledR}$ collection surfaces with bovine serum albumin and Tween-20, to measure cytokines and eicosanoids, respectively ${ }^{31}$. However, they reported possible false-positive eicosanoid results, and the need of vacuum-centrifugation prior to analysis ${ }^{31}$. Recently, we compared six condenser systems, and found a glass or silicone condenser more efficient, both in vitro and in vivo, for the recovery of 8-isoprostane and albumin in EBC, compared to aluminium, polypropylene, Teflon and the EcoScreen ${ }^{\circledR}$ condenser ${ }^{17}$.

In ventilated neonates, Cheah et al described a polyvinylchloride tubing, immersed in wet ice, to collect EBC, however, with insufficient sensitivity to detect hydrogen peroxide ${ }^{18}$. Other techniques for EBC collection in ventilated infants, children and young adults, have recently been proposed ${ }^{32-33}$.

Multiplexed liquid bead array was used to measure cytokines more accurately in only $50 \mu \mathrm{L}$ sample volumes of EBC. The detection level of cytokines was high, ranging from 95 to $100 \%$. Multiplexed liquid bead array is based on flow cytometry and microspheres (with faster and more reproducible liquid reaction kinetics, than solid planar assays), and allows multiplexing of up to 100 assays within one sample ${ }^{22}$. Reasons to introduce this technique were: (a) lack of sensitivity of conventional enzyme-linked immunosorbent assays to detect cytokines in 200 to $500 \mu \mathrm{L} \mathrm{EBC} 34$; and (b) variable level of simultaneous cytokine detection by cytometric bead array, ranging from 0 to $25 \%$, in $50 \mu \mathrm{L} \mathrm{EBC}$ in children ${ }^{13}$, and from 3 to $100 \%$, in 1000 to $2000 \mu \mathrm{L}$ lyophilised EBC in adults ${ }^{35-37}$. When compared with conventional assays, multiplexed immunoassays are highly sensitive and specific, detect bioactive and inactive molecules, are rapid (hours instead of day(s)), have good (but not yet excellent) precision with 
coefficients of variation ranging from 10 to $15 \%$, are not interfered by drugs, have a simple protocol, require small sample volumes, and allow simultaneous detection ${ }^{22}$.

In preschool children with different wheezing phenotypes, the central issue consists of finding a noninvasive measure to identify underlying (persisting) airway disease, such as atopic asthma. In contrast to preschool children with viral wheeze and healthy children, atopic asthma is characterised by a predominantly T-helper cell type 2 mediated chronic eosinophilic airway inflammation 1,3,6. Statistical analysis revealed a significantly decreased tumor necrosis factor-alpha in EBC in the atopic asthmatic group, compared to viral wheeze and healthy controls. Steroid-treated atopic asthmatic children had lowered levels of tumor necrosis factor-alpha in EBC. This is in accordance with studies on bronchial biopsies in atopic asthmatic inflammation showing significantly decreased levels of tumor necrosis factor-alpha after eight weeks of budesonide treatment ${ }^{38}$.

As supported by the findings of Shahid et al, who reported increased levels of interleukin-4 and decreased interferon-gamma in EBC in asthmatic children, the ratio's of interleukin-5 to tumor necrosis factor-alpha, and interleukin-13 to tumor necrosis factor-alpha in EBC were significantly increased in the asthmatic group, compared to nonasthmatics, although the difference between these fractions of interleukin-5 and interleukin-13 to tumor necrosis factor-alpha were mainly due to the lowered levels of tumor necrosis factor-alpha in EBC in asthmatic preschool children ${ }^{15}$.

The phenotypic classification in this study was performed on basis of parentally reported symptoms, a documented reaction on (inhaled) corticosteroids, medical records, and information of the responsible paediatric pulmonologist. Although a certain asthma diagnosis cannot be proven in this age group, a reasonable accuracy can be obtained using simple, clinically based parameters ${ }^{39}$. It is likely that children of the asthmatic group had allergic asthma on basis of recurrent wheezing that was not 'exclusively' viral triggered, a documented positive steroid response, the presence of allergic sensitisation in these children, and a positive family history of atopy in the first degree. On the other hand, we acknowledge that the presence of atopy in four children in the viral wheeze group may have influenced cytokine concentrations. Similarly, upper airway contamination through the use of facemasks without separated nose and mouth cavity, may have been another possible confounding factor in six children. Age was not a confounder in this study, as cytokine concentrations were not significantly related to age. This is particularly important as a difference of age existed between the healthy children and the children with wheeze (Table 1). Further evaluation of repeated cytokine profile measurements in distinct wheezing phenotypes is warranted.

Finally, we speculate that the proposed method of EBC collection may open a new window of opportunities in pediatric research, as it may allow noninvasive inflammatory profiling in nonsedated preschool children. 
In conclusion, we demonstrated the feasibility and efficacy of a novel closed glass condenser with breath recirculation system to collect EBC in nonsedated preschool children with and without wheezing illness, irrespective of the duration of EBC collection. Multiplexed liquid bead array enabled more accurate cytokine measurement in only small EBC sample sizes. In atopic asthmatic preschool children, tumor necrosis factor-alpha concentrations in EBC were significantly decreased, whereas the ratio's of interleukin-5 to tumor necrosis factor-alpha, and interleukin-13 to tumor necrosis factor-alpha were significantly increased, compared to nonasthmatic children.

\section{Acknowledgement}

The authors wish to thank the childhood asthma nurses, Irene Breugelmans, Jacqueline Frenken, and Paula Heggen, for their technical support in the collection of EBC (Dept of Paediatrics, Maasland Hospital, Sittard, the Netherlands); and last but not least the parents and children for their participation. 


\section{References}

1. Grigg J, Silverman M. Wheezing disorders in young children: one disease or several phenotypes? In Respiratory diseases in infants and children. U. Frey, and J. Gerritsen, editors. Eur Respir Mon 2006; 37: 153-169.

2. de Jongste JC. To wheeze or not to wheeze. Am J Respir Crit Care Med 2006; 174: 1281-1282.

3. Robinson DS, Hamid Q, Ying S, Tsicopoulos A, Barkans J, Bentley AM, Corrigan C, Durham SR, Kay AB. Predominant TH2-like bronchoalveolar T-lymphocyte population in atopic asthma. N Eng J Med 1992; 326: 298-304.

4. Merkus PJFM, Hislop AA. Lung development from infancy to adulthood. In Respiratory diseases in infants and children. U. Frey, and J. Gerritsen, editors. Eur Respir Mon 2006; 37: 8-21.

5. LeSouëf $P$, Kabesch M. Impact of genetic factors on lung development in health and disease. In Respiratory diseases in infants and children. U. Frey, and J. Gerritsen, editors. Eur Respir Mon 2006; 37: 93-107.

6. Schaub B, Lauener R, Prescott SL. Immunology and defence mechanism of the developing lung. In Respiratory diseases in infants and children. U. Frey, and J. Gerritsen, editors. Eur Respir Mon 2006; 37: 60-78.

7. von Mutius E. Epidemiology of respiratory diseases in infants and children. In Respiratory diseases in infants and children. U. Frey, and J. Gerritsen, editors. Eur Respir Mon 2006; 37: 1-7.

8. Martinez FD, Wright AL, Taussig LM, Holberg CJ, Halonen M, Morgan WJ. Asthma and wheezing in the first six years of life. N Eng J Med 1995; 332: 133-138.

9. Jöbsis Q, Rosias PPR. 2004. Analysis of exhaled breath condensate in children. In New perspectives in monitoring lung inflammation. P. Montuschi, editor. Taylor \& Francis Publishers. London, United Kingdom. 105-111. (ISBN 0415324653).

10. Rosias PPR, Dompeling E, Hendriks JJE, Heijnens JWCM, Donckerwolcke RAMG, Jöbsis Q. Exhaled breath condensate in children: pearls and pitfalls. Pediatr Allergy Immunol 2004; 15: 4-19.

11. Horváth I, Hunt J, Barnes PJ, on behalf of the ATS / ERS Task Force. Exhaled breath condensate: methodological recommendations and unresolved questions. Eur Respir J 2005; 26: 523-548.

12. Jöbsis Q, Raatgreep HC, Hermans PW, de Jongste JC. Hydrogen peroxide in exhaled air is increased in stable asthmatic children. Eur Respir J 1997; 10: 519-521.

13. Robroeks CMHHT, Jöbsis Q, Damoiseaux JGMC, Heijmans PHM, Rosias PPR, Hendriks HJE, Dompeling E. Cytokines in exhaled breath condensate of children with asthma and cystic fibrosis. Ann Allergy Asthma Immunol 2006; 96: 349-355.

14. Rosias PR, den Hartog GJ, Robroeks CM, Bast A, Donckerwolcke RA, Heynens JW, Suykerbuyk J, Hendriks HJ, Jöbsis Q, Dompeling E. Free radicals in exhaled breath condensate in cystic fibrosis and healthy subjects. Free Radic Res 2006; 40: 901-909.

15. Shahid SK, Kharitonov SA, Wilson NM, Bush A, Barnes PJ. Increased interleukin-4 and decreased interferon-gamma in EBC of children with asthma. Am J Respir Crit Care Med 2002; 165: 1290-1293. 
16. Baraldi E, Ghiro L, Piovan V, Carraro S, Zacchello F, Zanconato S. Safety and success of exhaled breath condensate collection in asthma. Arch Dis Child 2003; 88: 358360.

17. Rosias PP, Robroeks CM, Niemarkt HJ, Kester AD, Vernooy JH, Suykerbuyk J, Teunissen J, Heynens J, Hendriks HJ, Jöbsis Q, Dompeling E. Breath condenser coatings affect measurement of biomarkers in exhaled breath condensate. Eur Respir J 2006; 28: 1036-1041.

18. Cheah FC, Darlow BA, Winterbourn CC. Problems associated with collecting breath condensate for the measurement of exhaled hydrogen peroxide from neonates on respiratory support. Biol Neonate 2003; 84: 338-341.

19. Moeller A, Franklin P, Hall GL, Horak FJr, Wildhaber JH, Stick SM. Measuring exhaled breath condensate in infants. Pediatr Pulmonol 2006; 41: 184-187.

20. Huszár É, Szabó Z, Jakab A, Barta I, Herjavecz I, Horváth I. Comparative measurement of thromboxane A2 metabolites in exhaled breath condensate by different immunoassays. Inflamm Res 2005; 54: 350-355.

21. Rosias P, Robroeks C, Hendriks J, Dompeling E, Jöbsis Q. Exhaled breath condensate: a space odyssey, where no one has gone before ... Eur Respir J 2004; 24: 189-190.

22. de Jager W, Rijkers GT. Solid-phase and bead-based cytokine immunoassay: a comparison. Methods 2006; 38: 294-303.

23. de Jager W, Prakken BJ, Bijlsma JW, Kuis W, Rijkers GT. Improved multiplex immunoassay performance in human plasma and synovial fluid following removal of interfering heterophilic antibodies. J Immunol Methods 2005; 300: 124-135.

24. de Jager W, te Velthuis H, Prakken BJ, Kuis W, Rijkers GT. Simultaneous detection of 15 human cytokines in a single sample of stimulated peripheral blood mononuclear cells. Clin Diagn Lab Immunol 2003; 10: 133-139.

25. Robroeks C, Dompeling E, Rijkers G, Damoiseaux J, Jöbsis Q. Inflammatory markers in exhaled breath condensate, assessed by means of Luminex ${ }^{\circledR}$ technology, can differentiate between children with asthma, cystic fibrosis, and healthy controls. Eur Respir J 2007; 30 (Suppl 51): 498s-499s.

26. Griese M, Latzin P, Beck J. A noninvasive method to collect nasally exhaled air condensate in humans of all ages. Eur J Clin Invest 2001; 31: 915-920.

27. Latzin P, Beck-Ripp J, Hartl D, Bartenstein A, Noss J, Griese M. 8-Isoprostane in nasally exhaled breath condensate in different pediatric lung diseases. Eur J Med Res 2007; 12: 21-25.

28. Caglieri A, Goldoni M, Acampa O, Andreoli R, Vettori MV, Corradi M, Apostoli P, Mutti $A$. The effect of inhaled chromium on different exhaled breath condensate biomarkers among chrome-plating workers. Environ Health Perspect 2006; 114 : 542-546.

29. Horváth I, Donnelly LE, Kiss A, Kharitonov SA, Lim S, Chung KF, Barnes PJ. Combined use of exhaled hydrogen peroxide and nitric oxide in monitoring asthma. Am J Respir Crit Care Med 1998; 158: 1042-1046.

30. Soyer OU, Dizdar EA, Keskin O, Lilly C, Kalayci O. Comparison of two methods for exhaled breath condensate collection. Allergy 2006; 61: 1016-1018.

31. Tufvesson E, Bjermer L. Methodological improvements for measuring eicosnaoids and cytokines in exhaled breath condensate. Respir Med 2006; 100: 34-38. 
32. Muller WG, Morini F, Eaton S, Peters M, Jaffe A. Safety and feasibility of exhaled breath condensate in ventilated infants and children. Eur Respir J 2006; 28: 476-485.

33. Walsh BK, Mackey DJ, Pajewski T, Yu Y, Gaston BM., Hunt JF. Exhaled breath condensate $\mathrm{pH}$ can be safely and continuously monitored in mechanically ventilated patients. Respir Care 2006; 51: 1125-1131.

34. Rosias PPR, Dompeling E, Dentener MA, Pennings HJ, Hendriks HJE, Van lersel MPA, Jöbsis Q. Childhood asthma: exhaled markers of airway inflammation, asthma control score, and lung function tests. Pediatr Pulmonol 2004; 38: 107-114.

35. Sack U, Scheibe R, Wötzel M, Hammerschmidt S, Kuhn H, Emmrich F, Hoheisel G, Wirtz $\mathrm{H}$, Gessner C. Multiplex analysis of cytokines in exhaled breath condensate. Cytometry A 2006; 69: 169-172.

36. Gessner C, Scheibe R, Wötzel M, Hammerschmidt S, Kuhn H, Engelmann L, Hoheisel G, Gillissen A, Sack U, Wirtz H. Exhaled breath condensate cytokine patterns in chronic obstructive pulmonary disease. Respir Med 2005; 99: 1229-1240.

37. Matsunaga K, Yanagisawa S, Ichikawa T, Ueshima K, Akamatsu K, Hirano T, Nakanishi M, Yamagata T, Minakata Y, Ichinose M. Airway cytokine expression measured by means of protein array in exhaled breath condensate: correlation with physiologic properties in asthmatic patients. J Allergy Clin Immunol 2006; 118: 84-90.

38. Wilson SJ, Wallin A, Della-Cioppa G, Sandström T, Holgate ST. Effects of budesonide and formoterol on NF-kB, adhesion molecules, and cytokines in asthma. Am J Respir Crit Care Med 2001; 164: 1047-1052.

39. Castro-Rodriguez JA, Holberg CJ, Wright AL, Martinez FD. A clinical index to define risk of asthma in young children with recurrent wheezing. Am J Respir Crit Care Med 2000; 162: 1403-1406. 


\section{CHAPTER 9}

\section{General Discussion}

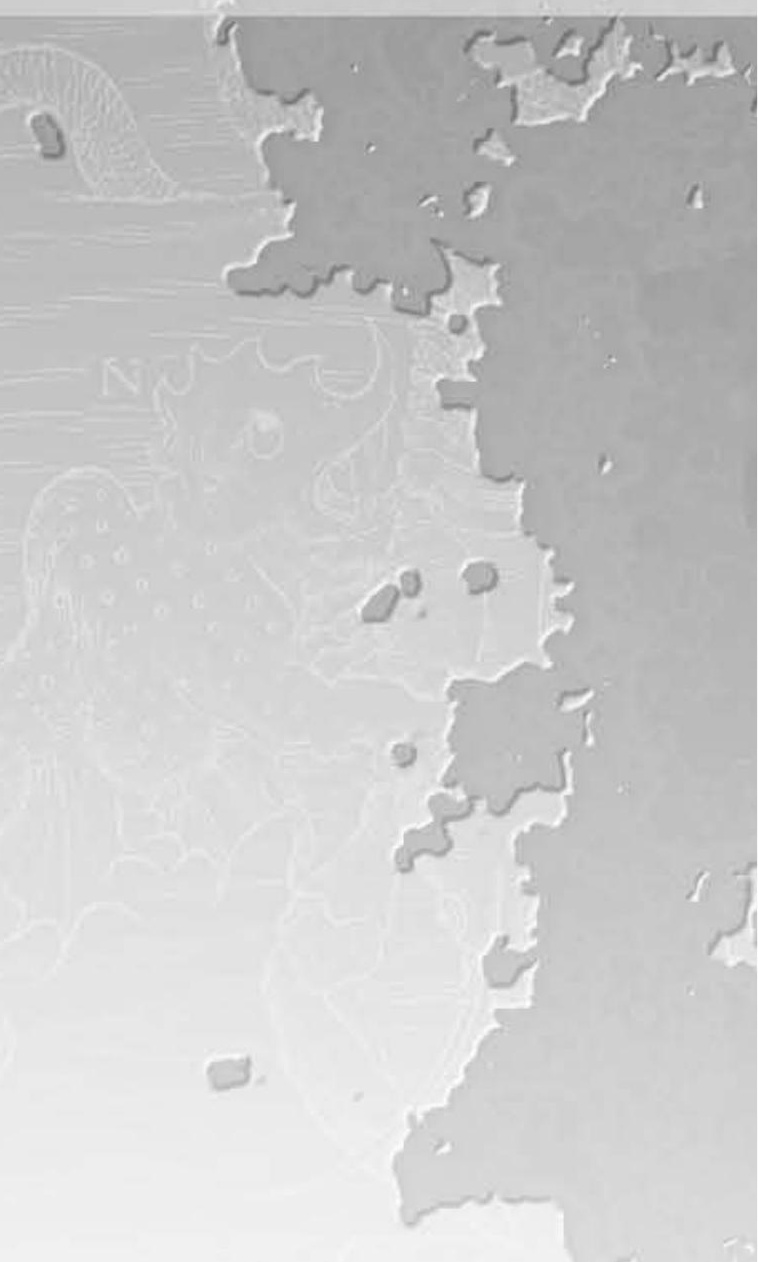




\section{Contents}

9.1. What is exhaled breath condensate?

9.2. Why should we study EBC?

199

9.3. Pearls and pitfalls of EBC

200

9.4. Cross sectional studies in children

201

9.4.1. A cross sectional study in children with asthma 202

9.4.2. A cross sectional study in children with cystic fibrosis 203

9.5. Development of a new condenser system 206

9.5.1. Phase 1: the Babel confusion 206

9.5.2. Phase 2: the condenser coating study 207

9.5.3. Phase 3: a new condenser concept emerges 209

9.5.4. Phase 4: the new condenser system 211

9.6. New sensitive techniques for the detection and measurement of biomarkers in EBC $\quad 214$

9.6.1. Cytokines in EBC 214

9.6.1.1. Why and how we tried to detect cytokines in EBC 214

9.6.1.2. Multiplexed liquid bead array and the measurement of cytokines in EBC 215

9.6.2. Free radicals in $\mathrm{EBC} \quad 216$

9.6.3. The measurement of other inflammatory markers in EBC 217

9.7. Application of new techniques in preschool children 223

9.8. What do we add? 226

9.9. What may or should be? 228

9.10. Epilogue 


\section{General Discussion}

The front cover of this thesis reminds us that in the eighth century before Christ, Homeros has written the Odyssey, an epic poem telling of the wanderings of Odysseus, a greek heroe of the Troyan war and king of Ithaca. ${ }^{1}$ It took Odysseus ten long years to return to his homeland and to finally regain the heart of his beloved queen Penelope. ${ }^{1}$ The methodological development of exhaled breath condensate (EBC) collection and analysis, the subject of this thesis, is also to some extend a telling of the long voyage we have made, instead of a clearcut report of stepwise proceedings, before our destination came into sight. In this way, the heart of Penelope consists of accurate diagnosis and customised care based on noninvasive techniques for all children with chronic respiratory inflammation.

\subsection{What is exhaled breath condensate ?}

In 1980, the pilot article on EBC entitled 'Surface-active properties of the exhaled air condensate, a new method of studying lung function', was published in Russian by Sidorenko et alia. ${ }^{2}$ The perestroika reforms and the policy of glasnost hastened the end of the former Soviet Union in $1991 .^{3}$ Soon after, EBC was rediscovered as a biphasic technique implicating, at first, the cooling of exhaled breath to collect the condensate, and, secondly, the analysis of the collected condensate. ${ }^{4}$ EBC contains respiratory droplets with volatile and (mainly) nonvolatile macromolecules that are released from the epithelial lining fluid of the airways, and that, subsequently, are 'drowned' in an excess of water vapour. ${ }^{4-5}$ There is evidence that abnormalities in EBC composition may reflect biochemical changes of the airway lining fluid. ${ }^{4}$ Moreover, the guiding and cooling of exhaled breath into a breath condenser system appears to constitute a noninvasive, rapid and relatively easy to perform method, as well as a technique that may be used repeatedly as it does not interact with the ongoing (patho)physiological processes in the airways, which, by consequence, may guarantee a high degree of safety to the subjected individual. ${ }^{6}$

\subsection{Why should we study EBC?}

In this section we substantiate the further methodological development of EBC collection and analysis, as argued in chapter 1.

Evidence-based medicine is the 'gold standard' for clinical practice and treatment guidelines, and is largely dependent upon distinct disease phenotypes. ${ }^{7-8}$ However, daily clinical reality confronts us with a natural diversity of complaints, which often reflects various dimensions of a broad spectrum of diseases. ${ }^{9-10}$ Heterogeneity is the hallmark of chronic respiratory inflammation, especially in growing children. ${ }^{10-17}$ However, current management guidelines are mainly based on symptoms and pulmonary function tests, and do not succeed in achieving optimal disease control. ${ }^{18-}$ 19 This is, at least in part, due to the lack of a tailored individual approach, especially in the younger child. ${ }^{18-19}$ 
Moreover, current conventional disease measures have some important limitations. There are many discrepancies between: (i) subjectively reported and objectively assessed airway symptoms; (ii) pulmonary function tests reflecting airflow limitation; and (iii) direct or indirect markers of airway inflammation, such as bronchoalveolar lavage fluid or bronchial challenge tests, respectively. Endobronchial biopsy, bronchoalveolar lavage and sputum induction are relatively difficult direct measures of airway inflammation and not suitable for routine use in clinical pediatric practice. Pulmonary function tests and sputum induction require more than minimal cooperation of a child, and thus, success rate substantially declines in children aged six to seven years or less. In general, procedures in favour of children should be suitable at any age, rapid and easy to perform, requiring only minimal cooperation, as well as harmless and painless, and thus, by definition, should never be invasive or semi-invasive. As chronic respiratory disease expression is heterogeneous, it seems only logical that noninvasive specific single markers (indicating diagnosis, disease control and/or airway inflammation), have to be assessed at an individual level. Moreover, if generally applied, a set of various markers is more likely to be useful in larger populations.

Therefore, it is crucial to define additional noninvasive markers of inflammation, in particular in children with chronic respiratory disorders, that can be applied in clinical practice over a wide range, that may be specific for the evaluation and monitoring of certain disease patterns, including early disease events, and/or response to treatment, and that may give relevant information on the individual child. One such noninvasive marker, nitric oxide, was discovered in human exhaled breath by Gustafsson et alia in 1991.20 Exhaled nitric oxide fraction is a marker of eosinophilic asthmatic inflammation. ${ }^{21}$ Only recently, in 2005, the first randomised controlled trial in asthmatic children on titrating inhaled corticosteroids using exhaled nitric oxide was published. ${ }^{22}$

Compared to current disease measures, and in particular exhaled nitric oxide, the noninvasive collection and analysis of EBC offers some theoretical advantages comprising: (i) an EBC collection procedure that may require only uncontrolled tidal breathing, instead of constant expiratory flow rates (with or without the use of dynamic flow restrictors); ${ }^{21}$ (ii) the potential of EBC to reveal the presence of multiple nonvolatile biomarkers, that play a role in the pathophysiology of various respiratory disorders, in contrast to only one specific volatile substance such as nitric oxide; and, subsequently, (iii) the potential to be useful in discriminating and/or monitoring of more than one inflammatory lung disease in subjects of all ages. Therefore, the development of EBC methodology may ultimately result in a promising new tool to measure various markers of chronic respiratory disease, especially in preschool children.

\subsection{Pearls and pitfalls of EBC}

In this section we separately discuss our findings, as presented in chapter 1.6, chapter 2 and chapter 4.1 , because these insights, in their very essence, were formative to our further research efforts. 
In chapter 1.6, we presented the methodology of EBC, corresponding to our knowledge at that time, and we found it to offer challenging new perspectives for the diagnosis and management of various inflammatory lung diseases, of particular interest for paediatric respiratory medicine. Moreover, EBC procedures are well tolerated, and even safe in children, aged four years and above, with and without asthma exacerbation. ${ }^{6}$

Subsequently, we proceeded with a systematic elaboration from a pediatric point of view, presented in chapter 2 , of the pearls and pitfalls of each single aspect of EBC methodology, comprising the collection, preservation and analysis of EBC. We identified many confounding factors that were, in general, attributable to the lack of a standardised collection technique and procedure, as well as to the lack of specific and highly sensitive analytical techniques.

By consequence, we did not wish to overstate the apparent simplicity of EBC. Moreover, we were triggered off by, on one hand, the constant flux of reports on highly variable marker concentrations in condensate in clinical studies using more or less inappropriate assays, and, on the other hand, by the various methods of EBC collection, as systematically reviewed in chapter 2 .

Hence, we put forward that these two key issues (id est variable marker concentrations in EBC, and various methods of EBC collection) might very well be mutually linked, at least in part, and until proven otherwise, as argued in chapter 4.1. All the above has led us to direct our research efforts primarily towards optimising the condensate collection system for the measurement of a given type of biomarker, prior to any standardisation at all, rather than focussing on pure clinical 'hit-and-run' EBC trials, that usually provide only limited cross sectional data in relatively small populations, with only median group differences, using very different techniques, including assays with inappropriate lower detection limits and poor reproducibility. On the other hand, we could not neglect the fundamental reasons why we were and still are involved in research on EBC. In fact, we ultimately want to develop a new and noninvasive tool to assess chronic respiratory inflammation, especially in preschool children. Thus, we simultaneously performed two clinical trials, although one may argue their early or preliminary status.

We now invite the interested reader to join us in systematically evaluating four topics on EBC that are addressed by this thesis, although there inevitably exists some overlap: (i) cross sectional studies in children with asthma and cystic fibrosis (chapter 9.4), (ii) development of a new condenser system (chapter 9.5), (iii) new sensitive techniques for the detection and measurement of biomarkers in EBC (chapter 9.6), and (iv) application of new techniques in preschool children (chapter 9.7).

\subsection{Cross sectional studies in children}

In this section we will mainly discuss our findings in two - early - cross sectional, clinical studies, presented in chapter 3 and chapter 7, in children with asthma and 
cystic fibrosis, respectively. In this - early - perspective, we have put on trial our knowledge on EBC at that time, in order to further direct and adjust our research planning.

\subsubsection{A cross sectional study in children with asthma}

In chapter 3, we presented a cross sectional clinical trial in a relatively homogenous and well-controlled population of 23 asthmatic children and 9 healthy controls. New exhaled markers, comprising exhaled nitric oxide, exhaled carbon monoxide, condensate acidity $(\mathrm{pH})$ and cytokines (in casu interleukin-6, interleukin-8, tumor necrosis factor-alpha, soluble tumor necrosis factor-alpha receptor 75 , soluble intercellular adhesion molecule-1), as well as albumin and C-reactive protein in EBC, collected using a cooled borosilicate glass distilling column, were compared with conventional disease measures, such as lung function parameters and the asthma control questionnaire of Juniper.

At first, it was shown that, conventional specific solid-phase enzyme-linked immunosorbent assays, in particular designed for use in blood- and/or bronchoalveolar lavage fluid-samples (with lower limits of detection ranging from 20 to $50 \mathrm{pg} / \mathrm{mL}$ ), were not sensitive enough to detect interleukin-6, interleukin-8, tumor necrosis factor-alpha, soluble tumor necrosis factor-alpha receptor 75, and C-reactive protein in 200 to $500 \mu \mathrm{L}$ of EBC. On the other hand, ultrasensitive enzyme immunoassays were only able to detect albumin in two out of 32 EBC samples (with a lower limit of 8 $\mathrm{ng} / \mathrm{mL}$ ), and were not able to detect soluble intercellular adhesion molecule-1 in EBC (with a lower limit of $3 \mathrm{ng} / \mathrm{mL}$ ). Thus, conventional and even ultrasensitive solid-phase enzyme immunoassays were not able to smoothly detect small proteins in condensate samples, mainly due to lower detection limits that were not suitable for use in this 'new' water vapour-dominated medium. Huszar et alia compared two types of (similar) immunoassays to measure thromboxane A2 concentrations in EBC collected with the commercially available EcoScreen ${ }^{\circledR}$ condenser. ${ }^{23}$ They reported vastly different absolute values, due to intrinsic analytical problems associated with these assays. ${ }^{23}$ Similarly, 30 fold differences in condensate levels of interleukin-4 in asthmatic children were found using different enzyme immunoassays, as well as different condenser systems. ${ }^{24-25}$ On the other hand, Leung et alia also used ultrasensitive sandwich enzyme immunoassays, and reported detectable and reproducible measurements of growth factors (in casu macrophage-derived chemokine, thymus and activation regulated chemokine, epidermal growth factor, AA isoform of platelet-derived growth factor, and vascular endothelial growth factor) and cytokines (in casu tumor necrosis factor-alpha and interleukin-4) in EBC collected in asthmatic children with the RTube ${ }^{\mathrm{TM}}$ condenser. ${ }^{24,26-}$ 27 Detectable levels were ranging from 27 to 100 per cent. ${ }^{24}$ In children with cystic fibrosis, Bodini et alia found interleukin-8 detectable using a similarly ultrasensitive immunoassay in 90 per cent of EBC samples collected with a glass condenser. ${ }^{28}$ However, these authors did not report the volume of EBC that was required to perform each measurement. $24,26-28$ It may be clear that these conventional immunoassays are not yet optimal for routine use in EBC. 
Secondly, our childhood asthma study had shown that not-deaerated condensate $\mathrm{pH}$ was significantly lowered in the asthmatic group, compared to controls, whereas this was not found using deaerated condensate $\mathrm{pH}$. At that time, the methodology of condensate $\mathrm{pH}$ measurements was quite controversial, and even provoked a fierce polemic in literature whether to deaerate EBC samples or not. ${ }^{29-37}$ Meanwhile, this particular acid issue has been extensively addressed by several other research groups. ${ }^{38-}$

${ }^{47}$ Condensate $\mathrm{pH}$ is not stable due to the presence of ambient and exhaled carbon dioxide. ${ }^{48-49}$ Therefore, deaeration or gas standardisation involves the bubbling a carbon dioxide-free gas through the EBC sample for several minutes, to remove carbon dioxide and bicarbonate from EBC, and to rise and stabilise EBC pH. ${ }^{48-49}$ Nowadays, the American Thoracic Society / European Respiratory Society Task Force on EBC states that gas standardisation is useful when samples cannot be assayed immediately, when one is not interested in exhaled carbon dioxide levels, or when the condensate $\mathrm{pH}$ is expected to be particularly acidic. ${ }^{48-49}$

Thirdly, we reported a discordant pattern of generally low correlations between measures of airway inflammation, clinical parameters of disease severity, and physiological variables such as spirometric assessment of airway calibre. These few positive findings are likely related to the very absence of any methodological EBC standardisation, including the use of inappropriate analytical techniques, and/or to the relatively homogenous and well-controlled study population. However, it is also plausible that this may have been a first subtle indication that the measurement of airway inflammation does reflect some unmet aspects of chronic respiratory disease. Airway inflammation is not the same as subjectively reported airway symptoms, nor is it the same as pulmonary function tests that only reflect airflow limitation. Hence, this may suggest an additional value of exhaled measures of inflammation, for the noninvasive management of childhood asthma.

Nevertheless, a rapid and ill-considered implementation of EBC in clinical trials may be not more than walking on thin ice. Recently, this was demonstrated, again, in a prospective study in 40 children with stable asthma eligible for inhaled steroid reduction. ${ }^{50}$ In this study, the authors report that EBC measurements of nitrite/nitrate levels and cysteinyl leukotrienes proved to be disappointing clinical tools, although they add that their results cannot be taken to suggest that EBC has no role in the monitoring of childhood asthma. ${ }^{50}$ However, some alternative and plausible methodological explanations have not been highlighted by this study, such as the use of a specific solid-phase enzyme immunoassay to measure cysteinyl leukotrienes, with a relatively high lower-limit of detection of $15.0 \mathrm{pg} / \mathrm{mL}$, designed for application in other mediums, but not EBC. ${ }^{50}$ Moreover, the authors mentioned they had to make arbitrary choices of what to measure due to the small volumes of condensate obtained by the commercially available EcoScreen ${ }^{\circledR}$ condenser, indicating an inefficient condensation process, or the need of large sample volumes required for analysis. ${ }^{50}$

\subsubsection{A cross sectional study in children with cystic fibrosis}

In chapter 7, we explored the ability of different exhaled inflammatory markers, including exhaled nitric oxide, condensate $\mathrm{pH}$, nitrite, nitrate, hydrogen peroxide, 8- 
isoprostane, and various T helper- 1 and $T$ helper- 2 cytokines, such as interferongamma, tumor necrosis factor-alpha, interleukin-2, interleukin-4, interleukin-5 and interleukin-10 in EBC, to discriminate between a large cohort of 48 children with cystic fibrosis and 50 healthy controls in a cross sectional study design. Furthermore, we used multiplexed cytometric bead array, as previously described by our research group, to measure several cytokines, simultaneously, in EBC collected using a cooled borosilicate glass distilling column. ${ }^{51}$

The cross sectional cystic fibrosis study showed that multiplexed detection of cytokines in only $50 \mu \mathrm{L}$ of EBC was possible, using cytometric bead array. This technique consists of a series of spectrally discrete particles that can be used to capture and quantitate soluble analytes (in casu cytokines). ${ }^{52-53}$ The analyte is then measured by detection of a fluorescence-based emission and flow cytometric analysis. ${ }^{52-53}$ In short, cytometric bead array generates data that are comparable to enzyme linked immuno sorbent assays, but in a multiplexed or simultaneous fashion, and obtains more results from a single small sample. ${ }^{52-53}$ In the cystic fibrosis study, interleukin-5 was the only nondetectable cytokine in EBC, compared to several nondetectable cytokines in our first report on cytometric bead array (tumor necrosis factor-alpha and interleukin-5 were nondetectable in children with cystic fibrosis, whereas interleukin-2, interleukin4 and interleukin-5 were nondetectable in healthy control children). ${ }^{51}$ The lack to detect any interleukin-5 is in agreement with the findings of Armstrong et alia in bronchoalveolar lavage fluid, and may be related to the presence of proteases in cystic fibrosis airways. ${ }^{54-55}$ The lack to detect (some) cytokines does not necessarily implicate that they are not present, as the detection method may lack sufficient sensitivity. In the cystic fibrosis study, the levels of detection of the other cytokines (interferongamma, tumor necrosis factor-alpha, interleukin-2, interleukin-4 and interleukin-10) ranged up to 42, and 20 per cent in children with cystic fibrosis, and healthy control children, respectively, compared to 25 and 14 per cent in our first report. ${ }^{51}$

Significantly more detections of interferon-gamma and interleukin-4 were found in EBC in children with cystic fibrosis compared to controls. Moreover, cytometric bead array did require only a small EBC sample size, as mentioned above, and in contrast to other reports, as noted below. ${ }^{56-58}$

In literature, no comparative data on cytometric bead array in EBC in children are (yet) available. On the other hand, in adults with acute lung injury or chronic obstructive pulmonary disease, cytometric bead array has also been described for the measurement of interleukin-1-beta, interleukin-6, interleukin-8, interleukin-10, tumor necrosis factor-alpha and interleukin-12p70 in EBC, collected with the EcoScreen ${ }^{\circledR}$, and only after lyophilisation (or freeze-drying) of $2000 \mu \mathrm{L} E B C$ and cryopreservation. ${ }^{56-}$ 57 The reported levels of cytokine detection in these subjects ranged from 37 to 100 per cent. ${ }^{57}$ Recently, Matsunaga et alia also reported the use of a membrane protein array to measure 40 different cytokines and chemokines in $1000 \mu \mathrm{L} \mathrm{EBC}$ in adult asthmatics using the EcoScreen ${ }^{\circledR}$, and found relative cytokine levels in 3 to 27 per cent of the samples. ${ }^{58}$ Interleukin-4, interleukin-8, interleukin-17, tumor necrosis factor- 
alpha, regulated on activation normal T-cell expressed and secreted (RANTES), interferon-gamma-inducible protein 10, transforming growth factor-beta, and macrophage inflammatory protein 1-alpha and 1-beta were significantly upregulated in asthmatics compared with healthy controls. ${ }^{58}$ Matsunaga et alia refer to a confirmation of good correlations between the relative levels obtained by using this method and the actual levels obtained by means of quantitative assays. ${ }^{58-59}$ In 22 adults, Schumann et alia reported the detection of erythropoietin and tumor necrosis factor-alpha in EBC collected using the EcoScreen ${ }^{\circledR}$, in 68 and 59 per cent, respectively. ${ }^{60}$ However, they did not report further details on the required volume of EBC, nor on sample processing. ${ }^{60}$

Furthermore, in the cross sectional cystic fibrosis study, the concentrations of interferon-gamma and nitrite in EBC were significantly increased, whereas exhaled nitric oxide levels were significantly decreased in the cystic fibrosis group, compared to controls. These results are in accordance with available data in literature on nitric oxide, ${ }^{61-70}$ nitrite (assessed in young adults with cystic fibrosis), ${ }^{62-63,71-73}$ as well as interferon-gamma (assessed in bronchial biopsies). ${ }^{74}$ Several hypotheses may explain lowered exhaled nitric oxide levels and higher nitrite concentrations in cystic fibrosis, including: (i) impaired diffusion of gasseous nitric oxide into the airway lumen due to viscous mucus in the cystic fibrosis airways, which in turn may result in conversion of nitric oxide into nitrite; 63,75 (ii) decreased expression of inducible nitric oxide synthase II in epithelial cells; ${ }^{70,76-80}$ and (iii) increased arginase activity in cystic fibrosis airways. ${ }^{81}$ Hence, we provided evidence for the discriminating ability, between children with cystic fibrosis and healthy controls, of three separate, exhaled inflammatory markers. Obviously, the clinical relevance of these findings for the individual child at long-term level remains yet to be determined. The concentration of hydrogen peroxide in EBC did not differ between children with cystic fibrosis and controls, which is in accordance with other reports. ${ }^{61,82}$ Also, condensate $\mathrm{pH}$ and the concentration of 8-isoprostane in EBC did not significantly differ between these study groups, which may be attributed to the mild to moderate cystic fibrosis severity in the study population. On the other hand, Montuschi et alia found significantly increased 8-isoprostane concentrations in EBC in 19 adult patients with cystic fibrosis, compared to normal subjects, ${ }^{83}$ whereas Carpagnano et alia found significantly lowered condensate $\mathrm{pH}$ in children with cystic fibrosis, than in healthy controls, and a further decrease in 10 children with cystic fibrosis exacerbation, compared to 10 stable cystic fibrosis patients. ${ }^{84}$

Using multivariate logistic regression models, a diagnosis of cystic fibrosis was best indicated by 8-isoprostane, nitrite and interferon-gamma in EBC. This particular profile of combined exhaled inflammatory markers, was able to discriminate children with cystic fibrosis from healthy controls, with an acceptable ratio of sensitivity (78 per cent) to specificity (92 per cent), and an area under the receiver operating characteristic curve of 0.906 . An exacerbation of cystic fibrosis was best indicated by 8-isoprostane and nitrite, with a sensitivity of 40 per cent, a specificity of 97 per cent, and an area under the receiver operating characteristic curve of 0.838 . Most indicative biomarkers of cystic fibrosis severity were exhaled nitric oxide and condensate $\mathrm{pH}$, with a sensitivity 
of 96 per cent, a specificity of 67 per cent, and an area under the receiver operating characteristic curve of 0.751 . In literature, to date, no comparable data are available. However, to clearly state, these indicative profiles do not at all intend to be an alternative assessment of cystic fibrosis diagnosis, as this would be almost redundant and even out of the question. In our opinion, such disease discriminating profiles of exhaled markers have to be identified, prior to any longitudinal clinical study on the noninvasive monitoring of chronic respiratory disease. Moreover, this study illustrates that the combination of various noninvasive markers into several specific profiles, may indicate different aspects of chronic respiratory disease. Hence, these combined noninvasive markers may even provide additional information, in contrast to each marker separately. Exempli gratia, in cystic fibrosis exhaled nitric oxide levels are usually low, whereas nitric oxide may indicate disease severity when combined with condesate $\mathrm{pH}$. This interesting 'synergisitic' effect warrants further exploration in a longitudinal setting.

In summary, it may be clear that the need for additional improvement of EBC methodology, prior to longitudinal clinical studies, was still incontestable.

\subsection{Development of a new condenser system}

In this section we will chronologically describe, in four phases, the development of a new breath condenser system, based on findings originating from chapter 4.2, chapter 5 and chapter 8.

\subsubsection{Phase 1: the Babel confusion}

In the methodological review, presented in chapter 2, we provided an overview of the vastly different techniques to collect EBC, at that time. Most widely used designs included imersion of a Teflon-lined tubing in an ice-filled bucket, and a double-wall borosilicate glass distilling column connected to a counter-current ice-water pump. Commercially available systems included the lamellar Teflon-like EcoScreen ${ }^{\circledR}$ condenser (Erich Jaeger GmbH, Hoechberg, Germany) and the hand-held disposable polypropylene RTube ${ }^{\mathrm{TM}}$ breath condensate collector (Respiratory Inc., Charlottesville, Virginia, USA). The EcoScreen ${ }^{\circledR}$ conducts exhaled air through a lamellar condenser with a sample collection vial inserted into an electrical cooling cuff. This design has been associated with deposition of frozen condensate on its inner lamellar walls. Likewise, immersed plastic tubing was even associated with complete obstruction of the collection lumen. Most of these condenser systems are connected to a two-way non-rebreathing valve and a mouth piece, whereas the RTube ${ }^{\mathrm{TM}}$, a portable hand-held condensate collector which consists of a re-usable and precooled aluminium sleeve that is placed over the outside of a disposable polypropylene vertical condensation or collection tube, is connected to one-way valves and a mouth piece. Recently, the thermostatically controlled polyethylene Turbo-Deccs (ItalChill, Parma, Italy) has joined this list. ${ }^{85}$ All systems are based on the principle of constantly cooling exhaled air, whereas the handheld plastic RTube ${ }^{\mathrm{TM}}$, placed in a pre-cooled sleeve, is highly susceptible to (higher) ambient temperatures during EBC collection. ${ }^{86}$ Hence, the 
confusing variety of physical characteristics associated with each specific condenser design constitutes one of the main obstacles for a smooth development of a standardised EBC sampling device.

\subsubsection{Phase 2: the condenser coating study}

As stated in chapter 4.1, we argued that the variability of biomarker concentrations may be associated, at least in part, and until proven otherwise, with the various designs of EBC collection. This culminated in the so-called coating study, as presented in chapter 4.2, and investigated the influence of different adhesive properties of inner condenser coating surfaces (in casu glass, silicone, aluminium, polypropylene, Teflon and the EcoScreen ${ }^{\circledR}$ condenser) on the measurement of eicosanoids (in casu 8isoprostane) and proteins (in casu human albumin) in condensate. We have shown that a condenser with a glass coating was more efficient for the measurement of these molecules in EBC, both in vitro as well as in vivo, when compared with other coatings, including the commercially available and Teflon-like EcoScreen ${ }^{\circledR}$ condenser.

The reported in vivo detectability and concentrations of 8-isoprostane in EBC in healthy subjects, were in line with available, but scarce data in literature. ${ }^{87}$ Moreover, when reviewing literature, according to an identical assay (enzyme or radioimmunoassay), and different condenser coatings, also higher 8-isoprostane concentrations were reported using a glass condenser compared with the EcoScreen ${ }^{\circledR}$ condenser. . $^{83,87-100}$

On the other hand, the reported isoprostane condensate recovery percentages in vitro were high and did not differ significantly between the condenser coatings. This may be a reflection of the higher overall mean condensate recovery of isoprostane (100 per cent) in contrast to albumin (52 per cent), which may in turn illustrate a different behaviour of these molecules during the expiratory phase of the EBC collection, as molecules with a higher molecular weight (id est 354 Dalton versus up to 80.000 Dalton, for 8-isoprostane and albumin, respectively) may experience more difficulties in their transition from respiratory fluid droplets and exhaled air, into the condensate. Conversely, an isoprostane overload in the in vitro experiments seems unlikely, when considering that the absolute amount in the condensate sample vials must have been very close to the concentrations found in vivo, as an isoprostane test solution of $42 \mathrm{pg} / \mathrm{mL}$ was nebulised. This may indicate that the nebuliser set-up was producing isoprostane aerosols that have been more effectively condensed as compared to the real EBC in vivo, and/or that the upper out of range plateau zone of the immunoassay was reached.

We also report in this study, a limited number of positive albumin detections in vivo, which in turn is in agreement with (i) the relatively few positive studies, at that time, on cytokines or proteins in EBC versus several positive reports on 8-isoprostane and leukotrienes in EBC; and with (ii) the methodological concerns raised by Tufvesson et alia on evaporation, loss of biomarkers in the condensate collection system and low biomarker concentrations in EBC (as further discussed). ${ }^{101}$ 
A possible plausible explanation for the superiority of glass coatings is mainly related to the fact that water acts as a bipolar vehicle, whereas the $\mathrm{pH}$ of exhaled breath ranges from 6.50 to 7.80 , and the isoelectrical point of human albumin is situated at $\mathrm{pH}$ 4.80. ${ }^{102}$ In other words, at higher $\mathrm{pH}$ values (such as reported in EBC) albumin acts as a negatively charged molecule in exhaled breath, that may be repulsed by the negatively charged glass condenser wall, and thus, may promote the recovery of albumin in EBC. In contrast, the same negatively charged albumin molecule may be attracted by aluminium metal ions that are positively charged, and thus, may hamper the recovery in EBC. Also, 8-isoprostane acts in an extremely hydrophobic manner, but will stick to neutral surfaces (such as Teflon) in the presence of aqueous solutions, to lipids and to detergents.

Furthermore, we acknowledge that variability of biomarker concentrations in EBC may, in part, be due to reported intrinsic problems of different immunoassays (as already discussed). ${ }^{23-25}$ Thus, to actually comprehend the possible impact or relevance of our finding, the reproducibility of the measurement of 8-isoprostane (or other eicosanoids) and proteins such as cytokines, should be additionally evaluated in vivo by using different condenser coatings as well as a reliable ultrasensitive analytical method (this issue will be addressed in the next chapter).

We believe that borosilicate glass, which is readily available and easy to use, should be considered as a more appropriate, instead of inferior, basic material for condenser systems than the Teflon-coated EcoScreen ${ }^{\circledR}$, at least for the measurement of eicosanoids and small proteins in EBC. Hereby, not only offering new and more perspectives to further develop the condensate collection system, but also illustrating that future guidelines for EBC standardisation should be prone to include the most valid condenser coating(s) to collect condensate and subsequently measure a specific disease marker.

Up to date, three other studies on the potential influence of sampling systems on biomarkers in the EBC have been published. ${ }^{86,101,103}$ Tufvesson et alia proposed a novel method to collect EBC using the EcoScreen ${ }^{\circledR}$ condenser of which all collection surfaces previously had been coated with bovine serum albumin (1 per cent) and Tween-20 (0.01 per cent), when measuring cytokines and eicosanoids, respectively. ${ }^{101}$ However, they also reported some major limitations, as (i) the preceeding coating procedure lasts 30 minutes, (ii) the Tween-20 coating may lead to false-positive (eicosanoid) results, and (iii) a 5 to 10 -fold concentration of the condensate sample was necessary, by vacuum-centrifugator, prior to analysis. ${ }^{101}$ Soyer et alia compared two commonly used commercially available EBC collection systems, the RTube ${ }^{\mathrm{TM}}$ and EcoScreen ${ }^{\circledR}$ condensers. ${ }^{86}$ They found that there was no difference for the measurement of acidity, but the concentrations of cysteinyl leukotrienes and eotaxin were significantly higher in samples collected with the EcoScreen ${ }^{\circledR}$, than with the RTube $^{\mathrm{TM}} .{ }^{86}$ Soyer et alia attributed these differences mainly to (i) the susceptibility of pre-cooled RTube ${ }^{\mathrm{TM}}$ sleeves to (increased) ambient temperatures over the recommended time course of a collection maneuvre, whereas the highest 
temperatures were measured at the one-way valve, near the mouth, however (ii) they also stated that differences in the materials could affect sample recovery. ${ }^{86}$ Recently, Prieto et alia compared the RTube ${ }^{\mathrm{TM}}$ and $\mathrm{EcoScreen}{ }^{\circledR}$, and reported that condensate $\mathrm{pH}$ values are dependent upon the collection device used. ${ }^{103}$

\subsubsection{Phase 3: a new condenser concept emerges}

The next step in our search for a more reliable condenser device, was to introduce a newly developed glass condenser system, as presented in chapter 5. Briefly, the condensation surface was enlarged using a glass condenser tube length of $90 \mathrm{~cm}$, condensate recovery was optimised using an inclined condensation tube with a downwards moveable condensate sweeping plunger, and exhaled breath flows were turbinately directed towards the cooled inner condenser wall by the plunger's multiple tangential and axial breath channels (Figure 1).

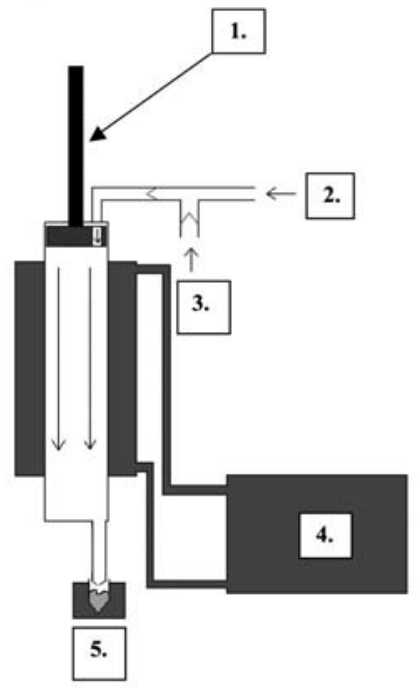

1. inclined glass condenser with a tube length of $90 \mathrm{~cm}$ (to enlarge the condensation surface), and downwards moveable plunger (to optimise condensate recovery from the inner condenser wall), with tangential and axial breath channels (to turbinately direct the tidally exhaled breath flows towards the cooled inner condenser wall) 2. swan-neck tubing (serving as gravitational saliva trap) and two-way nonrebreathing valve, connected to a mouthpiece

3. entrance of inspired room air

4. cooling unit consisting of a counter-current circulating ice-water pump

5. removable, cooled glass sample vial (to collect exhaled breath condensate)

Figure 1. Description of the new, optimised glass condenser system, as presented in chapter 5 .

In this study, 30 healthy adult subjects were chosen in order to eliminate possible confounding factors attributable to heterogenous disease expression and/or variability of disease control. Each subject was asked to perform four tests at different points in time, to assess within-day, between-day and between-week reproducibility of condensate volume, and of the measurements of hydrogen peroxide, 8-isoprostane, interleukin-2, interleukin-4, interleukin-5, interleukin-6, interleukin-8, interleukin-10, interleukin-13, and tumor necrosis factor-alpha (using a new technique for the detection of cytokines, as will be further discussed in chapter 9.6). Each of these four tests consisted of four sequential EBC collections, during 15 minutes, using ad random different types of condenser systems (the new optimised glass condenser, a silicone condenser, the former glass condenser, and the Ecoscreen ${ }^{\circledR}$ ). 
We demonstrated that the newly developed optimised glass condenser yielded significantly more condensate volume $(2025 \mu \mathrm{L})$, compared to the silicone, (former) glass and EcoScreen ${ }^{\circledR}$ condensers $(525 \mu \mathrm{L}, 712 \mu \mathrm{L}$, and $1237 \mu \mathrm{L}$ respectively), suggesting both an improved condensation process, and an increased opportunity to perform a broad spectrum of analyses using the new optimised condenser. Reproducibility of EBC volume, expressed by means of percentage of coefficient of variation, was comparable for the new condenser and EcoScreen ${ }^{\circledR}$ (ranging from 11 to 20 per cent, and from 9 to 19 per cent, respectively), but was significantly better compared to the silicone and (former) glass condenser (ranging from 20 to 37 per cent, and from 21 to 30 per cent, respectively). Hence, the optimised glass and EcoScreen ${ }^{\circledR}$ condenser were both significantly associated with less variation in the generated EBC volume, compared to the other condensers. Hereby, reducing a possible confounding influence of the variable quantity of EBC collected over a given time, and even within individuals.

In EBC collected with the new glass condenser system, significantly more positive hydrogen peroxide, 8-isoprostane, interleukin-2, interleukin-4, interleukin-5, interleukin-13, and tumor necrosis factor-alpha detections were found, supporting an improved sampling of EBC. Moreover, 8-isoprostane concentrations were significantly increased in EBC yielded by the new condenser, compared to the other three condensers, which is in accordance with the findings in the former coating study. On the other hand, reproducibility of hydrogen peroxide, 8-isoprostane and cytokine measurements in EBC, expressed by means of percentage of coefficient of variation, was equally variable for all condenser types, suggesting no significant influence of the type of condenser coating on reproducibility of biomarker measurements in EBC in healthy adults. In literature and to date, no formal study addressing this issue has been published, although biomarker reproducibility using other analytical techniques has been reported, ${ }^{104-106}$ and/or could not be calculated due to small number of subjects. ${ }^{87,107-108}$

Variations in biomarker measurements in EBC may be attributed to variations in the dilution and/or quality of condensate, that is influenced by different collection techniques and procedures, sample processing and storage conditions, and/or sensitivity of the analytical techniques used. ${ }^{107}$ The levels of the highly volatile hydrogen peroxide in EBC are susceptible to (yet) uncleared methodological issues that may be attributed to: (i) different cooling temperatures during collection; ${ }^{109}$ (ii) a circadian rhythm of exhaled hydrogen peroxide levels; ${ }^{110}$ (iii) the different methods of measurement with widely varying values for both healthy individuals and patients with respiratory disorders, with most of these values being close to the lower limits of detection; $82,87-88,104-105,111-124$ (iv) evidence of hydrogen peroxide flow dependency, as nontidal breathing or lower controlled exhalation flows lead to significantly higher hydrogen peroxide levels in EBC, when compared with higher controlled flows, and as tidal breathing during EBC collection incorporates multiple different flows in each breath; ${ }^{115}$ and $(v)$ the high level of chemical reactivity of hydrogen peroxide with salivary contamination, and exhaled nitrogen oxides and ammonia, forming various other compounds, including hydroxylamine, peroxynitrite and nitrate, by which 
hydrogen peroxide levels in EBC decline over time in storage, and by which it is likely that (some) hydrogen peroxide is consumed even during the time of collection. ${ }^{48-}$ 49,119,125-127 Isoprostanes are relatively stable end-products of in vivo arachidonate peroxidation, and are measured in EBC by immunoassay, that may be influenced by crossreactivity with closely related substances. ${ }^{107}$ We used commercially available enzyme immunoassays, that are very sensitive but lack in specificity, to measure 8isoprostane in $100 \mu \mathrm{L}$ of EBC, instead of radioimmunoassays that now have been qualitatively validated for these measurements, by reverse phase high performance liquid chromatography, as described by Montuschi et alia. ${ }^{128-129}$ However, the use of both enzyme immunoassays and radioimmunoassays may be associated with cross reactivity of antibodies. ${ }^{106}$ On the other hand, Cap et alia have used gas chromatography/mass spectrometry to quantify exhaled eicosanoids (in casu leukotrienes). ${ }^{130}$ Although the specificity of mass spectrometry detection ensures an unequivocal determination of the analysed substances, gas chromatography requires, in contrast to liquid chromatography, derivatisation procedures and corresponding sample pre-treatment for nonvolatile compounds. ${ }^{130}$ Therefore, to avoid more sources of errors, Gonzalez-Reche et alia recently presented a validated method for the simultaneous determination of arachidonic acid metabolites in $1000 \mu \mathrm{L}$ of EBC by liquid chromatography-electrospray ionisation tandem mass spectrometry, although this method still included an automated sample enrichment step. ${ }^{106}$ Other confounding factors may be age, diets rich in antioxidants, and smoking habits. ${ }^{107}$

Our findings on biomarker reproducibility were not altered by expressing the results as intraclass correlation coefficients or standard deviations, instead of coefficients of variation. Biomarker levels were assessed in condensate originating from healthy adults, and thus, may have been more pronounced in a steroid naïve population with documented chronic respiratory inflammation, and comparable levels of disease control. In diseased subjects, one may expect increased mean concentrations, and lowered coefficients of variation.

To recapitulate, the proposed new glass condenser had an improved condensation process and condensate recovery, using an inclined and enlarged condensation surface, with a condensate sweeping plunger, having tangentially and axially guiding breath flow channels. These improvements resulted in significantly increased EBC volumes and biomarker detections, including higher 8-isoprostane EBC levels, demonstrating a significant influence of the condenser system, in favour of the new optimised glass condenser. However, reproducibility of biomarker measurements in EBC in healthy adults was not influenced by the type of condenser.

\subsubsection{Phase 4: the new condenser system}

Finally, we introduced, in chapter 8, a new method for the collection of EBC, before and after breath recirculation, and demonstrated its feasibility in 70 preschool children, aged 4 years or less, with and without wheezing illness. Furthermore, we used the same analytical technique as previously mentioned to measure cytokines in the collected EBC (as will be further discussed in chapter 9.6 and 9.7). 
Preschool children, and in particular toddlers, do not simply intend to follow any instruction (to breath tidally into a facemask with separated nose and mouth cavity) unless they are willing to cooperate. Also, if toddlers tend to cooperate, they often do not sustain their effort for a relatively long time (initially condensation of exhaled breath often takes at least 5 to 10 minutes depending on the available condensation surface), as their willingness to cooperate may rapidly disappear, and/or as they can be distracted by anything at all. The collection of EBC in preschool children requires short sampling times. However, these are not always offered by the currently used and less efficient condensers, with open ended and relatively short-measured designs. These condensers are characterised by the loss of a highly variable amount of noncondensed exhaled breath, as condensation does not immediately occur, and/or does not continue to occur once the condensation surface is completely saturated. In addition, exhaled biomarkers may be lost in different EBC sampling systems, due to adhesive interactions between condenser coatings and exhaled biomarkers, as already discussed. Furthermore, EBC collection in preschool children is also hampered by suboptimal condensate analysis, associated with techniques that require relatively large volumes of EBC, and by consequence, necessitate again a prolongation of sampling times. For all the above reasons, a modification of the glass condenser was mandatory, in such a way that the condensation process was optimised with a high efficiency-to-time ratio. Hence, we were searching a design that would allow maximal condensation of all the exhaled breath that was gathered, whether in only a few minutes or after a prolonged period of time.

In short, the glass condenser system as previously described in chapter 5 (with enlarged condensation surface, inclined and optimised condensate recovery with plunger, and turbinately directed breath flow channels), was now closed and connected to a unique heated (at 37 degrees Celsius) breath recirculator system (Figure 2). The breath recirculation system itself consists of heated tubing (to guide the residual noncondensed exhaled breath, and to avoid condensation outside the condenser tube), a humidity sensor, a heated inert Tedlar ${ }^{\mathrm{TM}}$ gas sample bag (to collect all residual noncondensed exhaled breath), and a small ventilator system (to recirculate the residual noncondensed exhaled breath back into the condenser system for secondary condensation of exhaled breath).

The child exhaled tidally, as long as possible, through a face mask, with separated nose/mouth cavity, and two-way nonrebreathing valve, that was connected to the glass condenser system. During this condensation process, the formerly lost noncondensed exhaled breath was separately being collected in a gradually inflating inert TedlarTM gas sample bag. When the child ceased this procedure, EBC was collected by pushing downwards the plunger. Subsequently, the plunger was pulled up again, and the separately collected exhaled breath was recirculated, from the Tedlar $^{\mathrm{TM}}$ gas sample bag, back into the condenser system, to perform a secondary breath condensation, until the degree of relative humidity was less than 22 per cent.

This new concept of EBC collection before and after breath recirculation, allowed condensation of the totally exhaled breath volume, whether gathered after only a few minutes of EBC collection, or after a prolonged period. Moreover, the concept enabled 
the collection of significantly more EBC volume compared to the 'usual' (before breath recirculation) procedure, whereas, in toddlers with limited cooperation in time (and more often seen in the healthy group that was relatively unknown with the use of face masks), breath recirculation was often crucial to yield minimal but sufficient condensate volume. The cumulative nature of these methodological modifications resulted in an overall success rate of $83 \%$. Furthermore, the main issue was whether the concentration of cytokines, measured in the collected EBC, was affected by the recirculation process or not. We demonstrated that all cytokine concentrations in EBC collected before and after breath recirculation, were comparable and did not differ significantly. Hence, illustrating the efficiency of the breath recirculation system in generating an additional amount of equivalent condensate.

In literature, some attempts have been described to collect EBC in infants. ${ }^{117,131}$ Griese et alia presented a nasal collection system, that consisted of two serially connected polypropylene tubes and an electrical air suction pump, for the measurement of hydrogen peroxide and 8-isoprostane. ${ }^{131-132}$ However, they reported difficulties related to contamination with nasal secretions, and to the collection of only 20 to 30 per cent of the totally exhaled breath volume..$^{131-132}$ Cheah et alia described a bedside method for the collection of EBC, based on polyvinylchloride tubing, that was immersed in a column of wet ice, for the measurement of hydrogen peroxide in neonates who were ventilated or receiving nasal continuous positive airway pressure. ${ }^{117}$ However, they reported insufficient sensitivity to use their system for the detection of exhaled hydrogen peroxide. ${ }^{117}$ Recently, Moeller et alia proposed, a feasible and safe method to collect EBC, both orally and nasally, in tidally breathing infants. ${ }^{133}$ However, this method required sedated sleep, and was described without the assessment of any marker in the collected condensate. ${ }^{133}$ Last but not least, other techniques for the collection of EBC from ventilated patients, including infants, children and young adults, have recently been proposed. ${ }^{134-135}$

In our study, successful EBC collection was associated with an optimal distraction of the preschool children. We primarily combined strict parental cooperation (86 per cent), after preceding instructions by the coaching childhood asthma nurse, with an age appropriate cartoon (76 per cent), that was already started prior to entrance. In case of imminent failure to cope, a more active strategy was used on parent's advice, including children's stories (36 per cent), puppetry (15 per cent), and/or children's songs (12 per cent). Distraction was mainly hampered by insufficient parental stimulation and/or a history of ear-nose-throat surgery.

In literature, a variety of different distractors have been used for nonpharmacological pain or distress management in children of all ages, including watching cartoons, ${ }^{136-138}$ using party blowers, ${ }^{139}$ looking through kaleidoscopes, ${ }^{140}$ blowing bubbles, ${ }^{141-142}$ non-procedural talk, ${ }^{143}$ listening to short stories, ${ }^{144}$ humour, ${ }^{145}$ listening to music, ${ }^{146}$ puppetry, ${ }^{147-148}$ and virtual reality glasses. ${ }^{149-150}$ The management of a child's distress does not equal pain management. However, the latter may provide some hints to improve the child's coping with distress due to a noninvasive and 
painless but unfamiliar procedure, such as the collection of EBC, in particular in preschool children. In literature, distraction performed by mothers has been reported to be an effective analgesic factor. ${ }^{143-144}$ Moreover, children state that just having their parents present provides the most comfort when in pain, and they will recall that they were not left alone on a stressful occasion. ${ }^{136,151}$ Cohen et alia found that 4 to 6 year old children watching a popular cartoon series felt less pain, whereas Cassidy et alia found that watching television during an immunisation injection was not effective in reducing pain in a group of 5 year old children. ${ }^{137-138}$ Mason et alia suggested that a passive strategy, such as watching television, may be more effective than an active one, such as distraction with an interactive toy, for decreasing pain, because children's distress interfered with their ability to interact with the distractor. ${ }^{144}$

Hence, we introduced a novel, highly efficient, closed concept that enabled the collection of EBC, both before and after breath recirculation, and yielded sufficient as well as equivalent condensate in the 'diagnostically-nearly-unaddressed' population of (nonsedated) preschool children with or without wheezing illness.

\subsection{New sensitive techniques for the detection and measurement of biomarkers in EBC}

In this section we will discuss our findings, mainly related to the analysis of EBC to measure cytokines, and free radicals (as markers of oxidative stress), using new sensitive techniques as applied in chapters 5 and 8, and chapter 6, respectively.

\subsubsection{Cytokines in EBC}

\subsubsection{Why and how we tried to detect cytokines in EBC}

Cytokines are intercellular immune regulatory peptides involved in the orchestration of many different aspects of local and/or systemic inflammatory processes, including tissue repair, and thus, cytokines are associated with various chronic respiratory disorders, as indicated in chapter 1. This also implicates that these mediators constitute interesting research targets as the changing level of different cytokines, or in other words specific profiles of cytokines, may reflect parallel changes at certain stages in specific types of chronic respiratory inflammation. Furthermore, cytokines are low molecular weight proteins (ranging from 4.000 to 50.000 Dalton), that may be able to shift or migrate from the intrapulmonary compartment into the airway lumen, and, thus, may be exhaled, as suggested by two incidental reports, at that time, on their detection in EBC in children. ${ }^{25,71}$ Cunningham et alia reported the detection of the pro-inflammatory interleukin-8 in EBC in 30 per cent of children with clinically stable cystic fibrosis. ${ }^{71}$ Shahid et alia reported significantly increased mean levels of interleukin-4 and decreased mean levels of interferon-gamma in asthmatic children, compared with healthy controls, whereas lower levels of interleukin-4 were found under corticosteroid treatment. ${ }^{25}$ Hence, we were primarily interested in the detection of these small proteins in EBC in children, but at the same time, we were also very aware of the difficulties that we were facing, as our review (presented in chapter 2) had also made clear that EBC methodology was significantly hampered by the lack of specific and highly sensitive analytical techniques. In the early childhood asthma study, presented in chapter 3 , 
it was shown that conventional and even ultrasensitive specific solid-phase enzyme immunoassays were not able to sufficiently detect cytokines in EBC (chapter 9.4 above). Subsequently, a new technique, multiplexed cytometric bead array, was used in the early cystic fibrosis study, presented in chapter 7, and allowed the simultaneous measurement of several cytokines in only small condensate samples (chapter 9.4 above). However, the level of cytokine detection still did not reach 50 per cent, as already discussed.

Therefore, we were unremittingly pursueing amelioration. Moreover, all the above may only illustrate the very importance of rapidly transfering novel developments of 'nano-molecular' analytical technology, into the field of condensate-related research.

\subsubsection{Multiplexed liquid bead array and the measurement of cytokines in EBC}

In chapter 5, we not only investigated the in vivo reproducibility of different biomarkers in EBC using four different condenser types (including the new open glass condenser), but we also introduced a novel technique to, both more rapidly and precisely, detect and measure several cytokines simultaneously. Luminex's XMAP technology is a liquid bead array multiplexing system, built on proven, existing technology, including traditional chemistry, flow cytometry, microspheres (characterised by liquid reaction kinetics that are faster and more reproducible, than with solid planar assays), laser technology and digital signal processing, that are combined in a unique way and allow multiplexing of up to 100 unique assays within a single sample. ${ }^{152-153}$

When compared with conventional bioassays and solid-phase enzyme immunoassays, multiplexed immunoassays are highly sensitive (a few pg/mL), allow quatitative detection (in contrast to semiquantitative bioassays), have high specificity, detect bioactive as well as inactive molecules, have a growing analytical range (cytokines, phosphoproteins, antibodies), are rapid (hours instead of day(s)), have good (but not yet excellent) precision (coefficients of variation range from 10 to 15 per cent), are not interfered by drugs, have a simple protocol, require small sample volumes, allow simultaneous detection, and can be applied for multiple species (not only human). ${ }^{153}$ However, the initial set-up time is consuming and expensive. ${ }^{153}$

Cytokines were simultaneously measured by means of XMAP's technology in small EBC sample volumes of $50 \mu \mathrm{L}$. All cytokines (id est interleukin-2, interleukin-4, interleukin-5, interleukin-6, interleukin-8, interleukin-10, interleukin-13, and tumor necrosis factor-alpha) were now detectable in EBC, compared to our early studies based on cytometric bead array with 1 to 4 not detectable cytokines in EBC. ${ }^{51}$ The overall level of cytokine detection using multiplexed liquid bead array was 46 to 97 per cent, whereas the detection level using cytometric bead array was less than 50 per cent in similarly small EBC samples in children, ${ }^{51}$ and 3 to 100 per cent in large 1000 to $2000 \mu \mathrm{L}$ lyophilisated EBC samples in adults. ${ }^{56-58,60}$

In EBC collected with the new (open) glass condenser, significantly more detections of interleukin-2, interleukin-4, interleukin-5, and interleukin-13, and tumor necrosis 
factor-alpha were found, compared to the other condenser types. However, cytokine concentrations in EBC in healthy adults, and reproducibility of these cytokine measurements expressed as coefficients of variation (ranging from 5 to 78 per cent), did not significantly differ and were equally variable for all types of condenser (as previously discussed).

In chapter 8, the same multiplexed liquid bead array technique was applied for the measurement of cytokines in $50 \mu \mathrm{L}$ of EBC collected with the new closed glass condenser, before and after breath recirculation, in preschool children with and without wheezing illness. Also in this study, all cytokines (id est interleukin-4, interleukin-5, interleukin-6, interleukin-8, interleukin-10, interleukin 12p70, interleukin-13, and tumor necrosis factor-alpha) were detectable in EBC, and the level of cytokine detection in EBC ranged from 95 to 100 per cent.

Hence, we believe that optimisation of EBC collection, using the new glass condenser(s), and optimisation of EBC analysis, using rapid multiplexed XMAP measurement of cytokines in small EBC sample sizes, may all together open a window of opportunities, even in strained collection procedures, such as in young or dyspnoeic subjects (with less sustained efforts to cope with sampling procedures), by allowing the search for, and identification of, particular profiles of different exhaled markers, involved in the regulation of chronic respiratory inflammation, for diagnostic and monitoring purposes

On one hand, we acknowledge the fact that the introduction of novel analytical technique may be considered as a major confounding factor, as this technique still awaites further investigation of the reproducibility, sensibility, specificity and validity of its generated data on cytokines in EBC. For this purpose, the Standards for Reporting of Diagnostic Accuracy (STARD) initiative provides recommendations, including a checklist and flow diagram, towards complete and accurate reporting on diagnostic accuracy. ${ }^{154-156}$ On the other hand, we ultimately do not see an alternative approach other than the one proposed, to gradually introduce such novelties, because the first step, in our opinion, will always consist of establishing an accurate and rapid analytical technique, prior to any application in longitudinal clinical trials.

\subsubsection{Free radicals in EBC}

Oxidative stress, defined as an imbalance between oxidants (such as reactive oxygen species) and antioxidants (such as vitamin C) in favour of oxidants, also appears to play an important role in several inflammatory lung diseases. ${ }^{107,157}$ Hence, in our search for the application of new analytical techniques in EBC, we were also interested in the assessment of free radicals, that are considered the most direct markers of oxidative stress. ${ }^{107,157}$

In the study, as presented in chapter 6 , we used the most direct method to assess oxidative stress status in vivo in children with cystic fibrosis and healthy control children. This study did demonstrate the feasibility of electron paramagnetic resonance spectroscopy to directly and semi-quantitatively detect free radicals, in casu both 
oxygen- and carbon-centered radicals, in $500 \mu \mathrm{L}$ of EBC. We found a trend towards higher maximal peak heights of oxygen- as well as carbon-centered radicals in EBC in children with cystic fibrosis, compared to healthy controls. However, this difference did not reach statistical significance, and may be attributed to the small study population, and/or to the fact that also a normal lung exists in an oxygen-rich environment that makes this lung also susceptible to oxidative stress.

On the other hand, we found that this direct and nearly online technique required quite sophisticated equipement and personel, which makes it not readily available for practical use in a clinical setting.

We also examined the possible source of these free radicals. The findings of this study suggested that hydrogen peroxide is likely crucial for the generation of oxygen centered radicals, and that EBC may also contain compounds that enable in situ radical formation. Furthermore, free radicals do not likely result from salivary contamination, and thus, may originate from the lower respiratory tract. By consequence, this may provide further support that the content of EBC reflects the ongoing processes in the epithelial lining fluid.

Recently, Carraro et alia reported the application of metabolomics in the analysis of EBC, in asthmatic children. ${ }^{158}$ Metabolomic analysis, by means of high resolution ${ }^{1} \mathrm{H}$ nuclear magnetic resonance spectroscopy and multivariate statistical methods, provides biochemical profiles of low molecular weigth proton-containing endogenous metabolites in biological fluids, without requiring any preselection of measurable analytes, and allows both the detection of known metabolites as well as the prediction of unknown metabolites and novel biomarkers. ${ }^{158}$ Discrimination between asthmatic children and healthy controls, using the combination of exhaled nitric oxide and forced expiratory volume in one second had a success rate of 81 per cent, whereas selected nuclear magnetic resonance signals, corresponding to acetylated and to oxidized compounds, had a success rate of 86 per cent. ${ }^{158}$

\subsubsection{The measurement of other inflammatory markers in EBC}

Although we were primarily focused on the measurement of cytokines and free radicals in $E B C$, from a condensate analytical point of view, we concomitantly measured other inflammatory markers in $\mathrm{EBC}$, including hydrogen peroxide, nitrite, nitrate, condensate acidity, and 8-isoprostane. However, due to the increasing complexity of our own research efforts, and due to the fact that several other research groups have addressed or still investigate the methodology of these specific markers in EBC, we chose to incorporate the recommendations and workshop proceedings published by the American Thoracic Society \& European Respiratory Society Task Force on EBC, ${ }_{1}^{48-49,159}$ or to take into account, if possible, new and relevant methodological findings, as listed below.

\subsubsection{The measurement of hydrogen peroxide in EBC}

Superoxide anions $\left(\mathrm{O}_{2}^{-\cdot}\right)$ are rapidly reduced to hydrogen peroxide $\left(\mathrm{H}_{2} \mathrm{O}_{2}\right)$ by superoxide dismutase in several cell types. ${ }^{48,107}$ In the respiratory system, hydrogen peroxide may be 
released both from inflammatory and structural cells, including neutrophils, eosinophils, macrophages and epithelial cells. ${ }^{48}$ The most frequently used methods of measuring hydrogen peroxide in EBC are the colorimetric and fluorimetric assays, that are based on the ability of hydrogen peroxide to react with suitable substrates. ${ }^{48}$ Hydrogen peroxide is assayed by colorimetry using horseradish peroxidase-catalysed oxidation of tetramethylbenzidine, as described by Gallati and Pracht. ${ }^{107,160}$ Using the colorimetric method, most groups have reported $0.1 \mu \mathrm{M}$ as detection limit. ${ }^{48}$ The fluorimetric technique, described by Ruch et alia, uses the reaction substrates 3,3',5,5' tetramethylbenzidine, p-hydroxyphenylacetic acid, scopoletin, phenolsulphonphthalein, luminol 5-amino-1,2,3,4-tetrahydrophthalazine-1,4-dione or homovanillic acid. 107,161 Using the fluorimetric method, the lower limit of detection is $0.1 \mu \mathrm{M}$, although in one study this was lowered to $0.0005 \mu \mathrm{M}$ using automated flow injection to detect the fluorescence of the reaction product. ${ }^{48,113}$ Recently, an optimisation of this technique by increasing the buffering capacity of the reaction mix, has been published. ${ }^{105}$ Hydrogen peroxide, being highly volatile, evaporates rapidly and therefore, could be trapped by adding the substrates to the EBC immediately after sample collection and kept frozen until analysis. ${ }^{107}$ New techniques, such as online or real-time measurements using sensitive biosensors have been developed, although the imprecision in the low range is still high (28 per cent), but declines with higher concentrations of hydrogen peroxide. ${ }^{104,107}$

Data on hydrogen peroxide vary considerably, and most of them are even close to the lower limit of detection. ${ }^{48}$ Therefore, concern has been raised regarding the reproducibility of the colorimetric assay, and the use of more sensitive methods is advised. ${ }^{48,119-123}$ Furthermore, as already discussed in chapter 9.5, the levels of the highly volatile hydrogen peroxide in EBC are susceptible to (yet) uncleared methodological issues that may be attributed to a possible circadian rhythm, ${ }^{110}$ flow dependency, ${ }^{115}$ rapid chemical reactivity, ${ }^{119,125-127}$ and susceptibility to different cooling temperatures. ${ }^{109}$ Day-to-day intra-subject coefficient of variation was 43 per cent in healthy subjects, ${ }^{48}$ whereas we reported, in chapter 5 , overall coefficients of variation ranging from 22 to 29 per cent.

\subsubsection{The measurement of nitrogen oxides and related products in EBC} Nitrite $\left(\mathrm{NO}_{2}^{-}\right)$and nitrate $\left(\mathrm{NO}_{3}{ }^{-}\right)$are nitrogen redox forms that are present in the epithelial lining fluid of the human respiratory tract. ${ }^{48,107}$ The term nitrogen oxides (NOx) incorporates these two ions, as well as other oxides of nitrogen. ${ }^{48,107}$

Nitrite and nitrate have been detected in EBC by using spectrophotometric assays (Griess reaction), a fluorimetric method (2,3-diaminonapthalene (DAN) reaction), chemiluminescence assays, or ion chromatography followed by conductivity measurement. ${ }^{48,71-72,162-174}$ The reported detection limit of the DAN assay is $0.1 \mu \mathrm{M}$, and that of the Griess reaction is higher. ${ }^{48}$ The chemiluminescence technique is sensitive in the nanoM range. ${ }^{48}$ Caution must be taken when interpreting nitrite assays, as the compound cannot be considered stable at low $\mathrm{pH}$, and even at neutral $\mathrm{pH} .{ }^{48}$ Nitrate is considered stable, whereas its levels tend to be roughly 5 to 10 fold 
higher than nitrite levels, although this may vary in part because of changes in airway oxidative conditions. ${ }^{48}$ Most combined nitrite/nitrate assays rely on the formation of nitrite from nitrate. ${ }^{48}$ In this respect, enzymatic reduction was found to be better for nitrate determination in EBC, than cadmium reduction. ${ }^{48,166}$

Nitrogen oxides are present on every laboratory surface, including glassware and pipette tips. ${ }^{48}$ Readily diffusible ambient nitric oxide becomes oxidised and contaminates surfaces rapidly. ${ }^{48}$ Therefore, great precautions should be taken to avoid sample contamination. ${ }^{48}$ It is necessary to thoroughly rinse with highly pure water, any material that might come in contact with EBC, including devices used for collection, processing and assaying EBC. ${ }^{48}$

The reaction of nitric oxide and superoxide anions in the airways leads to the formation of peroxynitrite (ONOO-), which is a highly reactive oxidant species. ${ }^{48,107}$ Peroxynitrite reacts with tyrosine residues of proteins to form the stable product nitrotyrosine, that may be detected with specific antibodies, using a specific enzyme immunoassay with a detection limit of $3.9 \mathrm{ng} / \mathrm{mL} .{ }^{48,175}$ However, commercial enzyme linked immunosorbent assays presumably quantify proteins nitrated at more than one site, rather than single amino acids. ${ }^{48}$ Likely this means that nitrotyrosine levels mainly consist of nitrated proteins. ${ }^{48}$

Nitrosothiols (RS-NOs) are formed by interaction of nitric oxide or nitrite with gluthatione or other thiol containing molecules. ${ }^{48,107,176-177}$ Nitrosothiols can be measured by colorimetric assay, based on the cleavage reaction of nitrosthiols releasing nitric oxide, which is then oxidised to nitrite and detected by the assay. ${ }^{48}$ The detection limit is $0.025 \mu \mathrm{M} .{ }^{48} \mathrm{~A}$ more sensitive method is chemiluminescence analysis after reduction to nitric oxide in copper-cysteine or by ultraviolet light. ${ }^{48}$

There are no reported data on day-to-day intra-subject coefficient of variation of nitrogen oxides. ${ }^{48}$

\subsubsection{The measurement of condensate acidity $(\mathrm{pH})$}

Airway $\mathrm{pH}$ homeostasis is maintained by a balance of different buffer systems and the production and release of acids and bases in the airways. ${ }^{48}$ The acidity of EBC can be readily measured with $\mathrm{pH}$ electrodes and indicator dyes. ${ }^{31,39,48,178} \mathrm{Gas}$ standardisation (with a carbondioxide-free gas, such as argon and nitrogen) is recommended to stabilise $\mathrm{pH}$ of EBC, as already discussed in chapter 9.4.42,44,48 There is a debate as to whether orally collected $\mathrm{EBC} \mathrm{pH}$ reflects acidification of the lower airways, because of high ammonia content of the mouth. ${ }^{35-37,40,47-48,179-180}$ The $\mathrm{pH}$ of deaerated EBC is not affected by hyperventilation, duration of collection, duration or manner of storage (up to two years), and oral versus endotracheal collection. ${ }^{38,48,178}$ Recently, normative data for dearated EBC $\mathrm{pH}$ in all ages have been published, ${ }^{43}$ as well as in a prospective population-based birth cohort of 630 children. ${ }^{45}$ Reported day-to-day intra-subject coefficient of variation of deaerated $\mathrm{EBC}$ pH is 4.5 per cent, and 5 per cent using non deaerated EBC pH. ${ }^{41,48,178}$ 


\subsubsection{The measurement of 8-isoprostane in EBC}

8-Isoprostane, a stable prostaglandin-like product, is formed from arachidonic acid by the nonenzymatic action of reactive oxygen species, and, therefore, it is suggested to be a proprotional marker of oxidative stress. ${ }^{48,107}$ Commercial enzyme immunoassays are used to measure 8-isoprostane in EBC, with a detection limit of $3.9 \mathrm{pg} / \mathrm{mL} .{ }^{48,107}$ The assay was validated directly by gas chromatography / mass spectroscopy showing high correlation between added known amounts of 8-isoprostane and the concentration measured with the assay. ${ }^{48,128}$ However, reproducibility remains contradictory. ${ }^{48,107}$ Enzyme immunoassays may give false values owing to the presence of closely related substances in biological fluids that may potentially interfere with the assay. ${ }^{107}$ The potential disadvantage of measuring isoporstanes is that they are unstable at room temperature or on ice, and rapidly degrade ex vivo. ${ }^{107}$ Agents such as lipid peroxidation inhibitors and metal chelators may be added prior to freezing to stabilise (F2-)isoprostanes. ${ }^{107}$ A more sensitive and specific method to assay isoprostane in EBC is gas chromatography / mass spectroscopy. ${ }^{48}$ Recently, GonzalezReche et alia presented a validated method for the simultaneous determination of arachidonic acid metabolites in $1000 \mu \mathrm{L}$ of EBC by liquid chromatography-electrospray ionisation tandem mass spectrometry, as already discussed in chapter 9.5. ${ }^{106}$ There are no reported data on day-to-day intra-subject coefficient of variation whereas we reported, in chapter 5 , overall coefficients of variation ranging from 26 to 48 per cent in healthy adults. ${ }^{48}$

\subsubsection{The measurement of prostaglandines and thromboxanes in EBC}

Aracidonic acid, released from the cell wall by phospholipase $A 2$, is converted to prostaglandin endoperoxides by cyclo-oxygenase. ${ }^{48}$ Endoperoxides are then converted to prostaglandins, prostacyclin and thromboxane $A 2 .{ }^{48,181}$ Thromboxane A2 is rapdily converted to thromboxane B2, a chemically stable but biologically inactive metabolite, that can be measured. ${ }^{48}$

Prostaglandin E2 and thromboxane B2 can be measured by enzyme immunoassay and by radio immunoassay. ${ }^{48,128,182-185}$ The specificity of prostaglandin E2 measurement by radio immunoassay has been validated by reverse phase high performance liquid chromatography. ${ }^{48,128}$ The detection limit for thromboxane B2 is $13 \mathrm{pg} / \mathrm{mL}$ for the enzyme immunoassay, and $13.6 \mathrm{pg} / \mathrm{mL}$ for the radio immunoassay. ${ }^{48}$ Higher thromboxane B2 values were found by radio immunoassay, which is likely attributable to the 100 per cent crossreactivity of this assay (but not the enzyme immunoassay) with 2,3-dinor-thromboxane B2. ${ }^{48}$ The detection limit for prostaglandin $\mathrm{E} 2$ is $8 \mathrm{pg} / \mathrm{mL}$ using the enzyme immunoassay. ${ }^{48}$ There are no reported data on dayto-day intra-subject coefficient of variation. ${ }^{48}$

\subsubsection{The measurement of leukotrienes in EBC}

The cysteinyl-leukotrienes (leukotriene C4, leukotriene D4, and leukotriene E4) are released from inflammatory cells of the airways, in particular mast cells and eosinophils, and play a role in asthmathic airway inflammation. ${ }^{48,186}$ Leukotriene B4 is formed from arachidonic acid as a result of enzymatic hydrolysis of leukotriene A4, a potent activator of neutrophils and a proinflammatory mediator. ${ }^{48,187}$ Leukotrienes can be measured by enzyme immunoassay with detection limit of $15 \mathrm{pg} / \mathrm{mL}$ and $4.4 \mathrm{pg} / \mathrm{mL}$, 
respectively. ${ }^{48}$ The specificity of the immunoreactivity of the leukotriene B4 enzyme immunoassay was confirmed by using reverse phase high performance liquid chromatography. ${ }^{48,188}$ The correlation coefficient for two repeated leukotriene B4 measurements was 0.76.48,188 Reported day-to-day intra-subject coefficient of variation for leukotriene B4 is 2 per cent in a small group of healthy subjects. ${ }^{48,189}$

\subsubsection{The measurement of other markes of oxidative stress in EBC}

Aldehydes (malondialdehyde, 4-hydroxyhexanal, 4-hydroxynonenal, hexanal, heptanal and nonanal) are lipid peroxides which reflect oxidant-induced damage. $48,107,190$ Conversely, reduced glutathione reflects the antioxidant capacity. ${ }^{48,191}$ Aldehydes were detected in EBC using liquid chromatography-tandem mass spectroscopy which had a detection limit for different aldehydes between 0.31 and 1.07 nM. ${ }^{48,190,192}$ Glutathione was determined by high performance liquid chromatography with fluorescence detection, with a detection limit of $2.0 \mathrm{nM}{ }^{48,193}$ Reported day-to-day intra-subject coefficients of variation for different aldehydes are between 12 and 20 per cent. ${ }^{48,193}$ There are no reported data on day-to-day intra-subject coefficients of variation on EBC glutathione. When interpreting the results obtained for markers of oxidative stress, it should be borne in mind that malondialdehyde is not a specific product of lipid peroxidation. ${ }^{107}$ Although the levels of malondialdehyde and isoprostanes correlate well in vitro, there is 25.000 times more malondialdehyde as compared to isoprostanes, and the in vivo levels of isoprostanes are 28 -fold higher than those of malondialdehyde. ${ }^{107}$ The level of oxidative biomarkers in EBC can be affected by diet, smoking, diurnal variation and age. ${ }^{107}$

\subsubsection{The measurement of adenosine in EBC}

Adenosine is formed during the degradation of adenosine triphosphate (ATP) and has a wide range of effects in the respiratory system through its specific receptors. ${ }^{48,194}$ Adenosine can de determined by high performance liquid chromatography, and has been validated for EBC. ${ }^{48,195,196}$ The detection limit is $2 \mathrm{nmol} / \mathrm{L} .{ }^{48}$ There are no reported data on day-to-day intra-subject coefficient of variation, whereas mean intra-day coefficient of variation is 10 per cent in healhty subjects. ${ }^{48,196}$

\subsubsection{The measurement of ammonia in EBC}

Ammonia $\left(\mathrm{NH}_{4}^{+}\right)$produced during the urease hydrolysis and/or glutaminase activity in the airways may have important functions, including $\mathrm{pH}$ regulation. ${ }^{29,48}$ Ammonia is a volatile compound, and collection temperature and duration influences its level in $\mathrm{EBC} .{ }^{48}$ Ammonia can be readily measured spectrophotometrically in EBC. ${ }^{29,48}$ Most of EBC ammonia arises from the mouth. 5,48,182,197 Mean intra-day coefficient of variation is 60 per cent, with a broad range from 10 to 180 per cent. ${ }^{48}$

\subsubsection{The measurement of other molecules in EBC}

EBC contains other molecules that can provide important information, such as p53 mutation, ${ }^{198-199}$ deoxyribonucleinic acid, ${ }^{4,200}$ hepatocyte growth factor, ${ }^{201}$ erythropoietin, ${ }^{60}$ vitronectin, and endothelin-1.202 EBC collection may also be useful for rapid detection of infectious processes in the lung using polymerase chain reaction technology, such as tuberculosis. ${ }^{48,200,203}$ 
Table 1. State of the art on biomarkers in $\mathrm{EBC}$, including condensate $\mathrm{pH}$, in children with asthma or cystic fibrosis.

\begin{tabular}{llll} 
Biomarker in EBC & Asthma & CF & Reference \\
\hline Hydrogen peroxide & $\Uparrow$ & $\Uparrow$ & $61,124,209$ \\
8-isoprostane & $\Uparrow$ & $(-)$ & $92,93,95,99,129$ \\
Prostaglandin E2 & $=$ & - - & 93 \\
Cysteinyl-leukotrienes & $=/ \Uparrow$ & $(-)$ & $50 \S, 92,95,99,129,189,210^{*}-212$ \\
Leukotriene B4 & $=/ \Uparrow$ & $\Uparrow$ & $26,28,99,189,212,213$ \\
Nitrite & $=/ \Uparrow$ & $\Uparrow$ & $46,50 \S, 71,72$ \\
Nitrotyrosine & $\Downarrow /=/ \Uparrow$ & $=$ & $214 \pm, 215,216$ \\
Interleukin-4 & $\Uparrow$ & $(-)$ & 24,25 \\
Interleukin-8 & $(-)$ & $\Uparrow$ & 28,71 \\
Interleukin-10 & $=$ & $=$ & 51 \\
Interferon-gamma & $\Downarrow /=$ & $=$ & 25,51 \\
TNF-alpha & $=$ & - - & 24 \\
PDGF, VEGF, EGF & $=$ & - - & 24 \\
MDC & $\Uparrow$ & $(-)$ & 26,27 \\
Eotaxin & $\Uparrow$ & $(-)$ & 26 \\
Aldehyde & $\Uparrow$ & $(-)$ & 193 \\
Glutathione & $\Downarrow$ & $(-)$ & 193 \\
Metabolomics $\dagger$ & $\Uparrow$ & $(-)$ & 158 \\
Ammonia & $\Downarrow$ & $(-)$ & 212,219 \\
Condensate pH & $\Downarrow /=$ & $\Downarrow$ & $28,45-46,84,217-219$ \\
\hline
\end{tabular}

EBC exhaled breath condensate

CF cystic fibrosis

TNF-alpha tumor necrosis factor-alpha

PDGF platelet-derived growth factor

VEGF vascular endothelial growth factor

EGF epidermal growth factor

MDC macrophage-derived chemokine

$\Uparrow \quad$ significantly increased compared to healthy children

$\Downarrow \quad$ significantly decreased compared to healthy children

$=\quad$ no significant difference compared to healthy children

$(-) \quad$ no paediatric data

* $\quad$ levels in asthma decreased if treated with montelukast

$\S \quad$ levels in asthma unchanged compared with asthma exacerbation

$\dagger \quad$ oxidised and acetylated compounds

$\ddagger \quad$ levels in asthma decreased after treatment with inhaled corticosteroids

\subsubsection{Dilution factor of EBC}

The importance of a dilution factor is still being debated, and based on the assumption that the ratio of liberated solutes to exhaled water vapour is variable. ${ }^{48} \mathrm{~A}$ so called 
dilution factor can be determined from each EBC sample by determining the concentration of a substance in EBC, which has a well known concentration in sera and diffuses through the cell membranes, but is not produced in the alveoli or airways. ${ }^{48}$ Such a dilution marker would make it possible to calculate the real airway level of determined mediators in EBC. ${ }^{48}$ Many attempts have been made. ${ }^{5,197,204-207}$ The most simple of these is the measurement of conductivity of lyophilised EBC samples. ${ }^{206}$ Recently, this method was used by Baker et alia to develop the noninvasive measurement of breath glucose concentrations. ${ }^{208}$ These were obtained by multiplying condensate glucose concentrations by calculated dilution factors (estimated by dividing serum total cation concentration by condensate total cation concentration). ${ }^{208}$ They reported an elevated breath-to-blood glucose ratio in adult patients with cystic fibrosis, compared to healthy patients and diabetes mellitus patients. ${ }^{208}$

In Table 1, we provide a state of the art on the current measurements of biomarkers in $\mathrm{EBC}$, including condensate $\mathrm{pH}$, in children with asthma and cystic fibrosis.

Finally, we want to emphasize again that EBC constitutes a very different matrix than those employed in 'conventional' research and current clinical practice, and that various potential biomarkers (yet) have been detected in this exciting matrix. Furthermore, it may be clear that each of these biomarkers has its own physical, pathophysiological, biochemical, electrical, and/or even quantum-physical characteristics. Thus, this very diversity itself is of vital importance to its potential value in noninvasive inflammometry, but simultaneously, it is the main complicating factor in a smooth and stepwise advancement of research efforts.

\subsection{Application of new techniques in preschool children}

Finally, in chapter 8, we not only demonstrated the feasibility of a novel method to collect EBC in 70 nonsedated preschool children with and without wheezing illness (Figure 2). Also, we assessed EBC cytokine profiles, by multiplexed liquid bead array, in probably atopic asthmatic and nonasthmatic preschool children, and found significantly discriminating T-helper 2 to T-helper 1 cytokine ratios in EBC.

In children, wheezing is reported in no less than 30 per cent during the first three years of life. ${ }^{9}$ In preschool children, wheeze is poorly characterised, and may indicate a trivial viral cold, as well as an ongoing chronic lung inflammation. 9,220 On one hand, exclusively viral-triggered wheeze accounts for about two-third of wheezy children, and is characterised by acute episodes associated with viral (upper) respiratory tract infections. ${ }^{9,220}$ Between episodes, viral wheeze is not associated with eosinophilic airway inflammation, which has important therapeutic implications. ${ }^{9}$ These children have a good prognosis since 60 per cent will stop wheezing by the early school years. ${ }^{221}$ Transient, viral-triggered wheeze is not related to atopy and allergic conditions, whereas maternal smoking during pregnancy, premature birth and low birth weight are known risk factors. ${ }^{11}$ On the other hand, atopic asthma is associated with a cytokine pattern compatible with predominant activation of the T-helper 2 


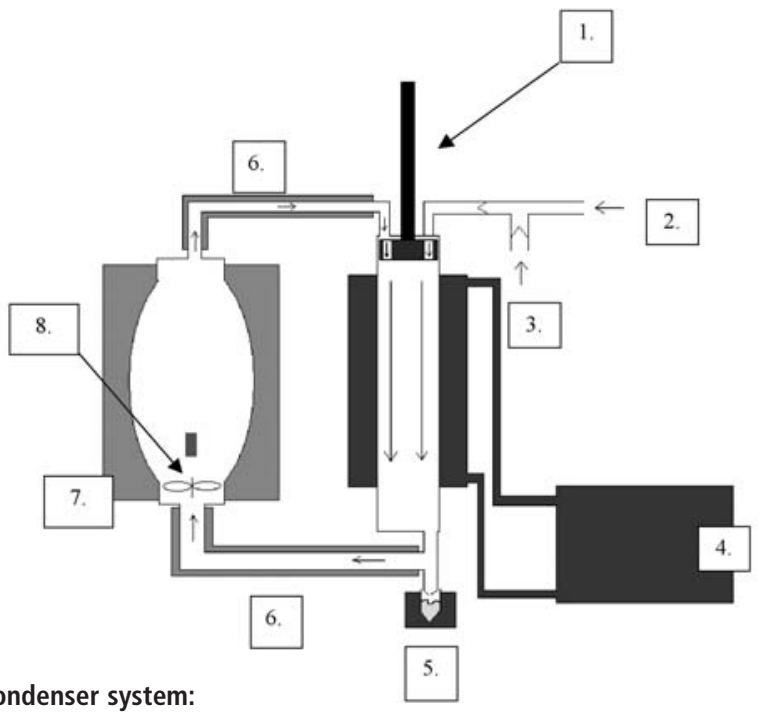

Description of the new condenser system:

1. inclined and closed glass condenser with a tube length of $90 \mathrm{~cm}$ (to enlarge the condensation surface), and downwards moveable plunger (to optimise condensate recovery from the inner wall of the condenser), with tangential and axial breath channels (to turbunately direct the tidal breath flows towards the cooled inner condenser wall)

2. swan-neck tubing (serving as gravitational saliva trap) and two-way nonrebreathing valve, connected to a face mask with separated nose and mouth cavity (8900 pediatric sizes oro-nasal masks, Hans Rudolph Inc., Kansas City, Missouri, USA)

3. entrance of inspired room air

4. cooling unit consisting of a counter-current circulating ice-water pump

5. removable glass sample vial (to collect exhaled breath condensate)

6. heated (at $37^{\circ} \mathrm{C}$ ) tubing (to guide the residual noncondensed exhaled breath, and to avoid condensation outside the condenser tube)

7. humidity sensor and heated (at $37^{\circ} \mathrm{C}$ ) inert TedlarTM gas sample bag (to collect all residual noncondensed exhaled breath)

8. small ventilator system to recirculate the residual noncondensed exhaled breath back into the condenser system (to allow secondary condensation of exhaled breath)

\section{Description of the new EBC collection procedure:}

The child exhaled tidally, as long as possible, through a face mask, with separated nose/mouth cavity, and twoway nonrebreathing valve (2), that was connected to the glass condenser system (1). During this condensation process, the formerly lost noncondensed exhaled breath was separately being collected in a gradually inflating inert Tedlar ${ }^{\mathrm{TM}}$ gas sample bag (6-7). When the child ceased this procedure, EBC was collected by pushing downwards the plunger (1). Subsequently, the plunger was pulled up again (1), and the separately collected exhaled breath was recirculated (8), from the Tedlar ${ }^{\mathrm{TM}}$ gas sample bag (7), back into the condenser system (1), to perform a secondary breath condensation, until the degree of humidity was $\leq 22 \%$.

Figure 2. Description of the new glass condenser system and exhaled breath condensate collection procedure. The new system enabled condensate collection in preschool children before and after breath recirculation. 
mediated immune response, ${ }^{222-223}$ and is characterised by chronic interval symptoms, with often an atopic personal or family history. ${ }^{9}$ Moreover, asthma is a heterogeneous disease, and diagnosis is hampered by features of the developing child undergoing (lung)growth, immune maturation and environmental influences. ${ }^{12-13,15}$

Furthermore, accurate diagnosis is hampered by the current lack of a reliable routine technique to assess different types of respiratory inflammation in preschool children.

Hence, these confounding issues make it hard to classify a wheezing phenotype in preschool children unequivocally.

By consequence, the central issue, in preschool children with different wheezing phenotypes, consists of finding a noninvasive measure to identify and discriminate underlying (persisting) airway disease, such as atopic asthmatic airway inflammation, ${ }^{222-223}$ from nonasthmatic states, such as recurrent viral wheeze and healthy children. ${ }^{9,15}$ Accordingly, statistical anaylsis revealed several significant differences between probably atopic asthmatic and nonasthmatic preschool children: tumor necrosis factor-alpha concentrations in EBC were significantly decreased, whereas the ratios of interleukin-5 to tumor necrosis factor-alpha and interleukin-13 to tumor necrosis factor-alpha in EBC were significantly increased in the probably atopic asthmatic group, compared to nonasthmatics. This is in accordance with the results of Shahid et alia, who reported an increased ratio of interleukin-4 to interferongamma in EBC in asthmatic children, aged 4.5 to 17 years. ${ }^{25}$ These findings may provide evidence for early skewing of the T-helper 2 to T-helper 1 balance in favour of an allergy-promoting T-helper 2 response. ${ }^{222-223}$

Although an accurate and firm asthma diagnosis cannot be proven in this young paediatric age group, a reasonable accuracy can be obtained using simple, clinically based parameters, as demonstrated by Castro-Rodriguez et alia. ${ }^{224}$ They developed two clinical indices for the prediction of asthma, based on the Tucson Children's Respiratory Study. ${ }^{224}$ A stringent index included frequent wheezing during the first three years of life, and either one major risk factor (parental history of asthma or eczema), or two out of three minor risk factors (eosinophilia more than 4 per cent, wheezing without colds, and allergic rhinitis). ${ }^{224} \mathrm{~A}$ loose index required any wheezing during the first 3 years of life, plus the same combination of risk factors described previously. ${ }^{224}$ Children with a positive loose index were 2.6 to 5.5 times more likely to have active asthma between ages 6 and 13, than children with a negative loose index. Risk of having subsequent asthma increased to 4.3 to 9.8 times, when a stringent index was used. ${ }^{224}$ Furthermore, they reported that 59 per cent of children with a positive loose index, and 76 per cent of those with a positive stringent index had active asthma in at least one survey during the school years. ${ }^{224}$ Over 95 per cent of children with a negative stringent index never had active asthma between ages 6 and 13.224

Therefore, the phenotypic classification of probably atopic asthmatic preschool children, in our study, was carefully assessed on basis of parentally reported symptoms 
including recurrent wheezing that was not 'exclusively' viral triggered, a documented positive response on (inhaled) corticosteroids, and medical records and information of the responsible paediatric pulmonologist on the presence of allergic sensitisation in these children, and a positive family history of atopy in the first degree. Hence, it is likely that these children had 'true' allergic asthma. Furthermore, support for an accurate asthma diagnosis comes from the significantly elevated T-helper 2 to T-helper 1 ratios in the probably atopic asthmatic group, compared to the nonasthmatic children in this study.

In conclusion, we demonstrated the feasibility of a novel method to collect EBC in preschool children, and subsequently assessed significantly elevated ratios of T-helper 2 to T-helper 1 cytokines in EBC in probably atopic asthmatic preschool children, compared to nonasthmatic preschool children.

\subsection{What do we add ?}

In this thesis, we described the development of EBC into a feasible and highly efficient, noninvasive method to assess, in children of all ages, various biomarkers of inflammation and oxidative stress. EBC is a bi-phasic technique implicating the cooling of exhaled breath to collect the condensate, and subsequently, the analysis of the collected condensate.

The first part of this thesis focused on EBC collection. Initially, condensate was collected using a wide diversity of condenser designs (as reviewed), including a borosilicate glass distilling column, as used in two - early - cross sectional studies in children, aged 5 years or more, with asthma and cystic fibrosis, respectively. Subsequently, we demonstrated that a borosilicate glass condenser was more efficient to measure 8-isoprostane and albumin in EBC, compared to five other condenser types. We mainly attributed this signifcant difference to distinct adhesive interactions between the inner condenser coatings and the exhaled biomarkers. Accordingly, glass was used as basic material to further optimise the condensation process. Hence, we presented an open glass condenser system with enlarged condenser surface, improved condensate recovery using an inclined condenser tube setting and a condensate sweeping plunger, with several tangential and axial breath flow channels to guide exhaled breath towards the cooled inner condenser wall (as shown in Figure 1). We demonstrated, in healthy adults, that the open glass condenser not only yielded significantly more EBC volume, but was also associated with more detections of hydrogen peroxide, 8-isoprostane, and several cytokines in the collected EBC, than other condenser types. Succeedingly, the condenser system was modified for use in preschool children. For this purpose, the glass condenser was closed with an unique, heated (at 37 degrees Celsius), breath recirculation system, in such a way that the formerly lost noncondensed exhaled breath was separately being collected in a gradually inflating inert Tedlar ${ }^{\mathrm{TM}}$ gas sample bag (as shown in Figure 2). When the child ceased the 'usual' EBC collection procedure, the separately collected exhaled breath was recirculated, from the gas sample bag, back into the condenser system, to 
perform a secondary breath condensation. This new concept of EBC collection before and after breath recirculation, allowed condensation of the totally exhaled breath volume, whether gathered after only a few minutes of EBC collection, or after a prolonged period. Moreover, this concept enabled the collection of significantly more EBC volume compared to the 'usual' (before breath recirculation) procedure, whereas in toddlers with limited cooperation in time, breath recirculation was often crucial to yield minimal but sufficient condensate volume (to analyse for biomarkers). Cumulatively, the success rate was 83 per cent in preschool children with and without wheezing illness. Furthermore, we demonstrated that all cytokine concentrations in EBC, collected before and after breath recirculation, were comparable, which illustrated the efficiency of the new method of EBC collection in preschool children.

The second part of this thesis focused on EBC analysis. Initially, an increasing number of biomarkers were detected (or not) in EBC, using a wide diversity of conventional assays (as reviewed). Incidental reports on detected biomarkers included hydrogen peroxide, nitrogen oxides, eicosanoids, (three) cytokines, and aldehyde/gluthatione (as reviewed). EBC consists of respiratory droplets with volatile and (mainly) nonvolatile macromolecules that are released from the epithelial lining fluid of the airways, and than 'drowned' in an excess of water vapour. Moreover, many different condenser designs were in use, and most conventional assays were not appropriate for use in this new medium as they were lacking sufficient sensitivity. Not surprisingly, biomarker reproducibility was often poor, and sometimes even highly questionable. Several research groups addressed these issues for specific biomarker measurements mainly by introducing analytical modifications, and/or by exploring in various study populations. Meanwhile, we demonstrated a significant interaction between the method of EBC collection and its subsequent analysis, and found glass condensers more efficient (as stated above). Also, we focused on the measurement of cytokines, as potentially highly interesting markers of airway inflammation in EBC, and on free radicals, as 'almost' direct markers of oxidative stress. On one hand, we tried to detect cytokines in large EBC samples by means of conventional specific assays, however without successful cytokine detection. Subsequently, we used multiplexed cytometric bead array to measure simultaneously different cytokines in small EBC samples, and reached a level of detection of nearly 50 per cent, in five out of six assayed cytokines. Succeedingly, we were able to increase the cytokine detection level at 95 to 100 per cent, in all (eight) assayed cytokines, by introducing multiplexed liquid bead array. On the other hand, we were also interested in markers of oxidative stress in EBC. We demonstrated the presence of free radicals in EBC by means of electron paramagnetic resonance spectroscopy, although this procedure is not likely suitable for future routine use. However, the presence of these free radicals in EBC may provide some further evidence for its reflection of the airway lining fluid.

The final part of this thesis focused at the clinical application of EBC. The cross sectional childhood asthma study showed low correlations between single exhaled inflammatory markers and conventional asthma measures. In children with cystic fibrosis, other exhaled inflammatory markers, including exhaled nitric oxide, were 
differently combined into several specific profiles, and were able to indicate diagnosis, exacerbation, and (to a lesser extent) disease severity, though confirmation in a longitudinal context is needed. In preschool children with and without different wheezing phenotypes, the new closed glass condenser with breath recirculation system, and multiplexed liquid bead array were used to assess T-helper 1 and T-helper 2 cytokine profiles in EBC. Hence, we demonstrated - noninvasively - significantly elevated T-helper 2 to T-helper 1 cytokine ratios in probably atopic asthmatic preschool children, compared to nonasthmatic children.

In summary, the noninvasive methodology of EBC collection and analysis has developed into a feasible and highly efficient method, that enabled noninvasive inflammometric profiling in nonsedated preschool children with different wheezing phenotypes. We believe that noninvasive inflammometric profiling will contribute to an improvement of diagnosis and customised care in children of all ages with chronic respiratory disease, whereas this inevitably will generate new insights that may ultimately lead to alter some of the previously agreed disease management strategies.

\subsection{What may or should be ?}

Obviously, the need for a standardised EBC methodology is incontestable. ${ }^{48-49,159}$ Although substantial progress has been made by improving and adapting the condenser system, as well as by introducing new ultrasensitive analytical techniques, some issues still remain unresolved and await proper investigation, as listed below. More than ever, the joint American Thoracic Society \& European Respiratory Society Task Force on EBC should diversify research efforts according to these issues, and coordinate multicentre research groups respectively.

(i) the origin and physiology of EBC

(ii) biomarker-tailored EBC collection method(s) and procedure(s)

(iii) subject-tailored EBC collection method(s) and procedure(s)

(iv) international consensus for methodological standardisation

(v) identification of biomarker profiles in different respiratory disorders

(vi) application in longitudinal noninvasive inflammometric clinical trials

(vii) validation of biomarker profiles through correlation with conventional direct measurements of inflammation, pulmonary function tests, and symptoms

(i) The anatomical origin and (patho)physiology of EBC remains to date largely unknown. Increasing insights in the mechanisms regulating the formation of $E B C$, including the exact anatomical sites of EBC particle formation, the influence of temperature, exhalation flow, salivary contamination, 225 and respiratory physiology itself,226-228 as well as the so-called 'dilutional' effects of water vapour on the content of EBC, including a possible marker of solubility, 5, 197,208,229-230 may contribute to an improvement of the EBC collection procedure resulting in adequate sample acquisition, and may clarify whether measurements should be standardised according to dilution, and/or expired breath volume, or not. Hence, these understandings may contribute to improved reproducibility. 
(ii) A biomarker-tailored EBC collection method and procedure implicates, at least, that for each type of marker the most valid condenser system is used, as well as the implementation of 'nano-molecular' analytical techniques that offer the best sensitivity and reproducibility. We advise the use of glass condensers to measure cytokines and 8-isoprostane in EBC. Furthermore, we advise the use of multiplexed liquid bead array to measure cytokines in EBC. However, it is not yet possible to give such recommendations for the measurement of other markers, as the possible influence of condenser coating and analytical technique are yet unknown.

(iii) A subject-tailored EBC collection method and procedure should be further modified for use in all ages, including newborns, as well as for use in ventilated subjects, including prematurely born infants prone to bronchopulmonary dysplasia.

(iv) International consensus for methodological standardisation of a particular EBC methodology and procedure for a given type of biomarker may be achieved through integration of both biomarker-tailored and subject-tailored EBC methodology.

(v) Identification of potentially specific and useful profiles of noninvasive biomarkers, measured in EBC and/or exhaled air, in different respiratory diseases. The combination of several noninvasive markers may provide additional information, as shown in the cross sectional cystic fibrosis study. Exempli gratia, Battaglia et alia reported the association of FeNO and 8-isoprostane in EBC, with small airways function assessed by the single breath nitrogen test, in steroid-naïve mild adult asthma, suggesting that these combined markers reflect small airway inflammation, and favouring for them a complementary role to spirometry in the monitoring of asthma. ${ }^{231}$

Also, this disease profile identification step may include a more general approach using factor analysis, which can help to reduce a large number of disease features, in casu biomarkers in EBC and other conventional or new disease measures, into a relatively small number of independent factors, and thus, grouping associated or correlated features. ${ }^{26}$ Factor analysis is essentially free of a predetermined hypothesis on any interrelated features (or biomarkers), and thus, factor analysis can be viewed as a hypothesis generating tool. ${ }^{26}$

Subsequently, cluster analysis may be used to detect clusters among a sample of individuals. ${ }^{9,232}$ Cluster analysis encompasses a number of different algoritms and methods for grouping objects of similar kind into respective categories. ${ }^{232}$ A general question facing many researchers, is how to organise observed data into meaningful structures. Cluster analysis is an exploratory data analysis tool which aims at sorting different objects into groups in a way that the degree of association between two objects is maximal if they belong to the same group and minimal otherwise. ${ }^{232}$ Given the above, cluster analysis can be used to discover structures in data without providing an explanation or interpretation. ${ }^{232}$ 
We deal with clustering in almost every aspect of daily life. ${ }^{232}$ Exempli gratia, the way food and beverage are displayed in supermarkets. Also, according to the modern taxonomical system employed in biology, man belongs to the primates, the mammals, the amniotes, the vertebrates, and the animals. ${ }^{10,232}$ Note how in this classification, the higher level of aggregation the less similar are the members in the respective class. ${ }^{232}$ Cluster analysis is not as much a typical statistical test as it is a collection of different algorithms that put objects into clusters according to well defined similarity rules. ${ }^{232}$ Cluster analysis methods are mostly used when we do not have any a priori hypotheses, but are still in the exploratory phase of our research. ${ }^{232}$ In a sense, cluster analysis finds the most significant solution possible. ${ }^{232}$ In general, whenever one needs to classify a mountain of information into manageable meaningful piles, cluster analysis is of great utility. 232

Hence, cluster analysis may detect clusters of correlated disease features, comprising biomarkers in EBC and other conventional or new disease measures, among a sample of individuals. ${ }^{9,26,232-235}$ Succeedingly, the utility of these clusters can be evaluated in clinical practice, which may accordingly lead to refining of the disease model or profile. , $26,232-235^{2}$

(vi) Application of exhaled biomarker profiles in longitudinal noninvasive inflammometric clinical trials. This requires the establishment of normal variations and age-dependent reference ranges in healthy control children, and an evaluation of the best sensitivity and specificity for each profile of biomarkers in healthy children and children with respiratory disease.

As correlation analysis in cross sectional observations cannot prove either the presence or the direction of causality, longitudinal clinical studies need to evaluate these different profiles of markers in the monitoring of various respiratory disorders. This includes an evaluation of their potentially predictive value for response to treatment, and exacerbation or relapse of disease, as well as their correlations with exhaled nitric oxide, pulmonary function tests and other conventional measures of disease control, such as symptom score, usage of rescue medication and quality of life questionnaires.

Ultimately, this may lead to the inclusion of noninvasive inflammometric profiling into specific management guidelines, and thus, enable future individualised therapeutic strategies.

(vii) Validation of biomarker profiles through correlation with direct measurements of inflammation, including induced sputum, bronchoalveolar lavage and endobronchial biopsies. Recently, Fireman et alia demonstrated a differential pattern of inflammation assessed by induced sputum eosinophil count and colorimetric measurement of hydrogen peroxide in EBC in adult patients with obstructive compared to restrictive lung diseases and persistent cough. ${ }^{236}$ Moreover, Fireman et alia reported no detectable levels of hydrogen peroxide in EBC in subjects with interstitial lung disease, in contrast to adults with obstructive lung disease, hence suggesting evidence for the specificity of hydrogen peroxide measured in EBC, which is mainly derived from the airways or 
bronchial compartment, and only to a lesser extend from the alveolar compartment. ${ }^{236}$ Jackson et alia reported no correlation between markers (in casu 8-isoprostane, hydrogen peroxide, total nitrogen oxides, acidity, total protein, total phospholipid and keratin) in EBC and bronchoalveolar lavage, in 49 adult patients undergoing bronchoscopy for diverse reasons, including lung transplantation. ${ }^{237}$ Gessner et alia reported no siginificant correlations between cytokine levels (in casu interleukin-1-beta, interleukin-6, interleukin-8, interleukin-10, interleukin-12p70 and tumor necrosis factor-alpha) in bronchoalveolar lavage fluid and EBC in a limited population of 14 adult subjects with an acute exacerbation of chronic obstructive pulmonary disease, requiring bronchoalveolar lavage for microbiological reasons. ${ }^{57}$ On the other hand, Lex et alia reported, in a subgroup of asthmatic children who were not treated with montelukast (but with high doses of inhaled and/or systemic steroids), a significant relationship between cysteinyl leukotrienes in EBC and reticular basement membrane thickening in endobronchial biopsies. ${ }^{210}$ Obviously, these findings are highly intrigueing, whether positive or negative, however, we strongly insist upon cautious interpretation in view of the many currently not (yet) standardised aspects of EBC methodology. To state once more, the need for standardised EBC methodology is incontestable, and should primarily and urgently be addressed using a coordinated multicenter approach.

Finally, we also want to point out that trained household dogs were able to detect biopsy-confirmed lung and breast cancer with 0.99 and 0.88 specificity, respectively. ${ }^{238}$ Currently more than 500 trace compounds in exhaled breath are known as volatile organic compounds (VOCs). ${ }^{239}$ Volatile organic compounds can be produced anywhere in the body, and are transported via the bloodstream, and exhaled through the lung. ${ }^{240}$ Therefore, looking at a set of volatile organic compounds may enable recognition and monitoring of different complex processes in the body. ${ }^{239}$ However, to date, huge variations exist between results of different studies, due to lack of standardisation, and associated technical problems of sampling and (automated and real time) analysis. $239-242$

Thus, noninvasive inflammometric profiling may ultimately encompass the assessment of various biomarkers in EBC, with concomitant volatile organic compounds, and may lead to the routine use of individual breathograms that may guide customised management strategies in chronic respiratory disorders and beyond ...

\subsection{Epilogue}

To recapitulate, Penelope's heart may not yet have been conquered entirely, but this thesis offers at least an improved EBC methodology, and thus, a spark of new perspectives for the management of both the younger as well as the older children with chronic respiratory inflammation. Methodological standardisation of EBC collection and analysis remains a prerequisite, and future investigations will demonstrate whether accurate diagnosis and customised care for all children with chronic respiratory inflammation can be achieved by additional routine noninvasive inflammometric 
profiling. In that way, EBC may prove to be the mythological lanus bifrons, ${ }^{1}$ the old roman god with two foreheads or faces, as shown on the back cover of this thesis, and often depicted with two keys, one closing the gateway of the past, the other one opening the gateway of the future ... 


\section{References}

1. Noyen P. Wij en de oudheid, klassiek vademecum. Van Looy, ed. De Nederlandsche Boekhandel, Antwerpen/Amsterdam, 1979.

2. Sidorenko Gl, Zborovskii El, Levina DI. Surface-active properties of the exhaled air condensate (a new method of studying lung function). Ter Arkh 1980; 52: 65-68.

3. Gorbachev M. Perestroika: new thinking for our country and the world. Harper and Row, eds, Perennial Library, 1988.

4. Scheideler L, Manke HG, Schwulera U, Inacker O, Hämmerle H. Detection of nonvolatile macromolecules in breath. A possible diagnostic tool? Am Rev Respir Dis 1993: 148: 778-784.

5. Effros RM, Hoagland KW, Bosbous M, Castillo D, Foss B, Dunning M, Gare M, Lin W, Sun F. Dilution of respiratory solutes in exhaled condensates. Am J Respir Crit Care Med 2002; 165: 663-669.

6. Baraldi E, Ghiro L, Piovan V, Carraro S, Zacchello F, Zanconato S. Safety and success of exhaled breath condensate collection in asthma. Arch Dis Child 2003; 88: 358-360.

7. Tonelli MR. The limits of evidence-based medicine. Respir Care 2001; 46: 1435-1440.

8. Centre for Evidence-Based Medicine. www.cebm.net/glossary.asp. Date last accessed: June 92007.

9. Grigg J, Silverman M. Wheezing disorders in young children: one disease or several phenotypes? In: Frey U, Gerritsen J, eds. Respiratory diseases in infants and children. Eur Respir Mon 2006; 37: 153-169.

10. Darwin C. On the origin of species by means of natural selection, or the preservation of favoured races in the struggle for life. London, John Murray, ed., 1859.

11. von Mutius E. Epidemiology of respiratory diseases in infants and children. In: Frey U, Gerritsen J, eds. Respiratory diseases in infants and children. Eur Respir Mon 2006; 37: 1-7.

12. Merkus PJFM, Hislop AA. Lung development from infancy to adulthood. In: Frey U, Gerritsen J, eds. Respiratory diseases in infants and children. Eur Respir Mon 2006; 37: 8-21.

13. LeSouëf $\mathrm{P}$, Kabesch $\mathrm{M}$. Impact of genetic factors on lung development in health and disease. In: Frey U, Gerritsen J, eds. Respiratory diseases in infants and children. Eur Respir Mon 2006; 37: 93-107.

14. Gerritsen J, Reijmerink NE, Kerkhof M, Postma DS. Gene-environment interaction and respiratory disease in children. In: Frey U, Gerritsen J, eds. Respiratory diseases in infants and children. Eur Respir Mon 2006; 37: 108-119.

15. Schaub B, Lauener R, Prescott SL. Immunology and defence mechanism of the developing lung. In: Frey U, Gerritsen J, eds. Respiratory diseases in infants and children. Eur Respir Mon 2006; 37: 60-78.

16. Custovic A, Lødrup Carlsen KC, Håkon Carlsen K. Allergy and the paediatric lung during development. In: Frey U, Gerritsen J, eds. Respiratory diseases in infants and children. Eur Respir Mon 2006; 37: 79-92.

17. Payne DN, Saglani S, Bush A. Remodelling in paediatric respiratory disease and impact on growth and development. In: Frey U, Gerritsen J, eds. Respiratory diseases in infants and children. Eur Respir Mon 2006; 37: 41-59. 
18. de Jongste JC, Baraldi E, Lombardi E. Clinically relevant early functional and diagnostic markers of lung disease in children. In: Frey U, Gerritsen J, eds. Respiratory diseases in infants and children. Eur Respir Mon 2006; 37: 120-141

19. Wildhaber JH, Sennhauser FH, Brand PLP. Asthma in school-aged children and adolescents. In: Frey U, Gerritsen J, eds. Respiratory diseases in infants and children. Eur Respir Mon 2006; 37: 191-216.

20. Gustafsson LE, Leone AM, Persson MG, Wiklund NP, Moncada S. Endogenous nitric oxide is present in the exhaled air of rabbits, guinea pigs and humans. Biochem Biophys Res Commun 1991; 181: 852-857.

21. American Thoracic Society. ATS/ERS recommendations for standardized procedures for the online and offline measurement of exhaled lower respiratory nitric oxide and nasal nitric oxide, 2005. Am J Respir Crit Care Med 2005; 171: 912-930.

22. Pijnenburg Mw, Bakker EM, Hop WC, de Jongste JC. Titrating steroids on exhaled nitric oxide in children with asthma: a randomized controlled trial. Am J Respir Crit Care Med 2005; 172: 831-836.

23. Huszar E, Szabo Z, Jakab A, Barta I, Herjavecz I, Horvath I. Comparative measurement of thromboxane A2 metabolites in exhaled breath condensate by different immunoassays. Inflamm Res 2005; 54: 350-355.

24. Leung T, Wong GWK, Ko FWS, Li C, Yung E, Lam CWK, Fok T. Analysis of growth factors and inflammatory cytokines in exhaled breath condensate from asthmatic children. Int Arch Allergy Immunol 2005; 137: 66-72.

25. Shahid SK, Kharitonov SA, Wilson NM, Bush A, Barnes PJ. Increased interleukin-4 and decreased interferon-gamma in exhaled breath condensate of children with asthma. Am J Respir Crit Care Med 2002; 165: 1290-1293.

26. Leung TF, Wong GW, Ko FW, Lam CW, Fok TF. Clinical and atopic parameters and airway inflammatory markers in childhood asthma: a factor analysis. Thorax 2005; 60: 822-826.

27. Leung TF, Wong GW, Ko FW, Lam CW, Fok TF. Increased macrophage-derived chemokine in exhaled breath condensate and plasma from children with asthma. Clin Exp Allergy 2004; 34: 786-791.

28. Bodini A, D'Órazio C, Peroni D, Corradi M, Folesani G, Baraldi E, Assael BM, Boner A, Piacentini GL. Biomarkers of neutrophilic inflammation in exhaled air of cystic fibrosis children with bacterial airway infections. Pediatr Pulmonol 2005; 40: 494499.

29. Hunt JF, Erwin E, Palmer L, Vaughan J, Malhotra N, Platts-Mills TA, Gaston B. Expression and activity of $\mathrm{pH}$-regulated glutaminase in the human airway epithelium. Am J Respir Crit Care Med 2002; 165: 101-107.

30. Kostikas K, Papatheodorou G, Ganas K, Psathakis K, Panagou P, Loukides S. pH in expired breath condensate of patients with inflammatory airway diseases. Am J Respir Crit Care Med 2002; 165: 1364-1370.

31. Hunt JF, Fang K, Malik R, Snyder A, Malhotra N, Platts-Mills TA, Gaston B. Endogenous airway acidification: implications for asthma pathophysiology. Am J Respir Crit Care Med 2000; 161: 694-699.

32. Effros RM. Endogenous airway acidification: implications for asthma pathophysiology. Am J Respir Crit Care Med 2001; 163: 293-294. 
33. Gaston B, Hunt JF. How acidopneic is my patient? A new question in the pulmonary laboratory. Am J Respir Crit Care Med 2002; 165: 1349-1350.

34. Effros RM, Gaston BM, Hunt JF. Do low exhaled condensate NH4+ concentrations in asthma reflect reduced pulmonary production? Am J Respir Crit Care Med 2003; 167: $91-92$.

35. Effros RM, Casaburi R, Jennifer S, Dunning M, Torday J, Biller J, Shaker R. The effects of volatile salivary acids and bases on exhaled breath condensate $\mathrm{pH}$. Am J Respir Crit Care Med 2006; 173: 386-392.

36. Effros RM. Exhaled breath condensate pH. Am J Respir Crit Care Med 2006; 173 : 1047-1048.

37. Hunt J. Exhaled breath condensate $\mathrm{pH}$, reflecting acidification of the airway at all levels. Am J Respir Crit Care Med 2006; 173: 366-367.

38. Leung TF, Li CY, Yung E, Liu EKH, Lam CWK, Wong GWK. Clinical and technical factors affecting $\mathrm{pH}$ and other biomarkers in exhaled breath condensate. Pediatr Pulmonol 2006; 41: 87-94.

39. Prince P, Boulay ME, Boulet LP. A fast, simple, and inexpensive method to collect exhaled breath condensate for $\mathrm{pH}$ determination. Ann Allergy Asthma Immunol 2006; 97: 622-627.

40. Brooks SM, Haight RR, Gordon RL. Age does not affect airway $\mathrm{pH}$ and ammonia as determined by exhaled breath measurements. Lung 2006; 184: 195-200.

41. Bloemen K, Lissens G, Desager K, Schoeters G. Determinants of variability of protein content, volume and pH of exhaled breath condensate. Respir Med 2007; 101: 1331-1337.

42. Borrill ZL, Smith JA, Naylor J, Woodcock AA, Singh D. The effect of gas standardisation on exhaled breath condensate pH. Eur Respir J 2006; 28: 251-253.

43. Paget-Brown AO, Ngamtrakulpanit L, Smith A, Bunyan D, Hom S, Nguyen A, Hunt JF. Normative data for pH of exhaled breath condensate. Chest 2006; 129: 426-430.

44. Kullmann T, Barta I, Lazar Z, Szili B, Barat E, Valyon M, Kollai M, Horvath I. Exhaled breath condensate pH standardised for CO2 partial pressure. Eur Respir J 2007; 29: 496-501.

45. Nicolaou NC, Lowe LA, Murray CS, Woodcock A, Simpson A, Custovic A. Exhaled breath condensate $\mathrm{pH}$ and childhood asthma, unselected birth cohort study. Am J Respir Cirt Care Med 2006; 174: 254-259.

46. Ratnawati, Morton J, Henry RL, Thomas PS. Exhaled breath condensate nitrite/nitrate and $\mathrm{pH}$ in relation to pediatric asthma control and exhaled nitric oxide. Pediatr Pulmonol 2006; 41: 929-936.

47. Hunt J, Yu Y, Burns J, Gaston B, Ngamtrakulpanit L, Bunyan D, Walsh BK, Smith A, Hom S. Identification of acid reflux cough using serial assays of exhaled breath condensate pH. Cough 2006 Apr 11; 2: 3 (doi:10.1186/1745-9974-2-3).

48. Horváth I, Hunt J, Barnes PJ. On behalf of the ATS/ARS Task Force on Exhaled Breath Condensate. Exhaled breath condensate: methodological recommendations and unresolved questions. Eur Respir J 2005; 26: 523-548.

49. American Thoracic Society. Workshop Proceedings: Exhaled nitric oxide and nitric oxide oxidative metabolism in exhaled breath condensate. Proc Am Thorac Soc 2006; 3: 131-145. 
50. Zacharasiewicz A, Wilson N, Lex C, Erin EM, Li AM, Hansel T, Khan M, Bush A. Clinical use of noninvasive measurements of airway inflammation in steroid reduction in children. Am J Respir Crit Care Med 2005; 171: 1077-1082.

51. Robroeks CMHHT, Jöbsis Q, Damoiseaux JGMC, Heijmans PHM, Rosias PPR, Hendriks HJE, Dompeling E. Cytokines in exhaled breath condensate of children with cystic fibrosis. Ann Allergy Asthma Immunol 2006; 96: 349-355.

52. BD Biosciences Cytometric Bead Array.

http://www.bdbiosciences.com/pharmingen/products/display_product.php?keylD=9.

Date last accessed: June 92007.

53. Morgan E, Varro R, Sepulveda H, Ember JA, Apgar J, Wilson J, Lowe L, Chen R, Shivraj L, Agadir A, Campos R, Ernst D, Gaur A. Cytometric bead array: a multiplexed assay platform with applications in various areas of biology. Clin Immunol 2004; 110 : 252-266.

54. Armstrong DS, Hook SM, Jamsen KM, Nixon GM, Carzino R, Carlin JB, Robertson CF, Grimwood K. Lower airway inflammation in infants with cystic fibrosis detected by newborn screening. Pediatr Pulmonol 2005; 40: 500-510.

55. Kelly MM, Leigh R, Carruthers S, Horsewood P, Gleich GJ, Hargreave FE, Cox G. Increased detection of interleukin-5 in sputum by addition of protease inhibitors. Eur Respir J 2001; 18: 685-691.

56. Sack U, Scheibe R, Wötzel M, Hammerschmidt S, Kuhn H, Emmrich F, Hoheisel G, Wirtz H, Gessner C. Multiplex analysis of cytokines in exhaled breath condensate. Cytometry A 2006; 69: 169-172.

57. Gessner C, Scheibe R, Wötzel M, Hammerschmidt S, Kuhn H, Engelmann L, Hoheisel G, Gillissen A, Sack U, Wirtz H. Exhaled breath condensate cytokine patterns in chronic obstructive pulmonary disease. Respir Med 2005; 99: 1229-1240.

58. Matsunaga K, Yanagisawa S, Ichikawa T, Ueshima K, Akamatsu K, Hirano T, Nakanishi M, Yamagata T, Minakata Y, Ichinose M. Airway cytokine expression measured by means of protein array in exhaled breath condensate: correlation with physiologic properties in asthmatic patients. J Allergy Clin Immunol 2006; 118: 84-90.

59. Huang RP, Huang R, Fan Y, Lin Y. Simultaneous detection of multiple cytokines from conditioned media and patient's sera by an antibody-based protein array system. Anal Biochem 2001; 294: 55-62.

60. Schumann C, Triantafilou K, Krueger S, Hombach V, Triantafilou M, Becher G, Lepper PM. Detection of erythropoietin in exhaled breath condensate of nonhypoxic subjects using a multiplex bead array. Mediators Inflamm 2006; 2006 (5): 18061 (doi 10.1155/MI/2006/18061).

61. Jöbsis Q, Raatgreep HC, Schellekens SL, Kroesbergen A, Hop WC, de Jongste JC. Hydrogen peroxide and nitric oxide in exhaled air of children with cystic fibrosis during antibiotic treatment. Eur Respir J 2000; 16: 95-100.

62. Ojoo JC, Mulrennan SA, Kastelik JA, Morice AH, Redington AE. Exhaled breath condensate $\mathrm{pH}$ and exhaled nitric oxide in allergic asthma and in cystic fibrosis. Thorax 2005; 60: 22-26.

63. Ho LP, Innes JA, Greening AP. Nitrite levels in breath condensate of patients with cystic fibrosis is elevated in contrast to exhaled nitric oxide. Thorax 1998; 53: 680684. 
64. Ho LP, Innes JA, Greening AP. Exhaled nitric oxide is not elevated in the inflammatory airways diseases of cystic fibrosis and bronchiectasis. Eur Respir J 1998; 12: 12901294.

65. Dotsch J, Demirakca S, Terbrack HG, Huls G, Rascher W, Kuhl PG. Airway nitric oxide in asthmatic children and patients with cystic fibrosis. Eur Respir J 1996; 9: 25372540.

66. Grasemann H, Michler E, Wallot M, Ratjen F. Decreased concentration of exhaled nitric oxide (NO) in patients with cystic fibrosis. Pediatr Pulmonol 1997; 24: 173-177.

67. Lundberg JO, Nordvall SL, Weitzberg E, Kollberg H, Alving K. Exhaled nitric oxide in paeditric asthma and cystic fibrosis. Arch Dis Child 1996; 75: 323-326.

68. Thomas SR, Kharitonov SA, Scott SF, Hodson ME, Barnes PJ. Nasal and exhaled nitric oxide is reduced in adult patients with cystic fibrosis and does not correlate with cystic fibrosis genotype. Chest 2000; 117: 1085-1089.

69. Elphick HE, Demoncheaux EA, Ritson S, Higenbottam TW, Everard ML. Exhaled nitric oxide is reduced in infants with cystic fibrosis. Thorax 2001; 56: 151-152.

70. Franklin PJ, Hall GL, Moeller A, Horak FJr, Brennan S, Stick SM. Exhaled nitric oxide is not reduced in infants with cystic fibrosis. Eur Respir J 2006; 27: 350-353.

71. Cunningham S, McColm JR, Ho LP, Greening AP, Marshall TG. Measurement of inflammatory markers in the breath condensate of children with cystic fibrosis. Eur Respir J 2000; 15 : 955-957.

72. Formanek W, Inci D, Lauener RP, Wildhaber JH, Frey U, Hall GL. Elevated nitrite in breath condensates of children with respiratory disease. Eur Respir J 2002; 19: 487491.

73. Tate S, MacGregor G, Davis M, Innes JA, Greening AP. Airways in cystic fibrosis are acidified: detection by exhaled breath condensate. Thorax 2002; 57: 926-929.

74. Wojnarowski C, Frischer T, Hofbauer E, Grabner C, Mosgoeller W, Eichler I, Ziesche R. Cytokine expression in bronchial biopsies of cystic fibrosis patients with and without acute exacerbation. Eur Respir J 1999; 14: 1136-1144.

75. de Winter-de Groot KM, van der Ent CK. Nitric oxide in cystic fibrosis. J Cyst Fibros 2005; 4 Suppl 2: 25-29.

76. Grasemann H, Ratjen F. Cystic fibrosis lung disease: the role of nitric oxide. Pediatr Pulmonol 1999; 28: 442-448.

77. Meng QH, Springall DR, Bishop AE, Morgan K, Evans TJ, Habib S, Gruenert DC, Gyi KM, Hodson ME, Yacoub MH, Polak JM. Lack of inducible nitric oxide synthase in bronchial epithelium: a possible mechanism of susceptibility to infection in cystic fibrosis. J Pathol 1998; 184: 323-331.

78. Kelley TJ, Drumm ML. Inducible nitric oxide synthase expression is reduced in cystic fibrosis murine and human airway epithelial cells. J Clin Invest 1998; 102: 12001207.

79. Steagall WK, Elmer HL, Brady KG, Kelley TJ. Cystic fibrosis transmembrane conductance regulator-dependent regulation of epithelial inducible nitric oxide synthase expression. Am J Respir Cell Mol Biol 2000; 22: 45-50.

80. Moeller A, Horak Fur, Lane C, Knight D, Kicic A, Brennan S, Franklin P, Terpolilli J, Wildhaber JH, Stick SM. Inducible NO synthase expression is low in airway epithelium from young children with cystic fibrosis. Thorax 2006; 61: 514-520. 
81. Grasemann H, Schwiertz R, Matthiesen S, Racke K, Ratjen F. Increased arginase activity in cystic fibrosis airways. Am J Respir Crit Care Med 2005; 172: 1523-1528.

82. Ho LP, Faccenda J, Innes JA, Greening AP. Expired hydrogen peroxide in breath condensate of cystic fibrosis patients. Eur Respir J 1999; 13: 103-106.

83. Montuschi P, Kharitonov SA, Ciabattoni G, Corradi M, van Rensen L, Geddes DM, Hodson ME, Barnes PJ. Exhaled 8-isoprostanes as a new non-invasive biomarker of oxidative stress in cystic fibrosis. Thorax 2000; 55: 205-209.

84. Carpagnano GE, Barnes PJ, Francis J, Wilson N, Bush A, Kharitonov SA. Breath condensate $\mathrm{pH}$ in children with cystic fibrosis and asthma: a new noninvasive marker of airway inflammation? Chest 2004; 125: 2005-2010.

85. Caglieri A, Goldoni M, Acampa O, Andreoli R, Vettori MV, Corradi M, Apostoli P, Mutti $A$. The effect of inhaled chromium on different exhaled breath condensate biomarkers among chrome-plating workers. Environ Health Perspect 2006; 114 : 542-546.

86. Soyer OU, Dizdar EA, Keskin O, Lilly C, Kalayci O. Comparison of two methods for exhaled breath condensate collection. Allergy 2006; 61: 1016-1018.

87. Van Hoydonck PG, Wuyts WA, Vanaudenaerde BM, Schouten EG, Dupont L, Temme EH. Quantitative analysis of 8-isoprostane and hydrogen peroxide in exhaled breath condensate. Eur Respir J 2004; 23: 189-192.

88. Kostikas K, Papatheodorou G, Psathakis K, Panagou P, Loukides S. Oxidative stress in expired breath condensate of patients with COPD. Chest 2003; 124: 1373-1380.

89. Montuschi P, Corradi M, Ciabattoni G, Nightingale J, Kharitonov SA, Barnes PJ. Increased 8-isoprostane, a marker of oxidative stress, in exhaled condensate of asthma patients. Am J Respir Crit Care Med 1999; 160: 216-220.

90. Montuschi P, Collins JV, Ciabattoni G, Lazzeri N, Corradi M, Kharitonov SA, Barnes PJ. Exhaled 8-isoprostane as an in vivo biomarker of lung oxidative stress in patients with COPD and healthy smokers. Am J Respir Crit Care Med 2000; 162: 1175-1177.

91. Carpagnano GE, Kharitonov SA, Resta O, Foschino-Barbaro MP, Gramiccioni E, Barnes PJ. Increased 8-isoprostane and interleukin-6 in breath condensate of obstructive sleep apnea patients. Chest 2002; 122: 1162-1167.

92. Baraldi E, Carraro S, Alinovi R, Pesci A, Ghiro L, Bodini A, Piacentini G, Zacchello F, Zanconato $S$. Cysteinyl leukotrienes and 8-isoprostane in exhaled breath condensate of children with asthma exacerbations. Thorax 2003; 58: 505-509.

93. Baraldi E, Ghiro L, Piovan V, Carraro S, Ciabattoni G, Barnes PJ, Montuschi P. Increased exhaled 8-isoprostane in childhood asthma. Chest 2003; 124: 25-31.

94. Biernacki WA, Kharitonov SA, Barnes PJ. Increased leukotriene B4 and 8-isoprostane in exhaled breath condensate of patients with exacerbations of COPD. Thorax 2003; 58: 294-298.

95. Zanconato S, Carraro S, Corradi M, Alinovi R, Pasquale MF, Piacentini G, Zacchello F, Baraldi E. Leukotrienes and 8-isoprostane in exhaled breath condensate of children with stable asthma and unstable asthma. J Allergy Clin Immunol 2004; 113: 257-263.

96. Psathakis K, Papatheodorou G, Plataki M, Panagou P, Loukides S, Siafakas NM, Bouros D. 8-isoprostane, a marker of oxidative stress, is increased in the expired breath condensate of patients with pulmonary sarcoidosis. Chest 2004; 125: 10051011. 
97. Bodini A, Peroni D, Vicentini L, Loiacono A, Baraldi E, Ghiro L, Corradi M, Alinovi R, Boner AL, Piacentini GL. Exhaled breath condensate eicosanoids and sputum eosinophils in asthmatic children: a pilot study. Pediatr Allergy Immunol 2004; 15: 26-31.

98. Back El, Frindt C, Nohr D, Frank J, Ziebach R, Stern M, Ranke M, Biesalski HK. Antioxidant deficiency in cystic fibrosis: when is the right time to take action? Am J Clin Nutr 2004; 80: 374-384.

99. Mondino C, Ciabattoni G, Koch P, Pistelli R, Trové A, Barnes PJ, Montuschi P. Effects of inhaled corticosteroids on exhaled leukotrienes and prostanoids in asthmatic children. J Allergy Clin Immunol 2004; 114: 761-767.

100. Sanak M, Kielbasa B, Bochenek G, Szczeklik A. Exhaled eicosanoids following oral aspirin challenge in asthmatic patients. Clin Exp Allergy 2004; 34: 1899-1904.

101. Tufvesson E, Bjermer L. Methodological improvements for measuring eicosnaoids and cytokines in exhaled breath condensate. Respir Med 2006; 100: 34-38.

102. Komatsu T, Oguro Y, Teramura Y, Takeota S, Okai J, Anraku M, Otagiri M, Tsuchida E. Physicochemical characterisation of cross-linked human serum albumin dimer and its synthetic heme hibrid as an oxygen carrier. Biochim Biophys Acta 2004; 1675: 21-31.

103. Prieto L, Ferrer A, Palop J, Domenech J, Llusar R, Rojas R. Differences in exhaled breath condensate $\mathrm{pH}$ measurements between samples obtained with two commercial devices. Respir Med 2007 May 2: epub ahead of print (doi: 10.1016/j.rmed.2007.02.023).

104. Gerritsen WB, Zanen P, Bauwens AA, van den Bosch JM, Haas FJ. Validation of a new method to measure hydrogen peroxide in exhaled breath condensate. Respir Med 2005; 99: 1132-1137.

105. Brooks WM, Lash $H$, Kettle AJ, Epton MJ. Optimising hydrogen peroxide measurement in exhaled breath condensate. Redox Rep 2006; 11: 78-84.

106. Gonzalez-Reche LM, Musiol AK, Müller-Lux A, Kraus T, Göen T. Method optimization and validation for the simultaneous determination of arachidonic acid metabolites in exhaled breath condensate by liquid chromatography-electrospray ionization tandem mass spectrometry. J Occup Med Toxicol 2006 May 17; 1:5 (doi:10.1186/1745-66731-5).

107. Rahman I, Biswas SK. Non-invasive biomarkers of oxidative stress: reproducibility and methodological issues. Redox Rep 2004; 9: 125-143.

108. Kharitonov SA. Exhaled markers of inflammatory lung diseases: ready for routine monitoring? Swiss Med Wkly 2004; 134: 175-192.

109. Goldoni M, Caglieri A, Andreoli R, Poli D, Manini P, Vettori MV, Corradi M, Mutti A. Influence of condensation temperature on selected exhaled breath parameters. $B M C$ Pulm Med 2005 Sep 1; 5: 10 (doi: 10.1186/1471-2466-5-10).

110. Nowak D, Kalucka S, Bialasiewicz P, Krol M. Exhalation of H2O2 and thiobarbituric acid reactive substances (TBARs) by healthy subjects. Free Radic Biol Med 2001; 30: 178-186.

111. Horvath I, MacNee W, Kelly FJ, Dekhuijzen PN, Phillips M, Döring G, Choi AM, Yamaya M, Bach FH, Willis D, Donnelly LE, Chung KF, Barnes PJ. Haemoxygenase-1 induction and exhaled markers of oxidative stress in lung diseases. Summary of the ERS Research Seminar in Budapest, Hungary, September 1999. Eur Respir J 2001; 18 : 420-430. 
112. Culpitt SV, Russell REK. The measurement of hydrogen peroxide in airway disease. Eur Respir Rev 1999; 68: 246-248.

113. van Beurden WJ, van den Bosch JM, Janssen WC, Smeenk FW, Dekhuijzen PN, Harff GA. Fluorimetric analysis of hydrogen peroxide with automated measurement. Clin Lab 2003; 49: 637-643.

114. Dekhuijzen PN, Aben KKH, Dekker I, Aarts LP, Wielders PL, van Herwaarden CL, Bast A. Increased exhalation of hydrogen peroixde in patients with stable and unstable chronic obstructive pulmonary diseases. Am J Respir Crit Care Med 1996; 154: 813816 .

115. Schleiss MB, Holz O, Behnke M, Richter K, Magnussen H, Jorres RA. The concentration of hydrogen peroxide in exhaled air depends on expiratory flow rate. Eur Respir $J$ 2000; 16: 1115-1118.

116. van Beurden WCJ, Dekhuijzen PNR, Harff GA, Smeenk FWJM. Variability of exhaled hydrogen peroxide in stable COPD and matched healthy controls. Respiration 2002; 69: 211-216.

117. Cheah FC, Darlow BA, Winterbourn CC. Problems associated with collecting breath condensate for the measurement of exhaled hydrogen peroxide from neonates on respiratory support. Biol Neonate 2003; 84: 338-341.

118. Rahman I. Reproducibility of oxidative stress biomarkers in breath condensate: are they reliable? Eur Respir J 2004; 23: 183-184.

119. De Benedetto F, Aceto A, Dragani B, Spacone A, Formisano S, Cocco R, Sanguinetti $C M$. Validation of a new technique to assess hydrogen peroxide: results from normals and COPD patients. Monaldi Arch Chest Dis 2000; 55: 185-188.

120. Van Beurden WJ, Harff GA, Dekhuijzen PN, van den Bosch MJ, Creemers JP, Smeenk FW. An efficient and reproducible method for measuring hydrogen peroxide in exhaled breath condensate. Respir Med 2002; 96: 197-203.

121. Zappacosta B, Persichilli S, Mormile F, Minucci A, Russo A, Giardina B, De Sole P. A fast chemiluminescence method for $\mathrm{H} 2 \mathrm{O} 2$ measurement in exhaled breath condensate. Clin Chim Acta 2001; 310: 187-191.

122. Razola SS, Ruiz BL, Diez NM, Mark HBJr, Kauffmann JM. Hydrogen peroxide sensitive amperometric biosensor based on horseradish peroxidase entrapped in a polypyrrole electrode. Biosens Bioelectron 2002; 17: 921-928.

123. Thanachasai S, Rokutanzono S, Yoshida S, Watanabe T. Novel hydrogen peroxide sensors based on peroxidase-carrying poly[pyrrole-co-[4-(3-pyrrolyl)butanesulfonate]] copolymer films. Anal Sci 2002; 18: 773-777.

124. Jöbsis Q, Raatgreep HC, Hermans PW, de Jongste JC. Hydrogen peroxide in exhaled air is increased in stable asthmatic children. Eur Respir J 1997; 10: 519-521.

125. Jöbsis Q, Raatgreep HC, Schellekens SL, Hop WC, Hermans PW, de Jongste JC. Hydrogen peroxide in exhaled air of healthy children: reference values. Eur Respir $J$ 1998; 12: 483-485.

126. Nowak D, Kasielski M, Pietras T, Bialasiewicz P, Antczak A. Cigarette smoking does not increase hydrogen peroxide levels in expired breath condensate of patients with stable COPD. Monaldi Arch Chest Dis 1998; 53: 268-273.

127. Latzin P, Beck J, Bartenstein A, Griese M. Comparison of exhaled breath condensate from nasal and oral collection. Eur J Med Res 2003; 8: 505-510. 
128. Montuschi P, Ragazzoni E, Valente S, Corbo G, Mondino C, Ciappi G, Barnes PJ, Ciabattoni G. Validation of 8-isoprostane and prostaglandin E2 measurements in exhaled breath condensate. Inflamm Res 2003; 52: 502-506.

129. Montuschi P, Mondino C, Koch P, Barnes PJ, Ciabattoni G. Effects of a leukotriene receptor antagonist on exhaled leukotriene $\mathrm{E} 4$ and prostanoids in children with asthma. J Allergy Clin Immunol 2006; 118: 347-353.

130. Cap P, Chladek J, Pehal F, Maly M, Petru V, Barnes PJ, Montuschi P. Gas chromatography/mass spectrometry analysis of exhaled leukotrienes in asthmatic patients. Thorax 2004; 59: 465-470.

131. Griese M, Latzin P, Beck J. A noninvasive method to collect nasally exhaled air condensate in humans of all ages. Eur J Clin Invest 2001; 31: 915-920.

132. Latzin P, Beck-Ripp J, Hartl D, Bartenstein A, Noss J, Griese M. 8-Isoprostane in nasally exhaled breath condensate in different pediatric lung diseases. Eur J Med Res 2007; 12: $21-25$.

133. Moeller A, Franklin P, Hall GL, Horak FJr, Wildhaber JH, Stick SM. Measuring exhaled breath condensate in infants. Pediatr Pulmonol 2006; 41: 184-187.

134. Muller WG, Morini F, Eaton S, Peters M, Jaffe A. Safety and feasibility of exhaled breath condensate in ventilated infants and children. Eur Respir J 2006; 28: 476-485.

135. Walsh BK, Mackey DJ, Pajewski T, Yu Y, Gaston BM, Hunt JF. Exhaled breath condensate $\mathrm{pH}$ can be safely and continuously monitored in mechanically ventilated patients. Respir Care 2006; 51: 1125-1131.

136. Bellieni CV, Cordelli DM, Raffaelli M, Ricci B, Morgese G, Buonocore G. Analgesic effect of watching TV during venipuncture. Arch Dis Child 2006; 91: 1015-1017.

137. Cohen LL, Blount RL, Panopoulos G. Nurse coaching and cartoon distraction: an effective and practical intervention to reduce child, parent, and nurse distress during immunizations. J Pediatr Psychol 1997; 22: 355-370.

138. Cassidy KL, Reid GJ, McGrath PJ, Finley GA, Smith DJ, Morley C, Szudek EA, Morton B. Watch needle, watch TV: audiovisual distraction in preschool immunization. Pain Med 2002; 3: 108-118.

139. Manimala R, Blount RL, Cohen LL. The effects of parental reassurance versus distraction on child distress and coping during immunizations. Child Health Care 2000; 29: 161-177.

140. Vessey JA, Carlson KL, McGill J. Use of distraction with children during an acute pain procedure. Nurs Res 1994; 43: 369-372.

141. Sparks L. Taking the "ouch" out of injections for children. MCN Am J Matern Child Nurs 2001; 26: 72-78.

142. French GM, Painter EC, Coury DL. Blowing away shot pain: a technique for pain management during immunization. Pediatrics 1994; 93: 384-388.

143. Gonzalez JC, Routh DK, Armstrong FD. Effects of maternal distraction versus reassurance on children's reactions to injections. J Pediatr Psychol 1993; 18: 239-248.

144. Mason S, Jonhson MH, Wooley C. A comparison of distractors for controlling distress in young children during medical procedures. J Clin Psychol Med 1999; 6: 239-248.

145. Dowling JS. Humour: a coping strategy for pediatric patients. Pediatr Nurs 2002; 28: 123-131. 
146. Arts SE, Abu-Saad HH, Champion GD, Crawford MR, Fisher RJ, Juniper KH, Ziegler JB. Age-related response to lidocaine-prilocaine (EMLA) emulsion and effect of music distraction on the pain of intravenous cannulation. Pediatrics 1994; 93: 797-801.

147. Linn S. Puppet therapy in hospitals: helping children cope. J Am Med Womens Assoc 1978; 33: 61-65.

148. Hodges C. Easing children's pain. Nurs Times 1998; 94: 55-58.

149. Hoffmann HG, Doctor JN, Patterson DR, Carrougher GJ, Furness TA 3rd. Virtual reality as an adjunctive pain control during burn wound care in adolescent patients. Pain 2000; 85: 305-309.

150. Sander Wint S, Eshelman D, Steele J, Guzetta CE. Effects of distraction using virtual reality glasses during lumbar punctures in adolescents with cancer. Oncol Nurs Forum 2002; 29: e8-e15.

151. Broome ME. Helping parents support their child in pain. Pediatr Nurs 2000; 26: $315-$ 317.

152. About xMAP technology. http://www.luminexcorp.com/technology/index.html. Date last accessed: June 102007.

153. de Jager W, Rijkers GT. Solid-phase and bead-based cytokine immunoassay: a comparison. Methods 2006; 38: 294-303.

154. Bossuyt PM, Reitsma JB, Bruns DE, Gatsonis CA, Glasziou PP, Irwig LM, Lijmer JG, Moher D, Rennie D, de Vet HC, STARD group. Towards complete and accurate reporting of studies of diagnostic accuracy: the STARD initiative. Clin Biochem 2003; 36: 2-7.

155. Bossuyt PM, Irwig L, Craig J, Galsziou P. Comparative accuracy: assessing new tests against existing diagnostic pathways. BMJ 2006; 332: 1089-1092. Erratum in: BMJ 2006; 332: 1368 .

156. Rutjes AW, Reitsma JB, Di Nisio M, Smidt N, van Rijn JC, Bossuyt PM. Evidence of bias and variation in diagnostic accuracy studies. CMAJ 2006; 174: 469-476.

157. Rahman I, Kelly F. Biomarkers in breath condensate: a promising new non-invasive technique in free radical research. Free Radic Res 2003; 37: 1253-1266.

158. Carraro S, Rezzi S, Reniero F, Heberger K, Giordano G, Zanconato S, Guillou C, Baraldi E. Metabolomics applied to exhaled breath condensate in childhood asthma. Am J Respir Crit Care Med 2007; 175: 986-990.

159. Silkoff PE, Hunt JF. ATS Workshop Proceedings : Exhaled nitric oxide and nitric oxide oxidative metabolism in exhaled breath condensate, Executive summary. Am J Respir Crit Care Med 2006; 173: 811-813.

160. Gallati H, Pracht J. Horseradish peroxidase: kinetic studies and optimisation of peroxidase activity determination using the substrates $\mathrm{H} 2 \mathrm{O} 2$ and 3,3'5,5'tetramethylbenzidine. J Clin Chem Clin Biochem 1985; 23: 453-460.

161. Ruch W, Cooper PH, Baggiolini M. Assay of $\mathrm{H} 2 \mathrm{O} 2$ production by macrophages and neutrophils with homovanillic acid and horseradish peroxidase. J Immunol Methods 1983; 63: 347-357.

162. Chladkova J, Krcmova I, Chladek J, Cap P, Micuda S, Hanzalkova Y. Validation of nitrite and nitrate measurements in exhaled breath condensate. Respiration 2006; 73: $173-179$. 
163. Balint B, Kharitonov SA, Hanazawa T, Donnelly LE, Shah PL, Hodson ME, Barnes PJ. Increased nitrotyrosine in exhaled breath condensate in cystic fibrosis. Eur Respir J 2001; 17: 1201-1207.

164. Dweik RA, Comhair SAA, Gaston B, Thunissen FB, Farver C, Thomassen MJ, Kavuru M, Hammel J, Abu-Soud HM, Erzurum SC. NO chemical events in the human airway during the immediate and late antigen-induced asthmatic response. Proc Natl Acad Sci USA 2001; 98: 2622-2627.

165. Kaneko FT, Arroliga AC, Dweik RA, Comhair SA, Laskowski D, Oppedisano R, Thomassen MJ, Erzurum SC. Biochemical reaction products of nitric oxide as quantitative markers of primary pulmonary hypertension. Am J Respir Crit Care Med 1998; 158: 917-923.

166. Dziedzic B, Mazanowska-Gajdowicz J, Walczewska A, Sarniak A, Nowak D. Comparison of cadmium and enzyme-catalyzed nitrate reduction for determination of NO2-/NO3- in breath condensate. Clin Chim Acta 2003; 335: 65-74.

167. Hunt J, Byrns RE, Ignarro $L$, Gaston B. Condensed expirate nitrite as a home marker for acute asthma. Lancet 1995; 346: 1235-1236.

168. Ganas K, Loukides S, Papatheodorou G, Panagou P, Kalogeropoulos N. Total nitrite / nitrate in expired breath condensate of patients with asthma. Respir Med 2001; 95 : 649-654.

169. Kharitonov SA, Donnelly LE, Montuschi P, Collins JV, Barnes PJ. Dose-dependent onset and cessation of action of inhaled budesonide on exhaled nitric oxide and symptoms in mild asthma. Thorax 2002; 57: 889-896.

170. Nightingale JA, Rogers DF, Chung FK, Barnes PJ. No effect of inhaled budesonide on the response to inhaled ozone in normal subjects. Am J Respir Crit Care Med 2000; 161: 479-486.

171. Corradi M, Pesci A, Casana R, Alinovi R, Goldoni M, Vettori MV, Cuomo A. Nitrate in exhaled breath condensate of patients with different airway diseases. Nitric Oxide 2003; 8: 26-30.

172. Kostikas K, Papatheodorou G, Ganas K, Psathakis K, Panagou P, Loukides S. pH in expired breath condensate of patients with inflammatory airway diseases. Am J Respir Crit Care Med 2002; 165: 1364-1370.

173. Corradi M, Montuschi P, Donnelly LE, Pesci A, Kharitonov SA, Barnes PJ. Increased nitrosothiols in exhaled breath condensate in inflammatory airway diseases. Am J Respir Crit Care Med 2001; 163: 854-858.

174. Fang K, Ragsdale NV, Carey RM, MacDonald T, Gaston B. Reductive assays for Snitrosothiols: implications for measurements in biological systems. Biochem Biophys Res Commun 1998; 252: 535-540.

175. Ischiropoulos H, Zhu L, Chen J, Tsai M, Martin JC, Smith CD, Beckman JS. Peroxynitritemediated tyrosine nitration catalyzed by superoxide dismutase. Arch Biochem Biophys 1992; 298: 431-437.

176. Wu W, Samoszuk MK, Comhair SA, Thomassen MJ, Farver CF, Dweik RA, Kavuru MS, Erzurum SC, Hazen SL. Eosinophils generate brominating oxidants in allergeninduced asthma. J Clin Invest 2000; 105: 1455-1463.

177. Mathews WR, Kerr SW. Biological activity of S-nitrosothiols: the role of nitric oxide. J Pharmacol Exp Ther 1993; 267: 1529-1537. 
178. Vaughan J, Ngamtrakulpanit L, Pajewski T, Turner R, Nguyen TA, Smith A, Urban P, Hom S, Gaston B, Hunt J. Exhaled breath condensate $\mathrm{pH}$ is a robust and reproducible assay of airway chemistry. Eur Respir J 2003; 22: 889-894.

179. Effros RM. Use of exhaled breath condensate in the study of airway inflammation after hypertonic saline solution challenge. Chest 2006; 130: 303.

180. Effros RM, Hunt J, Gaston B. Endogeneous airway acidifciation: implications for asthma pathology. Am J Respir Crit Care Med 2001; 163: 293-294.

181. Samuelsson B, Granstrom E, Green K, Hamberg M, Hammarstrom S. Prostaglandins. Annu Rev Biochem 1975; 44: 669-695.

182. Vass G, Huszar E, Barat E, Valyon M, Kiss D, Penzes I, Augusztinovicz M, Horvath I. Comparison of nasal and oral inhalation during exhaled breath condensate collection. Am J Respir Crit Care Med 2003; 167: 850-855.

183. Antczak A, Montuschi P, Kharitonov SA, Gorski P, Barnes PJ. Increased exhaled cysteinyl-leukotrienes and 8-isoprostane in aspirin-induced asthma. Am J Respir Crit Care Med 2002; 166: 301-306.

184. Montuschi P, Barnes PJ. Exhaled leukotrienes and prostaglandins in asthma. J Allergy Clin Immunol 2002; 109: 615-620.

185. Kostikas K, Papatheodouro G, Psathakis K, Panagou P, Loukides S. Prostaglandin E2 in the expired breath condensate of patients with asthma. Eur Respir J 2003; 22: 743-747.

186. Wardlaw A, Hay H, Cromwell O, Collins JV, Kay AB. Leukotrienes LTC4 and LTB4 in bronchoalveolar lavage in bronchial asthma and other respiratory diseases. J Allergy Clin Immunol 1989; 84: 19-26.

187. Claesson HE, Odlander B, Jakobssen PJ. Leukotriene B4 in the immune system. Int J Immunopharmacol 1992; 14: 441-449.

188. Montuschi P, Ragazzoni E, Valente S, Corbo G, Mondino C, Ciappi G, Barnes PJ, Ciabattoni G. Validation of leukotriene B4 measurements in exhaled breath condensate. Inflamm Res 2003; 52: 69-73.

189. Csoma Zs, Kharitonov SA, Balint B, Bush A, Wilson NM, Barnes PJ. Increased leukotrienes in exhaled breath condensate in childhood asthma. Am J Respir Crit Care Med 2002; 166: 1345-1349.

190. Corradi M, Rubinstein I, Andreoli R, Manini P, Caglieri A, Poli D, Alinovi R, Mutti A. Aldehydes in exhaled breath condensate of patients with chronic obstructive pulmonary disease. Am J Respir Crit Care Med 2003; 167: 1380-1386.

191. Mates M. Effects of antioxidant enzymes in the molecular control of ROS toxicology. Toxicol 2000; 153: 83-104.

192. Larstad M, Ljungkvist G, Olin AC, Toren K. Determination of malondialdehyde in breath condensate by high performance liquid chromatography with fluorescence detection. J Chromatogr B Biomed Sci App/ 2002; 766: 107-114.

193. Corradi M, Folesani G, Andreoli R, Manini P, Bodini A, Piacentini G, Carraro S, Zanconato $S$, Baraldi E. Aldehydes and glutathione in exhaled breath condensate of children with asthma exacerbation. Am J Respir Crit Care Med 2003; 167: 395-399.

194. Fozard JR. The case for a role for adenosine in asthma: almost convincing? Curr Opin Pharmacol 2003; 3: 264-269.

195. Huszar E, Barat E, Kollai M. Isocratic high performance liquid chromatographic determination of plasma adenosine. Chromatographia 1996; 42: 318-322. 
196. Huszar E, Vass G, Vizi E, Csoma Z, Barnat E, Molnar Vilagos G, Herjavecz I, Horvath I. Adenosine in exhaled breath condensate in healthy volunteers and in patients with asthma. Eur Respir J 2002; 20: 1393-1398.

197. Dwyer TM. Sampling airway surface liquid: non-volatiles in the exhaled breath condensate. Lung 2004; 182: 241-250.

198. Gessner C. Detection of mutations of the K-ras gene in condensed breath of patients with non small cell lung cancer (NSLC) as a possible non-invasive screening method. Pneumologie 1998; 52: 426-427.

199. Gessner C, Kuhn H, Toepfer K, Hammersmidt S, Schauer J, Wirtz H. Detection of p53 mutations in exhaled breath condensate of non small cell lung cancer patients. Lung Cancer 2004; 43: 215-222.

200. Vogelberg C, Hirsch T, Rosen-Wolff A, Kerkmann M-L, Leupold W. Pseudomonas aeruginosa and Burkholderia cepacia cannot be detected by PCR in the breath condensate of patients with cystic fibrosis. Pediatr Pulmonol 2003; 36: 348-352.

201. Nayeri F, Millinger E, Nilsson I, Zetterstrom, Brudin L, Forsberg P. Exhaled breath condensate and serum levels of hepatocyte growth factor in pneumonia. Respir Med 2002; 96: 115-119.

202. Carpagnano GE, Kharitonov SA, Wells A, Pantelidis P, Du Bois RM, Barnes PJ. Increased vitronectin and endothelin-1 in the breath condensate of patients with fibrosing lung disease. Respiration 2003; 70: 154-160.

203. Schreiber J, Meyer C, Rusch-Gerdes S, Richter E, Beck H, Fischer JF, Rosahl W. Mycobacterium tuberculosis gene-amplification in breath condensate of patients with lung tuberculosis. Eur J Med Res 2002; 7: 290-291.

204. Kietzmann D, Kah R, Muler M, Burchardi H, Kettler D. Hydrogen peroxide in expired breath condensate of patients with acute respiratory failure and with ARDS. Intensive Care Med 1993; 19: 78-81.

205. Gessner C, Kuhn H, Seyfarth HJ, Pankau H, Winkler J, Schauer J, Wirtz H. Factors influencing breath condensate volume. Pneumologie 2001; 55: 414-419.

206. Effros RM, Biller J, Foss B, Hoagland K, Dunning MB, Castillo D, Bosbous M, Sun F, Shaker R. A simple method for estimating respiratory solute dilution in exhaled breath condensates. Am J Respir Crit Care Med 2003; 168: 1500-1505.

207. Zacharasiewicz A, Wilson N, Lex C, Lo A, Kemp M, Donovan J, Hooper J, Kharitonov SA, Bush A. Repeatability of sodium and chloride in exhaled breath condensates. Pediatr Pulmonol 2004; 37: 273-275.

208. Baker EH, Clark N, Brennan AL, Fisher DA, Gyi KM, Hodson ME, Philips BJ, Baines DL, Wood DM. Hyperglycemia and cystic fibrosis alter respiratory fluid glucose concentrations estimated by breath condensate analysis. J Appl Physio/ 2007; 102: 1969-1975.

209. Dohlman AW, Black HR, Royall JA. Expired breath hydrogen peroxide is a marker of acute airway inflammation in pediatric patients with asthma. Am Rev Respir Dis 1993; 148: 955-960.

210. Lex C, Zacharasiewicz A, Payne DNR, Wilson NM, Nicholson AG, Kharitonov SA, Barnes PJ, Bush A. Exhaled breath condensate cysteinyl leukotrienes and airway remodeling in childhood asthma: a pilot study. Respir Res 2006 Apr 7; 7: 63 (doi: 10.1186/1465-9921-7-63). 
211. Shibata A, Katsunuma T, Tomikawa M, Tan A, Yuki K, Akashi K, Eto Y. Increased leukotriene $\mathrm{E} 4$ in the exhaled breath condensate of children with mild asthma. Chest 2006; 130: 1718-1722.

212. Carraro S, Corradi M, Zanconato S, Alinovi R, Pasquale MF, Zacchello F, Baraldi E. Exhaled breath condensate cysteinyl leukotrienes are increased in children with exercise-induced bronchoconstriction. J Allergy Clin Immunol 2005; 115: 764-770.

213. Montuschi P, Martello S, Felli M, Mondino C, Barnes PJ, Chiarotti M. Liquid chromatography/mass spectrometry analysis of exhaled leukotriene B4 in asthmatic children. Respir Res 2005 Oct 19; 6: 119 (doi: 10.1186/1465-9921-6-119).

214. Bodini A, Peroni DG, Zardini F, Corradi M, Alinovi R, Boner AL, Piacentini GL. Flunisolide decreases exhaled nitric oxide and nitrotyroine levels in asthmatic children. Mediators Inflamm 2006; 2006(4): 31919 (doi 10.1155/MI/2006/31919).

215. Celio S, Troxler H, Durka SS, Chladek J, Wildhaber JH, Sennhauser FH, Heizmann CW, Moeller A. Free 3-nitrotyrosine in exhaled breath condensates of children fails as a marker for oxidative stress in stable cystic fibrosis and asthma. Nitric Oxide 2006; 15 : 226-232.

216. Baraldi E, Giordano G, Pasquale MF, Carraro S, Mardegan A, Bonetto G, Bastardo C, Zacchello F, Zanconato S. 3-Nitrotyrosine, a marker of nitrosative stress, is increased in breath condensate of allergic asthmatic children. Allergy 2006; 61: 90-96.

217. Brunetti L, Francavilla R, Tesse R, Strippoli A, Polimeno L, Loforese A, Miniello VL, Armenio $\mathrm{L}$. Exhaled breath condensate $\mathrm{pH}$ measurement in children with asthma, allergic rhinitis and atopic dermatitis. Pediatr Allergy Immunol 2006; 17: 422-427.

218. Profita M, La Grutta S, Carpagnano E, Riccobono L, Di Giorgi R, Bonanno A, Pace E, Bonsignore G, Bousquet J, Vignola AM, Gjomarkaj M. Noninvasive methods for the detection of upper and lower airway inflammation in atopic children. J Allergy Clin Immunol 2006; 118: 1068-1074.

219. Carraro S, Folesani G, Corradi M, Zanconato S, Gaston B, Baraldi E. Acid-base equilibrium in exhaled breath condensate of allergic asthmatic children. Allergy 2005; 60: 476-481.

220. de Jongste JC. To wheeze or not to wheeze. Am J Respir Crit Care Med 2006; 174 : 1281-1282.

221. Martinez FD, Wright AL, Taussig LM, Holberg CJ, Halonen M, Morgan WJ. Asthma and wheezing in the first six years of life. N Eng J Med 1995; 332: 133-138.

222. Robinson DS, Hamid Q, Ying S, Tsicopoulos A, Barkans J, Bentley AM, Corrigan C, Durham SR, Kay AB. Predominant TH2-like bronchoalveolar T-lymphocyte population in atopic asthma. N Eng J Med 1992; 326: 298-304.

223. Chung EK, Miller RL, Wilson MT, McGeady SJ, Culhane JF. Antenatal risk factors, cytokines and the development of atopic disease in early childhood. Arch Dis Child Fetal Neonatal Ed 2007; 92: F68-F73.

224. Castro-Rodriguez JA, Holberg CJ, Wright AL, Martinez FD. A clinical index to define risk of asthma in young children with recurrent wheezing. Am J Respir Crit Care Med 2000; 162: 1403-1406.

225. Gaber F, Acevedo F, Delin I, Sundblad BM, Palmberg L, Larsson K, Kumlin M, Dahlen SE. Saliva is one likely source of leukotriene B4 in exhaled breath condensate. Eur Respir J 2006; 28: 1229-1235. 
226. Noble DD, McCafferty JB, Greening AP, Innes JA. Respiratory heat and moisture loss is associated with eosinophilic inflammation in asthma. Eur Respir J 2007; 29: 676681.

227. Reinhold P, Jaeger J, Schroeder C. Evaluation of methodological and biological influences on the collection and composition of exhaled breath condensate. Biomarkers 2006; 11: 118-142.

228. Liu J, Thomas PS. Relationship between exhaled breath condensate volume and measurements of lung volumes. Respiration 2007; 74: 142-145.

229. Effros RM, Peterson B, Casaburi R, Su J, Dunning M, Torday J, Biller J, Shaker R. Epithelial lining fluid solute concentrations in chronic obstructive lung disease patients and normal subjects. J App/ Physiol 2005; 99: 1286-1292.

230. Effros RM, Su J, Casaburi R, Shaker R, Biller J, Dunning M. Utility of exhaled breath condensates in chronic obstructive pulmonary disease: a critical review. Curr Opin Pulm Med 2005; 11: 135-139.

231. Battaglia S, den Hertog H, Timmers MC, Lazeroms SPG, Vignola AM, Rabe KF, Bellia V, Hiemstra PS, Sterk PJ. Small airways function and molecular markers in exhaled air in mild asthma. Thorax 2005; 60: 639-644.

232. The Statistics Homepage. http://www.statsoft.com/textbook/stcluan.html. Date last accessed June 92007.

233. Rosi E, Ronchi MC, Grazzini M, Duranti R, Scano G. Sputum analysis, bronchial hyperresponsiveness, and airway function in asthma: results of a factor analysis. $J$ Allergy Clin Immunol 1999; 103: 232-237.

234. Wardlaw AJ, Silverman M, Siva R, Pavord ID, Green R. Multi-dimensional phenotyping: towards a new taxonomy for airway disease. Clin Exp Allergy 2005; 35: 1254-1262.

235. Juniper EF, Wisniewski ME, Cox FM, et al. Relationship between quality of life and clinical status in asthma: a factor analysis. Eur Respir J 2004; 23: 287-291.

236. Fireman E, Shtark M, Priel IE, Shiner R, Mor R, Kivity S, Fireman Z. Hydrogen peroxide in exhaled breath condensate (EBC) vs eosinophil count in induced sputum (IS) in parenchymal vs airways lung diseases. Inflammation 2007; 30: 44-51.

237. Jackson AS, Sandrini A, Campbell C, Chow S, Thomas PS, Yates DH. Comparison of biomarkers in exhaled breath condensate and broncho-alveolar lavage. Am J Respir Crit Care Med 2007; 175: 222-227.

238. McCulloch M, Jezierski T, Broffman M, Hubbard A, Turner K, Janecki T. Diagnostic accuracy of canine scent detection in early- and late-stage lung and breast cancers. Integr Cancer Ther 2006; 5: 30-39.

239. Miekisch W, Schubert JK, Noeldge-Schomburg GF. Diagnostic potential of breath analysis, focus on volatile organic compounds. Clin Chim Acta 2004; 347: 25-39.

240. Schubert JK, Miekisch W, Geiger K, Noldge-Schomburg GF. Breath analysis in critically ill patients: potential and limitations. Expert Rev Mol Diagn 2004; 4: 619-629.

241. Anderson JC, Hlastala MP. Breath tests and airway gas exchange. Pulm Pharmacol Ther 2007; 20: 112-117.

242. Barker M, Hengst M, Schmid J, Buers HJ, Mittermaier B, Klemp D, Koppmann R. Volatile organic compounds in the exhaled breath of young patients with cystic fibrosis. Eur Respir J 2006; 27: 929-936. 